

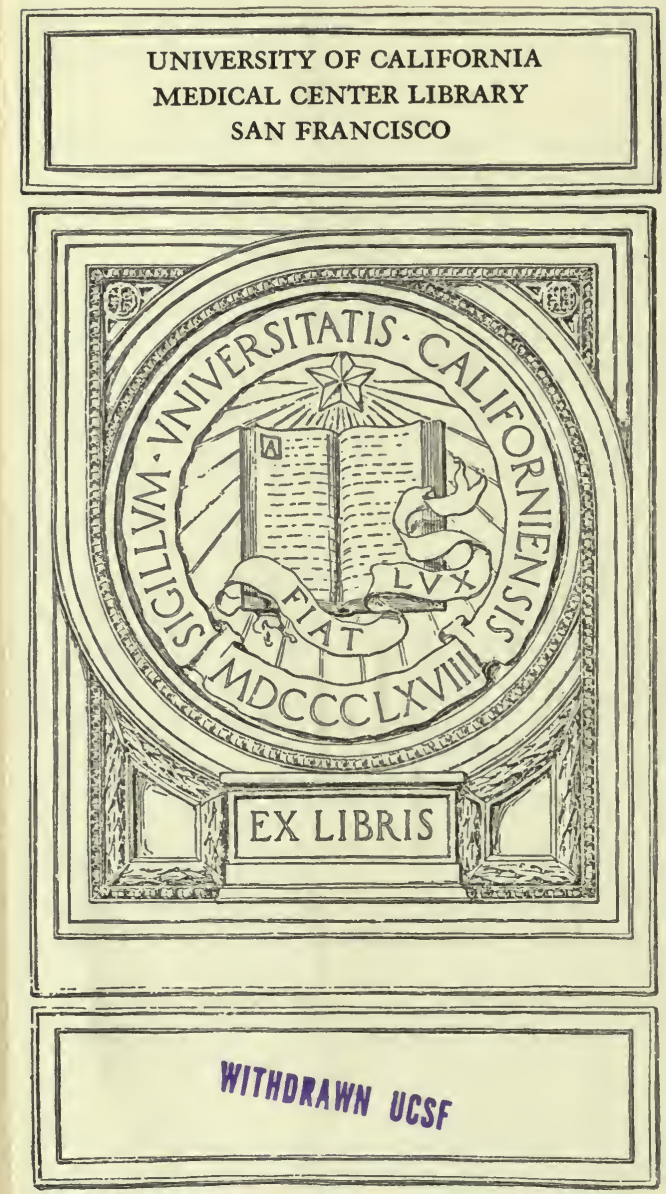
Lelcon M. Mara. 74t5.19,3 
Digitized by the Internet Archive in 2007 with funding from Microsoft Corporation 




\section{THE EVOLUTION OF}

\section{ANIMAL INTELLIGENCE}

BY

S. J.|HOLMES, $\mathbf{P}_{\text {н. }}$ D. ASSISTAST PROFESSOR OF ZOOLOGY IN THE UNIVERSITY OF WISCONSIN.

QL785

H75e

1911

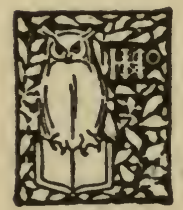

NEW YORK

HENRY HOLT AND COMPANY

1911 
Coptriaht, 1911

BX

HENRY HOLT AND COMPANY

CAMRLOT PRESS, 44\$-46 PBARL. STRERT, NEW YORK 


\section{PREFACE}

The investigations of recent years have added so much to our knowledge of the activities of animals that any adequate account of the whole field of animal behavior would require several volumes. The present work is confined to certain topics which bear upon the evolution of animal intelligence, and our treatment of even this part of the subject has been of necessity fragmentary. It has been our aim to give a fairly clear conception of the activities upon which intelligence is based, to show how intelligence is related to these activities, and to sketch the general course of the evolution of intelligence in the animal kingdom. No effort has been made to deal with all the classes of animals in which intelligence is manifested, and some groups which were not essential to the development of our theme have received little attention.

I wish to express my thanks to Prof. L. J. Cole and Prof. H. B. Torrey for their helpful criticisms of the manuscript of this book before it went to press. To Prof. L. T. Hobhouse, Prof. E. L. Thorndike and Dr. L. Witmer I am indebted for permission to reproduce the figures which are attributed to these writers in the text, and I am also indebted to the Macmillan Company for kindly allowing me to reproduce figures 15 and 16 from their publications. My greatest debt is to $\mathrm{mv}$ wife for help and encouragement in many ways.

S. J. H. 



\section{CONTENTS}

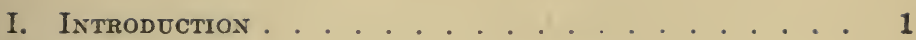

II. Reflex Actioi: . . . . . . . . . . . . . . . 11

III. The Tropisus . . . . . . . . . . . 18

IV. The Behavior of Protozod . . . . . . . . . . . . . 63

V. Instinct . . . . . . . . . . . . . . 91

VI. The Evolution of Instinct . . . . . . . . . . 115

VII. The Non-intelligent Modifications of Behavior . . . 139

Viil. Pleasure, Pain, and the Beginnings of Intelligence a 164

IX. Primitive Types of Intelligence in Crustaceans and

Molluscs . . . . . . . . . . . . . 180

X. Intelligence in InSeCtS . . . . . . . . . 191

Xi. Intelligence in the Lower Vertebrates . . . . . 218

- XiI. The Intelligence of Mammals . . . . . . . . . . 232

XiII. The Mental Life of Apes and Monkey.3. . . . . . 260 INDEXX . . . . . . . . . . . 283 



\section{THE EVOLUTION OF ANIMAL INTELLIGENCE}

\section{CHAPTER I \\ INTRODUCTION}

"If the doctrine of Evolution is true, the inevitable implication is that Mind can be understood only by observing how Mind is evolved."-Herbert Spencer, Principles of Psychology.

"Alle instinktiven Triebe und zweckbewussten Willensäusserungen dienen entweder der Erhaltung des eigen Lebens oder der Erzeugung und Pflege der Nachkommenschaft."-SchNeIDER, Der Thierische Wille.

"Si la psychologie humaine est légitime, la psychologie comparée I'est aussi, pour les mêmes raisons."-Claparède.

In the last two decades the science of animal psychology has had an unprecedented development. Previous to this time and subsequent to the appearance of the Origin of Species students of the animal mind were concerned in bringing forward proofs of the similarity of the mental processes of men and animals and in tracing the gradual unfolding of the mental powers in passing from lower to higher forms. The followers of Darwin in their efforts to show that evolution is applicable in the mental as well as the physical world were naturally prone to minimize the gulf separating the human and the animal mind which the traditional psychology had formerly taught was a wide and impassible one. 
Hence we find among writers of the period mentioned a tendency to interpret the actions of animals as the outcome of highly developed psychical faculties, and to accept rather too uncritically stories indicative of great sagacity on the part of animals with the end of showing that the brute creation does not stand so very far below us after all. The works of Romanes on Mental Evolution in Animals and Animal Intelligence are typical of the period and its tendencies toward anthropomorphism, which is now the bete noir of every dabbler in the subject of animal behavior. While Romanes has been criticized with a certain amount of justice for basing conclusions on anecdotes from more or less questionable sources he has the merit of bringing together a large number of facts regarding animal intelligence and of giving an able and lucid account of the general course of mental evolution, and there is no doubt that had his life extended into the period of more careful and accurate experimentation he would have been among the first to appreciate and encourage the newer animal psychology.

The advent of experimental psychology with its various appliances for observing and recording the manifestations of mental phenomena, the study of the functions of the nervous system by the experimental methods of the physiologists, and the growing vogue of methods of experimental analysis in biology in general could not fail to have a marked influence on the study of the mental life of animals. After the scientific world had comfortably settled down in the belief in continuous mental evolution, and the subject had mainly lost its controversial interest, attention became more strongly directed to the analysis of animal behavior with the end of explaining why animals act as they do. Then came the period of reflexes and tropisms and the analysis of complex behavior into simpler processes, with which we are now 
struggling. Animal psychology blossomed into an experimental science, proud of her new growth and often looking back with something of scorn upon the days of her infancy.

The position of animal psychology among the sciences is, however, a somewhat peculiar one. Concerning the conscious life of animals as distinguished from the objective facts of behavior - the life which falls within the peculiar province of psychology as distinguished from physiologyour knowledge rests upon an insecure foundation. We have no means of cognizing directly the conscious states of any creature besides ourselves and what we know of the psychology of our fellow human beings is based upon what we find taking place in our own minds. We infer consciousness in other beings because we are conscious ourselves, and we judge of the mental states in the minds of others, such as joy, sorrow, anger, or fear, from certain physiological manifestations which are like the accompanying manifestation of these mental states in ourselves. With beings much like ourselves our inferences may be fairly accurate. When thrown amid the people of other nations or races our judgments are more apt to be erroneous. And when we try to infer what goes on in the mind of a cat or a dog the difficulties are very greatly increased. We may feel convinced that the sensations of these animals and even the basic emotions, such as fear, anger, etc., are very similar to our own, but the difficulty of ascertaining what sort of intellectual life one of these creatures enjoys is evinced by the very different interpretations of the subject which have been made by competent psychologists. If we try to imagine what sort of psychic states are associated with the supra-œsophageal ganglion of an ant or a crayfish, analogy almost completely fails us. However much we may learn about the behavior of these creatures, 
we could never feel much confidence in any conclusions as to the kind of conscious states which make up their mental life. We may be asked, in what way do we know these animals have conscious states at all? May they not be as Descartes has considered all animals below man, merely unconscious automata? The question throws us back upon - what criterion we adopt of consciousness and upon this subject the opinions of psychologists present us with no end of differences.

The criterion of consciousness which is perhaps most widely adopted at the present time is the ability to learn by experience, or associative memory. Among those who have adopted this standpoint may be mentioned Bethe, Loeb and Bohn. Romanes and Lloyd Morgan, while they recognize that ability to learn is indicative of the presence of consciousness, hesitate to draw the conclusion that consciousness is absent in those animals which are devoid of associative memory. In his work on Animal Intelligence Romanes states that "because a lowly organized animal does not learn by its own individual experience, we may not therefore conclude that in performing its natural or ancestral adaptations to appropriate stimuli consciousness, or the mind element, is wholly absent; we can only say that this element, if present, reveals no evidence of the fact." Lloyd Morgan writes likewise in a guarded manner: "When we see that a chick, for example, pecks at first at any small object, it is difficult to say, on these grounds, whether it is a sentient animal or an unconscious automaton; and if it continued to behave in a similar fashion throughout life, our difficulty would still remain. But when we see that some objects are rejected while others are selected, we infer that consciousness in some way guides its behavior. The chick has profited by experience. But even this is only 
a criterion of what we may term effective consciousness. There may be sentience which is merely an accompaniment of organic action without any guiding influence on subsequent modes of behavior. In that case it is not effective; and whether it is present or not we have no means of ascertaining."

It may be argued that since learning in us is a conscious process that therefore all animals that learn are likewise conscious. The inference may be probable, though by no means necessary; but it would afford no ground for denying consciousness in animals in which learning does not occur. If I am pricked by a needle I am acutely conscious. The feeling of pain is aroused very directly, and it is difficult to see how it can be dependent in any way on associative memory. If my memory should fail me to the extent that I would straightway forget the experience every time I was pricked would not the pricking arouse the same painful sensation as before? Would not sound waves produce the sensation of hearing and retinal stimulation the sensation of light in the absence of any power of recalling similar sensations received in the past? Unless it can be shown that there is some relation of dependence of consciousness upon associative memory in ourselves there is little ground for setting up associative memory as a criterion of consciousness in animals. The criterion reverses the obvious relation of the phenomena. Instead of consciousness being dependent upon associative memory, associative memory implies the previous existence of consciousness. How can the existence of anything be dependent on the association of its elements, if these elements can exist only on the condition that they are associated? The criterion makes the existence of the more simple and general dependent on the existence of a special function within its own realm. 
One reason that has led to the adoption of the criterion of associative memory is the evidence afforded that the animal at this stage is guided by experiences of pleasure and pain. We repeat acts that bring us pleasure and avoid those that bring pain. Where in animals certain responses that have been made once tend to be performed more readily on subsequent occasions and other acts which are followed by avoiding reactions are discontinued, it is natural to infer that pleasure and pain accompany these different modes of behavior. Pleasure and pain have very commonly been spoken of as agents of reinforcement and inhibition. When the pleasure-pain response appears on the scene consciousness is commonly assumed to take a guiding hand in the determination of behavior. The advent of this type of behavior marks a critical period in the evolution of the animal mind and we shall consider it more closely in a subsequent chapter. There we shall attempt to show that this type of reaction does not involve the injection of any radically new element into its course of evolution. If we adhere to the doctrine of psycho-physical parallelism in any of its forms we cannot speak, in strictness, of pleasure and pain as agents in accommodation: they are only the signs of a certain kind of adjustment. This adjustment according to the theory of parallelism has its physiological explanation without calling upon the interference of psychical states. We might ask broadly: If psychical states do not as such interfere with the course of physical phenomena, how can we adopt any kind of behavior as a criterion of consciousness? I doubt if either Bethe of Loeb is willing to defend the view that consciousness is an agent in directing physical phenomena, and to accept the logical consequences of such a position. It can be shown, I believe, that this view creates many serious difficulties without giving us any real aid in 
explaining one. But a discussion of this question in all its bearings would carry us too far.

If there is no infallible test for the determination of the existence of consciousness in animals we are by no means led, as some physiologists would have us believe, to the denial of the possibility of a comparative psychology. If we can explain the behavior of lower organisms in terms of physiological laws without assuming any rôle of conscious states in determining their acts, and were able to extend the same kind of explanation to higher forms until ultimately the whole sentient creation were embraced in our system, the rejection of comparative psychology would logically lead, as Claparède has well shown, to the denial of human psychology as well. On the other hand, starting in with the assumption that human psychology is a legitimate subject matter for a science, there is no logical ground for refusing to draw inferences concerning the mental aspects of the behavior of apes, and other higher mammals; and if we can infer something of the mental life of the animals nearest ourselves we are warranted in extending our psychological inferences as far down in the scale as analogy permits us to go. How far analogy warrants us in going is capable of but a very indefinite answer. When we come to ants and spiders everyone may perhaps be allowed to have his own opinion; and there may be a more than sufficient compensation for our inability to reach conclusive proofs of our views regarding the psychic life of such creatures in having a perennial source of contention with which comparative psychologists may occupy themselves whenever they come together.

The existence of mind in the lower animals has something more than a theoretical interest. In our experiments on these creatures it would be unfortunate if we were mistaken 
in regarding them as unconscious automata and should proceed to cut them up in a ruthless fashion on that assumption. It may be, as Norman has attempted to show, that pain sensations in the lower invertebrates are not acute at most, and may be absent entirely, but not much would be lost by giving the animals the benefit of the doubt so far as is consistent with attaining the objects of experimental work.

The scientific instinct for continuity tempts us to ascribe some form of sentiency to all living forms. Certainly it is not possible to disprove the existence of consciousness of some sort in any organism. In the lowest animals it may be nothing more than a very dull form of sensibility. If we would avoid the assumption of an absolute beginning of consciousness we may hold that something akin to consciousness, but very much more primitive than any of the forms of it with which we are acquainted, exists in connection with all inorganic processes. Such a position affords a consistent viewpoint and has been accepted by many as enabling us to conceive the whole process of psychic evolution as one without any breaks or discontinuities anywhere in the series.

Our task in the present volume is to sketch briefly the evolution of behavior from its simplest manifestations in the reflex actions of the lowest organisms to its more elaborate expressions in the higher mammals. No attempt has been made to give a survey of behavior in all the groups of the animal kingdom. Beginning with simple reflex action we have described those forms of behavior which are commonly called tropisms and which are by many regarded as a comparatively direct outcome of reflex irritability. After an account of behavior of the lowest members of the animal kingdom we have given a general account of instinct, 
the analysis of instinct into simpler processes, and the different views of the origin and evolution of instinct. Considerable space is devoted to the transition between instinct and intelligence, and the evolution along the lines of plasticity and ready modifiability of behavior which has prepared the way for the appearance of intelligence. This is followed by a general and confessedly incomplete sketch of the gradual evolution of intelligence in the animal kingdom, and a discussion of some of the evidences for the existence in the higher animals of a certain power of making inferences which some modern psychologists have claimed . is not found in any sentient creature below man.

A comparative survey of the actions of animals shows us that behavior is very much the same sort of thing wherever found. It is one of the many valuable contributions of the great pioneer in genetic psychology, Herbert Spencer, to have shown the fundamental unity of biological and psychological processes in all their varied manifestations. Instinct, memory, volition and reason are all parts of that general process of adjustment of the organism to its environment, in which life in all its stages essentially consists. As we pass from lower to higher forms we have an increase in the complexity and perfection of the adjustments; the correspondence increases in space and in time, in definiteness and in generality, but everywhere it is "the adjustment of internal relations to external relations." This conception of mental life marks an important advance upon the psychology current in Spencer's early years; it set aside the arbitrary distinctions of the so-called "faculties" and prepared the way for a clearer insight into the gradual unfolding of mind which the labors of genetic psychologists are slowly giving us. 


\section{INTRODUCTION}

\section{BIBLIOGRAPHY}

Вонл, G. La Naissance de l'Intelligence. Paris, 1909.

Claparìde, E. Les animaux sont ils-conscients? Rev. Philos., 51, 24, '01. La psychologie comparée est-elle légitime? 1. c. Arch. de Psych., 5, 13, '05.

Huxley, T. H. On the Hypothesis that Animals are Automata and its History. '74.

Loes, J. Comparative Physiology of the Brain and Comparative Psychology. N. Y., '04.

Marshalt, H. R. Instinct and Reason. N. Y., '98.

Morgan, C. Lloyd. An Introduction to Comparative Psychology. London, '94. Animal Behaviour. London, '00.

Romanes, G. J. Animal Intelligence. N. Y., '83. Mental Evolution in Animals. London, '85.

Spencer, H. Principles of Psychology, 3d. ed. N. Y., '94.

Titchener, E. B. Were the Earliest Organic Movements Conscious or Unconscious? Pop. Sci. Mon., 60, 458, '02.

Washburn, M. F. The Animal Mind. N. Y., '09.

WasmanN, E. Instinkt und Intelligenz im Tierreich, 3d. ed. Freiburg, i. B., '05. 


\section{CHAPTER II.}

\section{REFLEX ACTION.}

"Pure reflexes are admirably adapted to certain ends. They are reactions which have long proved advantageous in the phylum of which the existent individual is a representative embodiment. Perfected during the course of ages, they have during that course attained a stability, a certainty, and an ease of performance beside which the stabllity and facility of the most ingrained habit acquired during an individual life is presumably small."-SHERrINGTON, The Integrative Action of the Nervous System.

The term reflex action is used in a wide and somewhat indefinite sense, but it is applied in general to responses of the organism which are evoked directly upon the application of a stimulus. In a typical reflex we have a sensory or afferent impulse set up in some sense organ and proceeding toward a ganglion or larger nerve center. From the latter an efferent impulse passes outward along a motor nerve, causing a muscular contraction. Frequently the impulse is reflected back near its point of origin, more or less after the fashion in which light may be reflected back to its source from a mirror and the reaction occurs in the stimulated part. It is from analogy with the reflection of light that the term reflex action is chosen, although the analogy, it must be confessed, is rather loose, and in some respects misleading. When one involuntarily winks the eyes after they are suddenly illuminated by a glare of light, impulses are set up in the retina which proceed along the optic nerve to the brain. Here they traverse certain established connections among the fibers, by means of which they become directed outward along the motor nerves to the muscles of the eye- 
lids causing them to contract. This process takes place in a small fraction of a second after stimulation, and occurs not only without the action of the will, but even in spite of efforts to prevent it.

Another reflex act, the so-called tendon reflex, may readily be observed by striking the large tendon which is inserted into the patella just below the knee. If the leg is hanging loosely a light blow on the tendon will cause the foot to be suddenly extended. Here the impulses set up by the blow proceed to the spinal cord, and are returned along motor nerves to the extensor muscles of the leg causing them to contract. If the nervous centers of the spinal cord are impaired, as occurs in certain diseased conditions, this reflex can no longer be evoked.

In a frog these spinal reflexes may readily take place if the spinal cord is cut across a short distance in front of the center which supplies nerves to the parts concerned. A stimulus supplied to the hind leg of such a frog causes the leg to be withdrawn. If in a frog whose brain has been destroyed the side of the body is stimulated by acid there may be produced, besides the twitching of the muscles near the stimulated part, a movement forward of the hind foot of the same side which often succeeds in wiping away the acid. If the stimulus is applied near the middle of the body both hind feet may be brought forward to remove it. And if the stimulus be applied to one side and the leg of the same side be held, the opposite leg may be brought into play, especially if the stimulus is a strong one, and may succeed in removing the offending substance. The accuracy of these movements, especially in the crossed reflex, is exaggerated in most accounts, but sufficient exactness is frequently attained to effect the removal of the irritating material.

Reflex action may occur in various degrees of complexity. 
In the simplest cases there is movement in the single part affected, as when a single tentacle of a polyp is withdrawn upon being stimulated. In other cases a single stimulus may produce combined movements of several parts, as when the various appendages of a brainless crayfish are set in motion when but one of them is stimulated. A stimulus on the right side of a frog may not only cause coördinated action in the various muscles of the hind leg, but the right fore leg may be applied to the stimulated part as well. And if the animal is rendered especially responsive by the injection of a solution of strychnine, contraction may take place in most of the muscles of the body.

One factor which is concerned in the complexity of the response is the strength of the stimulus. A light stimulus applied to the tentacle of a jelly fish usually causes a contraction of that tentacle only, but if the stimulus is stronger, the neighboring tentacles will also contract, and if still stronger, movements may be set up in the umbrella or disk which cause the animal to swim away. Complex responses are also produced if a stimulus affects many sense organs at once.

A further method of complication occurs in the so-called chain reflexes in which one action serves as the stimulus for a second, and this for a third, and so on. A frog with its cerebral hemispheres removed will respond to the movements of a fly in its vicinity by snapping at it. This complicated reflex causes the fly to be seized by the jaws; the stimuli caused by the juices of the fly acting on the taste buds of the frog's mouth set up the swallowing reflex, which involves complex and coördinated movements of the tongue and throat. When in the stomach the fly reflexly excites this organ to activity, resulting finally in the extrusion of the digested mass into the intestine, which in turn is reflexly 
excited to the performance of peristaltic movements and other functions.

Similarly a brainless crayfish will seize a bit of food in its small chela, pass it forward to the maxillipeds, which coöperate to bring it between the mandibles where it is chewed, after which it is swallowed, passing into the stomach, where it sets in action the gastric mill resulting in the further trituration of the food.

Reflex actions may be inhibited in various ways. If the spinal cord of a frog is severed, and a stimulus applied to the anterior cut end at the same time the hind toe is pinched, the withdrawal of the leg which occurs regularly under normal conditions may be prevented from taking place. Impulses passing down the cord block or inhibit impulses tending to pass down the motor nerves to the leg. Strong stimuli applied to the optic lobes or certain other parts of the brain of a frog produce the same effect. Reflex acts in animals generally take place more readily and more uniformly if the brain be destroyed, indicating that the brain acts as a constant inhibitory organ upon the lower nerve centers. Stimuli applied to other parts of the body may also inhibit reflexes. If one toe of a decapitated frog is strongly stimulated by being held in dilute sulphuric acid and the other toe stimulated by an electric current, the withdrawal of the latter will be delayed or entirely checked.

To designate as reflex action the direct responses of the lowest animals which are devoid of a nervous system is to extend somewhat the original meaning of the term. These responses, however, are now commonly spoken of as "reflexes" and they are very similar to the simple reflex acts of higher forms in which a nervous arc forms the pathway of the impulses. To a certain extent all living matter conducts stimuli and hence performs the function of nervous tissue. 
In the Protozoa this transmission may take place with great readiness, although there are not known to be any specialized pathways which the impulses follow. If the bell-animalcule Vorticella is touched, the long flexible stalk will quickly contract. A Stentor when stimulated contracts with great suddenness, and Paramœcium when it encounters a stimulus of any kind performs a stereotyped motor reflex which consists in reversing the stroke of the cilia, swimming backward, and turning toward the aboral side. This response is shown even by small pieces of the infusorian in much the same way. Most of the protozoa react to stimuli by some form of motor reflex. Even plants show reflexes, as in the drooping of the leaves of the sensitive plant, the curling of the tentacles of the sundew, the movements of the Venus' fly trap, and many other less manifest exhibitions of irritability.

A conspicuous trait of reflexes is their adaptiveness. The winking of the eye, the withdrawal of the frog's leg, the removal of acid from the side of the body, the snapping and swallowing of food are all actions which, in one way or another, secure the welfare of the individual. But the purposiveness is like that of a machine which is constructed to do a particular thing; it is the result of conformation and arrangement of its parts. By pressing a lever a machine may be made to perform a very simple act or produce an elaborate piece of music, according to the nature of the mechanism. Given the proper organization an animal may likewise perform acts of great complexity and adaptiveness in response to certain kinds of stimulation; the purposiveness of the behavior results not from choice, but from a sort of mechanical necessity. The explanation of this adaptiveness, like the explanation of the adaptiveness of a machine to perform a certain kind of work, lies in the causes that led to the production of a certain kind of 
structure. For a solution of this problem we are naturally led to the study of the evolution of organic life.

\section{RHYTHMICAL ACTIVITY}

Organisms perform many actions repeatedly which apparently go on by themselves independently of outer stimulation. Such actions may be viewed as responses, but the stimuli causing them are internal instead of external. The beating of the heart and the regular movements of respiration are familiar examples of such rythmical activity.

In the horse-shoe crab Limulus the abdominal appendages which bear the gills execute a regular to and fro movement which will occur as well if the nerve cord is cut between the thorax and the abdomen. Even if the nerve cord is cut between the several abdominal ganglia the appendages will still beat regularly, although all coördination of their movements is destroyed. Among medusæ there is a regular contraction of the disk or bell during swimming which usually disappears if the marginal nerve ring is removed, but Loeb has shown that if the jelly fish Gonionemus, after being operated on in this manner, is placed in sea water devoid of calcium salts the rhythmical pulsations will reappear.

Among the Protozoa rhythmical movements are shown in the regular swaying of Stentor, and the periodical contractions of Vorticella; and Loxophyllum, as is described in a later chapter, shows a rhythmical alternation of movements which are performed in much the same way by very small pieces into which the infusorian may be divided.

\section{BIBLIOGRAPHY}

Bethe, A. Das Centralnervensystem von Carcinus mœnas. Arch. f. mik. Anat., 50 and 51, '97. Allgemeine Anatomie und Physiologie des Nervensystems. Leipzig, '03. 
Lовв, J. Comparative Physiology of the Brain and Comparative Psychology. N. Y., '00.

Lukas, F. Psychologie der niedersten Tiere. Wien and Leipzig, '05.

Schrader, M. Zur Physiologie des Froschgehirns. Pflüger's Archiv, 41,75, '87.

Sherrington, C. S. The Integrative Action of the Nervous System. N. Y., '03.

UExKర̋LL, J. von. Umwelt und Innenwelt der Tiere. Berlin, '09. 


\section{CHAPTER III}

\section{THE TROPISMS}

"The understanding of complicated phenomena depends upon an analysis by which they are resolved into their simple elementary compounds."-Loeb, Physiology of the Brain.

"On s'est fait beaucoup d'idées fausses sur les tropismes; les littérateurs, les philosophes; les savants même, ont disserté sur eux d'une facon tout à fait fantaisiste, les uns raillant, les autres louant sans réserve, ce qu'ils n'avaient pas compris."-GEORGES BoHn.

\section{THE TROPISMS IN GENERAL}

Certain stimuli exercise a directive effect upon the movements of animals causing them to go toward or away from the source of stimulation. Such movements are commonly called tropisms. The flight of a moth toward the candle, the gathering of male moths around a box containing a female, the movements of protozoans away from regions of unusual heat or cold may be taken as illustrations of such directed movements.

No attempt will be made to formulate an accurate definition of the word tropism because usage has not established the meaning of the term with sufficient precision to render this possible. There is considerable difference of opinion in regard to the explanation of tropisms, and the kinds of behavior to which the term should be applied. In what follows phenomena will be described which have been commonly classed as tropisms however diverse they may be in character and causation.

The study of tropisms, which has attracted a large share of attention in recent years, was given a great stimulus by 
Loeb through his work "Der Heliotropismus der Tiere" and various later papers. The "Heliotropismus der Tiere" was a pioneer work; but perhaps its chief value lies not so much in the number of interesting facts and records of ingenious experiments it contains as in the general theory there advanced, which has been the means of stimulating many investigators to enter the field.

The book emphasized the idea that it is the business of the investigator not merely to describe the facts of behavior and marvel over their wonderful nature, but to try to explain them. It presented him with a theory which if true would carry us a step forward in the analysis of many kinds of behavior, especially in the lower organisms. The book shows the influence of Sachs, whose conception of the mechanism of tropisms in plants forms the nucleus of Loeb's theory. Loeb attempted to show that the phenomena of Heliotropism were essentially similar in plants and animals. The orientation of the body to the direction of the rays, the fact that the more refrangible rays are the more effective in producing the heliotropic response, and the dependence of light reactions upon light intensity and temperature are shown by plants and animals in much the same way. All of these effects are supposed to rest upon certain fundamental properties of living substance common to plants and animals. This conclusion was naturally a somewhat startling one, especially when the light reactions of highly developed animals which were commonly supposed to be due to psychic causes were placed in the same category with the turning of leaves and stems toward the sunlight.

The prospect of finding a mechanical explanation of the behavior of organisms is always an alluring one. In this case it proved to be especially so because the generalization included such apparently diverse phenomena, and 
could be applied with only a slight modification to other kinds of tropisms. "These tropisms," says Loeb, "are identical for animals and plants. The explanation of them depends first upon the specific irritability of certain elements of the body-surface, and second, upon the relation of symmetry of the body. Symmetrical elements at the surface of the body have the same irritability; unsymmetrical elements have a different irritability. Those nearer the oral pole possess an irritability greater than that of those near the aboral pole. These circumstances force an animal to orient itself in such a way that symmetrical points on the surface of the body are stimulated equally. In this way the animals are led without will of their own either toward the source of stimulus or away from it. Thus there remains nothing for the ganglion cell to do but to conduct the stimulus, and this may be accomplished by protoplasm in any form."

If, for instance, a worm were near a bit of food we might suppose that the substances diffusing from the food would strike one side of the body of the worm causing the muscles there to contract more strongly than the opposite ones. The worm would turn toward the food until both sides of the body were equally affected, when it would proceed directly toward the source of stimulation. Negative responses receive an essentially similar interpretation. The point that is emphasized by the theory is that choice or volition on the part of the animal is excluded; the actions of the creature are supposed to be mechanically determined. It is "forced" to go toward or away from the source of stimulation as the strength of the stimulus and the organization of its body determine. The moth flies to the candle, not because it is drawn by curiosity, as suggested by Romanes, or from any other conscious motive, but because it is compelled to orient its body so that sym- 
metrical points receive equal amounts of stimulation. The orientation of animals to heat, chemical substances, gravity, the electric current and currents of air and water is naturally explained in much the same way. Animal instincts may be analyzed into simple tropisms or may be conceived to be developed from them as a basis.

The tropism theory of Loeb and his followers has met with a certain amount of opposition, especially by Jennings, who showed that in many of the so-called tropisms of the lower organisms there is no definite orientation produced. In the gathering of Paramœcia in weak acid, for instance, the organisms are not forced into line with the diffusion currents and compelled to swim toward the chemical, but individuals which swim into the acid by chance remain there; whenever they attempt to pass from the dilute acid to water they reverse their course, and thus are kept confined to one region. While the chemotactic grouping of Paramœcia depends upon a definite reflex, it is produced in a manner quite different from Loeb's scheme of orientation. Many of the so-called tropisms of the infusoria and other asymmetrical forms were found to take place in accordance with the method followed by Paramœcium.

In some cases where orientation is effected it may take place more or less indirectly by the selection of random movements. In the earthworm and in the larvæ of blow flies which are negatively phototactic it has been shown by the writer that movements which bring the animal toward the light are checked or reversed and only those which happen to direct the animal away from the light are followed up. Whatever immediate orienting tendency the light may have in these cases is relatively unimportant as compared with the element of selection of favorable chance movements in directing the animal away from the light. The tropism 
does not as in Paramœeium occur independently of orientation, but the orientation is only indirectly produced instead of being the result of appropriate direct reflexes.

The movements of organisms toward or away from certain stimulations, even where they are quite directly caused, may be brought about in a variety of ways. They are by no means always the result of a forced orientation. Nevertheless such movements are commonly described as tropisms. Whether or not the tropic response is effected in one or the other of the ways we have described it may be just as much the result of reflex action and just as little the outcome of intelligence and volition.

\section{CHEMOTAXIS}

Movements toward or away from chemicals are naturally widespread. Many kinds of bacteria are markedly chemotactic. Englemann found that Bacterium termo gathers near the margin of the cover-glass where there is more oxygen than near the center. If green algæ are present the bacteria congregate around them as long as they are exposed to sunlight and are therefore giving off oxygen. If the slide is kept in the dark so that no more oxygen is produced and the oxygen present becomes evenly diffused the bacteria become uniformly scattered over the field. Englemann in an ingenious experiment also showed that if a spectrum were thrown on a long thread of the alga Cladophora the bacteria would congregate most abundantly in the red end of the spectrum where most oxygen is given off. The experiment affords a delicate test of the amount of oxygen evolved under the influence of the various kinds of light.

Bacterium termo and other species were found by Pfeffer to be attracted to various salts if they were employed in weak solution, as well as a variety of other substances of the 
most diverse chemical constitution. Many compounds were found to exercise a repellent effect, especially in strong concentration. Amœba reacts negatively to most chemicals that affect it. Where it comes in contact with the diffusing chemical the ectoplasm contracts; currents beginning in the stimulated region gradually extend through the body; pseudopods are thrust out opposite the stimulated part and the Amœba begins to crawl away. Positive chemotaxis probably plays a part in the food taking of Amœba, although its rôle has not been clearly worked out. In the

A

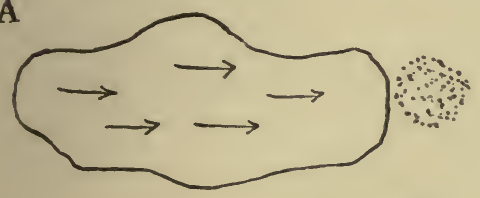

B

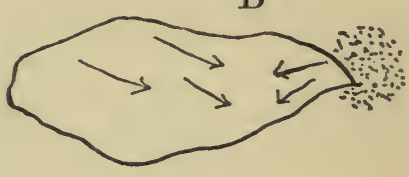

C

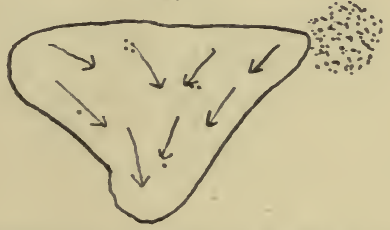

Fig. 1.-A. B. C. Sucessive phases of the reaction of Amøebs to a chemical (represented by the dotted area).

amœboid plasmodia of myxomycetes, which usually live upon decaying wood, Stahl has found that extract of bark produces a positive response.

Chemotactic reactions are as a rule pronounced among the infusoria. Paramœcia and some other forms collect in weak acids, while they are generally negative to stronger acids and to alkalies. If a drop of strong carbon dioxide solution is placed in the midst of a lot of Paramœeia the infusorians will form a ring about it. Being negative to the stronger acid at the center of the drop and positive to the weaker concentration that surrounds it they naturally collect in a 
band or ring whose diameter varies with the size and strength of the drop. As the solution diffuses and becomes diluted at the center, the ring widens and extends toward the center and after a time closes in to form a solid group. If two species of protozoa having a different attunement to carbon dioxide are used they may form two rings, one outside of the other.

The tendency of Paramœcium to form groups may be explained as due, in part at least, to their positive chemotaxis to carbon dioxide. If water containing Paramœcia is allowed to stand undisturbed for some time most of the

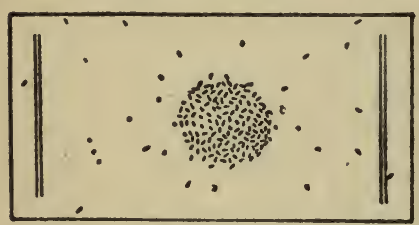

FrG. 2.-Showing the positive chemotaxis of Paramœcium to a drop of a weak solution of carbon dioxide. individuals will be found in groups or clusters as if they were drawn together by their social proclivities or by some object of common interest. But the cause of the association is much simpler. As Paramciœa give off carbon dioxide there is a greater quantity of it in a region where several Paramœcia happen to be associated. Positive chemotaxis to this substance tends to keep the cluster together as well as to retain other individuals which happen to come into the region, until finally most of the Paramœcia in the vicinity are assembled in the group. Other infusorians, such as Oxytricha and Loxocephalus, form associations which are not due to carbon dioxide or to any other acids since they show no positive chemotaxis to these substances. There is probably some substance which produces the grouping, although it has not yet been identified.

The chemotaxis of the lower organisms is to a certain extent related to the welfare of the individuals, although in only a general sort of way. The negative reaction to strong 
chemicals is a purposive trait, although many forms do not react away from solutions which are decidedly injurious. According to Massart Polytoma uvella may not be repelled even by the strongest chemicals. Other organisms while perfectly able to swim away, do not seem to be prepared for meeting such a situation as the presence of injurious chemicals by any appropriate response. If specimens of Loxophyllum meleagris and Paramœcium are placed together under a cover-glass and a small drop of acid applied to one edge the Paramœcia will avoid the acid, but the Loxophylla move about helplessly, many of them swimming directly into the strong acid, others which may be overtaken by the acid showing no more tendency to swim away from it than toward it. The result is that nearly all of the Paramœeia in the region of the diffusing acid escape, while nearly all of the Loxophylla perish.

The general tendency of Paramœcium to collect in all kinds of weak acid and to react negatively to alkalies is probably of little service to the organism. Bacteria show a positive reaction to various substances which they never encounter under normal conditions and whose presence can scarcely be of any benefit to them. On the other hand, the positive reactions of several species to oxygen, as well as the negative reactions of certain anaerobic species, are doubtless beneficial modes of response. It is not improbable that in many cases the response to substances that are not beneficial is the incidental result of the organization which causes positive responses to substances that are beneficial. For instance, it may be advantageous to Paramœcium to be constituted so as to react positively to weak solutions of carbon dioxide, and its positive response to other weak acids may depend upon the same peculiarity. While much of the chemotactic behavior of lower organisms may be indifferent 
as regards utility or may be positively injurious, a considerable amount of adaptiveness is shown, especially to substances which are habitually encountered. The situation is much as would be expected if starting with reactions which primarily showed no relation to utility organisms came to have their irritability modified and directed along serviceable lines to the extent, and only to the extent that was necessary to insure survival under the conditions to which they were naturally exposed.

Chemotaxis is shown by parts of organisms, especially the free cells such as spermatozoa, antherozoids, and leucocytes. Pfeffer showed that the spermatozoids of ferns would collect in capillary tubes containing a dilute solution of malic acid and he concluded that the presence of this substance in the archegonia is the means of drawing the spermatozoids to the egg cell and thus effecting fertilization. A similar rôle is supposed to be played by cane sugar in mosses. The white blood cells which have the property of crawling about much like Amœba are attracted by certain substances, and often gather in large numbers where there is a bacterial infection. If a small tube containing a culture of Staphylococcus aureus in agar is placed in one of the lymph spaces of a frog the white corpuscles will migrate into it in large numbers. A tube with the same culture medium, but without the bacteria will not be invaded, showing that it is the presence of some substance given off by the bacteria which causes the leucocytes to enter the tube.

The chemotactic movements of Amœba and related forms differ markedly from the scheme followed by the infusoria and many flagellates. In Amœba the part directly affected is the first to act and there is a more or less definitely directed series of movements away from the chemical. In the positive reactions of Paramcecium there is no orienta- 
tion of the body, no seeking of the stimulus and no attraction in any sense. The Paramœcia as they happen to approach a drop of dilute chemical to which they are positively chemotactic, swim into it without interruption, but when they encounter the other side of the drop and experierce the transition from weak acid to water they give the motor reflex or avoiding reaction and change their course. As often as the Paramœcium encounters this boundary it reacts in the same way. It behaves as if caught in a trap which presents no obstacle to its entrance, but effectually prevents its exit. Other Paramœecia swimming by chance into the drop are also caught there and soon a collection is formed which may ultimately include all the individuals of the region. In the negative response the method is much the same only it is the transition from weak to strong acid which causes the stimulation. The avoiding reaction is given in the same way in each case. All of the chemotactic responses take place without any orientation of the body, by a method of trial and error.

In the flagellate Chilomonas Jennings has shown that chemotactic grouping takes place just as in Paramoecium. In the bacterium. Spirillum he finds much the same method employed. Spirillum swims by the movement of flagella at one or both ends of the body. When stimulated it simply reverses its direction of movement. Positive and negative reactions take place in exactly the same way. What things are avoided and what are sought depends upon what acts as a stimulus causing the reversing reaction. Apparently these simple organisms have no power of orienting their bodies; they simply move back and forth, relying on chance to get them into a favorable situation. When such a situation has been reached the organisms remain relatively quiet. In several cases among the flagel- 
lates and in spermatozoids and swarm spores it has been supposed that there is a direct turning toward the chemical. This may occur in some forms and more especially the symmetrical ones, but it has not yet been established. Analogy with the effect of light on Euglena which may call forth either the motor reflex or a gradual swerving of its course toward the stimulated side makes the existence of a parallel response to chemical stimulation more or less probable.

The cœlenterates show scarcely any behavior which can be described as chemotactic although reaction to chemicals is of course general. If a Hydra is locally stimulated by a strong chemical which is allowed to diffuse against the body from a fine capillary tube there is contraction of the muscles in the stimulated area causing the body to bend toward the chemical. This is certainly not a teleological response; rather the reverse of one. A still stronger stimulus however will produce a general contraction of the body which enables the animal to avoid more serious injury. In planarians both positive and negative reactions may be induced. The common fresh-water Planaria maculata may be made to follow a piece of meat around in any desired direction. The substances diffusing from the meat seem to stimulate the worm to turn its head directly toward the food. Strong chemicals, on the other hand, cause it to turn directly away. Earthworms, according to Darwin, find food that is buried under the earth through the sense of smell. Disagreeable substances cause contraction and writhing about, which may bring the worm out of the region of the offending stimulus. A strong chemical applied to one side of the body may cause the animal to turn toward the other side, but the avoidance of such stimuli is mainly effected by general and random movements. 
Crustaceans are able to detect food at some distance and direct themselves toward it, but one may question if such phenomena should be classed under the head of true chemotaxis. Similarly with the olfactory reactions of ants. These insects follow a scent track with considerable accuracy. In this way they may be guided to food discovered by other ants and find their way back to the nest. The tendency to follow these tracks is doubtless instinctive, and so also is the action of a dog in following the trail of a rabbit. The behavior of the dog is on a much higher level than a mere tropism, and it is probable that the behavior of the ant is also, but to a less degree. But where to draw the line between such actions and chemotaxis proper is perhaps capable of only an arbitrary decision.

\section{GEOTAXIS}

Gravity exercises a directive effect upon the position and movements of many animals while in other forms it has little orienting power. The protozoans Euglena and Chlamydomonas commonly swim upward in the dark as well as in the light, but this reaction is checked at a low temperature of $5^{\circ}$ or $6^{\circ} \mathrm{C}$. Massart studied the geotactic movements of a number of unicellular plants and animals by placing them in a capillary tube open at either end so as to render the supply of oxygen the same above and below. He found that the sense of the geotactic response varies in allied species of the same genus, as for instance, Spirillum some of which are positive and some negative under the same conditions. The sense of the response could be changed in some cases by temperature. Thus Chromulina, which is negative at $15^{\circ}$ to $20^{\circ} \mathrm{C}$., becomes positive at a temperature of $5^{\circ}$ to $7^{\circ} \mathrm{C}$.

The geotaxis of Paramœcium is quite variable and often quite feeble. Generally there is a tendency to swim up- 
ward, but Miss Moore has shown that lack of food, changes of temperature and other factors may cause a reversal of the response. The infusorian Spirostomum has the peculiar trait of attaching itself to the bottom by means of a mucous thread at the posterior end and orienting itself in a vertical position.

Among the Coelenterates as in the Protozoa there are many forms in which geotaxis seems entirely absent. The fresh water Hydra will attach itself to the bottom or side of an aquarium or hang downward from the surface film with apparently equal readiness. Many anemones are equally indifferent to their position, but Sagartia, according to Torrey, will bend upward if attached to the side of an aquarium and slowly migrate to the top. Loeb found that if Cerianthus, which lives with the lower part of its body buried in the sand, is placed in an inverted position in a testtube the foot will curve downward and the bending will gradually continue until the animal finally straightens out into an upright position.

In jellyfish which generally swim with the oral side downward orientation has been attributed to the statocysts which occur on the margin of the umbrella. In Gonionemus, however, Murbach has shown that orientation is unimpaired after the destruction of all these organs, so they cannot be the exclusive seat of the reaction to gravity. The orientation is not one which is passively assumed for, as Murbach has shown, specimens which have been killed float with the oral surface upward.

In the Ctenophores the statocyst which is located at the aboral pole of the body is a more essential organ of equilibrium, for as Verworn has shown the removal of this organ is followed by loss of orienation to gravity. In some Cœlenterates-Antennularia (Loeb), Sertulariella (Driesch), 
Cormyorpha (Torrey)-geotropism is manifested in the direction of growth much as in the higher plants.

Among the worms geotactic migrations are manifested by Convoluta and were found by Bohn to vary with the tide as is described in another connection (Chapter VII). Destruction of the statoliths in this form was found to destroy its reaction to gravity. The sea-cucumber Cucumaria cucumis is described by Loeb as having a marked tendency to crawl upward. The upward migration occurs as well in inverted glass cylinders, showing that it is not the supply of oxygen which attracts the animal to the upper surface.

A tendency to vertical migration is shown by many free swimming crustacea. In the copepod Labidocera Parker observed that the females showed a marked negative geotaxis in the dark, but when exposed to light their geotaxis became positive. Whether they were illuminated from above or below did not alter their response. Although negatively phototactic they nevertheless swim downward when light falls on them from below.

Many crustaceans have statocysts which are especially concerned in the maintenance of equilibrium. In Mysis they are located in the inner branch of the caudal appendages. Delage found that if these organs were destroyed the animals had difficulty in maintaining their equilibrium, which was further increased by the destruction of the eyes. In the decapod crustacea the statocysts are situated in the basal joint of the antennules. Destruction of these organs is followed by a variable degree of loss of equilibrium in different species.

The most instructive and ingenious experiments in the functions of the statocysts were performed by Kreidl on the prawn Palæmon. In moulting, the lining of the statocysts is cast off and the statoliths or small particles of sand they 
contain are consequently ejected. The prawns replace these by small bodies which they pick up with their chelæ and put in the statocyst. Kreidl placed several Palæmons after moulting in a dish containing some small bits of iron, which the prawns put into their statocysts in place of the usual sand. If now a strong magnet was brought near, the bits of iron would be brought toward it and exercise a pull analagous to the vertical pull of gravity. Kreidl found that by changing the position of the magnet the Palæmons could be induced to orient their bodies in any desired position.

When in the web many kinds of orbweaving spiders hang with their heads down. Mosquitoes, on the other hand, when resting on a vertical wall usually have the reverse orientation. Other insects when under rocks or boards tend to hang down from the upper surface rather than rest on the lower one. Lady beetles, according to Loeb, when placed in a dark box uniformly crawl upward and come to rest at the highest point. Cockroaches prefer to rest on the vertical sides of a box rather than the top or bottom, but they do not seem to have a marked tendency to crawl upward to the highest point. A tendency to crawl upward is not uncommon in insect larvæ, especially those which feed on plants, a trait which is naturally of service in leading them to their food.

The tendency to maintain a certain orientation with respect to gravity is more common than the bent toward upward or downward migration. This is especially true of higher animals, and among the vertebrates orientation is practically the only response to this force. The inner ear in vertebrates plays an important part in the maintenance of the normal position, but a description of the numerous experiments on this subject would carry us too far. The presence of a specific sense organ for the maintenance of 
equilibrium is by no means general. Such organs occur in medusæ, ctenophores, turbellaria, crustacea, mollusks and vertebrates, and have been evolved along many independent lines of descent. They may be absent in many species of all these groups, excepting the ctenophores and vertebrates, without entailing any loss of the sense of equilibrium. Geotropic irritability in many cases seems to be quite generally distributed throughout the body. Where special organs of equilibration have been evolved orientation is generally only partially dependent upon them. In but few cases is orientation to gravity entirely destroyed when these organs are removed.

\section{THIGMOTAXIS OR STEREOTROPISM}

The lives of all animals are spent in more or less permanent contact with solid objects and reactions to the stimuli thus afforded are universal. Contact of various kinds means food, enemies, shelter and many other things of interest to the organism or its posterity. Any animal in order to stand the least chance of survival must be endowed with the power to react to contact with various solid objects in an adaptive manner. There are such varied modes of reaction to contact that the limitation of our descriptive terms is a matter of unusual difficulty. A contact reaction by a pseudopod of an Amœba and the heels of a mule are very different kinds of behavior although, on reflection, it is evident that they possess certain features in common. One class of reactions to contact has been termed by Loeb stereotropism, which he defines as "the peculiarity, possessed by some animals, of orienting their bodies in a definite way toward the surface of other solid bodies," and he distinguishes stereotropism from other responses, such as locomotor movements, which follow the application of a contact stimu- 
lus. Verworn coined the word thigmotaxis, which is practically synonymous with stereotropism, in order to designate "all those cases of barotaxis . . . . . . . in which the phenomena are caused by the more or less strong contact of living substance with solid bodies," the term barotaxis embracing reactions which are "called forth by pressure acting unequally on different sides" of the body. Rheotaxis caused by currents of air or water, geotaxis which according to Verworn is produced by differences in pressure on different parts and thigmotaxis are all classed by this writer as special cases of barotaxis.

Thigmotaxis may be positive or negative, the difference depending in many cases on the strength of the stimulus. This is shown by the reaction of the rhizopod Orbitolites.

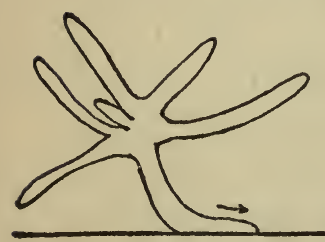

a

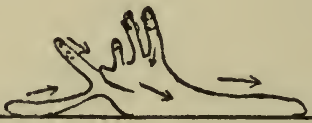

$b$

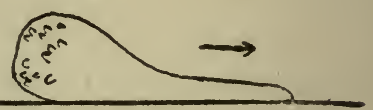

c

FIG. 3.-Showing the positive reaction of Amœba to contact with a solid object. (After Jennings.)

When quiet this form sends out long and very fine filamentous pseudopodia. When these are brought in gentle contact with another object the protoplasm flows out along the filament and finally draws the whole body toward the object. If the pseudopod is cut or pressed upon by a needle the protoplasm flows centrally and the pseudopod is withdrawn. Amœba when floating in the water usually sends long pseudopods out in various directions. If one of these strikes the bottom it commonly adheres to it; the endoplasm streams into it from the main body and finally the whole Amœeba begins to crawl in the direction of the attached 
pseudopod. Such a reaction is of evident service to the Amœba in leading it into contact with objects where it secures food and protection. The process of food taking itself is probably dependent to a certain extent upon a thigmotactic motion. Strong contact such as striking a pseudopod with a needle causes the reverse or withdrawing reaction. By repeated application of the stimulus to one side Amœba may be driven about in any desired direction.

Paramœcia were found by Jennings to react to contact by collecting against solid objects. Often bits of substance are fairly coated by these infusorians. The cilia in contact with the object cease beating and stand out at right angles to the body while the cilia of the oral groove and sometimes also in other parts of the body, continue their movement. Among the hypotrichous infusoria the tendency to keep in contact with solids is very strong. In these forms the cilia on the under side of the body are metamorphosed into cirri which are employed in running about over objects much in the same way as an insect uses its legs. An Oxytricha is described by Verworn as happening to get upon the round egg of the clam Anodonta. It ran about for hours unable to leave the surface since the egg rested on the bottom at only one point.

The infusorian Loxophyllum is usually engaged in gliding about on its right side. It is apparently indifferent as regards orientation to gravity, as it will move about on the under side of a surface film with its right side uppermost as well as on the bottom. When turned over on its left side it rights itself in several different ways. Even small pieces show the same tendency to keep the right side in contact with solids and they will also right themselves when turned over. Much of the righting movements of the lower animals consists in the effort to keep a certain side in 
contact with a solid rather than in any response to gravity. This is notably the case in the fresh-water Hydra. In Planaria there is an effort to keep the ventral surface in contact with some object whatever position in relation to gravity this may involve. Planaria maculata shows a modification of the thigmotactic response which Pearl has called goniotaxis. When placed in a dish these animals form groups in the angle between the bottom and sides. The amount of surface in contact with the solid is not appreciably greater than when the Planarian is on a flat surface, but what is sought by the animal is a situation such that the body becomes bent at an angle.

Thigmotaxis is a very common trait among worms in general. The effort to get into holes or crevices, or to work in under rocks, by which these forms secure protection from their various enemies, is to a large extent a manifestation of this type of reaction. Maxwell showed that if specimens of Nereis, which are usually found in burrows in the sand near the seashore, are placed in a dish with a number of glass tubes just large enough for them to enter, they will crawl into the tubes and remain there even when exposed to direct sunlight which is strong enough to kill them.

Most amphipods and many isopods are strongly thigmotactic and tend to collect in crevices between rocks or among masses of seaweed where they secure contact over a considerable surface of the body. Among insects the instinct to creep into crevices is a common trait. Earwigs if given an opportunity to wedge themselves under a glass plate will remain there, in spite of their negative phototaxis, even when exposed to strong light. The moth Amphipyra, although positive in its reaction to light, will cease its phototactic activities if given an opportunity to crawl under a glass plate, where it will remain quiet (Loeb). 


\section{RHEOTAXIS}

Under the head of rheotaxis are included the movements of animals as directed by currents. This response is shown even among very low forms. The plasmodium of the slime mould Aethalium when placed on a filter paper along which a current of water is passing slowly creeps opposite the direction of the flow. It is not improbable that spermatozoa migrate up the oviduct on account of the current which the beating of the cilia causes to flow toward the uterus.

Among fishes orientation to currents is a common phenomenon. Many fishes have the instinct to head up stream and swim against, the current. Lyon has shown that this is due in large measure to reactions to movements of objects in the visual field. In his experiments he used an aquarium with a glass bottom "so supported that the bottom was freely accessible. Close along the bottom, beneath the glass, could be drawn a long piece of white cloth with black strips painted across it. This would give the impression of a moving bottom. Fish (Fundulus) placed in the aquarium oriented themselves with the head in the direction of the moving bottom and swam along it to the end of the aquarium. Reversing the movement of the bottom reversed the orientation and movement of the fish."

The orientation of animals to currents has been explained as due to differences in pressure produced by the current in different parts of the body. It is obvious that such differences can be produced only when the current moves past the animal. Where the animal is entirely immersed and is carried along passively the effect, as Lyon points out, is the same as if it were in quiet water. It is like a man in a balloon carried by the wind. Moving at the same rate as the air about him he becomes conscious of motion only when he can see objects on the earth passing by beneath. 
In another experiment by Lyon fish were placed in a long bottle which was corked. When the bottle was pulled through the water the fish immediately swam opposite the direction of movement. If the bottle was allowed to flow down stream the fish would swim to the up stream end; if it was pulled up stream the fish would swim to the down stream end. It is evident that rheotaxis takes place through orientation to objects in the field of vision. In young lobsters Hadley has shown that rheotaxis is a sight response much as in fishes. In later stages when the lobsters keep closer to the bottom rheotaxis is gradually lost.

Blinded fish may orient themselves to currents so long as they are in contact with the bottom of the stream, but when they leave the bottom they lose entirely their rheotactic response, unless different parts of the stream with which they come in contact have different velocities.

Many insects tend to fly against the wind (anemotropism). This also is probably a sight reflex, since the insect receives pressure from the air only when flying against it. May flies, according to Radl, often hover over one spot, slowly rising and sinking, but keeping their bodies facing the wind and their long fore-legs stretched forward. The same trait is shown by many insects, especially flies, even when there is no perceptible breeze. Often a group of flies will kcep hovering near one, and will move as one's body moves always keeping away at about the same distance. Apparently we have to do here with an effort to maintain a certain relation to the visual field which so largely determines the rheotactic responses of fishes.

It is obvious that under the head of rheotaxis phenomena have been included which are quite unlike in their causation, some of them being reactions to pressure differences, others presenting interesting points of similarity to phototaxis. 


\section{COMIPENSATORY MOVEMENTS}

A class of phenomena having certain relations to rheotaxis are the so-called compensatory motions of animals. These may easily be illustrated by a common frog. If a frog be slowly rotated about a vertical axis it will turn its head and may begin to walk opposite the direction of movement. If it is tilted downward in front, the head will be raised, while if it is inclined upward, the head will be lowered. Various combined motions will be responded to by movements which tend to keep the head in the same position as before.

A pigeon when slowly rotated on a horizontal turntable turns its head opposite the direction of movement until it reaches a certain angle with the body when it is suddenly jerked back to its original position. It immediately repeats the previous movement until its head reaches again the maximum angle when it is jerked back again as before. If the head is held during rotations, compensatory motions followed by regular jerking back movements are performed by the eyes. Mammals show similar movements, and mice and several other forms run around on the turntable opposite the direction of rotation. An interesting form of compensatory movement is shown by the common domestic fowl. Hold an individual in the hands and move it slowly back and forth, up and down, or sidewise. If the fowl is not carried too far the head will keep in almost exactly the same position, the neck being often stretched out to its extreme length before the head follows the movements of the body.

It was formerly supposed that in vertebrate animals compensatory motions were dependent on the semicircular canals, but it was found that these motions still persisted after the semicircular canals were plugged up or extirpated, or after the nerves supplying them were cut. The otoliths 
2 are not necessary organs for these movements (Lyon).

In insects compensatory motions are easily observed. If flies, beetles and many other forms are rotated on a turntable they generally walk around opposite the direction of rotation. This reaction apparently depends upon the eyes since it is no longer performed if the eyes are blackened over. If robber flies or dragon flies are held in the hand and rotated the head will show reverse movements much as in the frog. In the crayfish and other higher crustaceans compensatory motions are shown by the eye stalks. If a specimen is rotated slowly about its long axis the eye stalks will move opposite the direction of rotation. Similar movements follow upon rotation about a vertical axis. Blacking over the eyes of the crayfish causes a diminution of compensatory motions upon rotation in a vertical plane, but produces little or no effect on movements of the eye stalks upon rotation about a dorso-ventral axis (Lyon).

In many cases the effort to keep a constant visual field is an important element in determining compensatory motions, but it is not the sole cause of such motions in all forms. Sight is probably of more importance than any other single factor, but static organs in some cases seem to play a part also. In the dog-fish, however, Lyon has shown that compensatory movements of the eyes regularly occur, although somewhat weakened, in specimens in which both the optic and the auditory nerves have been cut.

\section{PHOTOTAXIS}

Of the numerous papers on tropisms a greater number have been devoted to phototaxis than to any other subject. Only a very brief discussion of the results therefore can be attempted here. Investigation has shown that reactions to light do not fall under any one general scheme of explana- 
tion. Loeb early distinguished phototaxis or heliotropism from mere reaction to differences in the intensity of light (Unterschiedsempfindlichkeit) where there are no definitely directed movements and subsequently applied the term photokinesis to the latter phenomenon. The tube-dwelling annelid Serpula may be made to suddenly draw back if a shadow is thrown upon its expanded gills. If the light be suddenly increased no reaction occurs. In the bivalve Psammobia, Nagel found that sudden increase of light caused a retraction of the extended siphons; while many other species (Cardium, Mactra, Solen) would give a similar reaction to shadows. In this connection may be mentioned the reactions to shadows of the large leech Clepsine which is parasitic on turtles. If a shadow is thrown upon a lot of hungry leeches in a dish of water they will raise up and extend the anterior part of the body and sway it about in various directions. The function of this response is to enable the leeches to. attach themselves to any passing turtle and thereby secure their food.

Animals may form collections in shaded localities not because they are negatively oriented by the rays of light, but because light stimulates them to general activity, and when they happen to come into a place where they are less stimulated they become relatively quiet. Loeb found that if fresh water planarians are placed in a round dish in front of a window they collect at the sides of the dish which are more or less shaded instead of at the side farthest away from the window where they would naturally assemble if they were guided solely by negative phototaxis. In bright light these animals are active and when they wander into a shaded spot they move more slowly and thus tend to collect there. Parker, however, has shown that Planaria maculata is oriented to a certain extent by the rays of light, and Walter's 
extended studies prove that both phototaxis and photokinesis are factors which, in varying degrees, determine the behavior of this species.

Positive phototaxis is often combined with photokinesis. In the large amphipod Talorchestia there is a marked phototaxis. Specimens placed in a glass dish before the window or an artificial light keep hopping toward the light and struggling to get as near it as possible for hours at a time. Yet if individuals chance to get into a shaded region where they are less strongly stimulated they often remain there. Among positively phototactic insects similar behavior is not uncommon. Many insects are quite spasmodic in their phototaxis. They may run about in apparent unawareness of light and then suddenly become seized with an impulse to go toward it. These insects frequently keep in shaded localities most of the time and would ordinarily be thought to be negatively phototactic while in reality they only manifest a tendency to rest in shaded places into which they happen to wander. The proclivity to crawl under objects is commonly also, in part at least, a manifestation of positive thigmotaxis.

Among animals which regularly go toward or away from the light there are considerable variations in the method employed. While in many forms there is a direct orientation to the rays, in others the orientation is only brought about indirectly. Larvæ of blow flies commonly crawl away from the light, but by a method which I have elsewhere referred to as the selection of random movements. To quote from my previous account, "When strong light is thrown on a fly larva from in front, the anterior end of the creature is drawn back, turned toward one side, and extended again. Often the head is moved back and forth several times before it is set down. Then it may set the head down when it is 
turned away from the light and pull the body around. If the head in moving to and fro comes into strong light it is often retracted and extended again in some other direction, or it may be swung back without being withdrawn. If a strong light is thrown upon a larva from one side it may swing the head either toward or away from the light. If the head is swung toward the light, it may be withdrawn or flexed in the opposite direction, or, more rarely, moved toward the light still more. If it is turned away from the light the larva usually follows up the movement by locomotion. Frequently the larva deviates considerably from a straight path, but as it continually throws the anterior end of the body about and most frequently follows up the movement which brings it away from the stimulus, its general direction of locomotion is away from the light. In very strong illumination the extension of the anterior part of the body away from the light is followed by a retraction, since in whatever direction it may extend it receives a strong stimulus and the larva writhes about helplessly for some time. Sooner or later, however, it follows up the right movements."

The earthworm was found to orient itself in a similar manner. "If a strong light is held in front of the worm it at first responds by a vigorous contraction of the anterior part of the body; it then swings the head from side to side, or draws it back and forth several times, and extends again. If in doing so it encounters a strong stimulus from the light a second time it draws back and tries once more. If it turns away from the light and then extends the head, it may follow this up by the regular movements of locomotion. As the worm extends the head in crawling it moves about from side to side, and if it happens to turn it toward the light.it usually withdraws it and bends in a different direction. If it bends away from the light and 
extends, movements of locomotion follow which bring the animal farther away from the source of stimulus."

While orientation in the earthworm is ordinarily brought about mainly by the selection of random movements, light has a certain power to cause the worm to turn directly away from it, but this is only a minor factor under usual conditions. Harper has shown that if the earthworm Perichota bermudensis is exposed to very strong light it turns directly away from it, while in weaker light orientation is brought about by the method just described. In the leeches Clepsine and Nephelis negative orientation is effected in part directly, and in part by following up those random movements which bring respite from the stimulus.

Among the protozoa the light reactions of Stentor ceruleus have been found to occur in much the same way as the reactions of Paramœcium and other infusoria to chemicals. According to Mast the anterior end of Stentor is much more sensitive to photic stimuli than other parts of the body. If a a Stentor swims into a more highly illuminated region it gives the avoiding reaction, swimming back, turning to the aboral side and going ahead in a new direction. If light is coming into a dish from one side the Stentor gradually gets oriented to the direction of the rays. If it turns toward the light it gives the avoiding reaction and keeps on repeating the action until it becomes pointed away from the light, when it swims away in a fairly direct path. The infusorian could not be seen to turn directly away from the light; it swims away from the light because if it starts to swim in any other direction its course is checked and its direction of swimming changed.

Euglena viridis, like Stentor, was found by Jennings to give a motor reflex upon strong illumination. The anterior end of the body which contains the red eye-spot is more sensitive than other regions and if Euglena passes into a 
region of higher light intensity it is apt to reverse its movement and change its course. In this way it may avoid regions of strong illumination. In weak light, however, Euglena is positively phototactic. It swims in a spiral, but in a fairly direct path toward the light. If during its progress the light is carried to one side Euglena gradually turns until it is oriented to the direction of the rays. Although Jennings attempts to explain the orientation as a result of a modified motor reflex, I cannot see but that the method employed is one of direct orientation. Departures from the line are corrected, not as in the earthworm, by a lot of undirected movements until the right one is hit upon, but by an appropriate turn in the right direction.

Among a very large number or organisms in various phyla of the animal kingdom we find that there is a fairly definite and direct orientation to the rays of light. Deviations from the path to or from the light are checked by a movement which brings the animal into line again. In lower forms this movement is doubtless an involuntary one based upon the property of responding to a localized light stimulus by a direct reflex. Departure from the line of orientation subjects

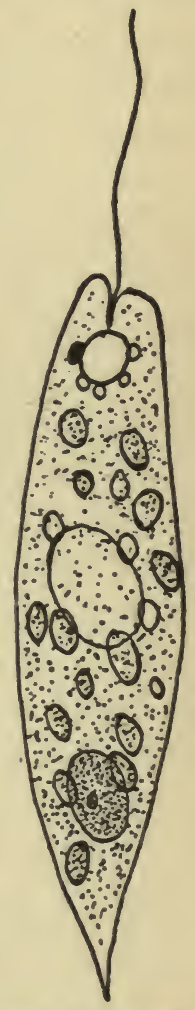

FIG. 4.-Euglena viridis. the animal to unequal stimulation on the two sides and the unequal motor activity thus produced brings the animal back into line again so that both sides are equally stimulated and locomotion takes place either toward or away from the light in the direction of the rays. The course of the animal is, as it were, automatically regulated. The mechanics of the 
process varies greatly in different animals. Orientation may be effected by the action of the cilia, flagella, muscles of the body wall, legs and wings; and the way in which special parts function to bring about orientation may be fundamentally different in different forms. In some cases the whole body is sensitive to light, in other cases only certain regions, and in many forms the response is entirely dependent upon the eyes.

There has been more or less controversy as to whether the phototactic reaction is due to the direction of the rays or to the differences in light intensity. A good part of this discussion has been based on misunderstandings. If an animal is oblique to the rays of light it naturally becomes stimulated with unequal degree of intensity on its two sides, which probably causes the orienting movements. There is little doubt that direction of light in the majority of cases, if not in all, causes orientation in this manner; it is possible, however, that in more or less transparent animals the direction the rays take through the tissues may determine orientation in a way analogous to the directive effect of the galvanic current, but at present we have no convincing evidence that such is the case.

It was shown by Loeb in all the animals he subjected to the experiment that it is the rays toward the violet end of the spectrum that are the most potent in producing the phototactic response. Red light has comparatively little orienting power and many phototactic animals react to it as to darkness. I have found, however, that the amphipod Orchestia agilis when brought into a phototactic dark room illuminated by light through ordinary red glass is markedly positive. Specimens in a dark box held so as to get the red light reflected from one wall still showed a positive response although the light was so dim I could scarcely see their movements. 
While some exceptions to the above rule have been pointed out by Minkiewicz and Bohn, it is one of very general validity and affords a striking parallelism to the phototactic movements of plants.

The phototactic response in animals may be modified or reversed by a variety of agents. Whether animals are positive or negative often depends upon the intensity of the light. This is well illustrated by the reactions of Volvox. This form consists of an almost spherical colony of cells each of which is furnished with a pair of flagella which serve as organs of locomotion. One axis of the colony is somewhat longer than the others and upon this axis Volvox commonly rotates while swimming. When exposed to a moderate light the colony swims toward it in a nearly straight line; when it happens to get out of orientation it turns directly back into line again. - If it reaches a point of too great intensity its movements become slower, its orientation less precise and it may stop or swim about slowly in various directions. If exposed to light above the optimum it orients itself in the reverse direction and swims away. Many flagellate protozoa and the swarm spores of many algæ are similarly positive in weak light and negative in strong. Among higher organisms reversals following change of light intensity are less common although there are several cases. The earthworm Allolobophora foetida which is commonly negative shows a slight positive reaction in exceedingly weak light (Adams). A great many positive forms remain positive in as strong light as has been brought to bear upon them and most negative species remain negative in as weak light as they respond to in any definite way.

The sense of the phototactic response is sometimes changed by exposure to light or darkness. Groom and Loeb found that the larvæ of Balanus are positive in the 
morning even to strong light, but later in the day they become negative in light of less intensity. This apparently determines the periodic depth migration of these forms, for they are usually found at the surface of the sea in the morning and in the afternoon in deeper water. If a culture is placed at any time in darkness for some hours, the larvæ when first exposed to light are positive, but later become negative, the change taking place more quickly the more intense the light. Similar effects of exposure have been found in other forms. A curious instance of the effect of previous exposure is afforded, however, by the amphipod Orchestia agilis. If specimens are subjected to strong light they are markedly positive and remain so for a long time. If they are suddenly transferred to light of weaker intensity they immediately show a decided negative reaction. This, however, is only temporary; within a few minutes or half an hour they all become positive again. If now they are exposed to still feebler light they again become negative. I have performed this experiment repeatedly and have found that these changes occur in the most decided and striking manner.

In some cases positive phototaxis may be actually increased, up to a certain limit, with the length of the exposure. Animals whose first responses may be hesitating or indefinite get, as it were, "warmed up" to the work, and finally become almost violent in their efforts to reach the light. The water scorpion Ranatra after having been kept in the dark for several hours is commonly negative; then it shows spasmodic fits of a positive response which grow longer and stronger until the creature chases wildly after the light and becomes wrought up into the highest pitch of excitement. I have found that fiddler crabs, which when first exposed to artificial light show signs of alarm and run away, gradually become more and more strongly positive and after a time 
become apparently oblivious to any other stimulus except the light which they slavishly follow.

The effect of temperature on phototaxis is by no means uniform. Loeb found that certain marine copepods and the larvæ of Polygordius which are positively phototactic may be rendered negative when subjected to a higher temperature. Strasburger found, on the other hand, that the swarm spores of many algæ become positive at a higher temperature and negative at a lower. The flagellate Chromulina, according to Massart, is positive at $20^{\circ} \mathrm{C}$. but negative at $5^{\circ} \mathrm{C}$. Orchestia agilis has been found by the writer to become strongly negative if dipped into water, but if the water is heated nearly to the point of producing death the reaction becomes positive.

The concentration and chemical nature of the medium also influence phototaxis. It was found by Loeb that negative specimens of Polygordius and certain copepods were rendered positive by increasing the salt content of the sea water, while the addition of fresh water rendered specimens negative which previously showed a positive response. Larvæ of Palæmonetes which are normally positive become negative if the sea water is diluted with half its volume of distilled water (Lyon).

Certain infusoria, Stentor viridis and Paramcecium bursaria, which contain chlorophyll go toward the light only when the supply of oxygen is insufficient (Engelmann), but whether the response is phototactic or photopathic is uncertain; at all events it seems to be an adaptation to lack of oxygen, for in the light oxygen becomes produced as in plants by the chlorophyll in the organism. The amphipod Jassa which is usually negative becomes markedly positive in foul sea water. Carbon dioxide and other acids were found by Loeb to cause positive phototaxis in Gammarus and Cy- 
clops. In the latter a weakly alkaline condition seems to induce a negative reaction. The experiments of $\mathrm{Mr}$. Jackson on Hyalella, a fresh water amphipod which is ordinarily negative in its response, have shown that a variety of substances cause a positive reaction. Mrs. Michener* in experiments on a number of diverse forms finds that if the response is negative it may be made positive by various chemicals, although normally positive forms are rarely if ever rendered negative. A wide range of chemicals was experimented with and a positive response was evoked by acids, salts, alkalies and various other substances, as in the experiments of Mr. Jackson, showing that there is no definite relation between the nature of the response and the class of chemical compounds employed as stimuli.

The effect of contact stimuli on phototaxis affords one of the most curious phenomena connected with the modification of the responses of organisms to light. In many cases contact causes an immediate reversal of the response. Miss Towle found that negative specimens of the ostracod Cypridopsis were rendered positive by being picked up in a pipette and dropped out again. Negative specimens when colliding with one end of a dish straightway became positive and swam to the other end. Yerkes obtained similar results in another ostracod, Cypris. Daphnia, which is ordinarily positive, may be made negative for a very short time by repeatedly picking it up in a pipette. The copepod Temora longicornis, which is usually negative, was found to become temporarily positive by being shaken (Pouchet). Positive specimens of Labidocera, on the other hand, may be made temporarily negative by handling them in a pipette (Parker).

Possibly allied to these effects is the curious reversal of phototaxis which occurs in certain terrestrial amphipods when thrown into water. Having observed that the terrestrial

*Experiments unpublished. 
Amphipoda are usually positively phototactic while the aquatic species are negative it occurred to me to try the effect of throwing terrestrial forms into water. Specimens of Orchestia agilis which were very strongly positive were employed. As soon as they were in the water they all immediately became strongly negative and remained so for days in various intensities of light. That the transformation is not due to change of temperature was shown by the fact that the same result was obtained whether the water was warmer or colder than the air, or at the same temperature. It is not improbable that it is the stimulus of contact afforded by the water that caused the reversal of the response.

In the water scorpion Ranatra contact stimuli were found to have a very marked effect on the insect's reaction to light. Handling these creatures throws them into a death feint which entirely inhibits, for a time, all phototactic response. It frequently happens that on recovery from the feint there is a negative response which later changes to positive. If specimens which are swimming at the end of a dish nearest the light are simply picked up by the breathing tube and dropped back into the water they immediately begin swimming with equal vigor in the other direction. They may be caused to reverse their phototaxis in this way repeatedly. The same effect can be produced if they are seized or stroked while under the water. Specimens which are making frantic efforts to go toward the light when in the air may be caused to become negative by simply dropping them into water. When taken out they usually show a marked negative response for some minutes, but later become positive.

The method by which animals orient themselves to light naturally varies with their nervous and muscular organiza- 
tion and the nature of their locomotor organs. There are comparatively few cases in which light orients an animal by causing directly a greater contraction of the muscles of the side most affected. The observations of Mast on the planulæ of Eudendrium indicate that these forms may be oriented in this way. Eudendrium planulæ are coneshaped organisms with the wide end in front, and having the body covered by cilia by means of which they swin through the water. According to Mast, "if the ray direction is but slightly changed after the planulæ are oriented
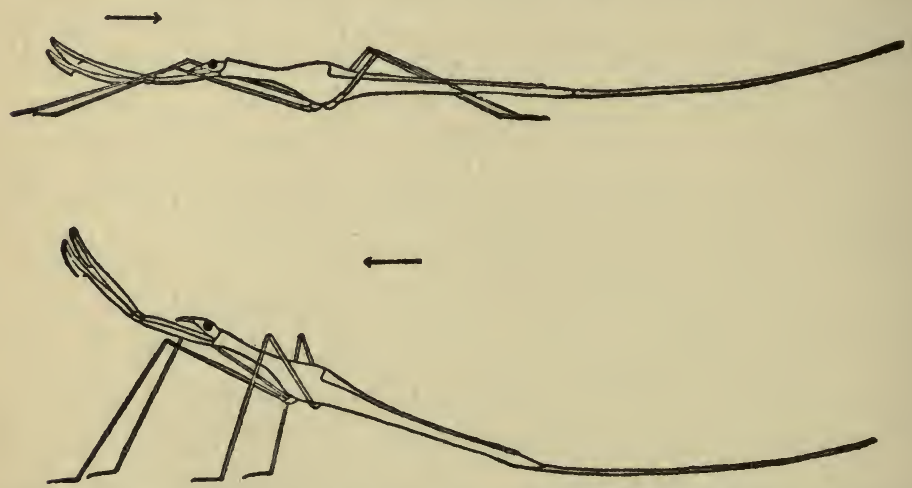

FIG. 5.-The water scorpion Ranatra, showing the different attitudes assumed according as the light falls upon it from in front or from behind. The arrows indicate the direction of the rays.

they do not turn directly toward the source of light in its new position, but merely swing the anterior end a little farther toward it each time. In the meantime the body gradually turns so as to become oriented again. If however the direction of the rays is changed to such an extent that the sides of the organism become fully exposed, they with very few exceptions appear to turn toward the light at once. In this process they swing the anterior end laterally until it nearly if not quite faces the source of light."

The larvæ of Arenicola according to Lillie orient them- 
selves to light by bending directly toward the more stimulated side. These larvæ swim by means of two bands of cilia around the body, and for a short time after hatching are markedly positive, swimming toward the light in nearly straight lines. If while the larvæ are swimming toward the light the position of the light is changed they bend toward the light until oriented in the direction of the rays. Certain salts were found by Lillie to inhibit muscular action while they did not interfere with the action of the cilia. Larvæ in solutions of these salts would continue swimming, but their phototaxis was entirely destroyed. Mast who has studied the orientation of the same form finds that "by using two sources of light so situated that the rays cross at right angles in the region where the specimen is located, and then alternately intercepting the light from each of the two sources, it can be seen clearly that the larva, by muscular movement, turns its anterior end toward the source of light directly. There is no trial in this process. It is an asymmetrical response to an asymmetrical stimulation."

Light has a certain orienting effect on Planaria maculata, even in specimens devoid of eyes although it is masked by a large amount of random activity. Planaria turns directly away from strong mechanical and chemical stimuli, as shown by Pearl, by lengthening the side stimulated instead of by contracting the opposite side. The effect of the stimulus is upon the muscles in the vicinity of the stimulated point. There is no ventral nerve cord with its numerous cross connectives such as we find in annelids and there seems to be no mechanism by which an impulse set up on one side can be transmitted more strongly to the muscles of the opposite side of the body than to any other region. The turning away is therefore effected in planarians in a very different way than in annelids, probably by the contraction of the dorso- 
ventral muscles near the stimulated point. It is not improbable that the negative phototaxis of an eyeless Planaria, like its turning away from strong stimuli in general, is due to the local effect of light in the region on which it impinges.

In the earthworm or leech turning away from strong light is accomplished in all probability by the contraction of the longitudinal muscles on the opposite side of the body, the result being in the nature of a crossed reflex which is so common in animals with an axial central nervous system. In the crustacean Eubranchipus which usually swims on its back there is a marked positive phototaxis if the animals are subjected to a rather small source of light. In ordinary daylight before a window they pay little heed to the light, but if taken into a dark room and exposed to light from an electric bulb they will swim toward it and follow it about in any direction. If they are oblique to the rays they bend the tail suddenly toward the more illuminated side one or more times until they become oriented.

In most crustacea as in most insects orientation is affected through the unequal action of the appendages on the two sides of the body. In a form which is positively phototactic light entering one eye sets up impulses which passing into the brain and nerve cord, cause, directly or indirectly, movements predominantly of flexion of the legs of the same side and of extension of the appendages of the opposite side of the body. If this is a sort of mechanical reflex process we should expect that, in a positively phototactic form, if one eye were destroyed or blackened over, the animal would move continually toward the normal side. This experiment of blackening over one eye was tried by the writer on the large sand flea, Talorchestia, and it was found that the specimens no longer went straight toward the light, but performed circus movements toward the side of the un- 
blackened eye. The same experiment was tried on several postively phototactic insects with the same results. In the small sand flea Orchestia agilis which is sometimes positive and sometimes negative in its reactions to light blackening over one eye causes circus movements toward the normal side when it is positive and in the reverse direction when it is negative. Since throwing this form into water changes its phototaxis from positive to negative it can be made to go around in a circle in either direction according to the medium in which it is placed. Similar circus movements after one eye was blackened over have been observed by Parker in Vanessa, by Hadley in the lobster, and by Rádl in various kinds of arthropods.

Not all phototactic insects, however, perform circus movements when blinded on one side. If the honey bee, for instance, which is strongly positive, is treated in this way it usually follows the light almost as directly as when in a normal condition. In the water scorpion Ranatra I have found that while in some specimens there is a strong tendency to perform circus movements toward the normal side, others go toward the light in a direct line. In some instances specimens which at first performed circus movements came after a number of trials gradually to straighten their path toward the light until finally they followed it in a straight line. Back swimmers, Notonecta, which at first performed circus movements and approached the light only after much wasted effort, were found to straighten their course and follow the light as well as if they had use of both eyes. These facts indicate that phototaxis may fall to a certain extent under the pleasure-pain type of behavior which will be considered in a later chapter. Light in some animals is followed much as an object of interest is pursued by a higher animal. If a creature learns to go to the light an element of satisfac- 
tion or pleasure is probably associated with the phototactic response.

There are a few cases in which positively phototactic species swim backward instead of forward toward the light. An instance of this kind was found by Lyon in Palæmonetes. Hadley found that larval lobsters swim with the head pointed away from the light whether they are postive or negative in their reaction. In the pycnogonid Anoplodactylus, Cole observed that in crawling toward the light the anterior end was in advance, but in swimming toward the light the animals moved approximately backward.

Fiddler crabs form an exception to most phototactic animals in that in going toward the light the body is oriented sidewise instead of with its longitudinal axis in the direction of the rays. These animals are strongly positive and, like Ranatra, their response becomes stronger with longer exposure. They are timid animals and often a sudden movement of the light will send them scuttling away in alarm, but after following the light for some time they become more oblivious to other stimuli and slavishy follow it with less show of fear. Orienting movements are different from those used in ordinary locomotion which is not the case with most forms. Other animals may orient themselves by walking faster, so to speak, on one side than on the other, but with lateral orientation special movements have to be performed in order to change the direction of locomotion. Here again it is difficult to apply the theory of forced orientation in its usual form, and we are led to conclude that the reaction to light is to a certain extent one of the pleasurepain type.

According to Rádl phototaxis has an intimate relation to vision. In a number of experiments Cole has found that reactions to light are influenced by the extent to which the 
eyes are capable of forming images. If animals are stimulated by two sources of light of the same degree of intensity but of different area, the forms without eyes or in which the eyes produce no image turn practically as often to the one source of light as the other while animals with eyes producing a distinct image will, if positively phototactic, generally turn toward the light of larger area. With the perfection of the organs of vision the primitive phototactic tendencies of animals may become modified so as to afford the basis for the reactions to special objects of the visual field which we find in the more highly developed instincts.

In many animals there is a strong reflex tendency to keep, so to speak, in statu quo with the visual field. This tendency accounts for many cases of so-called rheotropism as is shown by the experiments of Hadley on the lobster and Lyon on fishes. The same tendency is, as we have seen, manifested also in compensatory motions. Rádl has shown that in Daphnia and some other forms in which the eyes are movable there is an effort on the part of the eyes to become oriented to the rays of light. In the vertebrates in which the eyes are freely movable the same tendency is more or less pronounced. This trait may be connected with the involuntary tendency of animals to follow the movements of objects which cross their field of vision. Vision in the lower animals is concerned much more with the movements than with the form of objects. It may be possible to trace more accurately than has been done the relation between phototaxis, compensatory motions of the head and body, and the involuntary tendency to follow moving objects with the eyes. This field of investigation has been but little explored, but it is one which promises to be fruitful of significant results. 


\section{THERMOTAXIS}

Almost all organisms which are free to move go away from regions in which the temperature is injuriously high, and many, although a less number, withdraw from regions which are colder than a certain optimum. If the water near an Amœba is heated by a hot needle the animal will contract on the side nearest the needle, send out pseudopods in some other direction and crawl away. Paramœcium and other infusoria form groups in a region of optimum temperature by the same method employed in reacting to chemicals. When a Paramœcium swims into a region above the optimum it gives the motor reflex and goes in another direction. When it encounters a region below a certain temperature it behaves

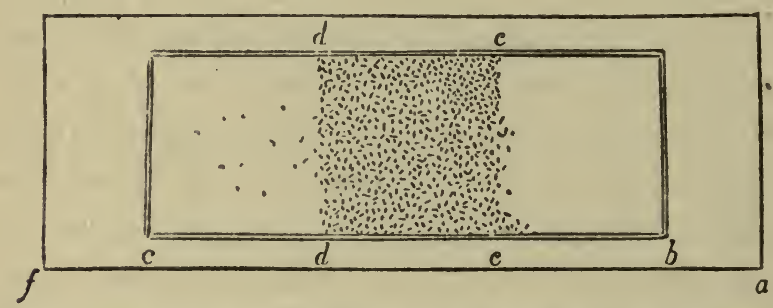

Fra. 6.-Reactions of Paramœcia to heat and cold. One end of the slide is heated to $35^{\circ} \mathrm{C}$. while the other end is kept on ice. The Paramœeia gather in an intermediate zone $d c$.

in the same way. If Paramœcia are placed in a trough one end of which is heated to $35^{\circ} \mathrm{C}$. while the other is placed upon ice the infusorians will form a band near the middle where the temperature ranges from $24^{\circ}$ to $28^{\circ}$ C. Previous exposure to higher or lower temperatures than those usually experienced changes the optimum to a considerable degree.

Most organisms above the protozoa turn directly away from hot or cold objects. Sometimes the animal may escape undue stimulation by making a number of random move- 
ments, trusting to luck to get it into a more favorable situation. A comparatively large element of random movement may be combined with a tendency to turn directly away from the stimulus, as is apparently the case in planarians.

The subject of orientation to heat rays has been little studied. With aquatic organisms it would be difficult to separate the reaction to heat rays and reaction to warmer or colder regions of the water. Of the effect of radiant heat alone on the movements of terrestrial organisms we have as yet very inadequate knowledge.

\section{ELECTROTAXIS}

Reactions to the electric current form no part of the behavior of animals under natural conditions. Nevertheless, many forms respond to the electric current in a very precise manner. An attempt to review the rather extensive literature on this subject would lead to a considerable amount of technical discussion, and an adequate treatment would require much more space than can be devoted to it here. The subject is one, however, which has an important bearing on the general theory of tropisms, and we shall therefore describe briefly some typical cases of electrotactic response.

An Amcba proteus placed in the pathway of a weak electric current assumes an elongated form and creeps toward the cathode. The protoplasm toward the end nearest the anode apparently contracts and with a stronger current may undergo a granular disintegration. Pseudopods are put out on the side toward the cathode and cause the flow of the protoplasm in that direction.

When Paramocium is subjected to the action of the current it swims with a fairly accurate orientation of the body toward the cathode. If two poles of a galvanic battery are 
inserted in the two sides of a drop of water containing Paramœcia the infusorians will soon all collect around the negative pole. In solutions of sodium chloride and certain other salts Paramœcium frequently swims backward toward the anode, and Bancroft has found that true anodal electrotaxis, in which the infusorians swim forward toward the anode, may occur for a short time in solutions of sodium chloride, sodium carbonate and other salts if the Paramœcia are washed in distilled water before being placed in the solutions.

Electrotaxis has been observed in cœlenterates, worms, mollusks, crustacea, the larvæ of insects and in fishes, tadpoles and salamanders. In general the reaction of worms and mollusks is negative and the reaction of crustacea positive. In tadpoles which orient their bodies parallel with the direction of the current the direction of orientation is dependent upon the strength of the current.

Orientation to the electric current is apparently brought about by the polar effect of the current upon the tissues of the body. In Paramœcium there is a direct orientation produced by the unequal beat of the cilia on the two sides. In cathodal orientation the forward phase of the stroke of the cilia is accentuated where the current leaves the body so that there may be a reversal of the effective stroke; where the current enters, the backward stroke continues so the organism naturally swings into line with the current. In higher organisms there is a distinctly evident polar effect upon the musculature of the body which can be seen to produce the orientation of the organism. The effect of the electric current on animals generally is to produce movements which are in a certain sense "forced," and the orientation so brought about affords an excellent example of a typical tropism as conceived by Dr. Loeb. 


\section{BIBLIOGRAPHY}

Bancroft, F. W. The Control of Galvanotropism in Paramœcium by Chemical Substances. Univ. of Calif. Pubs. Physiology, 3, 21, '06.

BoHn, G. Théorie nouvelle du phototropisme. C. R. Ac. Sci. Paris, 139, 890, '04. La Naissance de l'Intelligence. Paris, '09. Cole, L. J. Notes on the Habits of Pyenogonids, Biol. Bull., 2, 195, '01. An Experimental Study of the Image-forming Power of Various Types of Eyes. Proc. Am. Ac. Arts and Sci., 42, 335, ' 07.

Davenport, C. B. Experimental Morphology. N. Y., '97-99. Harper, E. H. Reactions to Light and Mechanical Stimulation in the Earthworm, Perichceta bermudensis. Biol. Bull., 10, 17, '05.

Holmes, S. J. Phototaxis in the Amphipoda. Am. Jour. Physiol., 5,211 , '01. The Selection of Random Movements as a Factor in Phototaxis. Jour. Comp. Neur. Psych. 15, 98, '05. The Reactions of Ranatra to Light, 1. c., 15, 305, '05. Phototaxis in Fiddler Crabs and its Relation to Theories of Orientation. 1. c., 18, 493, '08.

Holt, E. B., and LEe, F. S. The Theory of Phototactic Response. Am. Jour. Physiol., 4, 460, '01.

Jennings, H. S. Contributions to the Study of the Behavior of Lower Organisms. Carnegie Inst. Pubs. Washington, '04. Behavior of Lower Organisms. N. Y., '06.

Loeв, J. Der Heliotropismus der Thiere und seine Uebereinstimmung mit dem Heliotropismus der Pflanzen. Würzburg, 90. Studies in General Physiology, Chicago, '05. The Dynamics of Living Matter. N. Y. '06.

Mast, S. O. Light Reactions in Lower Organisms, 1, Stentor ccruleus. Jour. Exp. Zool., 3, 359, '06. Light Reactions in Lower Organisms, II, Volvox globator. Jour. Comp. Neur. Psych., 17, 99 , '07. Light and the Behavior of Organisms. N. Y., '11.

MendelssoHn, M. Ueber den Thermotropismus einzelliger Organismen. Pflüger's Archiv, 60, 1, '95.

Mrnkiewicz, C. Sur le chromotropisme et son inversion artificielle.

C. R. Ac. Sci. Paris, 143, 785, '06.

NAGEL, W. A. Der Lichtsinn augenloser Thiere, Jena, '96.

Nuel, J. P. La Vision. Paris, '04.

PARKer, G. H. The Phototropism of the Mourning Cloak Butterfly.

Vanessa antiopa. Mark Anniversary Volume, 453, '03.

Pö́trer, A. Studien über Thigmotaxis bei Protisten. Arch. f. Anat. u. Physiol, physiol. Abth. Suppl. 243, '00. 
RÁDL, E. Untersuchungen über den Phototropismus der Tiere. Leipzig, '03.

Strasburger, E. Die Wirkung des Lichtes und der Wärme auf Schwärmsporen. Jen. Zeit. n. F. 12, 551, '78.

Torelle, E. The Response of the Frog to Light. Am. Jour. Physiol., 9, 466, '03.

Verworn, M. General Physiology, N. Y., '99.

Walter, H. E. The Reactions of Planarians to Light. Jour. Exp. Zool., 5, 35 and 117, '07. 


\section{CHAPTER IV}

\section{THE BEHAVIOR OF PROTOZOA}

"One of the first lessons which the study of animal behaviour, in its organic aspect, should impress upon our minds is, that living cells may react to stimuli in a manner which we perceive to be subservient to a biological end, and yet react without conscious purposethat is automatically."-C. LLOYD MoRgan, Animal Behaviour.

The student of the evolution of mind naturally looks with interest to the behavior of those organisms which lie nearest to the root of the tree of life. What mental powers are evinced by the lowest animals, or whether, indeed, the lowest animals exhibit any mental powers at all are questions of fundamental importance to comparative psychology. Nevertheless with all the theoretic interest and importance attaching to the study of the powers and performances of these low forms it is somewhat surprising that until quite recently the subject attracted few serious investigators.

Binet in his book on the Psychic Life of Micro-organisms makes one of the first thorough-going attempts to estimate the extent of the protozoan mind. Among the psychic operations which he claims are manifested are:

1. "Perception of the external object;

2. "The choice made between a number of objects;

3. "The perception of their position in space;

4. "Movements calculated, either to approach the body and seize it, or to flee from it."

Choice is manifested according to Binet in the selection of food. Many species live on a few kinds of food and refuse others. This choice cannot be explained as due to physical 
causes; "it is one of the most incomprehensible of phenomena; it is exceedingly difficult to explain it without resort to anthropomorphism." Protozoa not only perceive external objects but "they also indicate, by their movements, an exact knowledge of the position occupied by these bodies. It might be said that they invariably possess a sense of position in space. The possession of this sense is absolutely indispensible to them, for it does not suffice them to know of the presence of an exterior body in order to approach it and seize it; they must furthermore know its position, so as to direct their movements accordingly.

"The simplest form of a sense of localization is met with in the Amœba which, when it closes about a nutritive particle, always emits its pseudopods at precisely that part of its body where the foreign substance caused the irritation. The most complicated instance of localization is met with in the Didinium, which we have so often cited; the Didinium knows exactly the position of the prey it follows, for it takes aim at the object of its pursuit like a marksman, and transpierces it with its nettle-like darts."

Instinct, memory, fear and a certain degree of intelligence are among the psychic endowments with which Binet credits the protozoa. A good sample of his interpretation of protozoan behavior is the following: "The Bodo caudatus is a voracious Flagellate possessed of extraordinary audacity; it combines in troops to attack animalcula one hundred times as large as itself, as the Colpods for instance, which are veritable giants when placed alongside of the Bodo. Like a horse attacked by a pack of wolves, the Colpod is soon rendered powerless; twenty, thirty, forty Bodos throw themselves upon him, eviscerate and devour him completely (Stein).

"All these facts are of primary importance and interest, 
but it is plain that their interpretation presents difficulties. It may be asked whether the Bodos combine designedly in groups of ten or twenty, understanding that they are more powerful when united than when divided. But it is more probable that voluntary combinations for purposes of attack do not take place among these organisms; that would be to grant them a high mental capacity. We may more readily admit that the meeting of a number of Bodos happens by chance; when one of them begins an attack upon a Colopod, the other animalcula lurking in the vicinity dash into the combat to profit by a favorable opportunity."

More recent investigations have shown that the behavior of protozoa gives no evidence of the high psychic development assumed by Binet. There has been a strong tendency on the part of certain investigators to explain the behavior of these low forms as due in large measure to comparatively simple physical and chemical factors. Others contend that the phenomena are much more complex and at present defy analysis into physical and chemical processes, while a few go further and maintain that we must assume some superphysical agency, a vital principle, or entelechy of some sort, to explain the results.

Much attention has been bestowed upon the activities of Amœba, which is generally assumed to be one of the most primitive of the protozoa. Amœba is a jelly-like organism with a clear, outer, relatively dense layer of protoplasm, the ectosarc, surrounding a more fluid, granular substance, the endosare, which contains the nucleus. The Amœba commonly moves by sending forth blunt processes or pseudopodia from the side of the body; material flows into the pseudopod which may increase greatly in size; then other pseudopods are put forth on the same side, the posterior part of the body being pulled, in the meantime, in the direction in which the 
pseudopods are protruded. The details of the movements vary considerably in different species. In Amœba verrucosa Jennings describes the locomotion as "in many respects comparable to rolling, the upper surface continually passing forward and rolling under the anterior end so as to form the under side." This is shown by placing in the water particles of soot some of which adhere to the surface of the animal; if a single particle be watched it will be seen to pass around, as the Amœba progresses, like an object on the surface of a rolling cylinder. The anterior edge of the Amœba is thin and flat and adheres closely to the substance while the thicker posterior edge is free. The movement is like the rolling of a contractile sac with semifluid contents. Amoeba limax has a similar method of locomotion but has few pseudopods. Dellinger who has studied the locomotion of Amoeba proteus describes a method of locomotion quite different from that found by Jennings. Dellinger hit upon the device of observing Amœba from the side, by means of a horizontal miscroscope. The Amœba sends out a pseudopod free into the water, which is then bent down and attached to the substrate; the posterior end is now raised and pulled forward; then another pseudopod is pushed out and attached like the first and the body pulled forward again. During the progress the Amœba is attached only at a few points on short improvised feet which are drawn in as the Amœba passes over them.

In a small unidentified species of Amœba the method of locomotion, as observed by the writer, differs from all the foregoing ones. There are broad ectoplasmic pseudopods put out at the clear anterior end, commonly first on one side and then on the other; the endoplasm flows into them and the hinder part of the body which contains the contractile vacuole is drawn forward. There is no rolling; particles on the 
surface of the hinder half of the animal may undergo little change of position for a long time.

There are various ways of imitating the movements of Amœba by drops of oil or other fluids subjected to changes of surface tension. If a drop of mercury is placed in dilute nitric acid and a piece of potassium bichromate placed near it the drop of mercury will bulge out toward the bichromate and may surround it. The bichromate as it diffuses against the mercury causes a diminution of surface tension at the region of contact. The stronger contraction of the rest of the surface film forces the mercury to protude at the weakest point, producing an out-pushing resembling the pseudopod of the Amœba. It has been contended that variations in surface tension account in great measure for the movements of Amœba and other Rhizopods much as in inorganic fluids. There is certainly a striking analogy between the phenomena in the two cases, but the studies of Jennings have shown that explanation of the phenomena is not quite so simple. Jennings argues that the currents in Amœba are not like those occurring in drops of fluid which are changing the surface tension because in the Amœba there are no lateral return currents which are present in the moving fluid and hence the surface tension theory cannot account for the Amoeba's changes of form. It must not be forgotten that we are dealing with substances of quite different consistency one of which has a cortical layer of considerable thickness and density which is entirely absent in the other, and that the behavior of internal currents may be affected by this factor; but aside from this, there are many facts which seem to indicate that the ectoplasm behaves more like a muscular layer than one whose contraction is entirely due to the surface film. Contracting pseudopods may become wrinkled, which could not occur if mere surface film contraction were responsible 
for the withdrawal. Sometimes pseudopods move back and forth as if they possessed a certain degree of flexibility and rigidity. The rolling motion of certain species offers another difficulty, so it cannot be said that, at present, the surface tension theory suffices to explain the movements of the organism. That it may play a part in the process is not improbable. It must not be forgotten that there are many surfaces within the mere outer layer, such as alveolar walls, etc., where surface tension may be a potent agent. In forms a little higher than Amœba we meet with a more or less fibrillar ectoplasm whose contraction occurs much as in an ordinary muscle fiber. It is not improbable that the fundamental features of contraction in the specialized ectoplasm of flagellates and infusorians are the same as in the unspecialized ectoplasm of the rhizopods on the one hand and in the more highly specialized muscular tissue of higher animals on the other. The cause of muscular contraction is one of the most obscure problems of physiology and until it is solved we shall probably be unable to explain the mechanism of the movements of the simplest animals.

In taking food Amœba has been described as flowing around an object and engulfing it in its endoplasm where it undergoes digestion. Surface tension has been supposed to play a part in the process. A fine splinter of glass brought against a drop of water will be quickly drawn in through the contraction of the surface film. A drop of chloroform may be made to draw in a glass splinter covered with shellac; after the shellac is dissolved the glass splinter will be extruded, through the force of surface tension, as from a drop of mercury, thus simulating both the ingestion of food and the defecation of the undigested residue (Rhumbler). The observations of Jennings on food taking in Amœba proteus show that the protoplasm does not flow around the 
object as if drawn by surface tenison; a small pseudopod is put out on either side of the food; these processes extend and curve around it until they meet, and then the object is drawn into the endoplasm. In Amoba proteus and limax "there is no adherence between the protoplasm and the food body," although there is adherence in Amceba verrucosa whose ectoplasm seems to be more adhesive to all kinds of objects.

Amœba like higher animals may follow its food. Jennings describes an Amœba attempting to engulf a spherical cyst of Euglena. As the Amœba came in contact with it the cyst rolled away; the Amœba followed; the cyst continued to be pushed ahead now one way and now another and the Amœba changed its course accordingly. After the cyst had

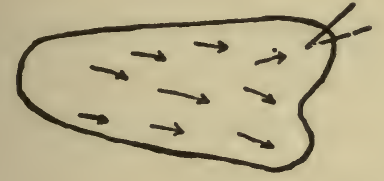

a

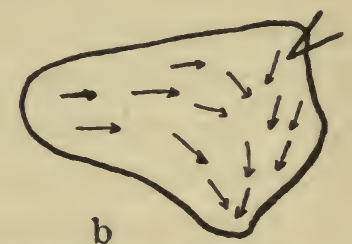

b

Fig. 7.-Reaction of Amœba to a strong mechanical stimulus. The arrows indicate the direction of the currents.

been rolled against an obstacle and the Amœba was about to succeed in capturing it, a large infusorian appeared on the scene and swept it away.

The reactions of Amœba to stimuli may be either positive or negative. To a strong mechanical stimulus such as contact with the point of a needle Amœba reacts by crawling away. Should the stimulus be applied at the anterior end the stimulated part stops, there is a local contraction of the ectoplasm and the granules begin to stream away from the point of contact. This stream meets the stream proceeding in the general direction of locomotion and the two combine 
to form a stream which issues in another direction. Stimulation of the posterior end causes the animal to quicken its pace. Stimulating a pseudopod causes it to be withdrawn; and by repeated stimulation the animal may be driven about at will.

To the weaker stimuli which are received by coming into gentle contact with solid objects, Amœba often reacts positively. If, when floating about in the water, one pseudopod comes in contact with a solid it adheres to it; there is a flow of granules toward the point of contact, from the rest of the body; this pseudopod enlarges, the others contract until most of the body has flowed into the attached pseudopod, when the Amœba crawls along the surface of the object. The utility of the negative response to strong mechanical stimuli is obvious since it enables the organism to avoid injurious agencies. The positive reaction tends to keep the Amœba in contact with solid objects where most of its food is secured and where it receives protection. Probably also it plays a part in determining the behavior toward food.

To injurious chemicals Amœba reacts much as to strong mechanical stimuli; it creeps away from regions of higher temperature, it reacts negatively to light. All these responses are purposive in that they are adapted to the preservation of the organism. Simple as Amœba apparently is it manages to cope very effectively with the conditions of its existence. One might conceivably construct a machine which would run of itself, gather the food needed to supply the energy used in its workings, avoid automatically contact with obstacles which would impair its running, move away from regions too hot or too cold for its efficient operation, protect itself by producing coverings in unfavorable situations, and guide itself into the most favorable regions for its maintenance; but what a wonderfully complicated mechanism it 
would have to be! Yet a simple, apparently almost structureless mass of jelly does all this and more. And if our mechanism had the property of repairing its own injuries and producing other pieces of mechanism like itself, its structural arrangements would be almost if not quite beyond our power to conceive. One cannot, therefore, but look with a feeling of admiration and wonder at so comparatively simple a creature as Amœba, which is capable of performing so much.

But the story does not end even here. In addition to all the adaptive properties mentioned Amœba has the power of modifying its behavior to suit new conditions. Toward water different from that in which it is immersed Amœba reacts negatively, but after remaining in such water for some time it resumes its usual activities. When first exposed to bright light it withdraws its pseudopods and remains quiet, but after continued exposure it adapts its behavior to the new conditions and again becomes active. After a short period of starvation Amœba moves about more actively than usual, whereas when it is gorged with food it becomes relatively sluggish. The condition of the animal determines its behavior in other ways and the changes of behavior are usually advantageous to the organism. The behavior of Amœba is essentially like that of higher animals; it avoids things which are injurious; it seeks things which are beneficial and it adapts its behavior to new conditions. Life is very much the same sort of thing whether in an Amœba or a man.

The chief rival of Amoba in the attentions of the comparative psychologist is Paramocium. This is a cigarshaped infusorian rounded in front and pointed at the posterior end, and covered by a uniform coating of cilia. It has an oblique oral groove leading posteriorly into a gullet into which are swept small particles which serve for food. 
By the action of its cilia Paramœeium swims through the water in a spiral course, rotating on its long axis to the left and keeping the oral side facing the center of the spiral. At times Paramœcium may swim backward, by reversing the effective stroke of the cilia, although the direction of rotation is unchanged.

Paramœcium is a common organism in vegetable infu-

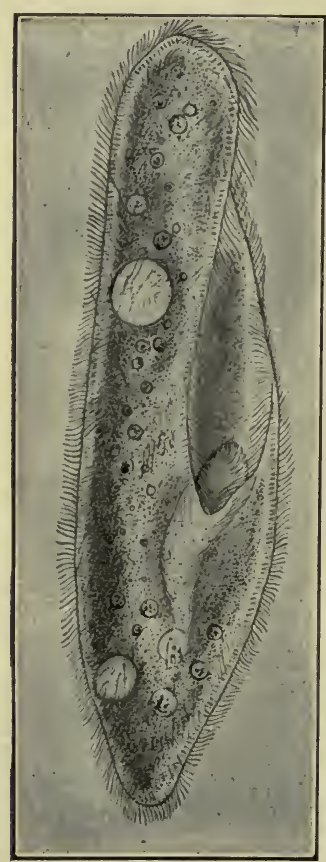

FIG. 8.-Paramœcium caudatum. (After Kellogg.) sions, where it subsists upon bacteria which are swept by cilia into its gullet. There seems to be little power of choice as to what substances are taken in; particles of India ink and carmine are swept in and swallowed in the same way as its normal food, and the organism selects its food only by swimming elsewhere when the materials swept in are unsuitable. Metalnikow, however, states that when Paramœcia are fed with carmine for fifteen days they gradually take in less of this substance and finally refuse it. Metalnikow's experiments were repeated by Schaeffer who failed to confirm these results when the carmine was kept in a condition such that it could be readily - ingested. Occasional individuals, however, failed to take in any of the substance, but examination showed that they were deformed or had recently divided so that the oral apparatus was not capable of sweeping in food. After thirtythree days the Paramœcia failed to show any appreciable diminution in the carmine ingested. 
Paramœcium is a very restless organism, swimming actively much of the time. Occasionally it remains quiet when in contact with solid objects. When manifesting its so-called thigmotactic response the cilia in contact with the solid remain stiff and immobile as if anchoring the animal to the spot, while the cilia over the rest of the body keep moving, although with diminished vigor. If bits of cotton wool are placed in the water Paramœcia are more apt to come to rest, owing to the greater opportunity afforded of

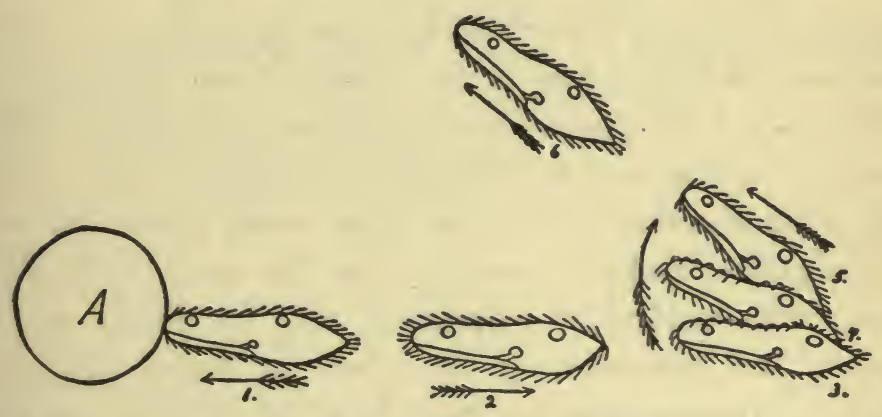

Fig. 9.-Successive stages of the motor reflex of Paramœcium. (After Jennings.)

securing contact stimuli. This trait keeps the Paramœeia among bacterial scums and in other situations where they may obtain their food.

The principal feature of the behavior of Paramœcia is what Jennings has called the "motor-reflex" or "avoiding reaction." It consists of swimming backward by reversal of the action of the cilia, turning to the aboral side and then going ahead again. This is the stereotyped response which Paramœcium gives in essentially the same way when encountering almost any kind of stimulus. If stimulated by a fine needle on the aboral side it will back off and turn toward instead of away from the stimulating object. Even 
when the posterior end is stimulated the Paramœcium may swim back directly against the needle. A slight stimulus at the posterior end often causes the infusorian to accelerate its swimming, but, with this exception, the nature of the response seems to bear no relation to the part of the body to which the stimulus is applied. The anterior end of the body is the most sensitive region, although stimuli at that point do not call forth any different kind of response, but only evoke the usual motor reflex with greater readiness.

The motor reflex or avoiding reaction has the effect of getting the animal away from injurious stimulations. Often, however, at first it may bring it into a worse situation than before; the Paramœcium may back into an injurious chemical, or turn toward a mechanical or other stimulus which affects its aboral side; if so, the motor reflex is repeated until the organism makes its escape from the unfavorable situation. The method of adjustment may be clumsy and indirect; had Paramœcium the power as higher organisms have, of turning directly away from the stimulus, its reactions would probably be more effective; but its restless activity and quick movements are a partial compensation for defects in precision of response.

The motor reflex may be carried out in varying degrees of completeness. The duration of the backward swimming and the amount of turning to the aboral side are subject to much variation. The two phases of the response may be greatly prolonged in a solution of potassium iodide. The Paramœcium swims backward for several minutes; then spins around toward the aboral side for a considerable time and finally swims forward. In ordinary water the distance the Paramuecium swims backward is increased with a stronger stimulus and the aboral rotation may continue until the infusorian describes several complete circles. With 
slight stimulations the first phase of the reaction may result in a momentary stopping of the course or even simply a slackening of speed, and the aboral turning may manifest itself in swinging the anterior side around in a little larger spiral than before. In fact this aboral turning may be regarded as but an accentuation of the process which in ordinary swimming keeps the aboral side facing the outside of the spiral. Sometimes, as in a dilute solution of sodium chloride, the Paramœcium stops swimming forward and turns around aborally, with its posterior end keeping nearly in one spot and its anterior end describing a wide circle.

Paramœcium, as we have described in a previous chapter, reacts negatively to both hot and cold water.

There seems to be no orientation here to the heat rays; when Paramœcium swims to a colder or a warmer region it gives the motor reflex and goes in another direction. Ordinary light has little effect upon Paramœcium but Hertel has shown that it gives a negative response to very power-

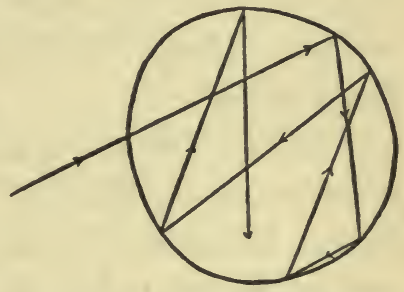

Fig. 10.-Course of Paramœcium in a drop of dilute chemical. ful ultra-violet rays. Its reactions to gravity are not decided and are influenced by various factors as is mentioned in the foregoing section on Geotaxis.

The behavior of Paramœcium is made up of a very limited number of stereotyped modes of response. It reacts to all sorts of stimuli by the same motor reflex carried out in various degrees of vigor according to the strength of the stimulus. But while very machine-like its behavior is at the same time highly plastic and adaptive. Conditions which are unfavorable act as stimuli, and the animal keeps on reacting until it gets into a region which is more favorable 
to its life. While we commonly speak of the positive reactions of the organism, strictly speaking there are, with the exception of its thigmotaxis, no positive reactions. If Paramœcia collect in weak acid it is not because the acid attracts them in any way; they are not stimulated even when they accidentally enter the acid; they react only when they pass from the acid into the water. It is not their positive reaction to the acid but their negative reaction to the water that causes what appears to be a positive chemotaxis. The same is of course true of their reactions to various other stimuli. Their life is one of continual avoidance. Only when conditions are favorable is there cessation of movement. If we do not wish to attribute to such creatures the power of choice we must admit that the method of behavior secures it the same advantages that choice affords.

The behavior of Paramœcium, like that of every other organism, is modified by changes of its internal condition. Strong induction shocks render Paramocium insensitive to weaker shocks and if individuals are kept for a time at a temperature higher than normal a higher temperature is required to cause the avoiding reaction. Individuals that have been kept without food become restless while well fed ones are more sluggish and more apt to come to rest against solid objects. Reactions to gravity are influenced by food and other conditions and thigmotaxis is markedly affected by temperature. Behavior may be modified by repetition of the same contact stimulus as described in the following quotation from Jennings: "If a bit of filter paper is placed in a preparation of Paramœcia, the following behavior may often be observed. An individual swims against it, gives the avoiding reaction in a slightly marked way, swimming backward a little; then it swims forward again, jerks back a shorter 
distance, then settles against the paper and remains. After remaining a few seconds, it may move to another position, still remaining in contact with the paper. Then it may leave the paper and go on its way. All this may happen without the slightest evident change in the outer conditions. So far as can be seen, the Paramœeium first responds to the solid by the avoiding reaction, later by the positive contact reaction, and still later suspends the contact reaction, all without any change in external conditions. The changes inducing the change in reaction must then be within the animal."

The behavior of Paramœcium is quite typical for infusorians in general, but different forms present some interesting modifications. What Maupas has called the "hunter ciliates" show a more highly developed behavior in taking food, as they not only exhibit a power of selection of certain kinds of food, but have a remarkable power of engulfing large objects. One of those whose habits are the best known is Didinium nasutum (Stein). The body is in the shape of a barrel; at the middle of the anterior end is a small projection where the mouth is located. The mouth, which is usually kept closed, leads to a pharynx lined with chitinous rods which can act as a sort of "seizing organ," in the capture of prey. This organ can be protruded and withdrawn, and may be opened out to a remarkable degree.

When Didinium in the course of its swimming comes in contact with a Paramœcium or other small organism, the seizing organ is shot forth into the body of the prey. The seizing organ is then drawn in and the mouth spreads open to receive the prey which is gradually pulled into the body of the Didinium.

The swallowing capacity of Didinium is almost incredible. Mast observed one of these infusorians which swallowed a Paramœecium ten times as large as its captor, the latter 
appearing as if forming a mere film over its engulfed victim. Nothing seems too large for Didinia to attack. Their powers of digestion seem equal to their voracity; according to Mast a Didinium will digest an ordinary Paramœcium once every three hours. According to Balbiani Didinium actively pursues its prey and when sufficiently near "it begins by casting at it a quantity of bacillary corpuscles which constitute its pharyngeal armature." Coming to closer quarters it thrusts forth its prehensible apparatus into its victim and drags it back toward its mouth. This behavior is referred to by Binet as a "most complicated instance of localization" involving a precise knowledge of the position of the prey at which the Didinium takes a definite aim.

We have here an instance of how easily one may be deceived in interpreting the behavior of lower organisms. There is no evidence that Didinium pursues its prey like a hunter. Mast has shown that it does not discharge trichocysts at a distance; in fact it has none to discharge; the loose trichocysts seen when Didinium attacks Paramœcium and which Balbiani thought were shot out by the hunter infusorian were derived entirely from the organism attacked. According to Jennings, Dininium reacts in much the same way "not only to objects which may serve as food, but to all sorts of solid bodies. In other words, the process is one of trial of all sorts of conditions. On coming in contact with a solid, Didinium 'tries' to pierce and swallow it. If this succeeds, well and good; if it does not, something else is 'tried.' In a culture containing many specimens of Didinium, the author has seen dozens of individuals reacting in this way to the bottom and sides of the glass vessel, apparently making persevering efforts to pierce the glass. Others 'try' water plants, or masses of small algæ, about 
which many specimens gather at times. Of course they get no food in this way." They make attempts on various other organisms with which they come into contact, but often fail on account of the toughness or large size of the organism attacked.

What seems at first to be choice of prey is really something quite different. The infusorian swallows what it . can and not what it will. "The apparent choice of food," says Mast, "is due to the fact that the seizing organ will adhere to some organisms and not to others. The Didinia come in contact with all sorts of objects in their random swimming and attempt to swallow all those to which the seizing organ will adhere." After all Didinium like Paramœcium is a pretty simple sort of a creature in its behavior. It has but a few simple tricks which it tries over and over again. Its going gunning with its armory of projectiles, its accurate sense of position and its marksmanship are all creations of the observer's fancy.

A protozoan exhibiting somewhat more complex behavior than is shown by Paramœcium is the large ciliate Loxophyllum meleagris. This organism usually glides along the surface of objects by means of cilia on the side of the body, but at times it may swim in a spiral manner through the water. If strongly stimulated while swimming it may back off and turn in another direction much as Paramœcium does, but the organism seems to be averse to swimming and generally takes advantage of the first opportunity to glide along over some solid object or the surface film. These gliding movements are carried on in a more or less rythmical way most of the time. The body is narrowed and elongated and swims forward for a short distance, then there is a contraction resulting in making the body shorter and broader and at the same time a reversal of the effective beat of the 
cilia which causes a backward movement. This is followed by a turning to one side, the oral in this case, after which Loxophyllum swims forward in a different direction. The performance is repeated time after time, and the infusorian is kept circling about in the same region, for, it may be, several hours. In this species there is a regular association between the elongation of the body and the backward strokes of the cilia, and between the contraction of the body and the reversed beat of the cilia, an association which is preserved even in the movements of small fragments of the body. If Loxophyllum is cut into several pieces these pieces may swim in a spiral course or glide over the surface of objects much like the entire organism. When they go forward they become narrow and elongated and when they swim backward they become shorter and wider, and they perform these movements in regular alternation, at the same time circling slowly toward the oral side. The factors which determine the peculiar traits of behavior in this species seem to be present in all parts of the body, for no matter how minute the fragments into which the organism is divided the action of the parts, so far as physical conditions permit, is the same.

Habitual contact with solid objects seems to have been the cause of the development in Loxophyllum of some features of behavior not found in other swimming infusoria. There are small bendings of the sensitive anterior end in various directions as if it were feeling its way along. There are undulations of the margin and bendings and twistings of the whole body. The food-taking movements as described by Oelzelt-Newin are quite complex and involve a number of coördinated acts. The organism glides over its food and when the large slit-like mouth is in the proper position the lips, which are usually tightly closed, open and begin a series of spreading movements which result in engulfing 
the object. Then there are righting movements which are brought into play when Loxophyllum is turned over on its left side. There is not, as we might be led to expect, but a single stereotyped method of righting. The organism rights itself by a number of very different methods which present an indefinite number of modifications. One cannot but wonder when watching the varied movements of this graceful and supple infusorian that a single cell is capable of such behavior.

One of the most highly developed types of behavior which has been carefully studied in the protozoa is exhibited by the large infusorian Stentor. There are several species of this genus, but all are trumpetshaped, with a mouth situated at the bottom of a depression at one side of the anterior end. The oral end of the organism is surrounded by a zone of membranellæ which at one end descends in a spiral course toward the mouth. The whole surface of the body is covered by uniform cilia, with the exception of a small area of naked protoplasm at the small end or foot, by means of which Stentor is able to attach itself to foreign objects. When free in the water Stentor is able to swim by

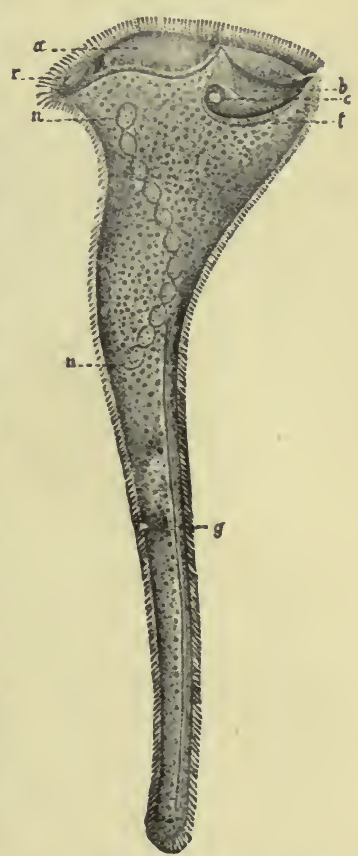

FIG. 11.-Stentor polymorphus. (After Stein.) the action of its cilia and membranellæ. Like Paramœcium it follows a spiral course and when stimulated it may perform the motor reflex, backing off by reversing the beat of its cilia, turning to the aboral side and then going 
ahead in another direction. To a degree unusual among infusoria Stentor has the power of changing the form of its body. It may extend into the form of a very long slender trumpet, or contract almost into a sphere. The ability to undergo these changes is due to the presence of numerous contractile threads or myonemes which extend for the most part longitudinally just beneath the outer layer of ectoplasm. Food taking in Stentor is accomplished with the aid of the cilia at the anterior end of the body and the membranellæ leading to the oral opening. The currents set up by the beating of these organs carry bodies to the mouth which has the power of taking in comparatively large objects, for one often sees rotifers, diatoms, algæ, and various protozoans in the endoplasm of the animal.

While swimming freely in the water the behavior of Stentor is in general similar to that of Paramœcium. The spiral swimming and the motor reflex in response to chemical, mechanical, thermal and electrical stimuli are much the same in both organisms. Stentors as a rule react to light which has little effect on Paramœeia. In Stentor cceruleus, which is negatively phototactic, sudden illumination evokes the motor reflex which after one or more trials enables the animal to reach a more shaded region. The anterior end is the region most sensitive to light and when the organism is pointed toward the light it gives the motor reflex, and swims in a different direction. If still pointing obliquely toward the light it may repeat the motor reflex and continue to do so until its anterior end is directed away from the source of stimulation, when the Stentor swims off in the direction of the rays.

When Stentor is attached it exhibits several peculiar types of activity. It may contract or extend the body, and it often sways about in various directions in a more or less 
rhythmical manner. To contact stimuli Stentor responds in a variety of ways dependent on the strength of the stimuli and the number of times they have been repeated. A moderately strong stimulus causes the Stentor to contract violently, but after a number of repetitions the contractions diminish in vigor and finally disappear. Jennings found that when Stentor is stimulated by a quantity of fine particles of India ink or carmine which were poured upon the disk by a capillary pipette, a regular series of responses was given. Frequently the Stentor would not respond at first, but would sweep the particles into its gullet continuously. Sooner or later, however, the organism would respond by bending to the aboral side. This may be repeated several times, but if it fails to afford relief from the stimulation another reaction is "tried." There is a sudden reversal of the action of the cilia and the particles are then thrown off the disk. The response is but momentary, however, and then the usual movements are resumed. If these two reactions are fruitless the Stentor contracts strongly, thus drawing its body out of the region of the impending particles. After a little it slowly extends again, and if the particles still fall on the disk the contraction may be repeated. If the stimuli still come after a number of such attempts to avoid them the Stentor makes several violent contractions in quick succession and breaks loose from its attachment and swims away. We have a series of reactions to the same external stimulus. If one reaction is unsuccessful another is tried until the organism finally obtains relief. These reactions are all of an adaptive character, so we can say that the creature is provided with a number of ways of meeting a given situation. The external stimulus remaining the same, the particular reaction that is given obviously depends upon the condition 
of the organism. For the physiological state A there is one reaction, for state $B$ another, and so on. As in a higher animal the behavior of Stentor depends upon its previous history. In a sense the organism may be said to profit by experience, although it cannot be said to learn, because there is no formation of new associations such as occurs in the learning of higher forms.

What are these internal physiological states to which the adaptive changes of behavior in Stentor are due? We have here two kinds of modification, as Jennings has pointed out, the failure to respond to a stimulus which at first evoked a reaction, and the replacement of one reaction by another. In regard to the first modification Jennings remarks that "It seems improbable that the change of behavior is due to fatigue, since the change occurs after but a single stimulation and a single contraction. It could hardly be supposed that these would fatigue the animal to such an extent as to prevent further contraction. And if we use stronger stimuli, we find that the animal continues to contract successively every time the stimulus is applied, for an hour or more." Even after the animal has ceased to contract strongly it may respond to a stimulus by bending to one side, thus showing, according to Jennings, that the failure to contract is not due to "a fatigue of the perceptive power, for the bending into a new position shows that the stimulus is perceived, though the reaction differs from the first one." Fatigue is usually associated in our minds with a condition indicative of exhaustion, and of such Stentor certainly gives no evidence after a few stimulations, but that there may be a slight degree of essentially the same state which when carried further we designate as fatigue, seems to me a possibility not ruled out by the experiments. It is possible, however, that the change in question may be due to something simi- 
lar to the phenomenon of acclimatization to chemicals and other agencies which is apparently a fundamental characteristic of living organisms.

The replacement of reactions by Stentor probably consists to a considerable degree in variations in the vigor and completeness of a single reaction. A gentle contraction may, owing to the bodily peculiarities of the animal, involve a turning to the aboral side, as its easiest channel of expression. With stronger contraction this would naturally be obscured, so that an apparently new response may result from the heightened irritability caused by the preceding stimuli. The succession of contractions resulting in the separation of the organism from its attachment naturally falls under the same interpretation, and is analagous to what takes place in an excised heart which, upon being given a single stimulus, may contract once or several times according to its condition of irritability. The successive contractile phenomena in Stentor are more or less analagous to those of summation of stimuli in an excised muscle. The reversal of the beat of the cilia is a separate reaction, although it may have a certain relation to the phenomenon of contraction. We are not justified in assuming that Stentor passes through a number of discrete internal states each of which has a correspondingly discrete motor response. The number of physiological states as in every organism is unlimited and the behavior of the animal shows us a series of reactions differing for the most part in degree of vigor rather than in kind, like the motor reflex in Paramœcium, which may be carried out in various degrees of completeness from a momentary slowing of speed to a prolonged backward swimming followed by numerous rotations toward the aboral side.

Schaeffer has carried on a series of careful experiments in 
which it was shown that when Stentor was offered either alternately or at the same time nutritious objects such as Phacus or Euglena and such substances as starch grains, powdered carmine or India ink, fine sand or sulphur, the former would be swept into the gullet and ingested, while the latter would usually be rejected. Conditions of hunger or satiety influence the selection of food. Very hungry Stentors may ingest indigestible particles of carmine or India ink, but when better fed the discrimination is more precise and only digestible material is taken in. Hungry Stentors differ from well fed ones also in the greater extension of the body and the greater activity of the membranellæ, but they are less responsive to mechanical stimuli.

The behavior of Protozoa, as we have seen, is influenced by their previous activity as well as by changes of external conditions. That behavior should be modified by these things is of course inevitable, for no organism is ever twice the same, and the life of every organism is one of constant adjustment to the external world. How far these changes indicate the presence of mind is a question about which there is much dispute. These changes are to a considerable degree of an adaptive nature, but the same may be said of many purely physiological processes occurring in our bodies. There are some phenomena described which have been interpreted as the acquirement of habit and even as learning by experience, but the observations on this score scarcely justify, in the opinion of the writer, the interpretations that have been placed upon them. Mr. Stevenson Smith has performed some experiments which lead him to the conclusion that Paramœcium is able to acquire advantageous habits. He placed a Paramœcium in a fine tube containing a small amount of water. The inner diameter of the tube was less than the length of the Paramœcium, so that the 
creature had great difficulty in reversing its course, having to bend its body in the form of a $U$ to get around. If the diameter of the tube is not too small the time which it takes the Paramœcium to turn, says Smith, "may gradually be shortened and a most surprising aptitude of turning be developed. . . . I have found a reduction of turning time, after the animals have been in the tube for twelve hours or more, from four to five minutes to a second or two, which is the minimum time in which the turns can be made." Although Paramœcia kept without food for twelve hours would diminish sufficiently in size to enable them to turn within the tube with much greater ease-a fact which Mr. Smith apparently has not considered-Day and Bentley, who have repeated Smith's experiments, have found that the greater facility in turning is acquired within a few minutes. It should be borne in mind that Paramœcium is an organism which takes in and excretes water many times more rapidly than even the specialized organs of excretion of higher animals, and that the abnormal conditions resulting from confinement within a very small amount of water may possibly cause a certain change in size within a short time. I have often observed a marked shrinkage in Paramœcia when they are placed in a medium of somewhat higher osmotic pressure. In abnormal conditions Paramœcia become more plump and the body seems softer and more flexible, and it is also possible that, since Paramœcium is endowed with a certain degree of contractility, the stimuli encountered through its frequent efforts to turn within the tube might cause a shortening of the body which would certainly occur in a more marked way in a Stentor and many other infusorians under these conditions. The experiment has its practical drawbacks as a means of testing habit formation or "learning," since the changes of size, form and con- 
sistency which the animals might undergo would so greatly influence the result. The fact described by Day and Bentley that Paramœcia which had acquired a facility of turning still showed the effects of their experience after having been placed for an interval of twenty minutes in their culture medium may well be due to the persistence of the purely physiological or pathological effects of their previous confinement.

Smith devised another experiment to show the modification of the reaction of Paramœcium to changes of temperature. A tube containing several Paramœeia was so arranged that either end could be heated or cooled at will. When one end was heated the Paramœeia would dart about at random, and when they swam into the cooler water they would often turn back to the hot water again. After the temperature of the two ends of the tube was reversed the animals would dart about much as before, reaching the cool water only after a number of trials. With repeated reversals, however, the movements of the Paramœcia became "slower and more regulated" and they would "seldom turn more than once toward the cold water before swimming in that direction." According to Smith, Paramœcium does not give evidence of the possession of associative memory, but he concludes that "its behavior may be modified to show the results of practice, both in a reduction of the time involved in performing a movement and in the increase of the suitability of the movement to accomplish the appropriate result." The modified reaction to temperature, I believe, may be accounted for not so much through the effect of practice in the performance of an act, but as a consequence of a general diminution of excitability. Take a few drops of a Paramœcium culture and place them on a slide. For a time the animals scurry about in the greatest haste and confusion, and frequently 
give the motor reflex with no apparent cause. After a time their actions become slower and more sober. Have we anything essentially different in the experiments of Mr. Smith? Possibly so, but I cannot convince myself of it from the results described.

Hodge and Aikins in their study of the daily life of a Vorticella observed that one individual, after having engulfed yeast cells for some time, refused them and persisted in so doing for several hours. What this fact signifies cannot be decided from the single observation reported; there are a number of possibilities, and the correct interpretation can be made only after carefully planned experiments.

There have been few systematic investigations with the end of testing the educability of the protozoa, and while granting the possibility that future work may compel us to modify our conclusion, it may be said that, thus far, there is no unmistakable evidence that the protozoa are capable of forming true habits or of learning by association.

\section{BIBLIOGRAPHY}

Binet, A. The Psychic Life of Micro-organisms. Chicago, '94. DAy, L. M. and Bentley, M. A Note on Learning in Paramœeium. Jour. An. Behavior, 1, 67, '11.

Delitnger, O. P. Locomotion of Amøbæ and allied forms. Jour. Exp. Zool., 3, 337, '06.

Gibbs, D. and Dellinger, O. P. The Daily Life of Amœba proteus. Am. Jour. Psych., 19, 232, '08.

Hodge, C. F. and Arkins, H. A. The Daily Life of a Protozoan. Am. Jour. Psych., 6, 524, '95.

Holmes. S. J. The Behavior of Loxophyllum, etc. Jour. Exp. Zool., 4, 306, '07. Rhythmical Activity in Infusoria. Biol. Bull., 13, 306, '07.

Jennings, H. S. Contributions to the Study of the Behavior of Lower Organisms. Carnegie Inst. Pubs. Wash., '04. The Behavior of Paramœeium. Additional Features and General Relations. Jour. Comp. Neur. Psych. 14, 441, '04. Behavior of Lower Organisms. N. Y., '06. 
Mast, S. O. The Reactions of Didinium nasutum (Stein) with Special Reference to the Feeding Habits and the Functions of the Trichocysts. Biol. Bull., 16, 91, '09.

Oelzelt-Newin, A. Beobachtungen über das Leben der Protozoen

Zeit. f. Psych. und Physiol. der Sinnesorgane, 41, 349, '06.

Prowazek, S. von. Einführung in die Physiologie der Einzelligen

(Protozœn). Leipzig and Berlin, '10.

PƯTTER, A. Die Reizbeantwortungen der ciliaten Infusorien. Zeit. f. allg. Physiol., 3, 406, '00.

Rhumbler, L. Physikalische Analyse von Lebenserscheinungen der Zelle. I, Bewegung, Nahrungsaufnahme, Defäkation, VacuolenPulsation und Gehäusebau bei lobosen Rhizopoden. Arch. f. Entwicklungsmech., 7, 103, '98. Zur Theorie der Oberflächenkräfte der Amöben. Zeit. f. wiss. Zool., 83, 1, '05. Die verschiedenartigen Nahrungsaufnahmen bei Amöben als Folge verschiedener Colloidzustande ihrer Oberflächen. Arch. f. Entwicklungsmech. 30, 194, '10.

Schatffer, A. A. Selection of Food in Stentor. Jour. Exp. Zool., 8, 75, '10.

Sмrт, \$. The Limits of Educability in Paramœcium. Jour. Comp. Neur. Psych., 18, 499, '08.

Verworn, M. Psycho-physiologische Protistenstudien. Experimentelle Untersuchungen, Jena, '89.

Watkins, G. P. Psychical Life in Protozoa. Am. Jour. Psych., 11,166 , '00. 


\section{CHAPTER V}

\section{INSTINCT}

"L'instinct sait tout, dans les voies invariables qui lui ont été tracées; il ignore tout, en dehors de les voies. Inspirations sublimes de science, inconséquences étonnantes de stupidité, sont à la fois son partage, suivant que l'animal agit dans des conditions normales ou dans des conditions accidentelles."-FABRE. Souvenirs Entomologigues. T. I.

"We are governed by instinct, as well as cats and goats."Voltaire. Philosophical Dictionary.

While it may not be necessary to define a term so well known as instinct, it may not be without interest to quote the following definitions which have been given by various writers:

"We may call the instincts of animals those faculties implanted in them by the Creator, by which, independent of instruction, observation or experience, and without a knowledge of the end in view, they are all alike impelled to the performance of certain actions tending to the well being of the individual and the preservation of the species."KIRBY AND SPENCE, Introduction to Entomology, 1858.

"A propensity prior to experience and independent of instruction." -Paley, Natural Theology.

"An action, which we ourselves require experience to enable us to perform, when performed by an animal, more especially a very young one, without experience, and when performed by many individuals in the same way, without their knowing for what purpose it is performed, is usually said to be instinctive. But I could show that none of these characters are universal."-DARWIN, Origin of Species.

Instinct is "compound reflex action."-Herbert SPEncer, Principles of.Psychology.

"Instinct is a general term comprising all those faculties of mind which lead to the performance of actions that are adaptive in character, but pursued without necessary knowledge of the relation bo- 
tween the means employed and the end attained."-Romanes, Article Instinct, Encyclopedia Britannica.

Instinct-"Purposeful action without consciousness of the purpose."-Von Hartmann, The Philosophy of the Unconscious.

"Instinct is inherited faculty, especially is inherited habit." Enmer, Organic Evolution.

"Qu'est-ce que l'instinct? Un mot."-G. BoHN.

"L'Instinct n'est rien."-Condillac.

The above definitions show how differently instinct has been conceived as regards its causation, although as to the kind of behavior to which the term is applied there is in general a broad basis of agreement. Some modern writers would have us discard the term instinct entirely on account of its vagueness and because, as commonly used, it carries with it certain connotations of which they do not approve. "Instinct," says Bohn, "is a legacy of the past, the middle ages, the theologians and the metaphysicians"-a word which does not stand for any well-defined reality. Consign it therefore to the dust bin, and describe behavior in other and more scientific terms. Instinct is a word whose connotation very naturally has varied according to the scientific and philosophical views of the writers who have employed it, but if we were to reject terms generally on this ground our language, even in science, would undergo an embarrassing amount of modification. There are few scientific terms, especially in psychology, which we should be willing to accept to-day with the meanings they had a hundred years ago. Stripped of its older metaphysical implications, which need not annoy us, and used to designate certain types of behavior, the term is a very useful one. It may not be possible to define it with precision. It is also difficult to define a child, a shrub or a tree. We know with a fair degree of clearness what is meant by the statement that nest building in birds and comb making in bees are instinctive. The 
same idea may be expressed by the use of "brand-new" scientific terms which have never been soiled by theologians and metaphysicians, but the need for a general term for kinds of behavior commonly classed as instinctive would still remain, and despite the efforts of a few comparative psychologists, the word instinct will I think continue in reputable use.

Illustrations of instinct abound everywhere and a very few will suffice. A flesh fly when first emerging from its pupa case is very soon ready for performing the various functions of its life. It guides itself accurately in flight, and deftly escapes its would be captors by quick and appropriate movements. It is drawn by the sense of smell to suitable objects for food. It avoids various kinds of injurious stimuli. It recognizes out of a vast number of animate objects the opposite sex of its own species. When ready to deposit its eggs it selects, out of a great variety of materials the proper substances to afford food for its future larvæ. Its acts are unguided by previous experiences; they are not prompted by reflection or thought; they result from a blind impulse urging the insect to discharge its energies in certain specific ways without knowing why. An organism of the degree of psychic development of a flesh fly may modify its acts to a certain degree through the effects of experience, but as a matter of fact such modification plays but a small part in the creature's life.

Some years ago the writer studied the behavior of a species of amphipod, Amphithce longimana, and compared the activities of the adult with those of the newly hatched young. Amphithœ lives in tubular nests which are usually lodged among sea weed. The nests are somewhat longer than the animal and are spun of a web-like material into which bits of sea weed are often incorporated which help to conceal 
the occupant. In its nest Amphithœ lies in wait for prey, ready to dart out upon any small creature which touches the ends of its long antennæ.

The activities of the adult Amphithœ, with the exception of those concerned in reproduction, are almost exactly parallelled by those of its young. I have taken the eggs from the maternal brood pouch shortly before hatching and kept them isolated in individual dishes. For some time after emerging from the egg the young were weak and had imperfect control of their movements, which were jerky and irregular. Soon the minute creatures could crawl and swim much like the adults, and the next day they began constructing nests which were the same in shape as those formed by their parents. The attitudes in the nest, the waving of the antennæ, the beating of the swimmerets, the restless movements of the legs and mouth parts, springing after food, belligerency toward passers by, the little unobtrusive signs of timidity, the reversal of position in the nest on the approach of danger and the general behavior outside of the nest were, on the next day after hatching, almost exactly the same as in older individuals. The only differences in behavior were due to the feebleness of the young and their imperfect control of their movements. The young are hatched with all the instincts necessary fully to equip them for the business of life. No experience is necessary to teach them what is advantageous for them to do.

It is this skill and apparent foresight exhibited in instinctive behavior that gives rise to a popular notion that animals are somehow mysteriously endowed with a.knowledge of those things which are necessary for their life. It is sometimes asserted that young ducklings will make for the nearest water before they have gained any experience of the neighborhood and in the absence of any signs by which the presence 
of water might be indicated; the ducklings just know instinctively where water is to be found. A friend of mine once urged as a fact of which our boasted scientific theories of instinct give no explanation the circumstance that the burrowing mammals of California, before an unusually rainy season, would leave their holes near the gulches and migrate to the hillsides. Long before any indications were furnished to the weather bureau the instinct of these animals was said to warn them of the danger of floods. Some time previous to the conversation the mammals were said to have emigrated from the lower parts of the valleys, and therefore a rainy winter was predicted. It so turned out, however, that the season in question proved to be an unusually dry one, and the wonderful instinct of the burrowing mammals gave them a false alarm. The migration of the mammals may or may not have taken place as reported, but the episode illustrates a very prevalent misconception of the nature and possibilities of instinct. Instincts frequently have a relation to future events, but that they involve a mysterious knowledge of things unpredictable by human reason still awaits proof.

With all their wonderful adaptiveness instincts are far from ideally perfect. Much of Mark Twain's remarks on the futility and imbecility, the wasted effort and labor at cross purposes shown in the behavior of ants may easily be verified by any observer. Flesh flies will deposit their eggs on the carrion plant (Stapelia hirsuta) whose odor resembles that of decaying meat on which the eggs are usually laid. The domestic hen will sometimes attempt to hatch out corn cobs or other inanimate objects, and her maternal instincts will lead her to foster ducklings as readily as her own kin. Sometimes animals devour their own eggs or young, as I have several times observed in cray- 
fishes and spiders; and in some centipedes the males will uniformly devour the eggs if they are not concealed by the female. Darwin states that in a South American species of Molothrus the instincts for securing proper care of the eggs are so imperfect that numerous eggs are simply dropped on the ground and abandoned.

Many instincts are at first not clearly defined. The young chick pecks at all sorts of small objects of good and bad taste alike. The young lamb will follow any sort of moving object of a certain size as well as its own mother. It is said to suck indefinitely at a piece of wool unless guided by some fortunate circumstance to the proper fount of nutriment. Young terns and many other young birds will not at first distinguish their parents, but will cuddle under one's hand in perfect confidence and contentment. They react in much the same way to a great variety of large moving objects. In most cases these mean the parent birds, and the instinct of the young becomes directed to their parents because the latter were the first living objects coming within their experience. Foster mothers of various kinds are adopted by many young birds and mammals as readily as members of their own species.

While many instincts exist in a completely developed state when the animal first enters upon active life, others are manifested only when it has reached a certain degree of maturity. Such have been called by Lloyd Morgan "deferred instincts." Instinctive fear in birds may not appear at first, but only after several days. Young nestling terns which for a short time after hatching will cuddle contentedly under one's hands, behave very differently before they are a third grown. They then scuttle away in wildest alarm upon one's approach and hide by crouching down in the grass, where they will lie perfectly quiet. The instinct of feigning 
death which does not occur in the young fledgling now appears on the scene; the young birds will allow themselves to be handled and pulled about without betraying a sign of life, and will even suffer their tail or wing feathers to be pulled out one by one without a wince. After a time, as if the bird recognized the futility of the ruse, the death feint is discontinued with a surprising suddenness to be followed by violent struggles, screams and pecking at its captor in its effort to make its escape. Later when the birds are able to fly the crouching and death feigning instincts disappear.

With birds which are hatched in a helpless and almost featherless condition most of the instincts of the species, with the exception of opening the mouth for food upon the appearance of a large moving object in their vicinity, are in abeyance. In such forms running, pecking, flight, etc., are none the less instinctive; they are simply kept from appearing on account of immaturity. The young of the mound-building bird will take wing when first hatched from the egg, but young swallows are not able to fly until after some weeks. That previous experience is not necessary to enable them to accomplish this feat is shown by the fact that young nestlings kept where they had no opportunity to use their wings until they were of the proper age for flight, were able to fly at their first attempt with perfect ease. That young birds are taught to fly by their parents is a popular myth. The instinct to fly is there in every case; its appearance is merely deferred, like the mating and nest building instincts, until the bird reaches a certain degree of development. Similarly with the running and swimming of mammals. A young puppy placed in the water will flounder helplessly and soon drown, but if an older dog is thrown into the water, though he may never have been in the water before, he will swim toward the shore. 
With animals which go through a profound metamorphosis in the course of their development we find correspondingly great changes in instinctive behavior. Nothing could be. more dissimilar than the instincts of the stealthy dragonfly nymph which prowls among the débris at the bottom of ponds and streams for its food, and the graceful and rapid darting of the full fledged dragon-fly as it chases its prey through the air. The transition between these two stages is very abrupt. When ready for its final moult the dragonfly nymph crawls upon the stem of some plant or upon a stone, its skin splits down the back, and out comes the imago, which needs only to dry its wings a little to be ready for its vita nuova in the world of sunshine. The difference between the behavior of the crawling, gnawing caterpillar and the active honey sucking butterfly; of the helpless wriggling grub and the honey bee; of the free swimming larva and the worm that burrows in the sand of the seashore are instances, out of thousands that might be given, of the great differences in instinctive behavior at different periods of life in forms which undergo marked metamorphoses in structure.

Where animals are hatched in the form of the adult we find little change in instinct. The young trap door spider, according to Moggridge, constructs its tiny tubular dwelling with its ingeniously fitted trap door in almost a perfect miniature of the adult nest. Montgomery finds that the young of the orbweavers Epeira scolpetaria and E. marmorea spin, at their very first attempt, a diminutive web of the same degree of perfection as that of the full grown spider. Here, as in the case of the amphipod previously described, the young closely resemble the older individuals. Where the change of form is greater, as in insects with a gradual or incomplete metamorphosis, there is a gradual change of instinct. The behavior of the tadpole graduates insensibly into the very 
different behavior of the frog. But with abrupt structural changes such as occur in insects with complete metamorphosis the changes in instinct at successive periods is equally great and often more striking.

The transitoriness of many instincts has been illustrated in some of the cases referred to, in which the instincts of larval life are superseded by those of a later period. The same trait is commonly manifested in the behavior of higher forms. Here the instinct may be fostered and continued by habit, and if it does not become aroused by the appropriate objects soon fades away. According to Spaulding, "A chicken that has not heard the call of the mother until eight or ten days old then hears it as if it heard it not. I regret to find that on this point my notes are not so full as I could wish, or as they might have been. There is, however, an account of one chicken that could not be returned to the mother when ten days old. The hen followed it and tried to entice it in every way; still it continually left her and ran to the house or to any person of whom it caught sight. This it persisted in doing, though beaten back with a small branch dozens of times, and, indeed, cruelly maltreated." If calves are prevented from sucking for some time after birth they frequently although not invariably lose the instinct to suck, and may then be safely returned to the mother. There is obviously an adaptiveness in this transitoriness of instinct in higher forms. Where the instinct finds no proper object to call it forth it is rather of advantage to the animal to be rid of it; the ground is in a measure cleared for the development of new adaptations.

Modern literature on animal behavior has much to say regarding the kinship of instinct and reflex action. Both are based on inherited organization; both consist to a considerable degree of purposive actions in relation to outer 
objects, although without a knowledge of the end they subserve. There is so complete a gradation of responses between simple reflexes and complex instincts that it becomes an arbitrary matter where the line is drawn between them. In ourselves coughing, sneezing, winking, hiccoughing, swallowing, vomiting, jerking back when tickled or painfully stimulated are commonly set down as reflexes. Sucking, biting, chewing, spitting out, making a face over disagreeable objects, grasping with fingers and toes, carrying objects to the mouth, etc., are usually classed as human instincts (Preyer). These acts are manifested by the human infant at a very early period and in much the same way by different individuals, and there can be no doubt that their relation to the inherited organization is the same as in the lower animals. Chewing, spitting out and making a face over a disagreeable taste are little more complex than the reflexes of swallowing and coughing. If not performed involuntarily, there is at least a strong involuntary proclivity to their performance which would express itself in action if not suppressed by an effort of the will. Swallowing, coughing and sneezing are likewise capable of voluntary suppression, so that we cannot separate these activities sharply on the basis of their relation to the will any more than on the ground of complexity.

In man the gradation from the simple to the more complex manifestations of instinct is not so obvious owing to the fact that human instincts are so closely interwoven with habits and the workings of intelligence; but in lower forms where intelligence is reduced to a minimum the relation is shown very clearly. In an animal such as the crayfish the relation of instinct and reflex action may be studied very advantageously by the experimental method. The crayfish has a number of well defined instinctive reactions such 
as locomotion by walking and swimming, darting back upon the approach of danger, seeking dark and protected situations, rearing up when threatened and holding the claws in a position for defence, withdrawing movements, moving toward certain odors and feeling about with the chelæ for food, seizing food in the chelæ and passing it to the mouth, chewing and swallowing, rejecting objects from the mouth, and a number of others. The crayfish may form associations to a limited degree, but if it had to rely entirely on its congenital endowment of instincts it would probably get through the world almost as successfully as it does with its modicum of intelligence.

The relation of instincts and reflexes in the crayfish has been studied with considerable thoroughness by means of operations on the nervous system. The nervous mechanism of the crayfish consists of a brain which gives branches to the eyes, first and second antennæ, and anterior part of the thorax; a ventral nerve cord consisting of a double chain of ganglia which is connected with the brain by commissures passing around the esophagus; and a small visceral system. The ganglia of the ventral nerve cord are connected by cross commissures as well as the longitudinal ones which form the larger part of the nerve chain, and they give off nerves which are distributed to the segments in which they lie. Typically there is a pair of ganglia in each segment of the body, but anteriorly the ganglia belonging to the segments bearing the mouth parts have become fused into a single sub-esophageal ganglion which supplies these appendages. The brain may be regarded as a nerve center homologous with the ganglia of the ventral nerve cord, but like the subesophageal ganglion, it is formed of more than one pair of ganglia which have been fused together.

Experiments on the crayfish show very clearly that the 
instincts of the animal are by no means monopolized by the brain, but that the various ganglia of the ventral nerve cord are the controlling centers of many activities. If we cut the commissures connecting the brain with the chain of ventral ganglia, the reactions of the eyes and antennæ take place in the usual way. If the eye stalk is stimulated it is withdrawn; if the antennules or antennæ are touched they are drawn back, but there is no reaction from the legs. On the other hand, if a leg is seized an effort is made to withdraw it; if this is not successful other legs may be employed to push against one's hand or the chelipeds may reach over and pinch the offender. The crayfish can walk in the usual manner, and when placed in the water it can swim as well as a normal individual. Its movements are more restless than before, owing to the lack of inhibitory impulses which under ordinary circumstances are issued from the brain. Food is seized by the chelipeds, passed to the mouth parts, chewed and swallowed; if stones or other innutritious objects are presented to the mouth parts they are at once rejected, showing that connection with the brain is by no means necessary for the proper discrimination of food.

If the commissures are cut farther back, between the subesophageal and the first thoracic ganglia, power of moving the legs still remains, although locomotion is somewhat impeded. If a leg is seized it is withdrawn or defended by the other appendages. Pieces of meat or paper given to the chelipeds are passed from one to the other and pressed between the mouth parts where they may be seized and swallowed. Often the mouth parts are tardy in responding, and the chelipeds may vainly persist for hours in pressing the object against them. Sometimes bits of food are torn to pieces and then offered to the mouth parts. Stones or other hard objects are not passed to the mouth, and if seized 
are soon rejected. The legs are almost incessantly engaged in cleaning movements, picking at one another, and at the abdomen and its appendages.

With the nerve cord cut between the first and second thoracic ganglia the responses of the parts in front of the cut are little affected, but those of the last four pairs of thoracic legs are much reduced in vigor. The chelæ still perform defensive movements, but the feeding movements no longer occur. Cutting the nerve cord further back interferes still more with the power of coördinated locomotion, although the withdrawing and defensive movements still persist. In fact, any pair of legs will perform these movements if the cord is cut both in front of and behind the ganglion supplying these legs with nerves.

Each ganglion is a reflex center regulating the movements of the appendages of the segment in which it lies. Into it impulses pass from the appendages and are sent out to muscles which effect the withdrawing or the defensive acts in response to the outer stimulus. When several ganglia are joined together, the impulses from the various appendages are coördinated; instead of a single adaptive reflex, we have a complex coöperative response, such as occurs in walking, cleaning movements and mutual defense of appendages which are seized. What a wonderful combination and coördination of impulses! From the simple reflex of the isolated segmental ganglion to the complex behavior of the brainless crayfish, and from this to the still more complex behavior of the normal animal there is a regular gradation. Nowhere can we draw a sharp line between reflex behavior on the one hand and instinct on the other. Both are based on a wonderfully complex and beautifully organized nervous mechanism.

Among the most remarkable of the instincts of crusta- 
ceans is the peculiar trait shown by several species of spider crabs of decking themselves out with a covering of seaweed, sponges, hydroids, etc., so that they are quite effectually concealed in their natural surroundings. Spider crabs kept in aquaria have been seen by several observers to snip off bits of seaweed with their pincers, reach over their backs and stick them down among the stiff curved hairs which occur on the upper surface of the carapace. The seaweeds and sessile animals thus transplanted often grow, so that the back of the crab comes to be a veritable botanical and zoological garden on a small scale. There are few instinctive acts which appear to be more the result of deliberate intention, yet the disguisement is not only instinctive, but, as Minkiewicz has shown, it is performed by crabs in which the brain is entirely cut off from connection with the legs by cutting the esophageal commissures that lead to the large ventral ganglion. The sense of wonder with which instinct was formerly regarded, and which the reflex theory might seem to rudely destroy, is a sentiment which can scarcely fail to arise when we contemplate the organization which makes possible the blind performance of such remarkable acts. Among the insects, as in the Crustacea, the seat of many instincts is in the ventral ganglia rather than in the brain. A decapitated fly is able to walk and fly and go through with elaborate movements of cleaning the wings, legs and body. In experiments made by the writer on the water scorpion, Ranatra, it was found that after decapitation the insects were able to walk and swim almost as well as before. In fact, they became much more restless and would walk about for hours without 'coming to rest; and when they finally became quiet they could be aroused by the slightest stimuli. When placed on their backs they would readily right themselves. If the tip of the breathing tube was seized while the 
insect was swimming its efforts to swim away would be performed with much greater vigor. If it does not effect its escape by this method it has recourse to a remarkably neat and apparently intelligent device. The hind legs are thrown back as far as possible, whereby they are enabled to grasp the breathing tube a short distance behind the body; then by exerting a pull they bend the body ventrally. This soon places the second pair of legs so that the offending object can be reached, when all four legs are employed to push the body away, which is very frequently accomplished. The behavior of a decapitated Ranatra in this situation certainly affords an excellent simulation, not only of purposive action, but also of considerable ingenuity in its accomplishment.

The reactions of the brainless frog form the stock illustrations of reflex action. The withdrawal of a foot when pinched is one of the simplest of these. When a drop of acid is placed on one side of the body the hind foot of that side is brought forward to wipe it off. With a somewhat stronger stimulus the fore leg of the same side may be moved back to the irritated spot. If the acid is placed on the middle of the posterior part of the back both hind legs are employed to remove it. We have here reflexes of a higher degree of complexity involving the coördinated movements of many muscles. If a frog with the greater part of its brain removed is taken in the hands it uses both hind legs to push against the hands, and at the same time inflates the lungs with air, causing the body to swell so that it more readily slips from the grasp. The use of the hind limbs and the swelling of the body may be regarded as two complex refle es excited by the same cause and which coöperate to enable the animal to effect its escape, but the behavior may equally well be described as an instinctive reaction. 
The clasping of the female frog by the male during the breeding season affords a typical example of instinctive behavior; nevertheless, it occurs in entire independence of the higher nerve centers. "The Abbe Spallanzani showed that a male frog may have its head cut off during copulation without ceasing to cling tenaciously to the female. Goltz went still further and cut off the head of a male, then cut the body through between the third and fourth vertebræ, and removed the viscera from the body cavity; the section of the frog that remained after these operations consisted of the first three vertebræ, the pectoral girdle and the fore legs. Yet when the skin of the inner surfaces of the fore legs was rubbed with the finger this segment would show the same clasping efforts as a normal male frog."

Nearly all the characteristic responses of the frog will take place in individuals deprived of the cerebral hemispheres which are the part of the brain usually considered as the seat of intelligence and volition. Such a frog, if given sufficient time to recover from the shock of the operation, will leap about and swim spontaneously, snap at insects which come within range, bury itself in the mud on the approach of winter, and in many other ways behave in a normal ranine manner.

Beginning with the anterior part of the brain and destroying successively the parts of the central nervous system lying behind it, we cause, one after the other, the various instinctive acts of the frog to disappear, until we have left only the reflexes of the posterior part of the spinal cord. We reduce the frog to a more and more simple type of reflex mechanism, but we cannot say where the animal ceases to be more than a reflex mechanism of a complicated kind. The behavior of the frog is almost entirely made up of instinctive and reflex acts, many of which have their seat 
either in the spinal cord or the lower centers of the brain. It thus resembles the segmental reflexes which constitute much of the behavior of worms and arthropods. In the frog, as Schrader has observed, the central nervous system "can be divided into a series of sections each of which is capable of performing an independent function." Its mode of action is hence of the same fundamental kind that we find in the nervous systems of the lower articulate animals.

The relation of reflex action to instinct which is disclosed through operations on the nervous system is shown also by a study of the gradual development of instinct through the animal kingdom. The behavior of the protozoa, as we have seen, consists mostly of rather simple stereotyped activities which have all the directness of the simple reflex acts of higher forms. The behavior of the lower Metazoa falls largely within the same general type. Tracing the evolution of behavior upward we find a gradual increase in the number, complexity and perfection of reflex acts. Where instinct may be said to begin is an arbitrary matter. If instinct be, as Spencer defines it, "compound reflex action," it begins of course-where reflex action passes from the simple to the compound, but this point is not so easy to mark as theoretically it might appear. It is commonly said that in reflex action only a part of the body responds, as in winking the eye, or jerking back the foot, whereas in instinctive behavior there is a response by the organism as a whole. This distinction is at times difficult to draw, and it is not consistently adopted by most writers, but it is perhaps as useful a distinction as can be made.

While instinct is most intimately related in its nature and origin to reflex action it would be an error to regard it as consisting of nothing but direct responses to external stimuli. The animal is not merely a machine responding to the 
various influences from the environment which affect it. It possesses a native fund of impulse which causes it to act in more or less definite ways independently of the stimulations of the outer world. Several modern writers have over-emphasized the element of responsiveness in instinct, as if an animal were like an instrument played upon by outer forces and had its actions fatally determined by the action of those forces on its own inner mechanism. Other writers have treated instinct as determined by a sort of internal impulsion. The latter conception is implied in the German word "Trieb," or driving force, and in Paley's "propensity prior to experience." Lloyd Morgan says in speaking of instinct: "Initiated by an external stimulus or group of stimuli, it is at any rate in many cases, determined also in greater degree than reflex action by an internal factor which causes uneasiness or distress, more or less marked, if it do not find its normal instinctive satisfactions. Take, for example, the before mentioned instinct of the great water-beetle to leave the pond and burrow in the bank when the time for pupation is at hand. There is something more here than a local response to an external stimulus; something more, it would seem, than mere reflex action. There are activities affecting the whole behavior of the organism, and there seem to be internal promptings of some kind due to organic conditions whose seat is in the body of the developing larva. Or take the migration of birds, their nest-building instincts, the activities involved in the rearing of their young; there is surely, it may be said, something in all this which may be distinguished, even if the line of demarkation be hard to draw, from reflex action. We cannot say more, however, than that the one is a more fully corporate act than the other."

It is without question that internal states form the prompt- 
ings of many instinctive acts. Hunger drives the lioness to seek for prey; sexual impulses lead to the search for mates; and a bird in confinement may become uneasy when the time for migration arrives. The same thing is even more conspicuously illustrated in the instinct of play. A lamb may frisk about from sheer good feeling. A kitten may crouch and spring as if upon a mouse when there is no external object to excite its action. And where the play activities are associated with external objects, the latter serve only to awaken the stored energy of impulse which may be nearly ready to discharge on its own account. The play impulse which may sometimes vent itself in random movements usually takes fairly definite channels of expression which are quite characteristic of particular species of animals. The energies of the young animal tend to discharge themselves in movements similar to those which form the regular behavior of the adult, and a certain degree of proficiency is reached in those activities which form the more serious occupations of later life. But the promptings to such behavior are due mainly or wholly to internal impulses.

The element of internally initiated impulse in instinct is not confined to higher forms. It is probably coextensive with animal life. Amid all the stereotyped responses of the Protozoa we have a large element of activity determined by internal factors. The almost constant swimming of many infusorians, and the regular rhythmical activity of others are, like the beating of the heart and other organic rhythms, the result of causes within the organism.

It is of course difficult in many cases to ascertain whether activity results, perhaps indirectly, from outer stimulations or from internal changes. In a great many cases the organism needs but a slight provocation to discharge its 
energies in instinctive acts. When the spider spins its web, when the wasp digs a hole and stores it with a certain kind of prey for its young, and when the bird builds its nest, and the beaver its dam there is of course response to certain features of the environment; there is also an innate propensity for the organic machinery to work in certain ways, much as a piece of clock work runs in a particular fashion after it has been wound up and set going.

Activity which is internally initiated is not fundamentally different from activity which we commonly call reflex; the stimuli by which it is evoked are internal instead of external; they result in many cases from the rhythms of organic functions, chance discharges of nervous energy due to various physiological changes, and various other factors. Such activities are to a high degree characteristic of particular species and are doubtless as rigidly determined by organization as are the direct responses to external stimuli.

The nature of the instinctive act that may be performed in a given situation is notoriously dependent upon the internal condition of the animal. The same stimulus may evoke in different states quite contrary impulses. The sight and smell of food may arouse an animal to vigorous efforts to secure it, or produce feelings of aversion and movements of avoidance, according to the creature's state of hunger or satiety. The sexual behavior of animals is dependent to a very marked degree upon internal conditions which are correlated with the production and maturation of the sex cells. Salmon begin their up-stream migrations, the male frog develops his tendency to clasp the female; birds herald the advent of the breeding season with courtship and song, and the males of many mammals show at this time an unusual degree of belligerency. The change 
in instinctive behavior during the breeding season may be due to the production of internal secretions which influence the irritability of certain parts of the nervous system, but, however caused, it is, like the varying responses to food, water, etc., pretty closely subservient to the needs of the species.

This dependence of behavior upon internal conditions naturally increases the range of its possible adaptations. Animals are often endowed with adaptive responses corresponding to this, that, or the other internal state. Previous exercise and many other factors change these internal states, so that what an animal may do in a given situation is not to be inferred from the external conditions alone. If one response does not suit the animal tries another, and so on. The condition of the animal is changed after one or more reactions and this change produces a different reaction to the stimulus.

According to Whitman, the leech Clepsine when it is stimulated may roll into a ball, hug the bottom, or crawl away. "If the leech has eggs it will not roll up, but if it has no eggs, or if it has young, it may adopt either mode of escape, while if it has eggs it has no choice but to remain quiet over them. The act of rolling up into a passive ball may be performed (a) under compulsion, as when it is her last resort in self defense; (b) under a milder provocation, as one of three courses of behavior, as when the resting place is turned up to light, and the choice is offered between remaining quiet in place, creeping away at leisure, or rolling into a ball and dropping to the bottom; (c) or finally, under no special external stimulus, but rather from internal motive, the normal demand for rest and seclusion, presumably very strong in Clepsine after gorging itself with the blood of its turtle host." "The differential reaction," says Lloyd 
Morgan, "according as the animal has eggs or not suggests intelligence; but," he adds-and this seems to me to be a more probable conclusion-that "it may be instinct varying according to the conditions of stimulation."

Varied activity under unfavorable conditions characterizes alike the behavior of the Protozoa and the most highly evolved animals. While not involving intelligence it performs, in a measure, the function of intelligence, as it gives the animal greater opportunities for making favorable adjustments: "Nature," says James, "implants contrary impulses to act in many classes of things, and leaves it to slight alterations of the conditions of the individual case to decide which impulse shall carry the day. Thus greediness and suspicion, curiosity and timidity, coyness and desire, bashfulness and vanity, sociability and pugnacity seem to shoot over into each other as quickly, and to remain in as unstable equilibrium, in the higher birds and mammals as in man. They are all impulses, completely blind at first, and productive of motor reactions of a rigorously determinate sort. Each of them, then, is an instinct, as instincts are commonly defined. But they contradict each other'experience' in each particular opportunity of application usually deciding the issue. The animal that exhibits them loses the instinctive demeanor and appears to lead a life of hesitation and choice, an intellectual life, not, however, because he has no instincts-rather because he has so many of them that they block each other's path."

At its first appearance intelligence is able to modify but slightly the course of instinctive behavior. It is a faculty which, as Hobhouse remarks, "arises within the sphere of instinct" and is devoted to the task of enabling the instinctive proclivities of the animal to work themselves out more effectively. The close connection of intelligence and instinct 
is shown by the fact that animals are so exceedingly stupid in everything not closely related to their instinctive interests. A cat pays not the least attention to a multitude of things going on around her, but the sight of a canary or the noise made by a gnawing mouse puts her on the qui-vive. Only a few objects have meaning; the rest do not form a part of what might be called her effective environment; to her they are non-existent.

Not only in lower forms, but in the higher members of the animal kingdom as well, intelligence may be said to be the handmaid of instinct. Animals profit by experience in order to live their life along the lines marked out for them by their instinctive make-up, and whatever pleasure or satisfaction their lives may bring is attained by following their instinctive bent. "Why," asks James, in a significant passage, "do the various animals do what seem to us such strange things in the presence of such outlandish stimuli? Why does the hen, for example, submit herself to the tedium of incubating such a fearfully uninteresting set of objects as a nestful of eggs, unless she have some prophetic inkling of the result? The only answer is ad hominem. We can only interpret the instinets of brutes by what we know of instincts in ourselves. Why do men always lie down, when they can, on soft beds rather than on hard floors? Why do they sit around the stove on a cold day? . . . Why does the maiden interest the youth so that everything about her seems more important and significant than anything else in the world? Nothing more can be said than that these are human ways, and that every creature likes its own ways, and takes to following them as a matter of course. Science may come and consider these ways and find that most of them are useful. But it is not for the sake of their utility that they are followed, but because in following them we 
feel that it is the only appropriate and natural thing to do. . . . And so, probably, does each animal feel about the particular things it tends to do in the presence of particular objects. . . . To the lion it is the lioness which is made to be loved; to the bear, the she-bear. To the broody hen the notion would probably seem preposterous that there should be a creature in the world to whom a nestful of eggs was not the utterly fascinating and precious, never-to-be-too-muchsat-upon-object which it is to her."

With increasing intelligence attention becomes devoted to things which are more remotely connected with instinctive interests, but even in ourselves instinct, in one form or another, supplies the basis of most of our springs of action. With us, as with the lower animals, self-preservation and the perpetuation of the stock afford, broadly interpreted, the main business of life.

\section{BIBLIOGRAPHY}

DARwin, C. Origin of Species, 1859. Posthumous essay on Instinct published in Romanes' Mental Evolution in Animals.

Hовноuse, L. T. Mind in Evolution, ' 01.

Hudson, W. H. The Naturalist in the La Plata. London, '95. James, W. Principles of Psychology, 2 vols. '90.

Morgan, C. L. Habit and Instinct, London,'96. Animal Behaviour, London, ' 00 .

Reimarus, H. S. Allgemeine Betrachtungen über die Triebe der Thiere. Hamburg, 1773, 3d ed.

Romanes, G. J. Animal Intelligence, N. Y., '83. Mental Evolution in Animals, London, ' 85.

Schnerder, G. H. Der thierische Wille, Leipzig, '80.

Schnerder, K. C. Vorlesungen über Tierpsychologie, '09.

Spaulding, D. A. Instinct, With Original Observations on Young

Animals. Macmillan's Mag. 27, 282, '73. Reprinted in Pop.

Sci. Mon. 61, 126, ' 02 .

Spencer, H. Principles of Psychology, London, 1855.

Wasmann, E. Instinkt und Intelligenz im Tierreich, 3d ed.,

Freiburg. i. B. '05. Translation of 2 nd ed. St Louis, '03. ZIEGLER, H. E. Der Begriff des Instinktes einst und jetzt. Jena, '10. 


\section{CHAPTER VI}

\section{THE EVOLUTION OF INSTINCT}

"The primary roots of instincts reach back to the constitutional properties of protoplasm, and their evolution runs, in general, parallel with organogeny. As the genesis of organs takes its departure from the elementary structure of protoplasm, so does the genesis of instincts proceed from the fundamental functions of protoplasm."Whitman, Animal Behavior.

"Instinct precedes intelligence both in ontogeny and in phylogeny, and it has furnished all the structural foundations employed by intelligence."-Ibid.

"It will be universally admitted that instincts are as important as corporeal structures for the welfare of each species under its present conditions of life. . . . If it can be shown that instincts do vary ever so little, then I can see no difficulty in natural selection preserving and continually accumulating variations of instinct to any extent that was profitable. It is thus, as I believe, that all the most complex and wonderful instincts have originated."-DARWIN, Origin of Species.

Efforts to explain the origin of instinct by gradual evolution were made from time to time before Darwin applied his theory of natural selection to the solution of the problem. The most noteworthy theory was Lamarck's doctrine that instinct is inherited habit. It is well known that actions frequently performed come in course of time to be performed automatically and unconsciously, as is illustrated by the familiar example of learning to play the piano. Granting that the modifications produced by habit are inherited, it is evident that the repetition of an action generation after generation would produce a congenital proclivity to its performance which might in time develop into a true instinct. Since habits are so frequently the result of intel- 
ligent experience, instinct was conceived by some writers as due to the gradual automatizing of such experience by frequent repetition; in the words of G. H. Lewes, instinct is "lapsed intelligence," a view which makes intelligence first in order of appearance and instinct a secondary result of a sort of psychic degeneration.

As Whitman has urged, according to the doctrine of Lewes, "we should expect to find the lowest animals free from instinct and possessed of pure intelligence. In the higher forms we should expect to see intelligence lapsing more and more into pure instinct." As every student of animal behavior now knows, we find just the reverse. Among low forms behavior is all but exclusively of the reflex type. Passing up the animal series we find intelligence gradually growing upon instinctive foundations. "In higher forms not a single case of intelligence lapsing into instinct is known. In forms that give indubitable evidence of intelligence we do not see conscious reflection crystallizing into instinct, but we do find instinct coming more and more under the sway of intelligence."

Herbert Spencer, who was keenly alive to the difficulties of the theory of lapsed intelligence as an explanation of the origin of instinct in general, put forward an ingenious speculation in which he attempted to derive instinct from reflex action and the inheritance of acquired associations between reflexes. In order to illustrate how an instinct might arise he takes a low aquatic creature with rudimentary eyes. "Sensitive as such eyes are only to marked changes in the quantity of light, they can be affected by opaque bodies moving in the surrounding water, only when such bodies approach close to them. But bodies carried by their motion very near to the organism will, by their further motion, be brought in contact with it. . . I In its earliest forms sight is, 
as before said, little more than anticipatory touch; visual impressions are, in all these creatures, habitually followed by tactual ones. But tactual impressions are, in all these creatures, habitually followed by contractions. . . . From the zoophytes upward touch and contraction form an habitual sequence; and hence, in creatures whose incipient vision amounts to little more than anticipatory touch, there constantly occurs the succession-a visual impression, a tactual impression, a contraction." This habitual association will link the two responses so that a contraction will follow immediately upon the visual stimulus. The effect of such experiences accumulated by heredity generation after generation is to establish a new congenital response which is of value to the species. With increased power of sensory discrimination the visual stimuli produced by smaller objects whose contact does not cause a protective contraction, but rather the activities of food taking, may in a similar manner become associated with movements of prehension, thus enabling the animal to react in different ways to objects at a distance. In this way Spencer supposes instincts to have been built up by growing out of simple reflex acts instead of being the outcome of a lapsed intelligence. Spencer's conception is more congruous with the general doctrine of psychic evolution and does not involve the assumption that the lower we go in the animal kingdom the more purely intelligent the actions of animals become.

The theory of Spencer, which was putforward in 1855, is based entirely on the assumption of the transmission of acquired characters like so many other of his psychological speculations. After the "Origin of Species" was published Spencer accepted the theory of natural selection, but assigned to it a subordinate rôle, especially in the evolution of mind. 
The Lamarckian theory of the origin of instinct has in more or less modified forms enjoyed a wide popularity among writers on genetic psychology. The veteran psychologist Wundt in his discussion of theories of instinct in his Human and Animal Psychology assumes unquestioningly the transmission of acquired characters, practically ignoring the dostrine of natural selection, and even representing that Darwin "explains instinct as inherited habit"!

One of the most extreme positions is that of Eimer who rejects the theory of natural selection and adopts the pure Lamarckian standpoint. One of his arguments in favor of this theory is drawn from the instincts of the mason wasp, Odynerus parietum. This species provisions its nest with larvæ which it paralyzes by stinging them in the ventral ganglia. After collecting several larvæ and storing them in a hole in the ground, the wasp lays an egg on the store of food, seals up the hole with clay, and then begins the construction of another nest. "What a wonderful contrivance"! exclaims Eimer, "What calculation on the part of the animal must have been necessary to discover it! The larvæ of the wasp require animal food. Dead food enclosed in the cell would soon putrefy; living active animals would disturb the egg, and accordingly the wasp paralyzes grubs and packs them like sacks of meal one after another in the cell. How did she arrive at this habit? At the beginning she probably killed larvæ by stinging them anywhere and then placed them in the cell. The bad results of this showed themselves; the larvæ putrefied before they could serve as food for the larval wasps. In the meantime the motherwasp discovered that those larvæ which she had stung in particular parts of the body were motionless but still alive, and then she concluded that larvæ stung in this particular way could be kept for a longer time unchanged as living 
motionless food. ... . In this case it is absolutely impossible that the animal has arrived at its habit otherwise than by reflection upon the facts of experience."

The careful studies of the Peckhams on the instincts of the solitary wasps have shown that many of the assumptions upon which Eimer rests his argument are erroneous. In the first place the Peckhams found that the insects stored as food were by no means uniformly paralyzed and that in

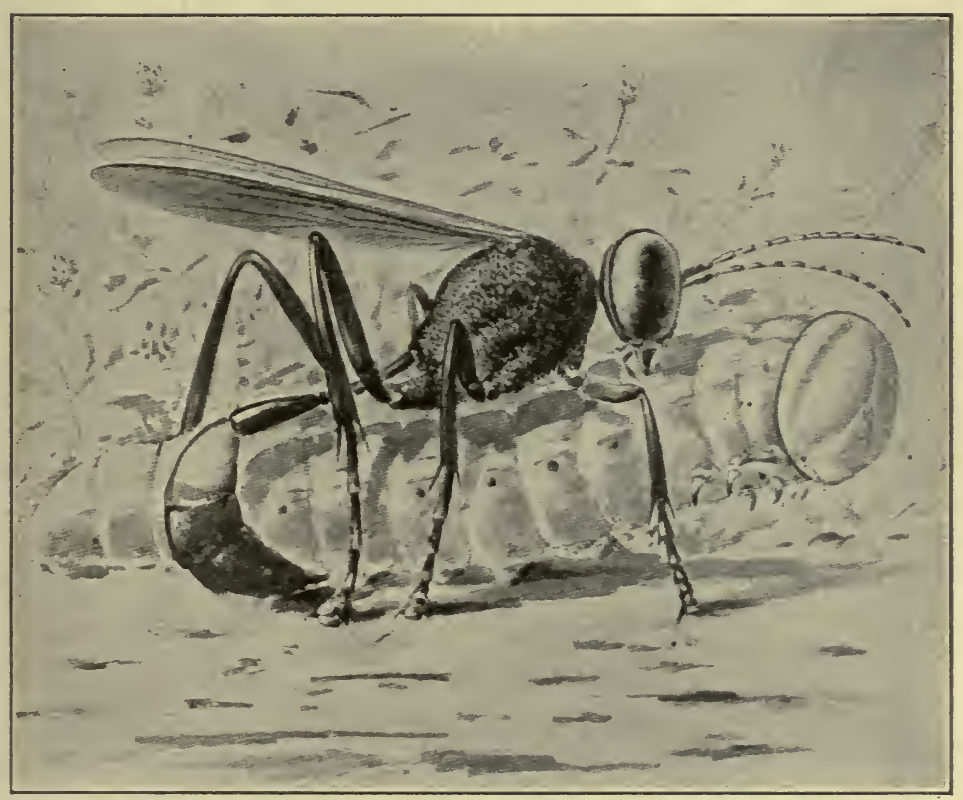

FIG. 12.-The wasp Ammophila stinging a caterpillar. (After Peckham.)

most nests several caterpillars died. Even where all were dead the wasp larvæ fed upon them, so that it is open to question if much is gained by having the prey in a paralyzed condition. The Peckhams conclude that "the primary purpose of the stinging is to overcome resistance and to prevent the escape of the victims, and that incidentally some 
of them are killed and others paralyzed." In Ammophila "the prey may be stung so slightly that it can rear and struggle violently or so severely that it dies almost at once, and in neither case is a break made in the generation of Ammophiles, since in the former, the egg or larva is so firmly fastened as to keep its hold, while in the latter the dead and decomposing caterpillar is eaten without dissatisfaction or injury."

An important fact which Eimer has apparently failed to consider is that in most of the solitary wasps the nest with its provision and egg is abandoned as soon as completed and never seen again, the wasp dying before its progeny emerges. The same is true among the more primitive bees, such as Osmia, where elaborate provision is made for the larva which only emerges the following year. The typical condition among the solitary species of both bees and wasps is one in which the parent never sees its own offspring, never has an opportunity of watching the results of its own experiments. Unless gifted with a truly preternatural intelligence what means has a solitary wasp or bee which never sees the larva or pupa of its own species of knowing what conditions of food and habitation are the most suitable for its progeny? Far from being the only possible explanation of the origin of the remarkable instinct he has cited, the doctrine of Eimer is improbable to the point of absurdity.

Romanes who has treated the evolution of instinct at length in his Mental Evolution in Animals regards both natural selection and use inheritance as important factors. Instincts due to the first factor he calls primary, while those due to the latter are called secondary. Several instances are cited in which it is claimed there is strong proof that certain instincts have been produced through the accumulated effects of experience. Other instances are given 
which point to a blended origin of instinct. The cases adduced by Romanes have been critically analyzed by Lloyd Morgan and Whitman, who have shown that they are of very doubtful value as evidence, and we need not repeat the arguments of these writers. One class of cases adduced by Romanes we shall mention since it shows how easily the facts may be misinterpreted. Wildness and tameness among birds are apparently inherited instincts. Most readers are familiar with the statement that birds on little frequented islands and in recently explored regions betray at first no marked fear of man and may frequently be knocked over with clubs, whereas in places where they have been hunted for several generations they become very wild, the fear of man being shown by the young birds as well as the old.

This fact is supposed to be explainable only on the assumption that the painful experiences inflicted by man have become associated with the appearance of the human form, and that this association is transmitted to the young birds, giving them an innate fear of man before they have had any experience with their persecutor. Those who have adopted this explanation have failed to consider the important rôle of imitation in the behavior of young birds. Fear is undoubtedly instinctive, and it may be aroused by large moving objects or unfamiliar appearances of any kind, but in general it may be said that a sort of tradition determines, to a very large extent, the objects by which fear is awakened. The excellent observations of Hudson on fear in birds have convinced him that the "fear of particular enemies is in nearly all cases-for I will not say all-the result of experience and tradition." Young birds have a marked proclivity to flee from objects at which their parents take alarm, and to scurry away upon hearing the parental danger signal. Habits of fear in regard to particular enemies are rapidly acquired and 
passed on. Hudson gives among other illustrations of this fact an account of some English sparrows which he was accustomed to feed from a window. "The bread and seed were thrown on to a low roof just outside the window, and I noticed that the young birds when first able to fly were always brought by the parents to this feeding place, and that after two or three visits they would begin to come of their own accord. At such times they would venture quite close to me, showing as little suspicion as young chickens. The adults, however, although much less shy than birds of other species, were extremely suspicious, snatching up the bread and flying away; or, if they remained, hopping about in a startled manner, craning their necks to view me, and making so many gestures and motions, and little chirps of alarm, that presently the young would become infected with fear. The lesson was taught them in a surprisingly short time; then suspicion was seen to increase from day to day, and about a week later they were scarcely to be distinguished in behavior from the adults. It is plain that, with these little birds, fear of man is an associate feeling, and that, unless it had been taught them, his presence would trouble them as little as does that of a horse, sheep, or cow."

The large Rhea of South America which is used for food and must have been hunted by savages for a very long period should certainly show a strong innate fear of man, but Hudson found that the young captured just after hatching would follow him about in perfect confidence. When he would imitate the danger note of the parents the young would rush to him in great terror, although no animal was in sight. "If," says Hudson, "I had caused a person to dress in white or yellow clothes for several consecutive days, and had he shown himself to the birds, I have no doubt that they would soon have acquired a habit of running in terror from 
him, even without the warning cry, and that the fear of a person in white or yellow would have continued all their lives."

Birds have been pursued by hawks for countless generations, but there is, according to Lloyd Morgan, no evidence that they have an instinctive fear of hawks, any more than of large moving objects in general which are seen in the air. Such fear is readily taught the young, and different species of hawks, as Hudson has shown, come to inspire different degrees of fear according to their varied powers of harm.

While instinctive fear of particular enemies may exist in certain animals, the evidence that it has in any case been recently acquired is entirely inadequate. There seems to be more evidence that wildness has been partially lost in the young of some domesticated animals. Darwin states that "hardly any animal is more difficult to tame than the young of the wild rabbit; scarcely any animal is tamer than the young of the domestic rabbit"; and also that the young of the tame duck are more tame than those of the wild duck -a statement which is confirmed by the observations of Dr. Rae. The evidence that the diminution of wildness is due to the disuse of the instinct is not, however, sufficient. The differences may have been due, in part at least, to differences among the wild ancestry of the species, or they may have arisen through selection, perhaps unconsciously,during domestication. The wilder individuals would be more apt to escape or fare ill than the tamer ones, and there would therefore be a certain tendency for selection to diminish the wild instinct. It would require more careful study and comparison of the instincts of the young of domesticated and of wild species than has yet been made to furnish adequate evidence for the loss of fear through disuse.

We shall not enter, at any great length, into a discussion of 
the supposed influence of the transmission of acquired characters in the evolution of instinct. The fundamental question is, of course, a biological one, and in whatever way it is decided the psychologist will have to shape his theories accordingly. Opinion among biologists has been setting rather strongly against neo-Lamarckism, and the same tendency is evinced among many writers on animal behavior, such as Lloyd Morgan, Forel, Groos, Whitman, Baldwin, and others. The strong resemblance between habits and instincts which has so often been commented upon, naturally disposes one to regard the latter as in some way derived from the former; nevertheless, it is especially in the field of instinct that the Lamarckian theory, which at first seems so plausible, is found upon critical examination to reveal its inadequacy.

In the insects, where we find so many striking examples of almost pure instinct, there are numerous highly complex instinctive acts which are performed only once in the lifetime of the individual. The larva of the promethus moth, for instance, when nearly ready to pupate, spins an elaborate cocoon in which it passes the winter. It lines the cocoon with a loose mass of silken threads which will lie next to its body; the outer layer is a firm resistant coat which is admirably adapted to keep out cold and moisture, and at one end, with apparent foresight, there is left an opening filled with loose silk through which the moth may push its way when emerging from the pupal case. Still more remarkable provision is apparently manifested in the way in which the cocoon is attached; it is usually spun against a leaf by which it is partly enclosed, and to guard against falling when the leaf breaks off, a strand of web is spun along the petiole to the twig. How could such a cocoon spinning instinct have arisen? Was it by reflection upon 
the results of experiment? To anyone who has made any first hand study of lepidopteran psychology the supposition that the ingenious mechanical devices shown in the cocoon were hit upon as the result of a series of experiments is about as probable as that a cat would be able to comprehend the differential calculus. Yet we read such phrases as "such calculation," "what wonderful contrivance," applied to such performances by some of the foremost students of animal psychology a couple of decades ago. How absurd they all seem now! To be able to improve a habit there must be an opportunity for repeating the action. Caterpillars might be supposed, by the mere act of once constructing a cocoon to have adapted their organization to this operation, and we might suppose that this modification affects the germ cells so that the next generation spins with somewhat greater facility. But caterpillars which constructed their cocoons badly would have no opportunity to improve, and their bad methods would be handed on, and confirmed more and more in their badness.

After the moth emerges from the cocoon she soon deposits her eggs upon a species of plant which affords suitable food for the larvæ. How did the moth come to have this instinct? Can any one believe that the moth watched the results of laying eggs on different kinds of plants and formed the habit of ovipositing on those upon which the larvæ happened to thrive?

Many of the most complex instincts of insects are in relation to constructing some sort of protective dwelling for the winter and in making provision for their progeny, and in neither of these cases is there, in most forms, room for improvement through profiting by failures. Protective dwellings are usually made but once, and in providing for the young there is usually no opportunity for the parent to 
observe the effect of its operations, so that if it makes mistakes it will go on doing so indefinitely. What we know of insect psychology renders it entirely out of the question to suppose that insects would be able to reflect upon their errors and mend their ways had they every opportunity to observe their deleterious effects. The offspring, instead of the parents, have to take all the consequences of the mistakes, and they if they survived would certainly not have enough wit, if they had the desire, to make things any better for the next generation.

As was first pointed out by Darwin, an important objection to the Lamarckian theory of instinct is afforded by the instincts of worker bees and ants. The instincts of these workers are among the most wonderful in the whole animal kingdom, and they are much more varied and highly developed than in the males and fertile females. As Darwin remarks "peculiar habits confined to the workers or sterile females, however long they might be followed, could not possibly affect the males and fertile females, which alone can have descendants. I am surprised that no one has hitherto advanced this demonstrative case of neuter insects against the well-known doctrine of inherited habit advanced by Lamark."

In the hive bee the activities of the queen, after the nuptial flight, are almost entirely confined to laying eggs; she takes no part in the household duties of the hive or in the care of offspring. The drone's sole function in life is to impregnate the queen; he takes no part in the work of the community. Gathering honey, making comb, caring for the young, keeping the hive clean, etc., are the result of instincts in the worker of which neither of the parents shows the least trace.

This apparently crucial argument against Lamarckism 
has been emphasized by Weismann and others, but, as Spencer has ably shown, the case is not so easily disposed of. According to Spencer the fact that certain structures and instincts occur in the workers which are not found in the fertile insects is not because the workers have acquired them since their separation as a distinct caste, but because the fertile insects have lost them. The worker caste is produced by lack of sufficient nutrition. There is a stunting of growth, a failure on the part of the reproductive organs to develop, and in ants an atrophy of the wings and wing muscles. In the early stages of the evolution of the social state the fertile female possessed all the instincts for making the nest, gathering food and caring for the young, as is now done in the more primitive social communities of bees and wasps. In social wasps, as a rule, the occupants of cells richly supplied with food emerge as fully developed females; where the food supply is limited the females are smaller and sterile, and with varied amounts of food various intermediate gradations of size are produced from the largest females to the smallest workers. The smaller individuals which on account of the partial atrophy of their reproductive systems take little or no part in reproduction busy themselves with building cells and storing them with food, and in taking care of the young. The fertile females live with the rest of the community and share its labors, but in the following year they scatter and form the nuclei of new colonies. At first the queen starts the nest, rears and cares for the young, and performs all the tasks incidental to her small household economy. When the young emerge they coöperate in the work of the queen. As the community grows the queen gradually withdraws herself from the labors shared by the workers and devotes herself more and more to laying eggs.

Among bees there are numerous gradations between the 
solitary forms and the highly organized social state represented by the hive bee. The various grades of social life which these insects present have been described in a very interesting little treatise by Buttel-Reepen on "Die stammsgeschichtliche Entstehung des Bienenstaates." The series of forms which Buttel-Reepen describes indicates very clearly that there has been a gradual specialization of function in the queen from a condition in which she performed all the duties of the household to one in which her functions are confined practically to reproduction. A sort of division of labor has come about so that the workers and the queen together perform the labors formerly accomplished by the queen alone. Herbert Spencer is therefore in the main right in his contention that the fact that the neuters have instincts not found in the queen is due to the queen's having lost them in specializing in the direction of increased capacity for reproduction. It is possible to maintain, therefore, that the transmission of acquired characters may have moulded the instincts of the worker caste up to that point in social evolution at which they came to be practically sterile.

The differences between the queen and worker are occasioned by differences in food. With a diminution of the food supply and a consequent arrest of development of the organs of reproduction there is a suppression of the reproductive instincts, but the fostering and household instincts are retained. The worker, we might say, halts at a phyletically older period. The queen with a richer food supply develops beyond to a stage in which what might have become worker characters are suppressed in the interest, perhaps of greater reproductive efficiency. The condition might be compared to what is found in certain parasitic isopods in which the adult female after having passed through aetive and highly organized stages of metamorphosis comes 
to degenerate into an almost shapeless mass devoted entirely to feeding and the production of eggs. If now the development of some of the females could be checked, by insufficient nutrition at an earlier period of metamorphosis we should have a caste of sterile forms more highly organized in structure and of more varied instincts than the fertile females. It would certainly be an error to conclude that the superiority of the sterile individuals was due to their having independently acquired, since the differentiation of the caste, characters which were not a part of the legacy of their parents.

This is, I think, a fair statement of the neo-Lamarckian side of the question. Granting that the theory is otherwise acceptable the Lamarckian doctrine is still open to serious objections when applied to the instincts of neuter insects. It would compel us to assume that all the adaptive structures and instincts of the worker bee were but the survival of a more primitive period of social evolution before the complete separation of the fertile and sterile castes, when presumably they might have been evolved through the inherited effects of habit. And not only should we have to assume that there had been no improvement in the non-reproductive activities since the queen had ceased performing them, but the theory would lead us to expect a certain amount of deterioration through disuse. It certainly cannot be supposed that during a period long enough for the queen to lose her wax glands, pollen basket, and all her instincts for gathering honey, making comb, and caring for the young, the structures and instincts of the workers should have suffered no degeneration. Instead of this there has undoubtedly been a decided improvement. Nowhere in social bees do we find so high a degree of structural adaptation, such varied activity, such perfect workmanship in the construction of comb with its varied cells for queen, drone and worker, and such complex 
social life as among the workers of the hive bee. If so considerable a portion of this remarkable evolution has occurred since the separation of castes excluded the Lamarckian factor from playing any helpful part, we might conclude that the Lamarckian theory is not necessary in order to account for the earlier stages of social progress.

In the hive bee we not only have the instincts of the more primitive forms carried to a high degree of perfection and specialization, but we have new instincts which must have arisen since the separation of the worker caste, since they have a direct relation to this very separation. Such, for instance, are shown in the remarkable behavior of bees when deprived of their queen. When the queen is removed from the hive and there is no other soon to hatch, the workers destroy a number of old cells and construct a new queen cell, and then proceed to feed the young grub that is enclosed on liberal quantities of royal jelly by means of which it is caused to develop into a new queen. In this case of the instincts which lead the bees to regulate the supply of queens the theory of inherited effects of experience, as Spencer has advocated it, cannot apply. The instinct cannot have antedated the separation of the castes because it is based upon the existence of caste differences.

Other difficulties are presented by the differentiations within the neuter class among ants and termites where there occur two or more kinds of sterile insects adapted by structure and instinctive endowment for different functions in the community. In many cases the evidence clearly points to the evolution of new adaptive characters in the worker caste, instead of merely the degeneration of the fertile insects. And where this has occurred the Lamarckian theory fails to explain the facts.

In the chapter on Instinct in the Origin of Species Darwin 
attempted to show that the main factor to which instincts owe their origin is natural selection. The necessity for an appeal to a previous intelligence was swept away, and while Darwin did not deny that the inheritance of acquired characters played a part in the development of instinct, he ascribed to this factor a very subordinate rôle, and, as we have seen, pointed out some very serious objections which beset the theory.

Darwin's theory assumes that instincts vary. Animals which are endowed with congenital variations of instinct which are advantageous to them will, other things equal, survive; those which have injurious variations will tend to perish. Fortunate variations of behavior may thus be accumulated along useful lines and build up complex and highly adaptive modes of behavior. That, as the theory requires, instincts, like corporeal structures, are subject to congenital variations we have abundant evidence. We should of course expect that variations in instinct would follow variations in structure, but we should scarcely expect from this standpoint to find instincts so variable as they are. Apparently a slight structural variation may produce a variation in instinctive behavior that seems out of all proportion to the cause.

Some of the most careful investigations of variations of instinct have been made by the Peckhams in their classical studies on the instincts of solitary wasps. Concerning Ammophila which stores its nest with caterpillars which it paralyzes by stinging them in the ventral ganglia, the Peckhams remark: "In the three captures that came under our observation, all the caterpillars being of the same species and almost exactly of the same size, three different methods were employed. In the first seven stings were given at the extremities, the middle segments being left 
untouched, and no malaxation was practised. In the second seven stings again, but given in the anterior and middle segments, followed by slight malaxation. In the third only one sting was given, but the malaxation was prolonged and severe." The severity of the stinging as indicated by the conditions of the caterpillars stored in the nest also varies. Of fifteen caterpillars which were stung by Ammophila urnaria the Peckhams found that "some of them lived only three days, others a little longer, while still others showed signs of life at the end of two weeks." And in summing up their observations on the stinging instinct these writers state that "out of forty-five species of our solitary wasps about one-third kill their prey outright. Of those that remain there is not a single species in which the sting is given with invariable accuracy. To judge from results they scarcely sting twice alike, since the victims of the same wasp may be killed at once or may live from one day to six weeks, or perhaps ultimately recover. Even the caterpillars of Ammophila, the most distinguished surgeon, live anywhere from two to forty days."

Contrary to the conclusions of Fabre, who contended that the instincts of Ammophila are practically undeviating, the Peckhams remark that "the one preëminent, unmistakable and ever present fact is variability. Variability in every particular-in the shape of the nest and the manner of digging it, in the condition of the nest (whether closed or open) when left temporarily, in the method of stinging the prey, in the degree of malaxation, in the manner of carrying the victim, in the way of closing the nest, and last, and most important of all, in the condition produced in the victims by stinging."

Among certain species of ants, Polyergus rufescens and several species of Formica and Lasius, whose larvæ ordinarily 
spin a cocoon, there are frequently individuals which fail to spin, and apparently they suffer no injury from this lack of covering. It is said, by many writers, that there is great variation in the pugnacity of ants, some individuals attacking all sorts of enemies with the greatest ferocity, while others are so cowardly that they flee on the least intimation of danger. In honey bees some forms have the instinct of making drone cells greatly exaggerated and there are great variations in the pugnacity of different stocks.

Careful studies which have been made of the behavior of the crayfish, the earthworm, Hydra and various protozoa have revealed a surprising degree of individual variability. In the field of tropisms striking variations are frequent among animals subjected to the same external conditions. Passing to higher organisms we find numerous records of the variation of instinct, especially in birds and mammals. Variations in the nest building of birds are common, and numerous instances have been compiled by Darwin in his posthumous essay on instinct. Bechstein states that in the nightingale some individuals show an inherited tendency to sing in the daytime instead of at night. There are many instances in which birds have apparently lost the instinct of migration. Certain breeds of domestic fowl have lost the instinct to incubate their eggs and among other breeds this instinct is notoriously variable.

Trainers of animals frequently remark upon the striking differences which are presented not only in aptitude for learning but in the habits and disposition of different individuals. Yerkes finds in the dancing mouse marked differences in sensitiveness to visual, auditory, tactual and olfactory stimuli in individuals of the same age and sex; striking differences also occur in their general habits and in docility. The peculiar dancing proclivity of this variety is of uncertain 
origin, but it is a suggestive fact that the same trait in varying degrees occasionally crops out in other varieties of mice, and Haake has described a similar curious variation in a species of shrew. Hereditary peculiarities of movement have been described many times both in man and in animals. Darwin quotes an account communicated by the Rev. W. Darwin Fox of a terrier which when begging moved her paws in a very peculiar manner very different from that of other dogs; "her puppy, which never could have seen her mother beg, now when full grown performs the same peculiar movement exactly in the same way. Another peculiar hereditary variation is reported in a letter by Dr. Huggins to Darwin, of an English mastiff which when first taken out, at the age of six weeks, from the house where he was born started back in alarm at the first butcher shop he had seen. Later when the endeavor was made to get him past the butcher shop he threw himself down and could not be induced by coaxing or threats to pass the shop. On enquiry it was found that the same peculiar antipathy was possessed by the father of the dog, by the grandfather and by two others of the latter's descendants

Illustrations of variations in instinctive behavior might be multiplied almost indefinitely, but what has been said will perhaps suffice to give some indication of the prevalence of such variation throughout the animal kingdom. So far as can be determined, variations of instinct have little regard to utility; they may be of service to their possessors, or, like Huggins' case of the inborn aversion of a dog to butcher shops, of no particular value, or positively injurious as in the occasional deterioration of the instinct of incubation. As instincts are no less important than corporeal structures in the struggle for existence, we can readily conceive how useful variations may be accumulated by natural selection, 
and in the case of many instincts it is not difficult to picture to one's self how natural selection may have brought them to their present state of perfection. To find, as we can in many cases, instincts in various grades of development in allied species of animals, while it shows the general course of their evolution, tells us little of their method of evolution. That instincts are variable, that they are often imperfect, that their general course of development has been along adaptive lines, and that, as Darwin emphasized, they are always primarily of value to the species possessing them and only incidentally of service to others, are facts indicative of the potency of natural selection in the evolution of instinctive behavior.

Evidence for the potency of selection is furnished by the study of the striking modifications of instinct which have taker place in animals under domestication. While only rarely has the attempt been made to modify instincts along particular lines by selection, yet they have doubtless been modified as the incidental result of selection on other lines. A sort of unconscious selection has probably played a part in modifying especially the emotional characteristics of animals. Ugly and vicious dispositions in dogs, for instance, would tend to be eliminated, and the qualities of affection, fidelity and other traits which commend the animals to the good graces of their keepers would be fostered. The useful instincts of the pointer and the setter, however they may have made their beginning, have certainly been developed to a considerable degree by continued selection. The curious instincts of tumbling and pouting which, as Whitman has shown, have their basis in traits of behavior found in pigeons in general, have been developed by the efforts of fanciers to an almost monstrous degree. The Indian subbreed of tumblers which has been bred for at least two-hundred 
and fifty years tumbles even when on the ground and continues to do so until taken up.

Whether or not other factors have piayed a part in the evolution of behavior we shall not here discuss. Certainly their claims cannot be said, at present, to rest upon a very satisfactory basis. If it may savor of dogmatism to contend for the all-sufficiency of natural selection, it is but an exhibition of folly to reject as of little worth the only hypothesis by which we can account for much of the evolution along adaptive lines which has taken place.

If we reject the Lamarckian theory it is still possible to conceive how the activities of organisms may after all have a guiding influence upon the course of evolution. It is a somewhat striking coincidence that three writers, J. Mark Baldwin, H. F. Osborn, and C. Lloyd Morgan, put forward independently, and at nearly the same time, a theory to explain how this guiding influence might take place without having recourse to the Lamarckian factor. There is considerable evidence from fossil forms, the structural adaptations of living organisms, and the interrelations of structure and behavior, which indicates that evolution has proceeded along lines corresponding to the modifications produced in the individual by its own activities. There can be no doubt that the adaptations acquired through these activities have frequently enabled the organism to survive in the struggle for existence. This power of individual accommodation, like other characteristics of the organism, is subject to a certain degree of congenital variability. It follows that those congenital variations which enable the organism to. acquire adaptive modifications with greater readiness will be preserved, and consequently variations in the direction of these acquired modifications will accumulate. Were it not for the adaptations acquired through the organism's ac- 
tivity congenital variations in certain directions might never have risen to the point at which they would be of service. Unless supplemented by acquired modifications they may never have attained a selective value. We might say then that it is the activities of the organism which to a considerable degree determine the selective value of its congenital variations. As Baldwin remarks, "Congenital variations, on the one hand, are kept alive and made effective by their use for adjustments in the life of the individual; and, on the other hand, adaptations become congenital by further progress and refinement of variation in the same lines of function as those which their acquisition by the individual called into play. But there is no need in either case to assume the Lamarckian factor. In cases of conscious adaptation, we reach a point of view which gives to organic evolution a sort of intelligent direction after all; for of all the variations tending in the direction of an adaptation, but inadequate to its complete performance, only those will be supplemented and kept alive which the intelligence ratifies and uses."

It is in the evolution of instinct, if anywhere, that the factor of organic selection would appear to be especially potent. The practical outcome of its operation is much the same as if the effects of experience were actually inherited, and we are thus enabled to explain, in terms of selection, phenomena which at first appear to furnish strong evidence for the transmission of acquired characters.

While we may recognize the value of the theory of organic selection, it is not clear that we should regard it as a new factor in evolution. It cannot, in strictness, be regarded as a compromise between Neo-Darwinism and Neo-Lamarckism. Rather it is one of the ways in which natural selection may be conceived to act. It consists of the selection of those congenital variations which facilitate the acquirement of 
adaptations. It is still natural selection; but the theory explains how, through natural selection, acquired modifications may determine the direction of evolution.

\section{BIBLIOGRAPHY}

BaLdwin, J. M. Development and Evolution. N. Y., '02.

BaLi, W. P. Neuter Insects and Lamarkism, Nat. Sci., 4, 91, '94. Cunningham, J. T. Neuter Insects and Darwinism, Nat. Sci., 4, 281, '94.

Darwin, C. Origin of Species, '59.

Ermer, O. E. Organic Evolution, '90.

Lewes, G. H. Problems of Life and Mind, London, '74-'80.

Morgan, C. L. Animal Life and Intelligence, '91. Habit and Instinct, London, '96. Animal Behaviour, London, '00.

Romanes, G. J. Mental Evolution in Animals, London, '85.

Spencer, H. Principles of Psychology, 1855. A rejoinder to Professor Weismann, Contemporary Rev., 64, 893, '93.

Weismann, A. The All-sufficiency of Natural Selection. Contemporary Rev., '64, 309 and 596, '93. The Evolution Theory, 2 vols., '04.

Whitman, C. O. Animal Behavior, Wood's Hole Biological Lectures for 1898 , '99.

Wundt, W. Lectures on Human and Animal Psychology, '94. 


\section{CHAPTER VII}

\section{THE NON-INTELLIGENT MODIFICATIONS OF BEHAVIOR}

"Both elements, automatism and plasticity, are found in different proportions with all animals from the highest to the lowest." Wasmann, Psychology of Ants and of Higher Animals.

While there is in all organisms a certain measure of useless if not positively injurious activity, the organic mechanism is a self regulating one, and meets varied conditions of life with appropriate changes of response. These adaptive changes in relation to different circumstances are found even in the lowest organisms. With the evolution of life they become more varied and more specialized and contribute to the development of intelligence which may be regarded as but one species of the comparatively large genus of adaptive variation of behavior. In accordance with a common usage the term intelligence is here restricted to those forms of behavior based upon the formation of associations. As Spencer has shown, intelligence is a part of the general process of adjustment which makes up the behavior of an animal. To a certain extent behavior is stereotyped and to a certain extent it is plastic. Both kinds of behavior are necessary in varying degrees in the life of all animals. In this chapter we shall consider some of the plastic features of behavior in which the element of association is not involved.

\section{ACTION OF COMBINED STIMULI}

Reaction to any given stimulus is often interfered with by a tendency to react to other stimuli received at the same 
time. An electric current which would cause a Paramœcium if swimming freely in the water to turn to the cathode, will usually produce no movement in a specimen in contact with a solid. The reactions of Paramœcium to chemical, thermal and mechanical stimuli are also greatly influenced by the same factor. Earthworms, as Darwin has observed, usually fail to react to light when mating or feeding. A striking illustration of the influence of the substratum in reactions to light is afforded by the leech Branchellion. When in a dish of water the leech reacts to a passing shadow by raising its anterior end and swaying it about. If the leech is in contact with its host, the torpedo, it pays not the slightest heed to passing shadows. In Ranatra the positive response to light is checked when the animal is feeding or cleaning itself and is quickly resumed when these operations are completed. And in fiddler crabs the positive reaction to light may be overcome by fear of an approaching object, although with longer exposure to light the phototactic response becomes the more potent one. Contact in many lower animals inhibits, as we have seen in a previous chapter, reactions to light and many other stimuli, and in higher forms it may profoundly modify behavior in relation to enemies.

To a considerable degree these changes of behavior are the results of the simple interference of reactions; but stimuli may act in such a way that they produce a marked physiological change in the organism, as when a contact stimulus brings about the death feint, and the lack of responsiveness is due then to the induced condition rather than to an antagonistic movement.

\section{DIMINUTION OF REACTION TO REPEATED STIMULATION}

Modifications of reaction due to the simultaneous reception of other stimuli are closely affiliated with modifications due 
to previous stimuli. A single stimulus when repeated with sufficient frequency sooner or later brings about a change of response. The most usual modification is a gradual cessation of the reaction. Light mechanical stimulation of the anterior end of Loxophyllum causes at first a ready response; several repetitions in close succession diminish the responsiveness so that a much stronger stimulus often fails to produce any noticeable effect. In a few seconds, however, recovery is apparently complete and the animal is as responsive as before. In Stentor, as we have seen, after a few light contact stimuli no further contraction takes place. Hydra, according to Wagner, if subjected to a slight mechanical stimulus such as is caused by tapping on the object on which it rests, usually contracts completely. "As the tapping continues this state of contraction is maintained for several seconds, sometimes even from onehalf to one minute; but sooner or later, in spite of continuous stimulation, the Hydra slowly expands. When it has reached its normal state of expansion it remains in that position as long as the stimulus is not increased, and even when it is slightly increased. . . . If the interval between the stimuli is considerably increased so as to allow the Hydra to expand fully after each contraction, the tap being given the moment expansion ceases, the result is a different one. There is in this case no change in the reaction after repeated stimulation. . . Recovery from the acclimatizing effect must, therefore, be very rapid."

Walter found that a planarian, if lightly jarred during its gliding movements, would halt momentarily and then continue its course. If the stimulus was repeated at intervals of a second the worm would halt with less and less certainty and finally glide along undisturbed. The effect of the stimulation was very evanescent for after a minute 
the behavior of the worm was the same as before. The writer has found that mosquito larvæ which descend quickly from the surface of the water when a shadow passes over them, cease to react after a number of trials but become as responsive as ever after a short rest.

Many forms which react by contraction to a sudden increase or decrease of illumination show similar modifications. The leech Clepsine, when a shadow is cast upon it, raises and elongates the anterior end of the body, but after a number of such reactions shadows produce no result. Mrs. Yerkes in experimenting on a tube dwelling annelid Hydroides found that shadows which at first caused the worm to retract into its tube, would, if repeated at brief intervals, produce no response. With longer intervals the response was more regular. Hargitt in studying the same form arranged a pendulum so that it would throw a shadow on the worm at regular intervals and found that "with the full second movement there was more or less constant reaction with each passing shadow. With the half second movement it was found that, after the first few beats, a considerable portion of the worms failed to respond at all, and with the quarter second beats almost all the colonies became indifferent to the presence of the passing shadows." A condition which Hargitt considers akin to fatigue is finally produced, in which the organism becomes comparatively irresponsive to light. Walter in his studies on the reactions of planarians to light finds that "when worms were placed in a field of non-directive light, parts of which were of two different intensities, the number of wigwag responses made at the critical line separating the two intensities grew less after the animals had repeatedly crossed the line. At first the new condition of sharply contrasted light intensities in the worm's field of locomotion called out a large 
percentage of wigwag responses. Later, however, by repeated experiences, the worm became familiar with this feature of its environment and made fewer wigwag motions," the percentage in a specimen of Planaria gonocephala becoming gradually reduced from 84 per cent. in the first " twenty-five crossings to 32 per cent. in the fourth twentyfive.

There are many bivalve molluses which retract their extended siphons or close their shells upon being stimulated by shadows, or in some cases when subjected to increased illumination, but after one or more repetitions of thestimulus, the number varying greatly in different species, the response is no longer made. Gradual cessation of response to a given stimulus may be due to (1) a fatigue of the motor apparatus, (2) to a dulling of the sensibility of receptors, or (3) perhaps to other states of the organism. With the first of these is not improbably to be classed the gradual diminution of the duration of death feint, which many animals show in successive feints. The death feigning attitude is one in which the muscles are usually rigid and the condition naturally involves more or less fatigue. As the feints decrease in length the body also becomes more relaxed and the attitude of the body less constant and characteristic. In lower forms the death feint but slowly wears itself out. In higher ones feigning is carried out only once or a very few times before the animal refuses to feign longer. Hence in many cases the factor of intelligence may come into play, but whether this will explain all cases where the response is given up suddenly appears doubtful.

A considerable part of the cases of cessation of reaction to a given stimulus are probably due, as Bohn contends, to a "fatigue sensorielle" or dulling of sensibility. This supposition is supported by the fact that the central apparatus 
is much more susceptible to the effects of fatigue than the afferent or efferent nerves. It is not a fatal objection to the theory of fatigue that the response falls off very quickly. An extreme sensitiveness may result from a certain condition of balance which a slight chemical change might overthrow without rendering the organism insensitive to stronger stimuli. A very high degree of sensibility is as a rule very easily affected. In ourselves the ability to detect a faint odor or taste is exhausted by a very few trials and in lower organisms where sensitivity is often exceedingly acute, there are, as we might expect, much greater fluctuations. It is not improbable that in many cases something analogous to fatigue may take place in the central apparatus in the pathway between the afferent and the efferent impulses. The animal might thus, without having either its receptors or its motor apparatus appreciably affected, fail to respond in the same way, if at all, to stimuli which at first brought about a reaction.

At times the response to a given stimulus may be increased instead of diminished with repeated application. Statkewitsch found that Paramœcia would often fail to respond to weak induction shocks, but where several were given the results were cumulative and the animals swam toward the cathode. Planaria after a period of rest are apparently in a condition of lowered tonus and fail to react in the usual manner to stimuli but if the stimuli are repeated the reactions appear and for a time may increase in vigor. An analogous phenomenon is presented in the responses to light of Ranatra and fiddler crabs which become more and more energetic with longer exposure to the stimulus. An interesting instance is afforded in the reaction of the tentacle of Cerianthus to repeated tactile stimuli. Bohn found that the tentacles when stimulated became flexed toward 
the mouth. Early in the morning repeated stimulation causes the tentacles to respond with increased energy; later, after a short period of increase of responsiveness, the tentacles react less vigorously, and toward evening they become insensible after a few stimulations.

Very similar phenomena were found to occur in the annelid Serpula when stimulated by shadows. The responses were variable; some individuals would show an increase of responsiveness followed by a decrease, while others would show a diminution from the beginning. Bohn has attempted to subsume the variations of responsiveness to a given stimulus under one general "law" resting on a physico-chemical basis. All stimulation according to him is followed at first by an increase and then by a decrease of reaction. In some cases the initial increase is so slight as not to attract attention and we apparently get a falling off from the start. In others the continued increase of responsiveness has not been followed long enough to discover the diminution which must come sooner or later. We may grant the latter part of Bohn's contention, but the first is much more difficult to substantiate.

\section{DIFFERENT KINDS OF RESPONSE TO A GIVEN STIMULUS}

Qualitative variations in the reactions to repeated stimulations are common. We have seen that they occur in an organism as low in the scale as Stentor. Hydra, according to Wagner, when repeatedly stimulated by a capillary glass rod at sufficiently long intervals will, if it does not in time ignore the stimuli entirely, come to respond in a new way; it bends to one side until the tentacles touch the bottom, then loosens the foot and attaches itself in another locality. Striking changes in the response to a given stimulus are furnished by the reactions of sea anemones. The anemone 
Aiptasia when a drop of water falls on its disk suddenly contracts. To several subsequent drops there is no further response. Then if the drops continue to fall the animal contracts still further and draws in its disk. If stimulated lightly by a rod the anemone contracts strongly. If, when it subsequently extends, it is again stimulated it responds in the same way, and continues to do so during a number of trials. Finally the anemone as it extends bends over in a new direction, and if the stimulus persists this reaction is repeated several times; then another direction of extension is tried and finally if the stimulus is not avoided the animal releases its foothold and crawls into a new locality.

Anemones have various methods of getting rid of foreign bodies on the disk, or even morsels of food, if much food has already been taken. The procedure in Stoichactis as described by Jennings is as follows: "The tentacles bearing the débris or the rejected food body collapse, becoming thin and slender, and lying flat against the disk. At the same time the disk surface in this region begins to stretch, separating the collapsed tentacles widely. As a result the waste mass is left on a smooth, exposed surface, the tentacles here having practically disappeared-though under usual conditions they form a close investment almost completely hiding the surface of the disk. Thus the waste mass is fully exposed to the action of waves or currents, and the slightest disturbance in the water washes it off. Under natural conditions this must usually result in an immediate removal of the débris. If this does not occur at once, often the region on which the débris is resting begins to swell, and becomes a strongly convex, smooth elevation, thus rendering the washing away of the mass still easier.

"But the process may go much farther. If the debris is not removed in the way just described, new reactions set in. 
If the mass is nearer one edge of the disk this edge usually begins to sink, while at the same time the tentacles between the edge and the waste object collapse and practically efface themselves. Thus a smooth, sloping surface is produced and the waste mass slides off the disk. If this does not occur at once, after a little time the region lying behind the mass (between it and the center of the disk) begins to swell, producing a high, rounded elevation, with tentacles plump and swollen. The waste mass is now on a steep slope, and is bound soon to slide down and over the edge. Sometimes by a continuation of this process the entire disk comes to take a strongly inclined position, with the side bearing the débris below. Often one portion of the edge of the disk after another is lowered in this way, till all the waste matter has been removed. The disk then resumes its horizontal position, with nearly flat or slightly concave surface." If the edge near which the foreign body is placed cannot be lowered the part external to the body may be raised while the surface toward the opposite edge is depressed so that the object may be rolled off the disk in another direction.

In Planaria, according to Pearl, repeated mechanical stimulation of the anterior end causes the worm to turn farther away at each succeeding stimulus, without at first causing any movements of locomotion. After a time the worm jerks back vigorously, bends the body strongly to one side and then extends usually toward the source of stimulus. Stronger stimuli soon alter the general physiological condition of the organism; "the animal becomes 'stirred up' generally, moves about with increased rapidity, its sensitiveness to stimuli becomes diminished, and it will give only the negative response to stimulation of the anterior end. . . . One may get totally different appearances from an individual 
which has been 'stirred up' from what are seen in the case of one which is in the normal condition."

In the earthworm repeated stimuli give rise to a great variety of reactions which have been classified by Jennings as follows:

"(a) The state of rest, in which the worm does not react readily to slight stimuli, such as a touch with the tip of a glass rod.

" (b) A state of moderate activity, in which a touch at the anterior end causes movement backward; at the posterior end movement forward, while lateral stimuli (in the anterior region) cause turning away from the side stimulated.

"(c) A state of excitement, after repeated stimuli, in which the animal persists in the direction of movement once begun, merely stopping for a few seconds when stimulated at the end which is advancing.

"(d) A state of greater excitement, in which stimuli merely cause the animal to hasten its movements in the direction in which it has started, without regard to the localization of the stimulus.

"(e) A state of still greater excitement, after long-continued and intense stimulation. Now the worm responds to a stimulus at the anterior end, that would in a resting worm cause only a comparatively slight reaction, by a rapid 'right-about-face.' The body is suddenly doubled at its middle, so that the anterior and posterior halves become parallel, with the two ends pointing in the same direction, then the posterior half is quickly whipped about, so that the whole worm is again straight, but is facing the opposite direction from that in which it was pointed before the reaction. . . .

"(f) A state of still more intense excitement, after repeated strong stimulation that is of such a character as to actually 
injure the tissues. The worm now responds to a repetition of the stimulus (and often when the new stimulus is only slight) by lifting the anterior fourth of the body into a vertical position, and waving it about in a frantic manner. This behavior is usually alternated with the right-about-face reactions, and with persistent rapid crawling forward and backward. ..." These reactions do not exhaust the list but are simply more typical features of an almost endless variety of modifications.

The causes of the change of response to a given stimulus may be many. The factor of fatigue is doubtless an important one, especially in the nervous centers. An afferent fiber may be connected with several motor pathways, so that slight variations in the ease with which impulses may travel along certain lines may determine the direction of motor discharge. A very slight degree of fatigue of any pathway might then be a cause of a change of response after one or a very few repetitions. An increase of transmitting function as a result of previous exercise may also play its part, so that we may say that the factors which produce an increase or decrease of responsiveness also effect the replacement of one response by another of a different kind. In the one case they modify the intensity of the reaction, in the other they act so as to switch off the action to other lines.

The fluctuations of tonus here and there in the nervous and muscular systems afford, as Uexküll has shown, a mechanism by which the responses of the organism may be varied to an indefinite degree. Every act of an organism alters the distribution of tonus in its body, and the way in which the organism responds to the next stimulation is naturally affected by this circumstance. Then variations in assimilation, respiration, excretion and other functions are constantly interfering directly or indirectly with the outcome. There is 
therefore no occasion for wonder if the organism responds in different ways to a given stimulus. The wonder would be if it always responded in the same way.

\section{INFLUENCE OF INTERNAL FACTORS ON BEHAVIOR}

That behavior of organisms in general should be greatly influenced by their internal condition is obvious. Hunger and repletion influence the activity of animals, even in the lowest forms. Even the white blood corpuscles when they have ingested a number of bacteria refuse to take in any more. Paramœcium, while it may not reject food swept into its gullet, behaves differently when well fed, and Stentor, as we have seen in a previous chapter, takes in objects when it is hungry which at other times are rejected. Hydras when hungry eagerly take in food, but they are quite indifferent to it when well fed. If starved for some time they become more active, extend and contract the tentacles and body, and move about in various directions as if to increase their chances of coming in contact with food. The jelly-fish Gonionemus when hungry swims about actively, frequently coming to the surface and settling slowly through the water, with its tentacles extended to catch its food. After a hearty meal the jelly-fish is more frequently at rest and has its tentacles contracted.

The effect of hunger on the movements of sea anemones is very striking. When starving, anemones will often take in such things as filter-paper and stones which they reject under ordinary conditions, as is well shown in the experiments of Torrey on Sagartia. Weak food stimuli produced by giving the anemones filter-paper soaked with dilute crab juice produce at first the food reaction, but in a little while the animal no longer responds (Nagel, Parker). If meat is offered the food taking activities continue for a long time. 
but eventually become weaker and may later be replaced by movements of rejection. That it is not the mere filling of the digestive cavity alone that determines the change of behavior is shown in an experiment of Jennings on Aiptasia, in which the digestive cavity was filled with filter-paper. When so filled that pieces of paper were repeatedly disgorged the anemones continued to take in new pieces. The metabolic conditions of the organism are therefore a determining factor in its behavior toward food.

To a certain extent though, the food taking is influenced by the previous local stimulations of particular parts of the body. Nagel and Parker have found in Adamsia and Metridium that the tentacles of a certain part of the body after being stimulated several times with filter-paper soaked in meat juice will refuse to carry it toward the mouth. If now the soaked paper is offered to other tentacles they give the usual food taking reaction. Similar behavior was observed by Jennings in Aiptasia, who found also that if one set of tentacles had carried several pieces of meat to the mouth until they refused to carry it longer, the other tentacles, while they might still carry the meat, would cease to respond much sooner than they would if the animal had not already received food. The animal according to Jennings "is a unit so far as hunger and satiety are concerned."

The effects of hunger and satiety on the behavior of higher forms are so general and so familiar that we need not pursue the subject further. As regards food animals in general are self regulating mechanisms, and if under certain conditions an injurious quantity of food is devoured, or material which is unwholesome is selected, the exceptional behavior only serves to emphasize the rule that the food taking of animals is on the whole pretty adequately adjusted to their needs. In higher forms this function is conscious and voluntary, 
but carry the process down the scale of life and it begins to take on the character of other organic regulations such as we find in the tissue cells of our own bodies; for even there the intake and assimilation of nutriment is regulated as in free organisms. In none of the animals we have described is there evidence of intelligence in the selection of food. The choice made is more readily explained in terms of what Bohn calls differential sensibility. The organism is so constructed that it responds to certain kinds of stimuli in one way and to other kinds of stimuli in a different way. But it also has the faculty of responding to the same stimulus in different ways at different times. Here it may be assumed that the different response is the effect of changes of internal conditions which alter the irritability of the animals. The stimuli set up by the presence of food in the digestive tract, the secretory activity of the cells, the processes of absorption and assimilation going on throughout the body afford a complex of influences affecting the neuro-muscular mechanism and naturally modifying its action.

In the sea anemones, contact tends to set in operation one or the other of two mechanisms-one involved in taking in food, the other in its rejection. These mechanisms are mutually inhibitory and often there is a struggle between them resulting in a hesitation or vacillation in the response of the organism. Internal conditions act as a sort of brake on one or the other mechanism and thus change the nature of the response to a particular external stimulus.

This type of behavior which has often been assumed to indicate consciousness if not intelligence is not anything which cannot be accounted for on the basis of reflex action. It is a type of behavior which is wide spread, in fact probably coextensive with animal life. If it is a criterion of intelligence we must assume that all animals are intelligent and 
not only that, but that the cells of our bodies are intelligent likewise.

The food taking activities of animals are admirably adapted to illustrate the essential unity of behavior throughout the animal kingdom. These activities have their roots in the fundamental processes of organic life. Intelligent food getting is based on fundamental instinctive tendencies, in fact is but a way in which these tendencies are shaped in order a little more effectually to reach the goal. The still hunt of the hungry lion, the expanded tentacles of the hungry anemone or jelly-fish, the restless activity of the starving protozoan are all expressions of a common state, and are dictated by a common need.

\section{HABITS}

Even very primitive animals may acquire ways of acting or responding to stimuli through the effects of their previous experience. These habits, if we may call them such, are usually not very permanent and tend to wear away after the determining cause is removed. Jennings has observed that specimens of the anemone Aiptasia annulata which live in crevices among the rocks where in expanding they have to bend their bodies in an irregular way still retain their irregular movements in expanding after they have been removed from their original habitats. This led him to make some observations on normal anemones subjected to repeated stimulations. In one case "an individual attached to a plane horizontal glass surface was bent in extension far over to the left. Stimulating it repeatedly, it contracted at each stimulation, then bent, in extending, again to the left. This continued for fifteen stimulations, one succeeding another as soon as the animal had become fully extended. At the next contraction the animal turned and 
bent over to the right. Now when stimulated it contracted as before, then bent regularly, in extending, over to the right. It seemed to have acquired a new habit-bending to the right instead of to the left." Observation showed that the bend of the body persisted in the contracted as well as the extended state, and that all parts extended proportionately and thus led to a repetition of the previous action. The habit of action in this case had a persistent structural basis in the bend of the body. If now the anemone was caused to contract very strongly in all parts so that it was no longer bent to one side in the contracted state it would lose its habit of bending when it subsequently expanded. The rôle of the nervous system in this case is a very doubtful one and it is not improbable that the so-called habit is merely a result of purely mechanical factors. The same may also be true of the habit of irregular bendings acquired as a result of living in crevices between the rocks, which might be compared to the difficulty experienced by a person whose body and limbs have been confined for a long time in any one position in making new movements.

Jennings has performed numerous experiments on the formation of righting habits in the starfish Asterias forrei. Starfish when placed on their backs have several methods of turning over. Different individuals have their personal peculiarities in this as in other respects, and in most specimens there is a tendency to use one particular ray or set of rays upon which to turn. These differences as Moore has pointed out may be due to inequalities in the size of the arms, injuries to certain arms, or any initial twist an arm may have had due to its previous position. Before any attempt to train a starfish was made the animal was put through a set of tests to determine the rays most commonly employed in the righting reaction. After this the 
starfish was prevented from using these rays and was allowed to turn only on those rays which it was least prone to employ. If, after a number of trials, the starfish came to employ the latter most frequently it would be fair to conclude that the animal had acquired a new habit of turning. After one or two days' training most of the individuals experimented on came to turn upon rays which they were at first disinclined to use. The effect of the training was not manifest, however, after twenty-four hours. In specimens "trained" for a week or more the habit formed persists, according to Jennings, for twenty-four hours or even several days. The data obtained on this subject were not extensive, and when we consider several sources of error involved, not entirely convincing; further work would be necessary before we could safely conclude that starfish form lasting habits.

How shall habit formation in the starfish be interpreted? Moore has shown that irritation of an arm inhibits its activity and causes the starfish to use other arms in the righting movements; and the operation of handling the animal during its "lessons" so as to prevent a certain arm from being used might produce a similar effect. There is no evidence that there is any element of association involved, and it is not quite clear whether the basis of the habit lies in the nervous system or in other parts of the organization.

\section{RHYTHMS IN BEHAVIOR}

Georges Bohn has the merit of having discovered that the rhythms of activity which are produced in many animals by regularly recurring external conditions such as the alternation of day and night and the periods of low and high tide may persist for some time after the animals are withdrawn from the direct influence of the outer periodic changes. 
Convoluta roscoffensis, a small green turbellarian worm which lives in sandy beeches overflowed by the tide, makes periodical depth migrations in the sand. At low tide the worms come to the surface where they form a green coat upon the shore. When the tide comes in the worms descend and thus avoid the shock of the waves. Bohn found that the same periodic migrations occurred in specimens which were taken from the shore and kept in an aquarium. If the worms were placed in a tube of sand a green ring could be seen to rise and descend synchronously with the ebb and rise of the tide. These rhythms persisted for several days after the worms were removed from the beach. Keeble has compared the vertical movements of Convolutas kept in the laboratory with the movements of specimens on the beach, and states that "for eight successive tides the animals in the laboratory maintain their rhythm, synchronous with the ebb and flow of the waters over the roscoffensis zone: then, though the rhythmic movement up and down may continue, its temporal periodicity loses precision, and, finally, the rhythm is worn down."

A parallel phenomenon was discovered by .Bohn in the diatom Pleurosigma. When the sea retired these diatoms were observed to form a brown scum over the sand. When the tide came in the diatoms descended. Placed in an aquarium they performed regular migrations for several days in accordance with the tidal rhythms. This periodicity failed to manifest itself in darkness and, therefore, according to Bohn, depends upon variations in phototaxis instead of the response to gravity. Bohn has reported that a curious tidal rhythm occurs in the small gastropod, Littorina rudis, which lives upon the rocks where it is only occasionally wet by the waves. At low tide these molluses withdraw into their shells and remain inactive. When 
the spray from the incoming tide begins to moisten them they emerge and begin crawling about. Their phototaxis changes with the tide, becoming negative when the tide is high and positive when it is low. Bohn placed Littorina in an aquarium and found that for several days they underwent changes in their phototactic responses parallel with those of specimens upon the rocks. Similar experiments have been made by Morse on a species of Littorina on the New England coast, but he failed to obtain any evidence of a tidal rhythm. And more recently Haseman has investigated the tidal rhythms of several species of Littorina, none of which showed any rythmical movements independent of the direct influence of the tides.

Among actinians Bohn has found in many cases daily rhythms due to the alternation of light and darkness superposed upon tidal rhythms. Both of these rhythms are influenced greatly by the nature of the habitat in which the anemones live. Individuals situated rather high upon the rocks and living therefore under strongly contrasted conditions in high and in low tide exhibit tidal rhythms to a marked degree; whereas those which live at depths in which they are little affected by the waves show little or no influence of the tide. Alternation of day and night affects anemones to a greater or less degree in all habitats; its influence is complicated by many factors, such as degree of exposure to the sun, depth of water, shock of waves, temperature, purity of the water, and various other causes. The daily rhythms differ greatly in anemones from different local situations, according to the influences to which the animals are adapted. These rhythms with their various characteristics peculiar to different habitats were found to persist for several days in aquaria, but they gradually wore away. 
Among higher invertebrates tidal rhythms have been observed by Drzewina in the hermit crab Clibanarius misanthropus. Specimens were collected at various times and kept in aquaria one end of which was shaded. Nearly all of the individuals manifested a positive phototaxis when the tide was high, and became negative when the tide was low. These regular changes persisted in the lot which was kept longest, for three weeks.

We have in these periodic variations of behavior habits of action in relation to different influences of the environment which have been acquired by the experience of the organism. These habits have probably not been acquired through intelligence in most cases and certainly not in the case of the diatoms, and it does not seem improbable that all of them may be dependent upon some general modifications of the organism as a whole rather than upon merely the mechanism of response to stimuli.

\section{HABITS VARIOUSLY CAUSED}

Habits may be due to a variety of causes. They may result from the repeated displacements of given structures. They may depend upon artificially induced organic rhythms. They may arise as the outcome of intelligently formed acts. What closely simulates a temporary habit may be the physiological effect of the summation of stimuli. An action system put in operation one or more times by a given stimulus may, up to a certain point, become increasingly responsive to that stimulus. There is an increase of the tonus of the parts concerned. If in righting itself a starfish comes to employ a particular ray, that ray as a result of its exercise may respond with increased readiness. Whether the temporary habits formed in the starfish studied by Jennings were due in part at least to an increase of tonus as the result 
of previous activity I do not pretend to say; but the case is cited as an illustration of a possible way in which a certain elass of habits may be interpreted.

Habit formation may be shown in the action of individual organs of our bodies. The stomach according to the researches of Pawlow readily acquires habits, and the influence of habit in the functioning of the intestines is generally familiar. Between such habit formation and the increase of an organ through action there is much in common, and between these phenomena and the adaptive changes of an organ in relation to its condition of stimulation there is doubtless a fundamental kinship. What Roux has called the "overcompensation of what is used" is a principle which probably manifests itself in all these cases.

\section{DECEPTIVE APPEARANCES OF INTELLIGENCE}

There are a great many cases which have been adduced as indicating intelligence and even a simple form or reasoning which may be explained like the phenomena we have described. It is frequently difficult to distinguish acts which are instinctive from those which an animal has learned to perform, and it is well in general to be guided by the principle enunciated by Lloyd Morgan, which is a sort of special case of the law of parsimony-namely, that "In no case may we interpret an action as the outcome of the exercise of a higher psychical faculty, if it can be interpreted as the outcome of one which stands lower in the psychological scale." One of the cases most suggestive of the power of forming associations in the Coelenterates is recorded by Fleure and Walton whose account is as follows:

"We have given a specimen of Actinia a scrap of filterpaper about once in twenty-four hours, placing it on the same tentacles each time. As a general rule the fragment was 
carried by the tentacles to the mouth and there swallowed, to be ejected as inedible after a longer or shorter period. After a few days, the number varying in different individuals from two to five days, the fragment is no longer swallowed and, in about an other two days, the tentacles will no longer take hold of it. This procedure is more regular in the case of pellets of paper than in the case of India rubber, in which results were very variable. The results seem to indicate a certain amount of persistence of impressions, when the latter are received several times in succession at short intervals.

"The first impression which persists is one in the mouth region leading to refusal of the pellet. As this is strengthened the sequence is further abbreviated, an inhibitory stimulus would seem to proceed from the mouth to the tentacles preventing them from gripping, when the stimulation due to contact with the filter-paper has passed from them to the mouth.

"A further point of interest is that what does persist seems to remain a property of the tentacles affected, and of that part of the mouth directly related to them. It does not appear to be a possession of the entire animal, for other tentacles, on the opposite side for instance, can be tricked subsequently, at any rate once or twice, before they too exhibit the inhibitory reaction." The effects of the experience were found to be lost after from six to ten days.

Whether or not we have in this instance the formation of a new association, as the behavior of the anemone seems to indicate, is not entirely certain. It is possible that the seat of the change of behavior is in the tentacles alone. Allabach has shown that after the tentacles of Metridium have responded to a stimulus a few times their production of mucus becomes much diminished and this probably affects their subsequent activity. If this factor would 
modify the irritability of the tentacles for some time it might explain the change of behavior. This may not be the true explanation of the phenomenon, but it will serve to show how careful we must be, in studying the behavior of lower organisms, about inferring the presence of associative memory. There have been almost no studies of the power of association in the Cœlenterates, where the various possibilities of error have been carefully excluded.

Darwin in his work on earthworms attributes a certain degree of intelligence to these creatures on account of their peculiar habits of plugging up their burrows with dead leaves. The worms pull in the leaves of the linden by their tips, while the leaves of the rhododendron which are smaller at the base are pulled in by the petiole. Pine needles which frequently occur in pairs with a common base are not seized by the small end, which would cause difficulity in getting both needles into the hole, but by the enlargement at the basal end. Darwin gave the worms triangles of paper and found that they usually seized these by the most acute angle in carrying them to their burrows. The conclusions of Darwin that the behavior of the earthworms indicates a certain degree of intelligence was a very natural one. Hanel, however, who has repeated and verified Darwin's experiments and performed a number of others, finds no ground for assuming any intelligence in the earthworm and ascribes the behavior of the animal to a series of more or less complex reflexes in relation to the form and chemical nature of the objects drawn in. There is no evidence of profiting by experience in the earthworm's behavior and, however complex the acts performed, there is nothing that is thus far known that precludes us from considering them as belonging entirely to the reflex type. 


\section{BIBLIOGRAPHY}

BoHN, G. Sur les mouvements oscillatoires des Convoluta roscoffensis. C. r. Ac. Sci., Paris, 137, 576, '03.

Les Convoluta roscoffensis et la théorie des causes actuelles. Bull. Mus. Hist. Nat., 9, 352, '03.

Intervention des influences passées dans les mouvements actuels d'un animal. C. r. Soc. Biol., Paris, 56, 789, '04.

Périodicité vital des animaux soumis aux oseillations du niveau des hautes mers. C. r. Ac. Sci., Paris, 139, 610, '04.

Oscillations des animaux littoraux synchrones des mouvements de la marée. Ibid., 139, 646, '04.

Mouvements de manège en rapport avec les mouvements de la marée. C. r. Soc. Biol., Paris, 57, 297, '04.

Les causes actuelles et les causes passees. Rev. Scientif., 3, 353 and 389 , ' 05 .

Le rhythme nycthéméral chez les actinies. C. r. Soc. Biol., Paris., 62, 473, '07.

La persistance du rhythme des marées chez l'Actinia equina. Ibid., 61,661 , '06.

Introduction à la psychologie des animaux à symmetrie rayonnée.' 1, Les états physiologiques des actinies. Bull. Inst. Gén. Psych., 7, 81 and 135, '07.

De l'acquisition des habitudes chez les étoiles de mer. C. r. Soc. Biol., Paris, 64, 277, 532, 633, '08.

Introduction à la psychologie des animaux à symmetrie rayonnée. 2, Les essais et erreurs chez les étoiles de mer et les ophiures. Bull. Inst. Gén. Psych., 8, 21, '08.

La naissance de l'intelligence, Paris, '09.

Darwin, C. The Formation of Vegetable Mould through the Action of Worms, with Observations on Their Habits. 'N. Y., '83. Fleure, H. J., and Walton, C, L. Notes on the Habits of Some Sea-Anemones. Zool. Anz., 31, 212, '07.

Ghinst, vaN DER. Quelques observations sur les actinies. Bull. Inst. Gén. Psych. Paris, 6, 267, '06.

Glaser, O. C. Movement and Problem Solving in Ophiura brevispina. Jour. Exp. Zool., 4, 203, '07.

HargitT, C. W. Experiments on the Behavior of Tubicolous Annelids. Jour. Exp. Zool., 3, 295, '06.

Further Observations on the Behavior of Tubicolous Annelids. Ibid., 7, 157, '09. 
Jennings, H. S. Contributions to the Study of the Behavior of Lower Organisms. Carnegie Inst. Pubs., Wash., '04.

Modifiability in Behavior. 1. Behavior of Sea Anemones. Jour. Exp. Zool., 2, 447, '05.

The Method of Regulation in Behavior and in Other Fields, Ibid., 2, 473, '05.

Modifiability in Behavior. 2. Factors Determining Direction and Character of Movement in the Earthworm. Ibid., 3, 435 , '06.

Behavior of Lower Organisms, N. Y., '06.

Behavior of the Starfish, Asterias forrei de Loriol. Univ. of Calif. Pubs. Zool. 4, 53, '07.

Keeble, F. Plant Animals. A Study in Symbiosis. Cambridge, ' 10.

Pearl, R. The Movements and Reactions of Fresh-Water Planarians. Quart. Jour. Mic. Sci., 46, 509, '03.

Preyer, W. Ueber die Bewegungen der Seesterne. Mitth. a. d. zool. Stat. zu Neapel, 7, 27, and 191, '86.

UExкర̈lL, J. von. Studien úber den Tonus. Zeit. f. Biol., 44, 269, '03; 46, 1, '04; 46, 372, '04; 49, 307, '07; 50, 168, '08.

Umwelt und Innenwelt der Tiere, Berlin, '09.

Washburn, M. F. The Animal Mind, N. Y., '09.

YERKES, A. W. Modifiability of Behavior in Hydroides dianthus. Jour. Comp. Neur. Psych., 16, 441, '06. 


\section{CHAPTER VIII}

\section{PLEASURE, PAIN, AND THE BEGINNINGS OF INTELLIGENCE ${ }^{1}$}

"Apprehensio sensitiva non attingit ad communem rationem boni, sed ad aliquod bonum particulare, quod est delectabile. Et ideo secundum appetitum sensitivum, qui est in animalibus, operationes quaeruntur propter delectionem."-Thomas Aquinas, Summa Theologica.

Psychologists nowadays with comparatively few exceptions agree in regarding intelligence not as a faculty standing in sharp contrast to instinct, as was formerly taught, but as one resting on a foundation of instinct, and gradually growing out of behavior of the purely instinctive type. The term intelligence is used here in the wider sense as embracing all those forms of profiting by experience through the formation of associations. It therefore includes psychic activity ranging from simple associative memory to complex trains of reasoning. What distinguishes intelligence from instinct is that in the latter the connections between acts are based upon hereditary organization, whereas in the former they are established through experience. The apparently new thing involved in intelligent behavior is the power of forming associations. So far as we can judge of the psychic states of an animal from its behavior, animal intelligence in its first manifestations consists in repeating acts which bring pleasure and in avoiding things which cause pain, and a discussion of the transition from instinct to intelligence naturally involves

${ }^{1}$ This chapter is taken with some modifications from an article of the same title contributed by the writer to the Journal of Comparative Neurology and Psychology. I am indebted to the editor for permission to reprint a considerable part of the article here. 
a consideration of the rôle of pleasure and pain as agents of accommodation.

The tendency of animals to repeat acts which result in pleasure and to discontinue or inhibit acts which bring them pain is a fundamental feature of behavior on the utility of which it would be superfluous to comment. But why do animals behave in this fortunate manner, and how did they come to acquire the faculty of so behaving? To our ordinary plain way of thinking it appears sufficient to say that a dog eats meat because he likes it, and that he runs away from the whip to avoid its painful incidence upon his integument. These acts are such natural and obvious things to do under the circumstances that to inquire why the animal does what it likes and avoids what is disagreeable may seem a sort of philosophic quibble which only a mind "debauched by learning" would think of indulging in. But a little consideration will show that we have here a real and very knotty problem, or rather set of problems, of the greatest importance to the student of genetic psychology.

There are few better illustrations of the modification of behavior through experiences of pleasure and pain than that afforded by the behavior of young chicks, which has been so well studied by Lloyd Morgan. A young chick when first hatched has the instinct to peck at all sorts of objects of about a certain size. If an object is a little too large the chick may hesitate. Should it venture to peck at the object and derive a pleasant taste from it the hesitation in the presence of similar objects becomes reduced and will finally disappear. If the chick in the course of its pecking seizes a caterpillar having a nauseous taste it is much less apt to seize a similar caterpillar a second time. The painful or unpleasant experience it derives in some way inhibits further action toward that class of objects. 
We have in this modification of instincts through the pleasurable or painful effects they produce the beginning of intelligence. The pecking, swallowing, and avoidance of certain objects are purely instinctive acts based on the chick's inherited organization. After its first experiences with pleasant or nasty caterpillars the chick is a different creature; it has learned by experience; and henceforth its acts, which at first were in a general way adaptive, become more perfectly adapted to its needs as the result of its learning. Instinct supplied the impetus to action and in a measure determined the direction of action, but intelligence refines upon the instinctive behavior and effects a closer adjustment to the environment.

In lower forms associations are formed as a rule with great slowness. Behavior is almost entirely instinctive, and the organism can be made to deviate from its stereotyped methods of action only with difficulty. It is probable that in low forms where associations of only the simplest kind can be established there is no association of ideas involved; and in fact there is no conclusive evidence of the existence of ideas even in animals quite high in the scale. Most animal learning consists in forming associations between certain sense experiences and certain actions which bring pleasure or pain. A common way of teaching an animal a trick is to try in various ways to induce it to perform the desired action and then to reward it by food or some other means of giving it pleasure. In this way the connection between the situation and the act is reinforced, and the act follows more readily when the animal is placed a second time under the same conditions.

Consider the case of a cat placed in a box which can be opened by pressing down a lever or pulling a string, as in the experiments of Thorndike. If the cat is hungry and food 
is placed outside, the animal will probably make vigorous efforts to escape by clawing and biting in various parts of the enclosure, which are the usual instinctive methods employed in similar situations. If the right movement is hit upon and the cat gets out and secures food, it will probably make its escape more readily than before when placed in the box a second time. After a number of trials the cat will come to make the right movements for escaping very soon after being placed in the box and its useless random movements will be discontinued. The connection between the perception of the mechanism of escape in the box and the act necessary to gain its liberty comes to be more and more firmly established in the cat's brain with repeated experiences. The cat perceives a number of things in the box and performs a number of different acts, but out of all these, associations are formed only between certain stimuli and those responses to them which bring pleasure to the animal.

Pleasure and pain have apparently a fundamental connection with the development of intelligent responses out of instinctive activity. Were there not something to clinch or strengthen the connection between certain stimuli and the appropriate responses to them the organism might perform random movements till doomsday without being a whit better off. It is a problem therefore of fundamental importance to ascertain in what the mechanism of this ability to profit by experience essentially consists. It is not mere habit, not the mere making more permeable certain preformed connections in the brain. One act would then be just as apt to be followed up as another. Whether an act tends to be followed or not depends on what it brings to the organism. Apparently we have to do with a selective 
agency which preserves or repeats certain activities and rejects others on the basis of their results.

The importance of random movements lies in the fact that they offer opportunities for making favorable adjustments. For the development of intelligence they play a rôle similar to that of variations in the process of evolution. The animal that does the most exploration is the one most likely to hit upon new advantageous adjustments. In the same way intelligent adjustments, as James has contended, are favored by a multiplicity of instincts, especially if these instincts are of a contrary or conflicting nature, for now one and now another instinctive tendency may be reinforced in different conditions to which it may be adapted. Instinctive fear may be modified through experience so that it is no longer attached to objects that are found to be harmless, while it may be intensified in relation to other objects that are found to be sources of injury. Where there is hesitation between the exercise of two instincts such as the tendency to pursue an animal as prey, and the instinctive fear which that animal may awaken, experience may quickly point out which proclivity is the more advantageous to follow. The pleasurepain reaction enables an animal to select, so to speak out of its stock of instinctive endowments those responses which are best adapted to the particular situations that confront it. It is a means of adapting instincts to new or inconstant conditions and thus of effecting a closer adaptation to the environment than that which would be possible by following purely congenital modes of response. The development of the pleasure-pain reaction marks one of the most important steps in the evolution of behavior, for the entire superstructure of intelligence in all its stages is based upon it, and it is not surprising that many writers regard it as an index of the beginning of consciousness, a point where a new 
entity is somehow mysteriously injected into the universe.

It is a general rule that what is pleasant is beneficial and what is painful is injurious, and, therefore, by following its desires and aversions an animal is guided in a tolerably safe course. Eating when hungry, drinking when thirsty, seeking warmth when cold, exercise when in a state of vigor, and rest when fatigued, all bring a state of satisfaction or pleasure. On the other hand, eating and drinking after a certain stage of repletion has been reached, or attaining too great a degree of warmth may be positively painful, the pain being correlated with carrying on these activities until they become injurious to the organism.

But it is well known that this correlation is not an absolute one. With complex creatures like ourselves with a multitude of different propensities and interests it is not infrequent that the pursuit of what is agreeable leads to all sorts of unfortunate consequences, even of a purely physiological nature. In the lower animals where pleasure is a safer guide than among ourselves, what is pleasant is not always what is organically good. Poisonous articles may be eaten with apparent relish and alcoholic liquors are readily imbibed even by such primitive creatures as bees and wasps upon their very first acquaintance with these intoxicants. But aside from exceptional cases, pleasure in the animal world is a sufficiently good index of what is beneficial that under conditions which ordinarily present themselves it seldom leads to injurious courses of action.

The relation between the pleasant and the beneficial is, however, probably not a primary one, and it is not improbable that it represents a connection established by natural selection, as was first maintained by Herbert Spencer. "If the states of consciousness which a creature endeavors to maintain are the correlatives of injurious actions and if 
the states of consciousness which it endeavors to expel are the correlatives of beneficial actions, it must quickly disappear through persistence in the injurious and avoidance of the beneficial. In other words, those races of beings only can have survived in which, on the average, agreeable or desired feelings went along with activities conducive to the maintenance of life, while disagreeable and habituallyavoided feelings went along with activities directly or indirectly destructive of life; and there must ever have been, other things equal, the most useful and long-continued survivals among races in which these adjustments of feelings to actions were the best, tending ever to bring about perfect adjustment."

This explanation which has become widely arcepted leaves a fundamental question unanswered. It does not explain why certain acts are stamped in and certain others stamped out. Of the mechanism of this process, which is the real problem involved in the pleasure-pain reaction, we are as ignorant as before. The explanation means that animals which took pleasure in following acts that brought them benefit were preserved and those that did not behave in this manner were eliminated. But why does an animal tend to repeat an act that brings it pleasure and avoid one that produces pain? It seems so natural for creatures to behave in this way that the existence of any problem here is usually unsuspected, but this is the problem that confronts us when we endeavor to obtain a clear understanding of the way in which intelligence develops out of instinct.

In the pleasure-pain response we have two problems of a quite different nature: (1) the problem of how behavior is modified by its results, and (2) the problem of why pleasure is associated with certain physiological activities, such as securing movements, and pain with others, such as avoiding 
movements. The latter problem is one whose solution appears hopeless. If we accept the doctrine of psychophysical parallelism in any of its forms, we must deny that psychic states are, strictly. speaking, the causes of physical changes. Why then should pleasure be connected with one kind of activity and pain with another? Why not just the reverse? This problem is, I believe, insoluble, because it is a question of the relation of the physical and the psychical; it is of essentially the same nature as the question why one kind of retinal stimulation produces a sensation of red and another a sensation of green. Physical and psychical states are correlated in particular ways; this we accept as a matter of observed connection. But why a certain kind of brain vibration is associated with a state of consciousness we call a sensation of red instead of some other state is a question upon which we may intend our minds indefinitely without the least profit. If we adopt any other theory of the relation of mind and body we are in no way better off. If we have to do with a preordained connection of pleasure with certain physiological activities and pain with certain others, this connection is no more intelligible if we admit the interaction of psychical and physical states than it is under the theory of parallelism. We can only say that such is the observed relation of the phenomena.

What is feasible to attempt to solve is the problem of the adaptive modification of behavior which we may say is the objective side of the pleasure-pain process. We are dealing with a series of physiological reactions and how they come to be modified. We may assume that psychical states enter into the chain of causes and effects that make up an animal's behavior, but it is not clear that such an assumption throws the least light upon our problem, and it is open to serious objections on both scientific and metaphysical grounds. We 
shall therefore consider the question purely from a physiological standpoint. Viewed objectively we find that in an animal's behavior certain acts when once performed tend to be performed with greater readiness under similar conditions a second time, while other acts once performed tend under similar conditions to be inhibited. This problem of learning, Baldwin observes "is the most urgent, difficult and neglected question in the new genetic psychology." Spencer with his characteristic insight into fundamental problems has grappled with it and has attempted to give a physiological explanation. Pleasure, according to Spencer, is the concomitant of heightened nervous discharge; pain the concomitant of lessened discharge. In an animal with a diffuse discharge of its nervous energy resulting in random movements, some of these movements bring a heightened nervous discharge with its psychic accompaniment of pleasure. This tends to reinforce the movement that brought the increase of nervous energy and to cause it to be repeated. Responses resulting in pain tend on account of the diminution of nervous discharge that follows to be discontinued, and in this way the organism is kept repeating certain acts and avoiding others. "Along with the concentrated discharge to particular muscles," says Spencer, "the ganglionic plexuses inevitably carry off a certain diffused discharge to the muscles at large, and this diffused discharge produces on them very variable results. Suppose, now, that in putting out its head to seize prey scarcely within reach, a creature has repeatedly failed. Suppose that along with the group of motor actions approximately adapted to seize prey at this distance, the diffused discharge is, on some occasion, so distributed throughout the muscular system as to cause a slight forward movement of the body. Success will occur instead of failure; and after success will 
immediately come certain pleasurable sensations with an accompanying draught of nervous energy toward the organs employed in eating, etc. That is to say, the lines of nervous communication through which the diffused discharge happened in this case to pass, have opened a new way to certain wide channels of escape; and, consequently, they have suddenly become lines through which a large quantity of molecular movements that were followed by success are likely to be repeated; what was at first an accidental combination of motions will now be a combination having considerable probability."

Bain's view of learning is much like that of Spencer. "We suppose movements spontaneously begun, and accidentally causing pleasure; we then assume that with the pleasure there will be an increase of vital energy, in which increase the fortunate movements will share, and thereby increase the pleasure. Or, on the other hand, we suppose the spontaneous movements to give pain, and assume that, with the pain, there will be a decrease of energy, extending to the movements that cause the evil, and thereby providing a remedy. A few repetitions of the fortuitous concurrence of pleasure and a certain movement, will lead to the forging of an acquired connection, under the law of retentiveness or contiguity, so that, at an after time, the pleasure or its idea shall evoke the proper movement at once."

The theories of Bain and Spencer are discussed in detail by Baldwin, who, while differing from these writers in certain points which need not here be dwelt upon, adopts essentially the same view as regards the mechanism of reinforcement and inhibition. With Bain and Spencer, Baldwin assumes that "the pleasure resulting from the first accidentally adaptive movement, issues in a heightened nervous discharge toward the organs which made the move- 
ment, a discharge which finds its way to the same channels as before, and so makes it likely that the same movement will be repeated, the external conditions remaining the same. . . . . Pleasure and pain can be agents of accommodation and development only if the one pleasure, carry with it the phenomenon of 'motor excess,' and the other, pain, the reverse-probably some form of inhibition or of antagonistic contraction."

The theories of Spencer, Bain and Baldwin are physiological since they attempt to explain the modifications of behavior, not through the influence of certain psychic states, but as the effect of the physiological conditions of which these states are the concomitants. The theories are all open to the objection that pleasure is by no means the constant concomitant of heightened nervous discharge. Laughing and crying are very similar in their physiological expression, though they go along with very different psychic states, A child who burns his hands and writhes about in agony certainly manifests a heightened nervous discharge, but he shows no tendency to put his hands again into the fire. Another outreaching movement of the child brings his hands toward a pleasant degree of warmth. The movement tends to be repeated. The nervous discharge in the first case is much greater than in the second, but in both cases it goes to the arm, though along somewhat different nerves. It is obvious, I think, that we cannot account for the difference between the responses to pleasurable and painful stimuli on the basis of any quantitative difference in the discharges to the part affected. It is a matter of nervous connection rather than quantity of nervous energy.

Pain-giving stimuli, owing to the arrangement of an animal's reflex arcs, are generally followed by a withdrawing movement of the part stimulated, but that there is a tendency 
for the "increased energy of the pleasure process" to flow "into the channels of the movement associated with pleasure" (that is, I take it, the movement which brings pleasure) is by no means evident. There is, I think, no primary tendency, as Spencer and Bain seem to think, for the nervous discharge to take the direction of the organ from which the pleasure is derived. Animals, it is true, move so as to bring an organ which is pleasantly stimulated again under the action of the stimulus, but this is often due to the discharge going mainly to a quite different part of the body, such as distant appendages, instead of to the part directly affected.

The theory of heightened nervous discharge as expounded by Spencer, Bain and Baldwin, fails to give us, I think, the desired explanation of the acquirement of individual accommodations, and one naturally turns to other theories of the psycho-physiology of pleasure and pain for light. Here, however, we are led into a veritable quagmire of psychological speculation, for there are few fields in which there are so many and so fundamental differences of opinion among competent psychologists. The physiological concomitants of pleasure and pain have afforded a subject of numerous laboratory studies and almost no end of theories. There is good evidence that pain sensations are produced by the stimulation of specific nerves, but as regards the physiological states accompanying pleasure and pain the results of experiments as well as opinions based on them are very discordant. And it is difficult to see how most of the pleasure-pain theories would help us to explain the mechanism of accommodation even if they were established, so that the outlook for the solution of the problem as it is commonly formulated does not seem, at present, an encouraging one. 
A new point of view in regard to our problem has been presented by Hobhouse in his Mind in Evolution. To illustrate this view let us recur to our chick. When a nasty caterpillar is seen for the first time the visual stimulus sets up a pecking reaction. This is followed by the stimulus of a bad taste which sets up various rejection movements, such as ejection of the food and wiping the bill. The order of events is:

Stimulus. . . pecking. . . bad taste. . . . rejection.

When the same kind of caterpillar is met with a second time the stimulus tends to elicit the rejection movements with which it has been associated instead of the movements of pecking. Is not the inhibition due to the fact that the stimulus has become associated with a response which is incongruous with the first? Movements of rejection and avoidance are incompatible with those of pecking and swallowing and it may therefore be unnecessary to look to any peculiarity of the physiological correlates of pain for an explanation of the inhibition of the original reaction. The stimulus becomes coupled with a new reflex arc; nervous energy is drained off in a new channel, and the future behavior becomes changed. If the taste is a very bad one, a great deal of energy is involved and the connection with the rejection response made very permeable and the rejection movement easily set up. If a person is confronted with a sight of some nauseating medicine he has recently taken, avoiding or rejection movements are set up, such as making a face, or even retching movements of the stomach. Is it not these movements or attempts at movements that really inhibit the taking of the medicine? This is evinced by the chick described by Lloyd Morgan, which after an experience with a nasty caterpillar approached one a second time, but stopped and wiped its bill and went away as if it actually 
repeated its first experience. Of course inhibition of the original response does not always involve contrary movements, but there may be impulses to such movements which do not issue in action. The principal feature in the modification of action through painful experiences is the assimilation of impulses incongruous with the original one.

In the reinforcement or stamping in of a reaction to a particular stimulus that brings pleasure, it certainly seems as if pleasure or its physiological correlate in some way serves to cement more firmly the association between the stimulus and the response. Let us consider, however, the case in which the chick pecks at a caterpillar which has a good taste. The presence of the caterpillar in the mouth excites the swallowing reflexes; in the presence of a similar caterpillar the pecking response is made more readily than before, and whatever hesitation there may have been at first disappears. Is not the difference from the pain-response due to the fact that there is an organic incompatibility between the first and second responses in the pain response, while there is an organic congruity or mutual reinforcement of these responses in the other? Pecking and swallowing form the normal elements of a chain reflex; when one part of the system is excited it tends to excite the rest, to increase the general tonus of all parts concerned in the reaction. According to the view here presented, whether a particular response to a stimulus tends to be repeated more readily or discontinued, depends not upon the peculiar physiological state which may be produced in the brain, but upon the kind of responses which the stimuli brought by the act call forth. If an outreaching reaction becomes coupled with a withdrawing response the result is inhibition. If the reaction, on the other hand, brings stimuli which produce congruent reactions the association formed with these 
latter reinforces the first reaction. The pleasure-pain response then resolves itself into the formation of associations. Withdrawing and defensive responses are usually initiated by pain giving stimuli, and the instinctive or random movement which brings a painful stimulus is inhibited under similar conditions in the future, not because of the pain of its physiological correlate, but because it comes to be associated with a withdrawing or defensive, and hence an incongruous or inhibitory reaction. Pleasure and pain thus interpreted have no mysterious power of stamping in or stamping out certain associations. Whether the result is reinforcement or inhibition depends on the way in which a reaction and the secondary responses resulting from the situation in which the organism is thereby brought, happen to harmonize.

The step from instinct to intelligence viewed as a physiological process involves, therefore, no essentially new element beyond the well known physiological properties of the nervous system, and we are not committed to any particular hypothesis as to the physiological accompaniments of pleasure and pain, or pleasantness and unpleasantness, in order to understand how behavior may become adaptively modified. How far the interpretation given will enable us to explain the development of intelligence I do not pretend to say. It may break down in attempts to apply it to higher forms of learning, but it affords a useful working hypothesis and takes us a way, I think, toward the solution of our problem.

\section{BIBLIOGRAPHY}

BArn, A. The Sensations and the Intellect, 3d. ed., '94.

The Emotions and the Will, 4th. ed., '99.

BaLdwin, J. M. Mental Development in the Child and in the Race. Methods and Processes, 2nd. ed., N. Y., '97.

Development and Evolution, N. Y., '02. 


\section{BEGINNINGS OF INTELLIGENCE}

Hовноuse, L. T. Mind in Evolution, '01.

HoLmes, S. J. Pleasure, Pain and the Beginnings of Intelligence. Jour. Comp. Neur. Psych., 20, 145, '10.

The Beginnings of Intelligence, Science, 33, 473, '11.

Marshali, H. R. Pleasure, Pain and Eesthetics, N. Y., '94.

Spencer, H. Principles of Psychology, 1855. 


\section{CHAPTER IX}

\section{PRIMITIVE TYPES OF INTELLIGENCE IN CRUSTACEANS AND MOLLUSCS}

It is scarcely possible at present to fix, even with the rudest approximation, the point where intelligence makes its first appearance in the course of evolution. There is little doubt that the step from instinct to intelligence has been made, not once merely, but several times. The intelligence of the higher Mollusca had, in all probability, an origin independent from that of the arthropods, and the intelligence of the vertebrates was probably developed independently of that of the other groups. Among the arthropods themselves it is not likely that the intelligence manifested by the arachnids had a common origin with that of the insects, and within both of these large groups intelligence may have been independently developed out of behavior of the purely instinctive type.

Intelligence grows out of the complexity and perfection of the nervous mechanism, and along whatever line organization reaches a certain degree of development intelligence appears on the scene. From what has been said in previous pages we are prepared to appreciate the fact that intelligence is not an entirely new power unrelated to the other activities of organic life, but a process growing out of other organic functions and having the same end as these other functions; it is, as Spencer has so well emphasized, but a higher phase of those processes of adjustment and regulation which make up the life of the animal. 
The criterion of intelligence which we have adopted-the power of forming associations-is one which is accepted by a considerable number of comparative psychologists. Unfortunately the term intelligence is used in a variety of senses by different writers-a fact which is in part responsible for the different expressions of opinion as to where in the animal kingdom intelligence makes its beginning. The acute Father Wasmann will have none of intelligence in any animal below man, but as he defines it, the term connotes the power of reasoning by the use of general concepts. The controversy which has arisen over this employment of the term is a matter for the lexicographer instead of the psychologist, and so long as a writer makes his peace with the dictionary we have no quarrel with him. We prefer, however, to employ the term in its more widely accepted meaning.

As stated in a previous chapter, there is no evidence that there is any power of forming associations in the Protozoa. In the Cœlenterata behavior, although of the reflex type, is often highly plastic and capable of being modified in many ways as the result of previous experience; but while intelligence has often been claimed for these forms, there is, in the opinion of the writer, no case in which the formation of associations is satisfactorily proven. The same statement may also be risked for that large and miscellaneous assortment of animals grouped under the term Vermes. The behavior of Echinoderms is certainly complex and plastic to a remarkable degree, but even in this group the power of forming associations is very doubtful. Preyer, who has made a very thorough study of the behavior of the starfish, claims to have discovered indubitable indications of intelligent action, but the later studies of Jennings and Glaser on the behavior of starfish and ophiurans failed to confirm Preyer's 
conclusions. A starfish may possibly acquire habits of a certain kind, but it is not proven that it is able to form associations.

We do not intend to deny the existence of intelligence in the groups mentioned; we think it not improbable that intelligence of a primitive sort may be discovered, at least in the more highly developed members of these divisions; but at the present time we can only grant the Scotch verdict of "not proven."

In the Arthropoda instinctive activity is frequently represented as reaching its culmination, and some investigators have gone so far as to assert that the behavior of these animals is made up entirely of instincts and reflexes. This opinion is in part based on a priori deductions from the organization of the nervous system and it is held to chiefly by morphologists and physiologists whose observation of the behavior of animals is limited and warped by preconceptions.

Bethe, who has done a large amount of thorough and valuable work on the anatomy and physiology of the nervous system of arthropods, and who has very successfully employed the results of these investigations in the analysis of normal behavior, was led to the somewhat extreme position of denying, not only associative memory, but consciousness as well, in all the arthropods. The complex behavior of these forms, according to him, can be analyzed in terms of reflex action, and there is consequently no ground for assuming any psychic elements whatsoever in these animals.

At the close of his important memoir on the nervous system of the crab Carcinus mœnas, there are described a few experiments which convinced Bethe that this animal is unable to profit by experience. Bethe placed a crab in an aquarium containing a devil fish, Eledone, which took up its station in a dark corner. The crab when placed in the 
aquarium quickly rushed, in obedience to its proclivity to shun the light, into the dark corner where it got into difficulties with the devil fish. Bethe now interfered and freed the crab from its captor and put it back in the aquarium. Back the crab went again into the arms of the enemy. Five successive times it repeated the performance (and another individual did the same six times) without learning to avoid the retreat of the devil fish.

In another experiment a piece of meat was placed in an aquarium containing some hungry crabs, and the hand of the experimenter was held over the meat. Whenever a crab seized the food the creature was maltreated and driven away; it was thought that if the crab were capable of learning it would come to associate the sight of the experimenter's hand with the painful experience following the seizure of the meat and keep at a distance. After several such experiences it went after the meat as at first, and Bethe concluded that the creatures were nothing but "reflex machines," without a glimmer of intelligence.

These few experiments by which the intelligence of the crab is summarily disposed of, form an almost amusing contrast to the long, detailed and exhaustive work on the anatomy and physiology of the nervous system. The experiments are obviously inadequate, not only because they are much too few in number, but because they do not afford the best opportunities for bringing out whatever power of forming associations a crab may possess. In the first experiment, granting that the crabs were not more afraid of Bethe than of the devil fish, as they had apparently as much reason for being, it would have been necessary for the crab to inhibit a strong instinct before it could manifest any tendency it may have acquired to avoid the dark corner with its sinister occupant. A crab when afraid makes for a 
dark hole if there is any within reach, and with its whole energies bent upon getting away from the large creature into whose hands it is taken, what wonder if the devil fish, if it would otherwise be remembered, should be temporarily forgotten.

The second experiment likewise is one which involves the conquest of a strong instinctive proclivity and it includes also too small a number of trials to be in any way convincing.

The later experiments of Yerkes on Carcinus were more fortunate in yielding positive results. The crabs were placed in a box one end of which led to an aquarium. The end nearest the aquarium was divided so as to afford a right and a wrong path to the water. With successive trials the crab came to learn, although with extreme slowness, to choose the right path. Other simple labyrinths were employed and the crab in each case succeeded, after a sufficient number of trials, in learning the way to the water. The work of Cowles on Ocypoda yielded confirmatory results, although the idiosyncrasies of the animal caused the results to be somewhat less clearly defined.

Experiments similar to those on Carcinus were performed by Yerkes and Huggins on the crayfish. A simple labyrinth was constructed consisting of a box having a small compartment at one end, and an opening at the other leading to an aquarium. From the open end a median partition extended back a short distance, and one of the passages so formed was closed with a glass plate. The crayfish liberated from the small compartment was provided with a choice of two paths only one of which would lead it to the water; and the endeavor was made to ascertain if the crayfish, after a number of trials, would unerringly choose the right path. The crayfish used were put through a number of preliminary ex- 
periments with both passages open to determine if they had any tendency to go toward the right or the left, and after it was shown that either path was chosen with equal readiness, the glass plate was inserted and the animals put again into the box. In the first experiment the crayfish took the correct path in 50 per cent. of the trials, and during the subsequent trials the percentage of correct choices gradually rose until in the final ten trials it reached 90 per cent. The improvement was very gradual, as is indicated by the following series of percentages of successful trials for each set of ten trips: $50,60,75.8,83.3,76.6,90$. Although slowly acquired, the habit of following the right path was not forgotten after an interval of two weeks.

Further experiments in which the box was thoroughly washed out after each trip to eliminate any guiding influence of odor or moisture gave similar results. If after a crayfish had learned to turn to the right, the right pathway was closed, the animal, after a number of trials, would turn to the left. One specimen which had come to turn to the left in the first fifty trials, turned to the left uniformly thereafter in the following fifty trips. The left side was then blocked by the glass and in the next fifty trips forty were successful. Finally the crayfish made but one error in fifty trials. Further changes in the position of the glass plate were made, but the crayfish after a number of trials adjusted itself to the new condition.

The docility of the crayfish is shown also by some experiments of the writer in which the animals were trained to come for food. To quote from a previous paper: "At first I would very slowly bring a piece of meat held in a fine forceps near the antennules. After the movements of the antennules and mouth parts, the grasping movements of the chelipeds would result in securing the meat. After some trials I would 
not allow the meat to be pulled away from the forceps until the crayfish struggled awhile to secure it; at the same time I moved my hand about so as to accustom the animal to my movements. There is a struggle between the instinct to flee from a large moving object and the instinct to secure a savory morsel which has been seized. With careful manage ment the latter instinct may be made to predominate over the former and gradually the fear of one's movements becomes much reduced. The crayfish finally came to associate the approach of my hand with being fed, and would rear up and hold out its larger chela much as in the ordinary posture for defense. . . One individual would greet me as I entered my room in the morning by raising up its chelipeds and coming toward me, and it would follow me about as I went from one side of its enclasure to the other. When fed, however, it would manifest no further interest in my movements."

The ability of hermit,crabs to form associations has been proven by the experiments of Spsulding on Pagurus longicarpus. Several specimens of this active species were placed in an aquarium supplied with running water. A dark screen was made so that it could be placed in the middle of the aquarium lesving only a narrow slit on either side through which the crabs could pass from one compartment to the other. As the hermits are positively phototactic they tend to keep in the lighter half of the aquarium, and to make the lighting of the two parts as different as possible one side of the aquarium was covered with heary dark paper. When the screen was put in the aquarium, and all the crabs placed behind it, they quickly made for the openings at the sides of the partition and went out into the light. Every day the screen was inserted for a given interval in the aquarium, and a piece of fish put behind it. The number of crabs entering 
the darkened part after the food was noted and the length of time required for the crab to enter. On the first day only three out of the thirty crabs used availed themselves of the food. The number gradually increased on succeeding days, and the average time of their response decreased c.ntil, on the eighth day, all the crabs but one entered the dark enclosure, and most of them entered with little delay.

"After a few days of this treatment immediately upon the insertion of the screen the crabs became most agitated, some hurrying and scurrying about, others making almost directly for the openings." An association was evidently formed between the appearance of the screen and the experience of being fed, and this association led the animals to act counter to their natural proclivity to seek the light.

The experiments of Drzewina on Pachygrapsus, in which it was shown that the crabs which were compelled to go through a certain opening in order to get nearer the light gradually learned the way and arrived more quickly in the compartment of their enclosure which was most illuminated, show a similar power of forming associations.

In the Mollusca we meet with indications of intelligence of a primitive sort in the movements of gasteropods such as the limpets, which have the faculty of making considerable journeys from their accustomed stations on the rocks and returning to their orginal position. Bethe has studied the homing of limpets and has come to the conclusion that these animals simply follow their own slimy trails and are guided back to their resting place by a kind of chemotaxis. No intelligence is required by the limpets; they simply obey a blind tropism.

Lloyd Morgan experimented with limpets by removing them for some distance from their scars on the rock and noting how many found their way back within a given time. 
The results of his experiment are summed up in the following table:

No. removed

25

21

21

36
Distance in inches

6

12

18

24
Later

21

13

10

1
Number returned

In 4 tides

$\ddot{5}$

5

6

1
..

.

2

3

While the majority found their way back when removed but a few inches, only one returned from a distance of two feet. The return of the limpets was watched in many cases and found to be "fairly, but not quite direct." When the limpets reach their scar "they twist and turn about so as to fit down in the normal position, which is constant. When they come up the wrong way round they rotate pretty rapidly through the 180 degrees to get into position."

According to Bohn, Patellas when they have remained for some time in a certain position, whether horizontal, vertical or oblique, orient themselves in a similar position after they have been removed from their original habitat. Even if they are allowed to remain on their particular scars and the rock to which they adhere is turned in another position they become uneasy and crawl around until they find a niche in which they may lie in their previous orientation.

It is among the active and highly organized cephalopods with their large and complex nervous centers and highly developed organs of vision that we naturally expect to find the highest degree of psychic development. Unfortunately we have very few observations on this head. Schneider relates that a young octopus which be observed in the Naples aquarium made an attack on a hermit crab living within a shell upon which were several anemones. In approaching the crab the octopus was stung by the nettling cells of the anemones and quickly withdrew. There- 
after it carefully avoided further contact with the crab. Older octopi, according to Schneider, contrive to extract the hermits from their shells without being stung. The observations of Schneider on the young of the octopus were verified by von Uexküll in Eledone which also learned to avoid a torpedo from which it had received an electric shock.

Kollmann gives an acount of an octopus which was placed in an aquarium with a large lobster and several other animals. The octopus manœuvred constantly in order to seize the lobster, but the latter was on the alert and usually made its escape, and on one occasion inflicted a severe cut on its adversary's arm. The lobster was finally seized in an unwary moment and surrounded by the long and powerful arms of its captor. It was liberated by an attendant and placed in an adjoining aquarium separated from the first by a cement partition which projected about $2 \mathrm{~cm}$. above the surface of the water. The octopus then, although the lobster was out of its sight, made a sudden spring over the partition and soon caught and overcame its prey.

It is difficult to estimate the psychic aspect of a single act such as this. According to Kollmann it shows that the octopus has the power of representing the absent lobster and of remembering where it was placed; but it is not safe to go farther than to say that a certain amount of intelligence was probably involved.

\section{BIBLIOGRAPHY}

Bethe, A. Das Nervensystem von Carcinus mœnas I, Arch. f. mik. Anat. 50, 460 and 549, '97; II, 1.c. 51, 447, '97.

Drzewina, A. Les reactions adaptives des Crabes. Bull. Inst. Gén. Psych. 8, 235, '08.

Kollmann, J. Aus dem Leben der Cephalopoden, Vierteljahrschr. wiss. Philos. 1, '77. 
Morgan, C. L. Animal Behaviour, London, '00.

Schneider, G. H. Der thierische Wille, '80.

Spaulding, E. G. An Establishment of Association in Hermit Crabs, Eupagurus longicarpus. Jour. Comp. Neur. Psych. 14, 49, '04.

UEXKÜLL, J. von. Physiologische Untersuchungen an Eledone moschata. Zeit. fur Biol. Vols. 28, 30, 31, '92-'95.

Wrldcox, M. A. Homing of Fissurella and Siphonaria. Science, n. s. 22,90 , ' 05 .

Yerkes, R. M. Habit Formation in the Green Crab, Carcinus granulatus. Biol. Bull. 3, 241, '02.

Yerkes, R. M., and Huggins, G. E. Habit Formation in the Crawfish, Cambarus affinis. Harvard Psych. Studies 1, 565, '03.

Yona, E. La psychologie de l'escargot. C. r. et Trav. Soc. Helv. Sci. Nat. '93, 127. 


\section{CHAPTER $\mathrm{X}$ \\ INTELLIGENCE IN INSECTS}

"Si tous les actes instinctifs des Insectes portaient constamment l'empreinte évident d'une nécessité aveugle, il y aurait beaucoup moins à admirer en eux qu'on ne le fait communément. Ce qui excite surtout notre surprise, c'est que fréquemment ils s'accommodent aux circonstances, et que leurs actes prennent alors une telle apparence de raison, qu'il faut y regarder de près pour ne pas les attribuer à une véritable combinasion d'idées.-LACordaIRE, Introduction d l'Entomologie.

In the insects manifestations of intelligent behavior are much more common and more striking than in the crustacea and molluses. It is a general rule that the degree of intelligence in these forms runs parallel with the degree of complexity and perfection of their instincts and with the degree of development of the nervous system and sense organs. Among primitive groups of insects the intelligence manifested is very slight, while it reaches its culmination in the hymenoptera whose instincts have long been objects of wonder and admiration.

The power of associating certain appearances with food might be expected to occur among the earliest manifestations of intelligence, and we find many illustrations of this ability even among the more primitive insects. Miss Sondheim kept a damsel fly larva in a dish of water, where it was frequently fed. At first the larva scuttled away in fear whenever Miss Sondheim approached, but after a time its timidity was overcome. Later it became so tame that it would take flies out of her hand, and came toward her whenever she approached. Finally it would come out of the 
water and climb upon her hand in order to get the food. Another larva which was worked with failed to profit in the least from repeated efforts to train it. Forel similarly trained a large water beetle, which at first fled upon his approach, to come toward him for food. The beetle came to eat when on the table, whereas naturally it feeds only in the water, but it still retained its old method of turning over on its back before eating, which it did very clumsily when out of its nàtural element. Lubbock trained a wasp to come for food, and finally it would allow itself to be taken into the hand and stroked, whereas at first it would show strong resentment at attempts of this kind. Very similar results were obtained by Adlerz in a species of sand wasp.

Mr. J. Wodsedalek has recently made an extended study of the formation of associations in the May-fly nymph Heptagenia interpunctata (Say), which is very common near the University of Wisconsin, where the work was carried on. Although negatively phototatic, the nymphs were trained to go toward a stone (to which they had a strong propensity to cling), at increasingly great distances against the rays of light, until finally they would go toward it at a distance much greater than they could be induced to do at first. They were also trained to come for food, and by repeated stirring up, several lots of nymphs came to be so afraid that whenever the observer approached they would scurry about with every appearance of great alarm. Nymphs placed in other dishes where they were not disturbed showed practically no signs of fear. It is of interest to find in these primitive insects that behavior is modified in the two ways which in higher forms we should have little hesitation in regarding as indicative of pleasure and pain.

There are several instances of the "training" of ants. 
Formica rufibarbis is a very pugnacious species and the odor of one's hand readily provokes it to a fight. Wasmann gradually trained a worker of this species, offering it honey on the end of a needle, and after it came to accept the food without hesitation, placing the honey on his finger where it came to be accepted with no manifestation of fear or hostility.

Insects, like higher animals, learn to avoid injurious substances which they at first attempted to use for food. Reuter placed near a nest of ants some syrup containing poison. The ants partook of the syrup eagerly, but soon ejected it from their stomachs; after a little they came to avoid the syrup although numbers of them were commonly near it.

The ability of insects to find their way back to their nest or home is developed in many cases to a very remarkable degree. Bethe, possessed of the idea that insects are reflex machines incapable of learning by experience, explains this power in the case of ants as an instance of chemotaxis; but in the bees and wasps which find their way back from considerable distances through the air, where scent tracks would not persist, he is driven to assume some mysterious power, acting in a manner analagous to magnetic force, which guides these insects to their goal. Ants have the instinct to follow the scent tracks left by their feet in going from the nest, but as Cornetz has shown, they generally do not follow these at all closely, and usually return by a much more direct course than the irregular path which is commonly taken in their outgoing journeys for food. The power of return exhibited by bees and wasps is shown pretty clearly by the experiments of Lubbock, Buttel-Reepen, the Peckhams, Wagner and others to depend upon the individual experience of these insects. The homing of insects takes 
place in essentially the same way as the homing of carrier pigeons, and involves an acquaintance with the locality gained by previous exploration. The Peckhams found that solitary wasps before their first departure from the nest make elaborate "locality studies," circling around the nest in wider and wider courses and at the same time flying higher and higher in the air. Speaking of an Ammophila which for some time previously had been exploring a garden in

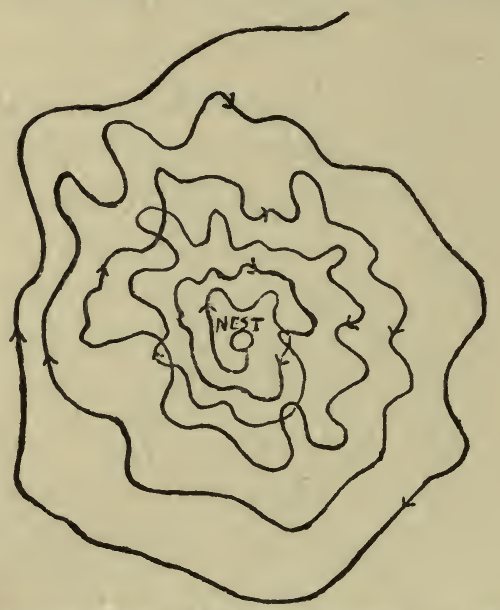

Fig. 13.-A locality study of the wasp Sphex. (After Peckham.)

search of a place to dig a nest, the Peckhams say, "At last a spot is selected and she begins to dig, but two or three times before the work is completed she goes away for a short flight. When it is done, and covered over, she flies away, but returns again and again within the next few hours to look at the spot and, perhaps, to make some little alteration in her arrangements. From this time on, until the caterpillars are stored and the egg laid, she visits her nest several times a day, so that she becomes perfectly familiar with the neighborhood, and it is not surprising, after all, that she is able to carry her prey from any point in her 
territory in a nearly direct line to her hole-we say nearly direct, for there was almost invariably some slight mistake in the direction which made a little looking about necessary before the exact spot.was found.

"After days passed in flying about the garden-going up Bean Street and down Onion Avenue, time and time againone would think that any formal study of the precise locality of a nest might be omitted, but it was not so with our wasps. They made repeated and detailed studies of the surroundings of their nests. Moreover, when their prey was laid down for a moment on the way home, they felt the necessity of noting the place carefully before leaving it." Similar "locality studies" varying more or less in character, are made by many other genera of wasps, but after a number of flights from home the preliminary circling about becomes gradually reduced, and finally the insects fly away in a straight line.

The rôle of visual memory is shown in the way in which wasps are disconcerted by a change in the region about their nests made during their absence. "Aporus faciatus," say the Peckhams, "entirely lost her way when we broke off the leaf that covered her nest, but found it, without trouble, when the missing object was replaced. All the species of Cerceris were extremely annoyed if we placed any new object near their nesting places. Our Ammophila refused to make use of her burrow after we had drawn some deep lines in the dust before it. The same annoyance is exhibited when there is any change made near the spot upon which the prey of the wasp, whatever it may be, is deposited temporarily." Even a slight change so disconcerted the wasps that they were obliged to hunt for a long time before recovering their prey.

Belt has recorded a very interesting case of a wasp, Polistes carnifex, which had caught a caterpillar too large to be carried 
to its nest. After chewing the caterpillar for some time the wasp bit it in two and rolled up one of the parts in order to carry it away. As if it had in mind returning for the other piece the wasp circled about, forming larger and larger circles, then departed for a distance, but returned as if to get another look at the situation and flew away. In less than two minutes the wasp again appeared on the scene, having probably disposed of its burden in its nest. It had difficulty in finding the remainder of the caterpillar and returned repeatedly to the same seed pods near which the prey was located. Whenever in flying about it came near the pods it would alight and continue the search on foot. Its persevering efforts were rewarded by the discovery of the remainder of the caterpillar; then it seized its prey eagerly, and "as if there was nothing more to come back for, flew straight to its nest without taking any further note of the locality."

Similar behavior is shown in the trial flight of bees. When young bees, or bees which have been carried into a new place, make their first excursions from the hive they circle about as they rise through the air before venturing very far away. Only after having flown back and forth from the hive several times do they finally come to dispense with their preliminary movements of exploration. If young bees are removed from the hive, even for only a short distance, before they have made their trial flight, they fail to find their way back. On the other hand, old bees may be removed for a long distance and almost all succeed in returning. The distance from which bees are able to find their way home depends upon the character of their surroundings, and particularly upon the distances they have been in the habit of going for honey. Romanes took bees from a hive which was situated near the sea, carried them in a boat a short distance from 
the shore and set them free. That they might be easily recognized the bees were previously made to walk in bird lime and the hive was carefully watched for their return, but none found their way home. Another lot of bees was then liberated on the shore not far from the hive. In this region there were no flowers, consequently it was one not frequented by the bees, and they were no more successful in finding their way back than in the first experiment. A number of bees were next carried inland where they had been in the habit of foraging for honey, and liberated; nearly all quickly found their way back to the hive.

Buttel-Reepen found that if a hive is carried into a new locality a considerable distance from its original situation and concealed among shrubbery or between buildings so that it cannot be seen from a distance, and the old bees are removed before they have made a trial flight; they usually fail to return even if they have been taken but one-hundred feet from the hive. If the hive is removed to a short distance of a few rods, numbers of the bees return to the original position of the hive and fly about as if in search of the hive, although the latter may be in plain sight. The memory of bees for the position of an object is apparently better than their memory of the object itself. In this the insect mind acts rather differently from that of higher animals for which the object, wherever situated, is the thing that usually determines action.

Insects seem chained down to topographical relations and free themselves from their guiding influences only with difficulty. This is illustrated by Fabre's experiments on the mason bee, Chalcidoma muraria. During the absence of the bee Fabre removed her nest the distance of one meter. The bee returned to the old locality of the nest, but failed to discover her own. When another nest was placed in the 
position of the old one the bee would work upon it as if unaware of the substitution. The same trait is shown in the interesting experiments of Turner on the homing of burrowing bees. Melissodes, the first form worked with, digs holes in the ground and makes excursions from the nest at quite regular intervals. During the bee's absence a rectangular piece of white paper with a hole in the center was placed over the nest so that the hole of the paper coincided with that of the burrow. The bee when returning circled about the nest, hovered over the paper, and then circled about again; after repeating such performances for two minutes she entered the nest. On her next return she hovered about for half a minute and made her entrance. During her next absence a hole was made in the ground about four inches away and covered by the white paper as before, while a piece of watermelon rind with a hole in the center was placed over the burrow. When the bee returned she hovered over the melon rind and circled about for a minute as if appreciating that things were not quite as they should be and then entered her nest. The melon rind was then removed and a rectangular piece of white paper was arched over the nest so as to form a covering open at either end. The piece of paper with the hole in the center was left where it was in the preceding experiment. When the bee returned she circled around for about a minute and then went into the hole in the middle of this paper. The insect was deceived, but only temporarily, for she quickly came out of the artificial hole, entered one end of the tent-like covering, and found her hole. The arrangements were left undisturbed during the next three flights of the bee, and the insect found her nest with little loss of time, as she did also when the tent was turned at right angles to its previous position.

In another experiment the tent was removed for a short 
distance and a black piece of paper with a hole in the center was placed over the nest so that the hole in the paper lay directly over the opening of the nest. The bee returned and entered her nest after hovering for but a few seconds over the black paper. Finally all the accessories were swept away and the region around the nest covered uniformly with green grass leaving the opening uncovered. On her return the bee was disconcerted, circled about the nest for about two minutes and finally entered it.

The hole of another species of burrowing bees was found near one of a series of bricks which formed the border of a walk. Near the hole was the cover of a bottle. During the absence of the bee Turner punched holes of the same diameter as the bee's nest and bearing the same relation to the other bricks as the nest did to the brick near it. The top of the bottle was placed near one of these artificial holes. On her return the bee alighted some distance away and came along the series of bricks until she encountered the hole near the bottle cover when she immediately plunged into it. She quickly recognized her error, withdrew, and soon found her own hole. During her second absence holes were punched in front of several more bricks on either side of the nest, but the bee on her return once more entered the hole near the bottle cover. She emerged, hovered over the spot, and again entered the same hole, but soon came out and found her own nest. Evidently the bottle cap served as a landmark indicating the position of her nest. The environment of the different holes was so similar that a change in the position of this one object changed the principal feature of the local topography.

There is no support here for Bethe's theory of a mysterious force, the assumption of a dead reckoning process, or the "kinæsthetic reflex" of Pieron. The results are only 
explicable on the assumption that the bee has a memory of space relations and guides her flight accordingly. This conclusion is supported by the results of Turner's experiments on the homing of the mud dauber, which are in principle the same as the foregoing, although differing much in detail.

In bees and wasps the memory of locality is shown by'their returning repeatedly to the same spot for food. Forel in experimenting on the power of vision and the formation of associations in bees made use of variously colored paper flowers on each of which he placed a drop of honey. The artificial flowers were placed among some Dahlias which the bees were visiting. A red paper flower was brought near a bee resting on a Dahlia, but the bee was at first so occupied in gathering honey that she could be induced to visit the red flower only when the honey was brought within reach of her proboscis. The bee's back was then marked with red paint in order that she could be distinguished from other bees. When the bee returned from the hive she went straight for the artificial red flower, then to a blue artificial flower with a yellow center and finally back to the first. Another bee which visited a white artificial flower was painted yellow. On her return from the hive she flew to the same artificial flower and then visited two others and did not return to the Dahlias. Later the bulk of the bees which for a long time had, with few exceptions, ignored the artificial flowers seemed to have their attention directed to them by other visitors and threw themselves upon the artefacts in swarms. After they had devoured the honey the bees began to go back to the Dahlias, but when colored artificial flowers devoid of honey and hence lacking an attractive odor were placed among the plants, many bees began to visit them and examine them carefully as if they expected to find honey there. These facts, as Forel rightly 
concludes, "can only be explained by an association of space form and color memories with memories of taste."

We are certainly justified in concluding that insects are not mere reflex machines incapable of learning by experience. They can form associations very quickly in many cases. They give evidence of memory. They have a remarkable ability for retaining impressions of topographical relations. We may not be compelled to admit that they have ideas, but it must be granted, I think, that a wasp which after cutting a caterpillar in two and carrying away one part, came back and searched diligently for the remainder, retained somehow an impression of the missing part and its location. If out of sight it was not out of mind. The hunting of the wasp is instinctive and when we see a wasp flitting about here and there in a feverish search for prey we cannot assume that it carries in its mind an image of the object of its pursuit. But the case is different with a wasp which has secured its prey and comes back to find it. The prey and its position are represented by some sort of "engram" in the nervous center of the wasp, which is formed by the various stimuli, optical, olfactory and tactual, which resulted from the encounter. If the wasp does not have an idea of its prey it has something which plays a rôle similar to that of ideas in ourselves. As the wasp when it has disposed of the second moiety of the caterpillar no longer returns, its mental content is evidently changed by having carried the part to its nest. If there is something representing "part-of-caterpillar-among-leaves" that leads the wasp on its hunt, we may conclude that there is also something corresponding to "part-of-caterpillar-now-in-nest" which prevents further search.

I realize that one is on treacherous ground in trying to interpret the workings of the insect mind. Forel, whose 
judgments on animal psychology are usually conservative, attributes to insects an "ability to instinctively draw inferences from analogy." Some of the facts adduced are the following: After bees had been trained to come to artificial flowers of a certain color for honey they deserted the Dahlias upon which they had been working and began to work upon other artefacts of different colors and in various positions. The bee may be supposed, according to Forel, if we interpret him correctly, to go through with a mental process corresponding to "This appearance means honey; therefore this other similar appearance likewise means honey; I will investigate it." The behavior of the bee may indicate a step toward rational procedure, but we are hardly justified in assuming that any act of comparison between similar flowers takes place in the insect's mind. A certain appearance has been associated with the act of sucking honey. This association leads the bee to visit the same artificial flower again; or we may say that this object tends to set in action the honey-getting activities. If the same object causes the return of the bee we do not appeal to any inference from analogy. If now a similar object provokes the visit of the bee, it may mean simply that the stimulus is sufficiently like the first to set the honey-getting activities in motion. The bee gets a different perception from the second object, but it does not necessarily recognize that it is different from and at the same time similar to the first. What appears in many cases to be reasoning from analogy, involving judgments of likeness, is really based on nothing more than lack of discrimination. While granting that a simple act of inference may be performed by the bee, the facts do not, I think, require us to conclude that it actually is performed.

Another case involving a decided approach to reason, 
according to another prominent student of conservative judgment, Professor Lloyd Morgan, is furnished by the observations of the Peckhams on a solitary wasp Ammophila which, after filling up its hole with dirt even with the surface of the ground, picked up a small pebble in her mandibles and

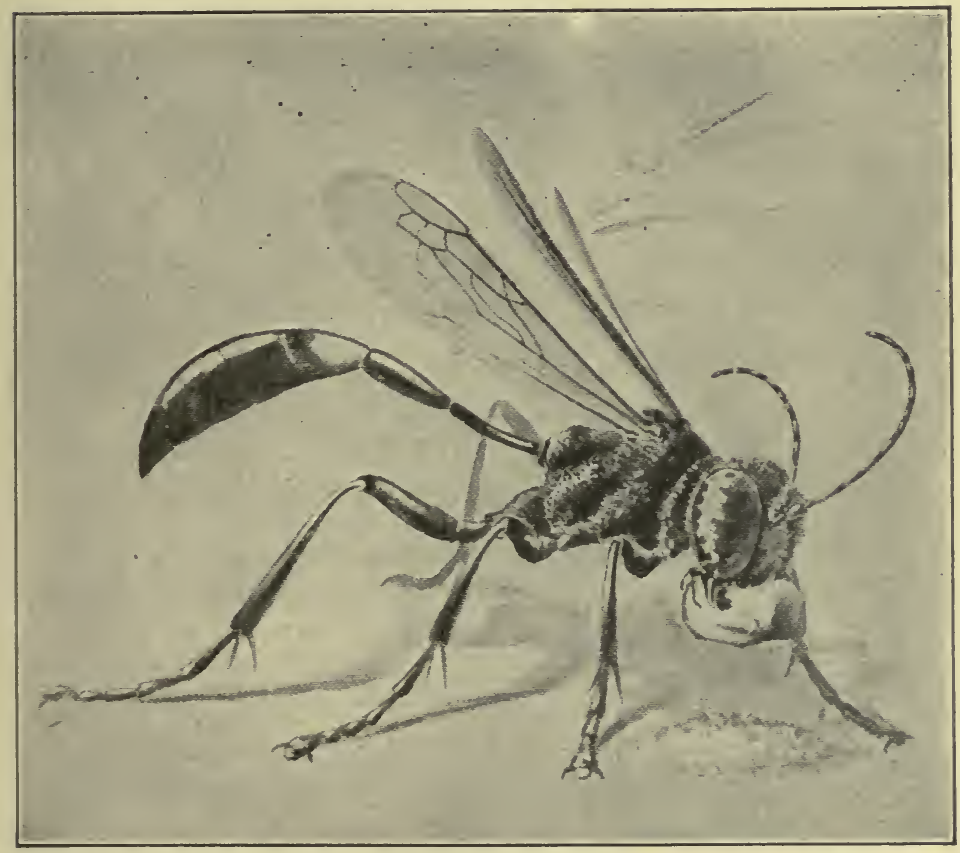

FIG. 14.-The wasp Ammophila using a stone to pound down the dirt in its hole. (After Peckham.)

used it to pound in the loose dirt placed in the hole, "Before we could recover from our astonishment at this performance," write the Peckhams, "she had dropped her stone and was bringing more earth, and in a moment we saw her pick up the pebble and again pound the earth into place with it. Once more the whole process was repeated, and then the little creature flew away." According to Morgan, "here 
we have intelligent behavior rising to a level to which some would apply the term rational. For the act may be held to afford evidence of the perception of the relation of the means employed to an end to be attained, and some general conception of purpose." Truly a "tool using animal!" But in estimating the psychic aspect of the performance we must bear in mind that the act is one which borders closely upon the normal instinctive behavior of the insect. The seizure of pebbles in the mandibles and the packing in of dirt are parts of the instinctive process of filling up the hole. The wasp combines two features of its hole-filling instinct in a rather unusual way. Does she really perceive the relation of means to end? I am not so sure that she does.

Many readers who peruse this chapter will miss the wonderful accounts of insect ingenuity which they may have expected to find. The literature of insect behavior contains these in abundance. Run through the files of Nature, Science Gossip, Der Zoologische Garten, La Nature, The Zoologist, the older numbers of the Annals and Magazine of Natural History, and The American Naturalist, the various entomological journals, and works of travellers with a leaning toward natural history; and peruse the many volumes that have been written on the instincts and intelligence and reasoning power of animals, and you will encounter an enormous mass of material, some of it carefully recorded, much of it not, more of it vitiated by anthropomorphic interpretation which one cannot help feeling has biased the observer in his account of the facts, but the data that can be employed in drawing conclusions regarding the degree of intelligence shown by the forms observed is disappointingly small. Animals are observed overcoming obstacles or meeting unusual situations, and the occurrence is straightway recorded as an illustration of sagacity, something for which 
"mere instinct" will not account. In most cases there has been no previous study of the animal's behavior with a view to ascertaining the nature and limitations of its instinctive performances. Ants are observed to build bridges over water or other substances which they are desirous of crossing, by bringing grains of sand or bits of earth and dropping them until they can effect a passage. The ants are then credited with ingenuity, reason, imagination and other mental qualities which human beings would employ to overcome a similar difficulty. And taken by themselves the facts seem to justify such conclusions. Light on the matter, however, is thrown, as in so many other cases, by a study of the creature's instincts, which shows that the apparent feat of engineering is the result of an instinctive propensity of the ant, slightly modified perhaps to meet the particular occasion.

Wasmann, in an instructive experiment, placed on the nest of Formica sanguinea a watch glass filled with water in the center of which was a sort of island on which were isolated a few pupæ. The ants brought sand and threw it into the watch glass until they had formed a passage way to the pupæ, which were then carried away. Ingenuity, surely, one is tempted to say! But the next experiment inspires caution. A watch glass with no island and no pupæ was placed in the nest. This was filled like the previous one. At least one important factor in the ants' activities is the instinct to cover offending objects which cannot be removed -an instinct analagous to that of bees, which leads them to cover over with propolis objects too large to remove from the hive. If a dog performed similar actions in endeavoring to reach an object otherwise inaccessible we should be justified in attributing to the animal a considerable degree of intelligence. Some intelligence may have been involved in the behavior of the ants, but not necessarily more than a very 
little. The celebrated instance adduced by Leuckart of ants bringing grains of sand to cover a streak of tobacco solution across their trail may be explained in a similar way. Another instance. Kirby and Spence record a case communicated by a German artist, whom they were assured was "a man of strict veracity." A dung beetle, having made a pellet for the reception of its eggs, found that it was unable to roll the pellet out of a depression into which it had fallen. The beetle then repaired to a dung heap near by and returned with three companions, with whose assistance the ball was rolled out, after which the three beetles took their departure. This is one of the evidences from which insects are considered to be "able to communicate and receive information, which, in whatever way effected, would be impracticable if they were devoid of reason."

Blanchard in his "Metamorphoses, Mœurs et Instincts des Insectes," gives an account of a very similar performance, which the author considers to evince "une intelligence de la situation vraiment étonnante, et une facilité de communication entre les individus de la même espèces, plus surprenante encore." Here again we must take into consideration the normal instinctive behavior of these insects. Frequently two or more beetles are found rolling the same ball. As Fabre has shown in his careful studies of the sacred scarab, an allied beetle with similar habits, such associations are dependent on quite different motives than the altruistic desire of rendering assistance. The helpful comrades turn out to be bent on getting the ball for themselves. Sometimes they abandon the task voluntarily; often they wage a combat with the original owner. The succoring of a comrade in distress is only an appearance which a fuller study of the habits of these insects places in a quite different light. These cases illustrate a common source of erroneous 
conclusions in the study of animal intelligence, one which is responsible for a great multitude of stories of doubtful value. Observations may have been recorded faithfully and-accurately, but where they have not been made by investigators thoroughly acquainted with the general behavior of the forms observed, mistaken interpretations are almost certain to arise. On the other hand, one is tortured by the feeling that our experimental methods often fail to give us a true measure of an animal's possible attainments, and that it is just in meeting exceptional situations which occur in the animal's natural course of life that the highest manifestation of its intelligence is reached.

A factor which markedly affects the behavior of many insects, especially the social ones, is the influence of numbers. Small stocks of bees, according to Buttel-Reepen, lose their spirit and allow themselves to become the prey of moths and robber bees which are not so easily tolerated by larger stocks. They work with less vigor and fight with less courage, as if conscious of the fact that in numbers there is strength and that their number is small. Forel says of ants that "the courage of each ant grows in proportion to the number of her comrades or friends and diminishes in just the proportion that she is isolated. . . The same worker ant, which in the midst of her associates, is ready to face death ten times over, when alone and twenty steps away from her nest, becomes cowardly, avoids the least danger, and seeks safety in flight from an ant much weaker than herself." In regard to Formica sanguinea Wasmann states that "if a numerous population inhabits a rotten fir stump, on the surface of which we find some of the ants running about, a gentle kick will at once call forth a whole army ready for the fray. In a moment the whole surface of the stump is covered with thousands of ants 
furiously hurrying to and fro. But if the colony is weak, the same kick, which at other times calls forth an army, will have the contrary effect. The ants which just before were running about the surface disappear through the entrances of the nest as if by magic, and deathlike quiet succeeds."

Wagner in his valuable studies on the behavior of bumble bees, has observed that the bees of well populated nests are much more pugnacious than those from nests containing few members. In regard to the household activities of bumble bees Wagner remarks that "Wenn eine Hummel allein mit der Ausbesserung des Nestes beschäftigt ist, so erscheint ihre Tätigkeit, obwohl wie stets geschäftig, doch wenig energisch und intensiv. Kaum hat sich jedoch der ersten Hummel eine zweite angeschlossen, so nimmt bei gleichen sonstigen Bedingungen die Energie der Arbeit zu und wächst bei jedem neu hinzutretenden Mitarbeiter mit voller Augenscheinlichkeit. Gans dieselbe Erscheinung habe ich auch bei Grabwespen beobachtet." The "brooding" of the cells, gathering food, and various other activities increase in vigor with increase in numbers, so that the population of the large nests seems larger and that of the small nests smaller than it is in reality.

The influence of numbers upon the industry and courage of social insects has been adduced as a proof of a high degree of intelligence. That a populous ant colony will make an attack upon a neighboring nest, while a colony with few members shows a disinclination for warfare, may give the appearance of a conscious realization of strength and a power of reflecting upon the probable issue of an encounter. As Wagner has pointed out, the explanation of such phenomena may lie in the effect upon the individual of various stimuli caused by its associates. The ant or bee commonly 
receives from other members of its community numerous olfactory, tactile, and perhaps auditory stimulations to which it instinctively responds. These stimulations produce a condition of general nervous irritability which spurs the insects on to activity and makes them ready to combine in an attack upon an enemy. Whether or not similar effects, as Wagner contends, are produced in solitary insects-and I am not convinced that they are, from the evidence adduced-it is undoubtedly true that social insects are dependent upon the stimuli received from the coöperation of others to a remarkable degree. The confusion produced by the loss of a queen and the gradual languishing of a swarm in which no queen can be supplied, show how sensitive are bees to changes in their social environment. Among bees, ants and termites signs of anger by one individual may awaken the whole community to a high pitch of excitement. Each individual then serves to arouse the others, and the larger the community the greater the mass effect.

Closely associated in many cases with the influence of numbers is the effect of imitation. The activities of insects not only arouse the energies of their fellows, but they also direct their efforts and in this manner secure coöperation toward a common end. Ants keep together in their foraging expeditions and often follow the "scouts" which act as leaders, guiding the expedition to the nest to be pillaged. "In artificial nests," says Wheeler, "one usually sees a particular activity started by one or a few workers, which have more initiative or respond more quickly to a change of conditions than the great bulk of the colony. The movements of such individuals attract the attention of others in their immediate neighborhood and these forthwith proceed to imitate their more alert companions. Then the activity 
spreads like a conflagration till it has seized on most or all the members of a community." It is in their attacks upon enemies that imitation in ants is especially marked. An attack by an ant is the signal for others to join in the fray. Sometimes a strange ant may be tolerated in a nest until it happens to arouse the animosity of one of the members, when various others fall to and help to dispatch the intruder.

Wasmann states that several beetles of the species Dinarda dentata were received as guests in a nest of Formica sanguinea and had lived there for some time and propagated. $\mathrm{He}$ then placed in the nest a specimen of an allied species of Dinarda which was attacked and killed. This aroused the killing propensities of the other ants which fell upon the Dinarda dentatas, and the guests which had been kept for so long met their fate. That ants in their treatment of aphids are influenced by imitation is indicated by the fact, signalized by Forel and Adlerz, that Formica sanguinea, which very rarely make use of honey dew as food, readily adopts the custom of its slaves upon perceiving them solicit the aphids for their sweet exudation. Slave making ants readily adopt guests which are received in a friendly manner by their slaves, although they would otherwise be apt to attack them, and slaves in turn are disposed to be friendly to the guests which they perceive to be tolerated by their masters.

In treating of insect intelligence we shall find it instructive to consider its failures as well as its exceptional manifestations. As Forel has remarked insects are exceedingly stupid as regards everything not closely related to their instinctive interests. But even when the latter are involved, they usually fail to make the simplest and most obvious inferences. A striking case is furnished by the Amazon slave-making ant, Polyergus rufescens, which on account of the remarkable 
military tactics displayed in its frequent warlike expeditions against other ants might be expected to rank among the most intelligent of insects. Polyergus is dependent upon its slaves for food, having almost completely lost the instincts for food taking from its long habituation to parasitic habits. There is no physical peculiarity which prevents these ants from getting their own food, and occasionally they take liquid food when by chance the mouth parts are brought in contact with it. As Lubbock, Wasmann and others have shown the Amazons if deprived of their slaves will starve to death in the midst of plenty without making the least effort to secure food of their own accord. As Wasmann observes, "their hunger does not compel them like other animals to seek for food themselves, but only to beg food of other ants by taps of their feelers. The sensitive perception of food placed immediately before them, in spite of their feeling of hunger, does no longer excite in them the natural impulse of tasting it." We should naturally expect that a creature possessing the rudiments of intelligence would be able to associate the appearance and odor of food with the act of feeding. Possibly the Amazons might, if skillfully managed, be taught to form this association, but that they do not do so under the stress of starvation shows how poor in resources is the emmet mind.

To the same purport we may cite the following quotation concerning ants from Sir John Lubbock: "In order to test their intelligence, it has always seemed to me that there was no better way than to ascertain some object that they would clearly desire, and then to interpose some obstacle which a little ingenuity would enable them to overcome. Following up, then, the preceding observations, I placed some larvæ in a cup which I put on a slip of glass surrounded by water, but accessible to the ants by one pathway in which was a 
bridge consisting of a strip of paper $2 / 3$ inch long and $1 / 3$ inch wide. Having then put a Lasius niger from one of my nests to these larvæ, she began carrying them off, and by degrees a number of friends came to help her. I then, when about twenty-five ants were so engaged, moved the little paper bridge slightly, so as to leave a chasm, just so wide that the ants could not reach across. They came and tried hard to do so; but it did not occur to them to push the paper bridge, though the distance was only about $1 / 3$ inch, and they might easily have done so. After trying for about a quarter of an hour, they gave up the attempt and returned home. This I repeated several times.

"Then, thinking that paper was a substance to which they were not accustomed, I tried the same with a bit of straw 1 inch long and $1 / 8$ inch wide. The result was the same. I repeated this more than once.

"Again I suspended some honey over a nest of Lasius flavus at a height of about $1 / 2$ inch, and accessible only by a paper bridge more than 10 feet long. Under the glass I then placed a small heap of earth. The ants soon swarmed over the earth on to the glass, and began feeding on the honey. I then removed a little of the earth, so that there was an interval of about $1 / 3$ of an inch between the glass and the earth; but, though the distance was so small, they would not jump down, but preferred to go round by the long bridge. They tried in vain to stretch up from the earth to the glass, which, however, was just out of their reach, though they could touch it with their antennæ; but it did not occur to them to heap the earth up a little, though if they had moved only half a dozen particles of earth they would have secured for themselves direct access to the food. This, however, never occurred to them. At length they gave up all attempts to reach up to the glass, and went round by the paper bridge. 
I left the arrangement for several weeks, but they continued to go round by the long paper bridge."

The facts above stated should render us suspicious of conclusions regarding the high degree of intelligence which ants have been supposed to manifest in certain of their activities, especially in their powers of communication, in their military manœuvers, and in the keeping of slaves and guests. A foraging ant finds some sugar, or a dead insect too heavy to carry to the nest, and she goes home, communicates by means of striking with the antennæ with other ants, and then returns with several companions to her prize. Or it may be that some of the "scouts" of a marauding species discover a nest of a species preyed upon, and after visiting her own nest and making her report, guides an expedition of warriors to the habitation of the enemy. The older writers on ants and some of the modern ones have made much of their power of communication, and in reading their accounts one might almost be led to believe that ants have a language with a large vocabulary, and hold elaborate dissertations on the food discovered, the whereabouts of their enemies, their strength, and the most feasible way in which to conduct an attack. That some power of communication exists has been abundantly shown, but for the most part it consists of signs instinctively made under certain conditions and which are instinctively responded to by other ants. In spite of the valuable investigations of several of the foremost myrmecologists our knowledge of ant "language" is very imperfect. Among the actions which have been considered to be involved in communication are striking with the antennæ, butting with the head, opening the jaws, beating the floor with the abdomen, and the production of sounds by various kinds of apparatus for stridulation. What the particular things may be which are signified by these various 
acts-if they do signify particular things-has not been discovered. The general upshot of a long series of experiments by Lubbock is that an ant, while having the power of leading others to food, is unable to inform its comrades as to the whereabouts of food so that they may reach it by themselves. Lubbock allowed ants to take food and go back to the nest; when these ants returned accompanied by several companions the former were caught in order to discover if their companions would then be able to find the food alone. This they rarely succeeded in doing, although they would scurry about in various directions as if seeking something. These facts seem to show that the communication of the location of food or other desirable objects is, as Romanes has expressed it, "in the nature of some sign amounting to no more than a 'follow me." While ants may not be able to talk about things in their sign language, they apparently express their different feelings and inclinations in ways which are intelligible to other ants. Wasmann has compiled a sort of vocabulary of signs made by the antennæ-a "Wörterbuch der Fühlersprache," which is about as extensive as Mr. Garner's language of apes. According to the vigor and frequency of the strokes of the antennx, and the part of the body stroked, the ant which is addressed may be importuned for food, warned of danger, or induced to coöperate with the communicant in various activities. Naturally one is inclined to be skeptical regarding what seems like many of the romantic tales of animal psychology, but Wasmann is expressing little more than the general opinion among students of ant life regarding the powers of communication possessed by these insects, and the conclusions of so careful and experienced a myrmecologist and one withal so little to be suspected of a tendency to "humanizing the brute" are deserving of the most careful consideration. 
The power of communication among bees is very limited. As the result of a long series of experiments on honey bees Lubbock has concluded that these insects do not lead one another to places where they find food. After numerous observations and experiments on bumble bees Wagner has come to a similar conclusion for these forms. In both hive bees and bumble bees the angry hum of a few bees is taken up by others and a sort of communication of anger spreads through the group. Similarly a note of distress, the "heulen," of the hive bee which frequently follows upon the loss of the queen, spreads from the bees which first discover the loss. Another note is predominant in swarming time, which sometimes evokes swarming activities in neighboring hives (Buttel-Reepen). In bumble bees where the language of sound is apparently more simple, the hum of the wings, according to Wagner, serves solely as a warning of the presence of danger- "die Hummeln mit Hilfe ihrer Flügel nur von drohender Gefahr und von nichts anderem Kunde geben können." All of the varieties of sound which the bumble bees make with the aid of their wings have not the least effect upon their comrades, with the single exception of the peculiar note emitted in time of danger which serves most efficiently to arouse other inhabitants of the nest. There is nothing in the communication of ants or bees that calls for the exercise of much intelligence. Their language, like the language of animals everywhere, consists solely of instinctively made and instinctively recognized signs.

\section{BIBLIOGRAPHY}

Bethe, A. Dürfen wir den Ameisen und Bienen psychiche Qualitäten zuschreiben? Pflüger's Archiv., 70, 15, '98.

Noch einmal über die psychiche Qualitäten der Ameisen, l.c. 79, 39 , '00. 
Die Heimkehrfähigkeit der Ameisen und Bienen, zum Teil nach neuen Versuchen. Biol. Cent., 22, 193 and 234, '02.

Buttel-REepen $H$. von. Sind die Bienen Reflex-Machinen? Biol. Cent. 20, 97, 177, 209, '00. Trans. by M. H. Geisler, A. I. Root Co., '07.

Zur Psychobiologie der Hummeln. Biol. Cent. 27, 579, 604, '07. Cornetz, V. Trajets de Fourmis et Retours au Nid. Mem. Inst. Gén. Psych. No. 2, '10.

Le Sentiment Topographique chez les Fourmis. Rev. des Idees, Dec., '09.

Un Regle de Constance dans les Trajets Lointains de la Fourmi Exploratrice. Ibid, Dec. '10.

Emery, C. Intelligenz und Instinkt der Tiere. Biol. Cent., 13, 151, '93.

Escherich, K. Die Ameise, '06.

Die Termiten oder weissen Ameisen. Leipzig, '09.

FABRe, J. H. Souvenirs Entomologiques, 10 vols. Paris, '79-'04. Forel, A. The Senses of Insects (Translation.) London, '08. Ants and Some Other Insects. (Trans. by W. M. Wheeler.) Monist, 14, 33, '04.

Le Mémoire du Temps et l' Association des Souvenirs chez les Abeilles. Bull. Inst. Gén. Psych. 6, 258, '06.

Kirby. W. and Spence, W. An Introduction to Entomology, 4 vols. 1st. ed. 1815,7 th. ed. 1856.

Luвbock, Sir J. Ants, Bees and Wasps, N. Y., '83.

On the Senses, Instincts and Intelligence of Animals, with Special Reference to Insects. N. Y., '88.

McCook, H. C. Ant Communities, N. Y. '09.

Pecknam, G. W. and E. G. On Instincts and Habits of the Solitary Wasps. Wis. Geol. and Nat. Hist. Survey, Bull. No. 2, . '98. Wasps, Social and Solitary. Boston, '05.

Sondherm, M. Wahrnehmungsvermögen einer Libellenlarve. Biol. Cent. 21, 317, '01.

Turner, C. H. Do Ants Form Practical Judgments? Biol. Bull. 13,333, ' 07.

The Homing of Ants. Jour. Comp. Neur. Psych. 17, 367, '07. The Homing of the Mud-dauber. Biol. Bull. 15, 215, '08.

The Homing of the Burrowing Bees (Anthophoridæ). Ibid, 15, 247, '08.

Experiments on Color-vision of the Honey-bee. Ibid. 19, 257, '10. 
WAGNer, M. Psychobiologische Untersuchungen an Hummeln. Zoologica, 46, '07.

Wasmann, E. Die psychiche Fähigkeiten der Ameisen. Zoologica, Heft. 26, '99.

Comparative Studies in the Pyschology of Ants and of Higher Animals (Trans. from 2nd. ed.), St. Louis, '05.

WHEELER, W. M. Ants, N. Y., '10. 


\section{CHAPTER XI}

\section{INTELLIGENCE IN THE LOWER VERTEBRATES}

"To the minnow every cranny and pebble, every quality and accident of its little native creek may have become familiar; but does the minnow understand the ocean tides?"-Thomas Carlyle.

If an extra mundane observer were ignorant of the evolution of the vertebrates beyond the Silurian or the Devonian epochs it is doubtful if he would pick out these animals as the ones destined to surpass all others in psychic development. The numerous species of highly organized cephalopods that thronged the seas, the trilobites with their highly developed organs of vision, the gigantic eurypterids that crawled over the bottom of the shallow oceans, the crustaceans, the terrestrial arachnids and the rapidly evolving group of insects might all have been regarded as having as much promise of future psychic development as the back-boned "winners of life's race." And most of the branches of the vertebrate tree really developed no further than their invertebrate competitors. From among the diverging branches of this phylum one only contained the stock that led to the mammals and culminated in man.

A comparative anatomist looking back upon the course of evolution might have said: The vertebrates were obviously the forms with the most promising psychological future. Many of these ancient forms doubtless possessed a cerebral cortex, a sort of appendix to the central nervous system, whose especial business it is to take care of the establishment of associations. The opportunity was open to them through the increase in size and complexity of the association centers 
for a career of an almost unlimited mental development. The molluses and the arthropods, on the other hand, have a different sort of a brain. They have no cerebral cortex; therefore they cannot form associations and consequently they are but more or less complicated "reflex machines." So with certain of the vertebrates, the bony fish whose cerebral cortex is represented by a membrane of non-nervous tissue over the basal ganglionic centers, they too must be chained down to the routine life of reflexes and instincts, with no power of learning, no ability to profit by experience. So our comparative anatomist might have argued and so indeed some comparative anatomists have argued. This contention as we have seen is far from justified in the arthropods, and we shall see that it is equally groundless as regards the vertebrates with no cerebral cortex.

Every angler can doubtless furnish evidence of the learning of fishes. In trout streams that have been much frequented the fish become much more wary of the bait than at first, and some of the old, experienced fishes can be induced only with great difficulty to take the line. On the other hand, certain fish will allow themselves to be caught and hauled out of the water repeatedly without conquering their propensity to dart at the bait.

No one can read very much in comparative psychology without frequently encountering the story of Möbius' pike -a story which the professor was fond of repeating in his lectures and which came to be looked forward to as a regular annual event by his students. This celebrated pike was kept in a part of an aquarium separated by a glass plate from an adjoining part which contained several minnows. The pike made frequent dashes for the minnows and each time received a bump against the glass plate. After about three months of attempts to catch the minnows the pike 
became convinced that his efforts were fruitless and they were given up. The glass partition was then taken away. The pike which had come to associate darting at the minnows with bumps on its nose left the minnows unmolested thereafter, being apparently unaware of the removal of the impediment to catching its prey. The interpretation of the experiment of Möbius was questioned by Bateson, whose experiments on the intelligence of fishes gave in general negative results, but it was confirmed by the investigations of Triplett on the educability of the perch. Triplett used an aquarium divided in the middle by a glass plate; in one compartment he placed a male and a female perch for a period of thirty minutes three times a week, after which they were removed and fed on worms. Soon after the two perch were put in one compartment some minnows were introduced into the other. The perch immediately began the pursuit and frequently butted their heads against the glass, especially when the minnows drew near. The efforts of the fish, especially the female, were very vigorous, but near the end of the period both had given up the chase. In the next trial the perch vigorously pursued the minnows, but with somewhat less energy than in the first experiment. For a month the behavior of the perch continued much the same.

The minnows and perch were then kept in the two parts of the aquarium as in the experiments of Möbius and remained there a week. The perch seldom collided with the partition, although they watched the minnows frequently. When angle worms were placed on the other side of the partition the perch dashed violently against the glass for some time in their efforts to reach them. They had learned to avoid the minnows, but the suggestion aroused by the worms on which the $y$ were regularly fed proved too strong for them. After the perch had ceased their futile efforts to catch the minnows 
one of the latter was placed in the compartment of the larger fish. It was treated at first much as before, but after a little "the perch became more demonstrative toward it, but restrained themselves from striking, so long as it quietly avoided them." When the minnow made a quick movement the perch were more apt to dart after it and on one occasion it had to be rescued. After a time the pursuit of the minnows became less eager and although they were followed the instinct to dart at them was generally inhibited.

The formation of an association in relation to the glass partition was shown by the fact that when the partition was removed the fish behaved much as if it still remained. "The male swam out to the place, stopped, made little bumps forward as if expectng to strike the usual obstruction, and was plainly at a loss. He then turned and swam down as if following the glass." Often the fish would swim to the mark where the plate had been and then turn back.

These experiments showed that the natural instinct of the perch to charge after the minnow was inhibited, although not completely so, and that the fish came to associate the appearance of a certain region of the aquarium with the experience of being bumped. Pieron found that a cyprinoid fish, Carassius auratus, would snap at live worms placed in a glass. tube, but the number of attacks in a given time gradually grew less on the following days. The glass tube was placed in the water for twenty-seven minutes each time. In the first experiment the fish made 117 attacks, on the three successive days the attacks were 58,38 , and 25 in number. Several days later the number of attacks had diminished still more. The tube was then left in the aquarium and the fish soon came to ignore it entirely, and even refused to eat the worms when they were placed free in the water. When the number of attacks on the tube diminished they could be 


\section{INTELLIGENCE IN LOWER VERTEBRATES}

augmented if the tube was placed in a different part of the aquarium or by feeding the fish with a few of the worms.

That fish readily associate certain stimuli with food has been shown by several observers. Herrick found that catfish which at first would seize pieces of cotton which were brought in contact with its barbels would gradually cease to react to them. After a few trials the fish would make a movement toward the cotton, but it was soon checked. Finally the cotton could be rolled over the barbels or other parts of the body without eliciting any response. The fish probably recognized the cotton through the sense of touch as it made little difference if, at any time, red cotton was substituted for white. Washburn and Bentley in their experiments on the creek chub showed that this fish is able to associate different colors such as red and green with food. The chub in one set of experiments was fed out of a pair of red forceps which were let into the water alongside of a green pair. Although a meal worm was placed in the red pair the fish often snapped at the green forceps first, but after a number of trials the green forceps were ignored. When the fish had been given a number of worms the forceps were put in empty. The fish continued to snap at the red pair and - avoid the green regardless of their relative positions. Red and green forceps of different degrees of brightness were used and precautions were taken to eliminate the influence of odor, but in the last 40 experiments in which no food was placed in either forceps and the relative position of the forceps exchangred after each trial the fish snapped at the red pair every time. It is probable, therefore, that the chub is able to distinguish colors as opposed to mere differences in brightness-although the proof of this is not entirely conclusive-and it is very evident that it is able to form associations with a fair degree of rapidity. 
Many fish can easily be trained to come toward one for food. I have trained goldfish so that they would swim toward my hand to be fed, when I put it over the aquarium, and $I$ find upon enquiry that many others have done the same. A sunfish which I kept for several months would take bits of snail meat out of my fingers; whenever my hand was brought near the water the sunfish would approach and hold its mouth near the surface in readiness to snap at the food. I gradually accustomed the fish to jump out of the water for the food to a distance of nearly three inches. I would often put my hand near the water as if I were holding a piece of meat. The sunfish would almost invariably come to the surface in a position of readiness for a leap, but it would not jump at my empty fingers. A piece of dark colored snail meat not much larger than a pin's head or a small black mark on the end of my finger would be sufficient, however, to cause a jump. I noticed also that the fish came to be very attentive to my general movements, and whenever I drew near the aquarium it would be found pointed toward me with its head near the glass; and if I walked around the aquarium the fish would faithfully follow.

Reighard in an investigation of warning coloration in fishes fed a colony of snappers with small fishes of the genus Atherina. Some of the Atherinas were stained red and others were unstained, some of the red ones were rendered unpalatable by putting in their mouths parts of the tentacles of a large jelly fish, which were plentifully supplied with nettling cells. Red Atherinas were readily taken when thrown into the water, but those which had been made unpalatable with the tentacles of the jelly fish, while snapped up at first, were generally avoided after a few trials. Thereafter the snappers avoided the red Atherinas which had not been rendered unpalatable. They had come to associate the 
red color with the irritation caused by the tentacles so that the red came to be a "warning color." Subsequently uncolored Atherinas were given them which were for the most part instantly taken. Red Atherinas were offered after an interval of eight days when they were very sparingly taken and then refused entirely, and again after an interval of twenty days when they remained entirely untouched.

There are a number of instances of fishes coming to be fed when a bell was rung or some other sound made, but it is probable as Kreidl has shown in one instance that the fish associated the food with the appearance of the person making the sound rather than with the sound itself.

The memory of topographical relations seems to be well developed in certain fishes as in certain insects. It is manifested most clearly in those forms which have a more or less fixed habitation or which build a nest for their eggs. A good illustration of this faculty is afforded by a species of Goby studied by Mlle. Goldsmith. This species, Gobius minutus, is commonly found in tide pools under a shell of some bivalve mollusc where it may lie half buried in the sand. That the fish recognizes its shell by sight is shown by the fact that when Mlle. Goldsmith drove a specimen from under its shell and placed the aquarium where it was kept in the dark the fish did not succeed in finding its shell during twenty-four hours: when light was admitted it discovered the shell at once. The experiment was repeated many times with different individuals, with the same result.

The ability of Gobius to learn a certain path to its shell is shown in the following experiment: A goby was placed in an aquarium divided in the middle by a glass plate which left a narrow passage way at one end. The shell of the goby was placed in one compartment $\mathrm{C}$ and the fish was driven through the passage way into the adjoining part of 
the aquarium. In its endeavors to reach its nest the goby swam against the glass partition ten times and then found the passage. It was then driven from its shell into the adjoining compartment again. It now rammed its head against the partition six times, then found the passage and entered its shell. In the next trial the fish made only three or four attempts to go through the glass plate, and after this it found the passage way at once. In a short time the fish had learned the way to its nest and thereafter followed it with little hesitation.

After this set of trials the goby, now left to itself, began to explore the aquarium of its own initiative, by making excursions farther and farther from the nest, keeping close to the outer wall and returning each time by the same route by which it set out. When it arrived at the partition it bumped against it, but after two or three trials it stopped a little short of the barrier and continued to do so in its subsequent excursions.

After the habit of avoiding the glass plate had become well established the plate was removed. The goby nevertheless continued to follow the old path in its journeys to and from the nest. Even when the fish had happened two or three times to cross the place where the partition had been, it still persisted in taking the old round-about course from one part of the aquarium to the other. Finally after the fish had crossed directly several times the old habit became gradually broken up and the fish paid no attention to the place where the partition had been located. In one interesting experiment Mlle. Goldsmith filled the shell of a goby with mastic and placed it in its old position. The goby came to its shell and endeavored to get under it, trying first its accustomed point of entrance, and then making attempts to dig under it in various other places. It dug 
each time in a new place as if bearing in mind its failures at other points. After a time the goby seemed to become discouraged and left the shell, but returned at times and resumed its attempts to enter. After an hour and a half the goby gave up its efforts entirely. The next day the mastic was removed and the shell placed in its original position. After several hours the goby had not entered the shell and swam by it for a long time without giving it the least attention. The shell was then removed to another part of the aquarium. As soon as the goby perceived the shell it quickly made for it and installed itself under it as if it had discovered a new shell instead of the old one. With the goby as with the mason bee, Chalcidoma, the place which a thing occupies is its chief recognition mark. The same shell in a new place was for the goby a new object, with promise of being a suitable domicile which, it had come to recognize, the shell in the old place was not.

In this connection the experiment of Lloyd Morgan on the behavior of a male stikleback is of interest. "A nest had been built on a round glass bell jar which stood near a window. Some aquatic vegetation grew in the tank, and the nest was built on the window side. An experiment was made by turning the large bell jar through a right angle. The male stickleback searched for its nest in the old direction on the window side, that is to say, the same position in reference to the incidence of the light. The search was, of course, fruitless, and a new nest was begun in this position. Presently the old nest was discovered, and was then vigorously destroyed in just the same way as the nest of a rival is pulled to pieces and scattered. Here a new incidence of light and new direction of shadows seemed to have completely transformed the visual situation."

The Amphibia, notwithstanding the fact that they have 
a cerebral cortex, which is lacking in the bony fishes, cannot be said to surpass the latter in the development of intelligence. The tailed amphibians are notoriously sluggish and give every appearance of extreme stupidity. Nevertheless they show a remarkably acute and delicate sensibility and a power of very rapid action on occasions which is belied by their general appearance and customary slow movements. Our knowledge of their intelligence is slight. Few have attempted to educate such apparently unpromising subjects and neither Brehm, Büchner nor Romanes gives any remarkable cases illustrative of their sagacity. Professor Whitman, in his interesting account of the behavior of Necturus, considers that this animal has a certain amount of intelligence which is involved in its learning by experience how to direct its movements, but he assumes nothing beyond this. Pieron has observed that if worms enclosed in a glass tube are introduced into an aquarium with specimens of Triton, the amphibians make a large number of attempts to seize the worms before showing any noticeable falling off in the number of their fruitless efforts; fish under similar circumstances learn to avoid the worms much more quickly. In another experiment a quadrangular flask containing several worms was placed on its side for a half hour a day in an aquarium, containing six tritons. Sometimes the animals found the entrance by chance and ate some of the worms. With the exception of one individual which seemed to learn the way fairly quickly there was no marked increase in the facility with which the tritons entered the flask. The experiment, while not thorough-going, indicates that associations in these animals are usually formed but slowly.

Among the Anura there have been several studies on the intelligence of frogs and toads. These animals are capable of forming simple associations, but their powers are very 


\section{INTELLIGENCE IN LOWER VERTEBRATES}

limited. Abbot placed a large fly on a piece of thin mica surrounded by needles so that the frog would be pricked in its efforts to seize it. This did not prevent the creature from snapping at the fly indefinitely. "In one instance the frog, which had been fasting for seventy-two hours, continued to snap at the needle protected fly until it had entirely skinned its upper jaw." This convinced Abbot that "the wits of a frog were too limited to be demonstrated." Knauer found that frogs would snap at worms on the other side of a glass plate and persist in doing so at intervals all day without learning that their attempts were futile.

On the other hand, several cases are recorded of frogs as well as toads being trained to come for food. Toads often occupy for a long time a particular retreat to which they return after making their nocturnal tours, thus showing that they have a memory for location. Yerkes in his studies of habit formation in frogs finds that frogs learn very slowly. In the experiments performed the frogs were placed in a long box furnished with a tank filled with water at one end and divided so that the frog would have to take a certain course from the point of entrance to get into the tank. The labyrinth employed was very simple, but it took from 50 to 100 trials for a frog to learn to avoid the closed passages and to reach the water by the most direct route. The associations once formed were found to persist for over a month.

Schaeffer's recent experiments on habit formation in frogs have shown that frogs may learn to avoid disagreeable objects after a very few trials. When offered hairy caterpillars the frogs would eagerly snap at them and then quickly eject them from the mouth. After from four to seven such experiences the frogs came to leave the caterpillars alone. 
In another set of experiments frogs were offered earthworms which had been dipped in chemicals. These worms were frequently snapped at and swallowed. The diet produced in some cases symptoms of uneasiness and some of the frogs would avoid eating earthworms for several days afterward, although they would partake freely of other kinds of food.

An apparatus was arranged so that the frogs would receive an electric shock every time they snapped at a worm. These frogs would avoid food altogether for a few days after the shock. "Whether an association was formed in this case, or whether the result is due simply to the persistance of the effect of the strong stimulus is uncertain. That the frogs learn to avoid certain kinds of food more quickly than they learn to follow a particular path may, as Schaeffer suggests, be due to the fact that the discrimination of food is so common an experience in the course of a frog's daily life. The greater severity of the penalty for error may be also a factor.

What has been written on intelligence of reptiles is for the most part in the form of scattered, casual observations. We have several records of the taming of different reptiles, of their following their keepers, their distinguishing between different persons, and their coming when called. Delboeuf kept two lizards in captivity and in time they became quite attached to their keeper. They would run to him from across the room when called and crawl upon his body in the hope of being fed. Each showed jealousy if any attention were paid to the other.

Gilbert White in his Natural History of Selbourne gives an account of a tortoise which distinguished between different persons and became much attached to an old lady so that "whenever the good old lady came in sight who had 
waited on it for more than thirty years, it always hobbled with awkward alacrity toward its benefactress, while to strangers it was altogether inattentive." Jesse writes of a young alligator which followed its master about the house like a dog, "scrambling up the stairs after him, and showing much affection and docility."

The formation of habits in turtles has been studied by Yerkes. A simple labyrinth was employed through which the turtle was left to find its way. Fifty trials were made, six or eight being given each day, and the time recorded which the turtle required to make its escape. The way was learned with a fair degree of rapidity, the time taken in successive trips being shortened rapidly at first and then more slowly.

In other experiments turtles learned not to fall off a board after a number of trials. More recently habit formation has been studied in the turtle Chrysemis by Casteel, who found that the animals learn to discriminate between colors and to distinguish different series of parallel lines of the same size, but with the lines of different width. Learning was slow, since on the average " 183 trials were necessary to establish discrimination." As in the frog what was acquired was not soon forgotten; one specimen showed "perfect memory" for a line pattern two weeks after it had been learned.

In general it may be said that the intelligence of reptiles is on a higher level than in fishes and amphibians. The subject is one upon which we have little well established information, and it affords an interesting field for future investigation.

\section{BIBLIOGRAPHY}

Bateson, W. On the Sense Organs and Perceptions of Fishes. Jour. Mar. Biol. Ass. United Kingdom, 1, 225, '87. 
Casteer, D. B. The Discriminative Ability of the Painted Turtle. Jour. An. Behavior, 1, 1, '11.

Delboeuf, J. Quelques Reflexions Generales à propos de la Psychologie des Lezards. Rev. Scient. 4, 805, '95.

Edinger, L. Haben die Fische ein Gedächtniss? Allg. Zeitung.

'99. (Trans. in Smithsonian Rep., '99, 375.)

Goldsmith, M. Récherches sur la Psychologie de quelques Poissons

Littoraux. Bull. Inst. Gén. Psych., Paris, 5, 51, '05.

Gurley, R. R. The Habits of Fishes. Am. Jour. Psych., 13, 408, '02.

Herrick, C. J. The Organ and Sense of Taste in Fishes. Bull. U. S. Fish Comm., 22, 237, '03.

Holmes, S. J. The Biology of the Frog, N. Y. '06.

Landors, H. Haben die Fische Gedächtniss? Zool. Garten, 38, 124, '97.

Lecaillon, A. Sur quelques Faits Relatifs à l'Ethologie et. la Psycho-Physiologie des Batraciens. Bull. Inst. Gén. Psych., 8,142 , '08.

Mбвго, K. Die Bewegung der Thiere und ihr psychischer Horizont. Schrift. d. naturwiss. Ver. f. Schleswig-Holstein, 1, 113, '73.

Reighard, J. An Experimental Field-study of Warning Coloration in Coral-reef Fishes. Carnegie Inst. Pubs. 103, '09.

Schaeffer, A. A. Habit Formation in Frogs. Jour. An. Behavior, 1,309 , '11.

Thorndike, E. L. A Note on the Psychology of Fishes, Am. Nat., $33,923, ' 99$.

Triplett, N. B. The Educability of the Perch. Am. Jour. Psych., $12,354, ' 01$.

Washbern, M. F. and Bentley, I. M. The Establishment of an Association Involving Color Discrimination in the Creek Chub, Semotilus atromaculatus. Jour. Comp. Neur. Psych., 16, 113, '06. Yerkes, R. M. The Instincts, Habits and Reactions of the Frog. I. Associative Processes of the Green Frog. Harvard Psych. Studies, 1, 579, '03.

Space Perceptions in Tortoises. Jour. Comp. Neur. Psych., $14,17,{ }^{\prime} 04$. 


\section{CHAPTER XII}

\section{THE INTELLIGENCE OF MAMMALS}

"Le première partie de cet ouvrage démontre que les bêtes sont capable de quelques connoissances. Ce sentiment est celui du vulgaire: il n'est combattu que par des philosophes, c'est à dire, par des hommes qui d'ordinaire aiment mieux une absurdité qu'ils imaginent, qu'une "vérité qui tout le monde adopt."-Condrllac, Traité des Animaux.

"The power of association over brutes is very evident in all the tricks which they are taught; and the whole nature of each brute, which has been brought up among others of the same species, is a compound of instinct, his own observations and experiences, and imitation of those of his own species."-HARTLEY, Observations on Man.

"Animals pass from one imagination to another by the connection which they have felt before; for example, when his master takes a stick, the dog fears a whipping. And in many instances children with the rest of mankind proceed nowise differently in their passages from thought to thought."-Leibnitz, New Essays Concerning Human Understanding.

Until quite recently most of our knowledge of the psychology of mammals, as of other animals, was obtained simply by watching them. In this way has been accumulated a large fund of information concerning their instincts and habits, and to a certain extent their general intelligence. But in this as in other fields of investigation, the method of experiment has come to be indispensable when the attempt is made to study the phenomena analytically. There is of course no especial magic in the experimental method; it is simply a means of improving the conditions of observation. And in animal psychology especially, the method may have drawbacks which counterbalance some of its advantages. 
The labyrinth and puzzle box devices of our psychological laboratories have the advantage of enabling us to study animal behavior under strictly controlled conditions, and they readily yield results in a form capable of easy tabulation, but they have been criticized with a certain measure of justice on the ground that the artificial conditions to which the animals are exposed make them appear more stupid than they really are. A fox in its wary prowlings for prey or in its attempts to outwit its pursuers may manifest a considerably higher degree of intelligence than it would show if confined to a box from which it had to liberate itself by raising levers and pulling bolts. In wild animals especially there is a falling off of spirit and initiative when they are placed in an artificial environment. The lion of the desert is a very different creature from the lion of the circus; the keenness and alertness with which the one conducts his hunt for prey, stand in marked contrast with the melancholy and reluctant performances of the other when under the trainer's whip; Other animals such as raccoons and some monkeys take to a life of confinement much more readily, and therefore afford particularly valuable subjects for experiment. Those experiments are of the most value which stimulate to the greatest extent the free exercise of an animal's faculties, and in order to secure this result an animal's instinctive interests and promptings should be given, so far as possible, free play.

The experiments of the last few years have given us a more just estimate of the nature and limitations of the intelligence of the higher animals than we formerly possessed. Animal psychologists have come to scrutinize their results much more closely and to be much more cautious in their statements regarding what goes on in the mind of the animal studied. The interpretation of what mental processes are 
involved in most animal performances is a matter of much difficulty. We may be guided on the one hand by analogy with ourselves, which leads us to infer that actions similar to our own are accompanied by similar mental states; and by the law of parsimony on the other, which forbids us to assume the existence of higher mental qualities if the phenomena can be explained in terms of simpler mental processes. In the imperfect state of our knowledge these two guides often lead to opposed conclusions. If we applied the principle of Morgan to the psychology of our fellow human beings we should be continually led astray. So in our interpretations of the psychology of the higher animals we may very frequently be "missing it" more or less widely in our adherence to this principle. The antecedent probability in favor of not giving the animal the benefit of the doubt diminishes as we ascend the scale of psychic life. We may suspect that our interpretations "fall short," but our opinions cannot be said to rest on a secure basis until we are able to support them by experimental proof. The principle of Morgan affords a check to the natural tendency to "anthropomorphism" which is a common human failing; it throws the burden of proof on whomsoever attempts to establish the existence in animals of higher faculties, and if the positive conclusions to which it permits us to come fall short of the truth we can at least rely on them so far as they go.

As a typical instance of the workings of the animal mind we may cite the performances of Professor Lloyd Morgan's dog, Toby, which had learned how to open a gate that led out of his master's yard. The gate was fastened by a latch, but swung open by itself if the latch was raised. Whenever the dog desired to make his escape he put his head between the bars, lifted the latch and went out. Such an act might 
of course have been the result of the dog's studying the hinges, latch and general make-up of the gate, and concluding that if the latch were raised the gate would be free to swing open. Such a course would be a very natural one for a human being, but few would consider that a dog would be likely to follow it. The dog might, however, learn to open the gate by watching someone do it and then imitating him. In this case the dog might be thought to conclude that "since a man lifted the latch and went out, therefore, I can lift the latch and go out." As a matter of fact the dog learned to make his escape in neither of these ways. His method of learning the trick which was watched from the beginning was as follows: Being placed in the yard from which he was anxious to escape Toby poked his head between the bars of the fence in various places and by chance placed it under the latch and raised it, when the gate swung open and he scampered out on the street. The method pursued was one of trial and error. The fortunate movement which effected the dog's liberation was associated with the perception of the latch, but the association was not perfect at first. Only after ten or twelve experiences, in which the number of times the dog poked his nose through wrong places gradually diminished, did he learn to go directly to the right place, and raise the latch.

The experiments of Thorndike have convinced him that the intelligence of animals is limited to the type that we have just considered. He holds that animals do not draw inferences and that, barring the apes, it is doubtful if they have ideas. Thorndike's experiments were among the first systematic attempts to get at the nature and limitation of animal intelligence by means of experimental methods. Through his pronounced spirit of iconoclasm toward anecdotal psychology and anthropomorphism Thorndike was 
led to adopt an extreme position which has not been justified by future experiments and which was not consistent with many of his own results. Though extreme, the reaction against the method of writers who based their deductions concerning animal intelligence on stories and casual observations was none the less wholesome, as it succeeded in stimulating the study of animal intelligence by more careful and critical methods than those formerly employed.

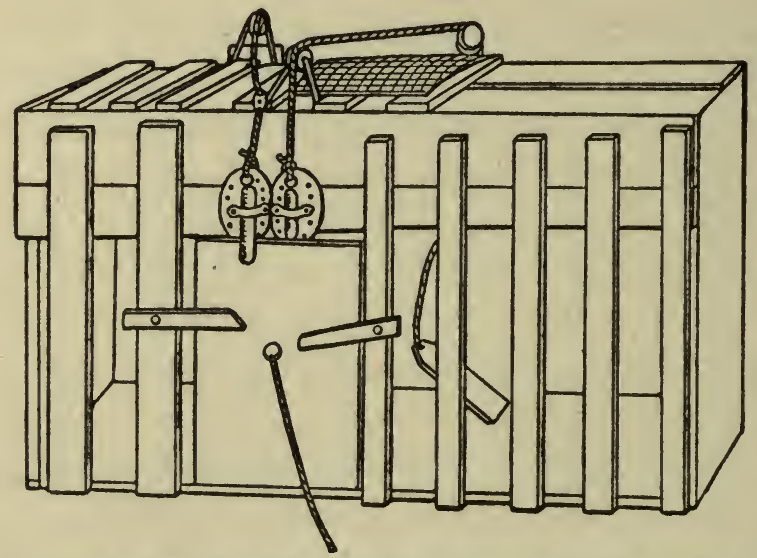

Fra. 15.-Puzzle box used in the experiments of Thorndike on cats. (After Thorndike.)

In most of Thorndike's experiments boxes were employed from which animals could escape by raising a lever, pulling a cord, or by some such simple device. In some cases various combinations of these devices were used. A hungry cat or dog was confined in the box and food was placed on the outside so that it could be seen. The animal in its efforts to get out and obtain the food would usually begin by biting and clawing the bars of the box. Sooner or later a lucky movement would raise a lever or pull a cord so that the door of the box would open and allow the animal to get the food. After this the animal would be put into the box 
a second time, when it usually recommenced its bitings and clawings, but it generally effected its escape more quickly than at first. The experiment was then repeated until the animal had perfectly mastered the means of escape. The time taken to escape was recorded and was found to diminish, as a rule, with successive trials.

In one set of experiments a cat was liberated from the box whenever she licked herself, and in another set whenever she scratched herself. Although there could be no perceptible relation between the means employed and the end achieved, the cats learned to make the appropriate movement after being put in the box, although their association curves showed a gradual descent. There is a curious tendency for the act to be performed less and less vigorously. "The licking degenerates into a mere quick turn of the head with one or two motions up and down with tongue extended. Instead of a hearty scratch, the cat waves its paw up and down rapidly for an instant."

Previous experience is a factor which influences the quickness of forming associations. "After getting out of six or eight boxes by different sorts of acts the cat's general tendency to claw at loose objects within the box is strengthened and its tendency to squeeze through holes and bite bars is weakened; accordingly it will learn associations along the general line of the old much more quickly. Further, its tendency to pay attention to what it is doing gets strengthened, and this is something which may properly be called a change in degree of intelligence." None of the acts performed by cats and dogs in his numerous experiments exhibits, according to Thorndike, any power of reasoning and usually no association of ideas. A point upon which Thorndike lays especial stress is the gradual descent of the curves representing the times required in forming the asso- 
ciation. If there were any element of inference involved there ought to be, according to him, a sudden vertical descent of the time curve. "Where the act resulting from the impulse is very simple, very obvious, and very clearly defined, a simple experience may make the association perfect, and we may have an abrupt descent in the time curve without needing to suppose inference. But if in a complex act, a series of acts or an ill-defined act one found a sudden consummation in the associative process, one might very well claim that reason was at work. Now, the scores of cases recorded show no such phenomena. The cat does not look over the situation, much less think it over, and then decide what to do. It bursts out at once into the activities which instinct and experience have settled on as suitable reactions to the situation, 'confinement when hungry with food outside.' It does not ever in the course of its successes realize that such an act brings food and therefore decide to do it and thenceforth do it immediately from decision instead of from impulse. The one impulse, out of many accidental ones, which leads to pleasure, becomes strengthened and stamped in thereby, and more and more firmly associated with the sense-impression of that box's interior. Accordingly it is sooner and sooner fulfilled. Futile impulses are gradually stamped out. The gradual slope of the time curve, then, shows the absence of reasoning. They represent the wearing smooth of a path in the brain, not the decisions of a rational consciousness."

Even ideas are unnecessary, according to Thorndike, to account for most feats of animal intelligence. The cat, which after having made a lucky movement and escaped from the box and got some fish, might be supposed to associate the appearance of the mechanism of escape with the idea of the pleasure resulting from eating the food. But, 
according to Thorndike, the learning of the cat may be accounted for more simply. The sight of the means of escape in the box, instead of calling up the idea of the previously experienced good taste of the fish, has become associated simply with the movement necessary to effect an escape. The consciousness involved in the acts consists therefore of immediate sense impressions and the impulses to action with which they have been associated; the animals "have no images or memories at all, no ideas to associate."

The learning of the animal, according to this view, is on a level with the semi-conscious perfection of many of our own activities, such as catching a ball and playing tennis, where certain perceptions come to call forth very quickly the appropriate motor response without the intervention of ideas. We do not reason about our movements in such cases but the right ones come to be performed as the result of stamping in the movements that brought success. Few of us have paid particular attention to the movements of the tongue in chewing food, but a little observation directed to the subject cannot fail to impress one with the deftness with which this member, otherwise so unruly, avoids being bitten, and with the efficient way in which it helps to masticate the food. The tongue probably performs many of its movements instinctively, but it has doubtless learned a good deal by experience, without being consciously directed.

Thorndike's theory of the nature of animal intelligence has the principle of parsimony in its favor, but its author has endeavored to give it further support by a number of experiments designed to test the presence of ideas in the animal's mind. One of these was as follows: A cat was made to go through a door into a box where she was shut in. By pulling a loop the cat gets out and eats fish. After being put in through the door a number of times and fed when- 
ever she made her escape, the cat came to enter the box of her own accord. Does she associate the idea of being in with the idea of eating fish and enter accordingly? Thorndike endeavored to answer this question by dropping cats into the box through a door in the top, and then feeding them as before when they got out. The cats had the same opportunity of associating the idea of being in the box with the idea of eating fish, but the element lacking was the impulse to walk in through the door. All of these cats, three in number, failed to enter the box after fifty, sixty and seventy-five trials respectively. "Either a cat cannot connect ideas, representations, at all," says Thorndike, "or she has not the power of progressing from the thought of being in to the act of going in. ... The impulse is the sine qua non of the association. The second cat has everything else, but cannot supply that."

In several other experiments cats and dogs were placed in a box, and the experimenter would take the paw of the animal and make the movement necessary to open the box, after which the animal would be allowed to go out and get food. This was repeated ten or fifteen times and then the animal was left to its own devices. After numerous experiments of this sort with various kinds of boxes it was found that the animals uniformly failed to profit by this mode of instruction. None of the animals which failed to get out of a box of their own accord succeeded in escaping after having been several times put through the necessary movements. They had the opportunity to associate the idea of certain movements with escaping and getting food, at least provided they paid attention to what was being done with them. But the animal's own impulse to do the act was lacking. "The animal cannot form an association leading to an act unless the particular impulse to that act 
is present as an element of the association; he cannot supply it from a general stock. The groundwork of animal associations is not the association of ideas, but the association of idea or sense-impression with impulse."

Notwithstanding his general attitude of opposition to the, doctrine of association of ideas in animals, Thorndike records a few experiments which led him to the conclusion that in certain cases such associations may occur. In one case a hungry cat was placed in a box and the experimenter sat about eight feet away from it. At intervals of about two minutes he would say, "I must feed those cats." Ten seconds afterward he would take a piece of fish, go to the box and hold it so that the cat was compelled to climb up the front of the box to obtain it. Would the cat after a number of trials come to associate (A) the sound of the words with (B) the sense impression of the experimenter's movements in taking the fish and walking to the box, and climb up (C) before it had experienced the second term (B) of the association? If so Thorndike concludes that the action of the cat "is to be explained by the presence through association, of the idea (B)." The possibility is left open "that (A) was associated directly with the impulse to (C), although that impulse was removed from it by ten seconds of time." But Thorndike thinks this is "highly improbable, unless the neurosis of (A), and with it the psychosis, continues until the impulse to (C) appears. But if it does so continue during the ten seconds, and thus get directly linked to (C), we have exactly a representation, an image, a memory in the mind for eight or ten seconds." Leaving out of question the existence of an idea of (A), during the interval, why should we say that it is "highly improbable" that (A) should become directly linked with (C)? The implication of the argument is that the time separating the two 
events is too great. But if (A) can be associated with (B) over an interval of ten seconds why can it not be directly associated with the impulse (C) over an interval but slightly greater? Ten seconds after (A) the cat sees (B), eleven seconds after she performs (C). That the cat had previously associated (B) and (C) does not necessarily play any part in the process. The experiment proves only that some sort of a neurosis persists from (A) during ten or more seconds of time; but it fails to afford any proof of the rôle of the idea (B) in the process. It shows the persistence of impressions, not the association of ideas. Indirectly it may support the theory of association. If the neurosis of (A) persists and is accompanied by consciousness in the form of an idea of (A), ideas of (B) probably occur also, and if ideas occur why may they not become associated as well as impressions and impulses? Such ideas may be more like after-images in ourselves, but no sharp line can be drawn between the latter and ideas properly so called. While such an experiment as the one described may not prove the association of ideas it may serve to make association more probable by showing the persistence of impressions.

The experiments of $\mathrm{L}$. W. Cole on the raccoon yielded better evidence of the existence of ideas than the investigations of Thorndike, owing perhaps to the greater degree of intelligence of the animals employed. Raccoons learned to get out of a box with seven fastenings consisting of two buttons, two loops, a thumb latch, a treadle and a hook. They were first put into boxes with one or two of these devices, and when these were learned others were added until the above combination was reached, which seemed to be about the limit of a raccoon's learning capacity. The raccoons in attacking the fastenings did not take them up in any constant order in successive trials, but they showed a 
good memory for any combination they may have learned. Three raccoons which had learned to open the box with seven fastenings were put into the box again after an interval of 147 days. Only one individual succeeded in undoing all of the seven fastenings and escaping. His times in four successive trials were $34,28,131$, and 182 seconds. The other two worked most of the fastenings, but generally failed to undo a horizontal lock. Davis found that raccoons remembered how to undo the fastenings of a puzzle box for over a year.

One significant feature of the raccoons' method of attack on their problems is that they employ different means of accomplishing the same result. They worked fastenings with either the right or the left paw or with both together. "All of the raccoons turned a button once or twice with the nose in early trials, then settled down to working it with the paw." This looks very much as if there were something besides the sensori-motor associations assumed by Thorndike. We cannot say that there is nothing but the association of the sight of a certain object with a particular impulse to movement, if in effecting a certain change an entirely different organ is substituted for the one previously employed. When an animal moves with its paw a fastening it formerly moved with its nose it gives evidence of being guided by an idea of what it is setting out to accomplish.

Evidence for the existence of ideas was derived also from other sources. It was found that raccoons were able to associate being in a box with getting food after they came out, so that when they were dropped in, as in the experiment with the cats, they came after a while to go into the box of their own accord. The motor impulse to enter the box was not in these cases an element in the association 
that was formed. Apparently the thought of being in the box made the raccoons go in.

Cole found that the raccoons were aided in learning the mechanism of escape from the box if they were put through the appropriate movements. Not only was the average time required for such animals to escape from the box shortened as compared with the time required by the individuals which were unaided, but several animals which failed entirely to make their escape succeeded in getting out after having been several times put through the act. This result may be indicative of the existence of ideas, but not entirely conclusive, as it might be explained possibly as the result of the animal's attention having been limited to a certain part of the box. This might direct his efforts toward the spot where he would be more likely to hit upon the fortunate movement. Raccoons which had come to climb upon a box and enter through a hole in the top after having several times dropped through the hole would dodge in through the door if it were left open after their exit. As in the cases where the raccoons learned to escape by themselves, they used different paws to undo various fastenings, although one fore paw was almost always used when the experimenter guided their actions. Whether or not the raccoon repeats the action he is put through depends much upon his convenience. If it is the easiest way he will continue as he was taught; if not he is apt to substitute some other method.

If a raccoon has learned to undo a latch, turn a button, or pull a loop, he attacks the same object when it is placed in a different part of the enclosure. Davis, however, attained a different result with some of his raccoons, which would often spend considerable time in vain clawing about where the fastening had been placed. Probably these different results depend upon differences in the previous experiences 
of the animals, or their differences in temperament and general intelligence, which Davis finds are very marked. In one case a loop was left lying upon the top of the box. When seen by the raccoon it was clawed back into the box and then pulled. Is this merely the blind association of perception with motor impulse? I think not.

Cole found that if food was put in a box and the place where the raccoon had formed the habit of entering was closed, the animal would attempt to enter the box at other places. In one experiment a tight box was used with a hole through the top. After the raccoon had entered through the hole and obtained food a number of times the hole was closed and an opening made under one side of the box. At first the animal attempted to enter in the usual way, but finding his passage barred soon left it; after a second attempt he discovered the side opening, entered and secured the food. The side opening was then closed and a wire cylinder eighteen inches high placed on end over the original opening at the top of the box. Thirty seconds after the raccoon was released he had climbed up the outside and down the inside of the cylinder and entered the hole. The piece of apple in the box could not be seen, nor smelled, according to Cole, for "the room was full of the odor of apple." The animal apparently retained an image of the apple in the box and realized that if he could not reach it in one way he might in another.

Such behavior, in which an animal's activity seems to be directed to achieving a certain end, is not uncommon. A case described by Hobhouse is suggestive. A dog was held at the back of a house with which he was unfamiliar and saw his master enter by the back door and appear at a window in the same side of the house. "After trying to follow his master through the back- unsuccessfully, because 
the door is shut- he makes off round two corners to the front door, and so into the dining-room. He had never been in this room before, but has once been from the back into the house by the front door. The experiment is once repeated, and the dog remembers this route five days later. On arriving at the house on this occasion, he is taken through a side door into the dining-room, and then out at the back. $\mathrm{He}$ first finds his way in through the front as mentioned, and then for a further trial both front and back door are shut. The dog goes to and fro from one door to the other, and then suddenly goes right off around the house, and in by the side door - a route which he had never taken before. There may have been an element of chance in this success, but, on the whole we seem to have a series of acts dictated by the desire to find the master operating on the remembrance of the modes of entrance."

The ability of animals such as horses to find their way back for miles over a road which they have only followed once is indicative of something more than mere sensorimotor association. I well remember a horse we once owned whose memory for the proper turns in the road he had taken in going away from home I had often tested and found to be almost infallible. Like many other horses he was a much more willing traveller when homeward bound, but whether he was influenced by an idea of hay and oats and rest to be enjoyed at the end of his journey it might be hazardous to say. If the homing of the animal were due to a blind sensori-motor association, we should have to assume that the sight of particular objects along his course came to be associated with particular movements; object A, for instance, with a slight turn to the right, and object $B$ with a slight turn to the left, and so on. If the animal passed over the road again in the same direction we might 
suppose that these various objects, by association, called forth muscular impulses similar to those originally given, thereby causing the animal to keep the same path as before. But on the return the objects are not only met with in a different order, the visual fields of the animal present in many respects a quite different aspect, and the muscular impulses given at the various turns are just the reverse of those given as various landmarks were encountered during the outgoing journey. Must we not assume that in the animal's mind, as in our own, there is a consciousness of the general space relation of objects seen along the journey and the animal's own changes of position in relation to those objects? Does not the horse feel that he is going away farther and farther from his barn, although the latter cannot be seen, and does he not in some way keep the general topographical situation in mind amid all the panoramic scene-shiftings in his field of vision? If the horse does not have clearly defined ideas he seems to possess some consciousness of unperceived objects and their relation to present ones. Horses and other animals commonly find their way home over routes very different from the ones on which they set out, even in places, such as woods, where they cannot perceive the general landscape. We may say of course that the animal is guided by a "sense of direction," but if we ascribe this faculty to the animal in any but a mystical sense, we can scarcely escape assuming that there is something that fulfils the function of a representative consciousness of the absent elements of the situation. The animal which makes for home by a new route cannot be said to be guided by sensori-motor impulses in relation to certain trees or rocks, because these objects have not been associated with any impulses in the animal's experience. If we examine our own mental experience in such a situation it 
will be evident that we have a consciousness of an outlying region beyond our immediate sphere of perception which stands in a definite relation to the latter, and that the object of our search lies in a certain direction. When the perceptual and the ideal content of our minds get disjoined we have the horrible consciousness of being lost. If the ideal content were absent and we had nothing to depend upon but a store of sensori-motor associations would we be able to get back to our starting place? I think not. And without this content I fancy the horse would be as helpless as ourselves.

Whether animals draw inferences of a simple sort is a subject we shall dwell upon further in the chapter on the mental life of apes and monkeys. It is not at all likely that animals have any power of abstract or conceptual reasoning; as Morgan remarks they probably "do not think the therefore," but mental action essentially inferential in character may not involve any processes of a complicated kind. As Binet has attempted to make clear in his work on the Psychology of Reasoning, there is a fundamental similarity between reason and simple perception. The shape and color of an orange recall the sensations of odor, taste, touch and muscular movements which we have experienced in connection with such visual impressions in the past. These various states are combined in a percept which seems to us a simple object. The visual impression has assimilated various other attributes, and we therefore tend to act differently toward such appearances on the basis of this association. The sweet taste may cause us to reach out for the orange and we might justify our procedure by a process of reasoning about the relation of the various attributes of the object. But we certainly do not do so before the sweetness of the orange is borne in upon us. 
The sweetness occurs to us very quickly and directly, and with it, if we are hungry, the impulse to seize, and eat the orange. In this, as in most affairs of life, we arrive at the conclusion first and reason about it afterward. Our conscious reasoning is a process of reviewing and verification which can usually be dispensed with, rather than one of discovery. The animal that reaches for an object which it has learned is good to eat gets along without the retrospective review. He may go through with mental processes of various degrees of complexity. The visual sensation may call up directly the impulse to seize and eat the orange. It may call up along with the latter the taste and other attributes of the orange. It may call up the taste and other attributes which in turn arouse the impulses to seize and eat. The various mental steps may be present in different degrees of vividness. The relation of different states may be attended to; the animal may finally come to "think the therefore," and so on.

"Inference," says Hobhouse, "is one function, from the simplest case quoted by Mr. Morgan of the chick, up to the highest elaboration of experience by the human intellect. The differences are differences in articulateness on the one side, and comprehensiveness on the other." There is good reason to believe that animals profit by the association of ideas, and that they do certain acts, not for their own sake, but as a means to an ulterior end which is kept in mind. If we do not choose to designate the mental operations involved in such behavior by the term reason we must at least admit that they are on the road to it.

How far along animals like dogs, raccoons and elephants may be on the highway toward reason properly so-called it is impossible at present to state. I have read critically a good many stories of animal intelligence which have left 
in my mind a general conviction that animals are capable of drawing simple conclusions, but there are alternate possibilities of interpretation in many cases, and incompleteness of data in so many others that I am unable to present any number of instances in which inference of a very articulate kind is indubitably shown. The subject is one on which we need more experiments performed by investigators acquainted with the animal's previous history and keenly alive to the various possible psychological interpretations which may be put upon an animal's behavior. The difficulties and pitfalls of the subject are far beyond the realization of most of the contributors to our data on comparative psychology. There is a large amount of material too carefully recorded to be cavalierly rejected as worthless, but too incomplete to be accepted as entirely conclusive on the subject of animal inference; it will doubtless prove of great value in suggesting lines for future work.

A case in point is the following account of two dogs, contributed by Mr. Stone to Romanes' "Animal Intelligence." "One of them, the larger, had a bone, and when he had left it the smaller dog went to take it, the larger one growled, and the other retired to a corner. Shortly afterward the larger dog went out, but the other did not appear to notice this, and at any rate did not move. A few minutes later the large dog was heard to bark out of doors; the little dog then, without a moment's hesitation, went straight to the bone and took it. It thus appears evident that she reasoned-'That dog is barking out of doors, therefore he is not in this room, therefore it is safe for me to take the bone.' The action was so rapid as to be clearly a consequence of the other dog's barking."

The behavior described will not appear to anyone familiar with dogs as anything improbable. The doubtful feature 
is the syllogism in the dog's mind. The dog probably did not reason the matter out in the explicit fashion indicated by the words employed by Mr. Stone, and perhaps the writer would not insist that he did. The bark may have made the small dog aware that the large dog was out of the room and that it was safe for him to seize the bone. He may not have thought that therefore he could safely seize the bone, but the large dog being away the small one just went after the bone because he was no longer restrained. It is possible, though less likely, that the bark simply served to direct the attention of the small dog from whatever object it was bestowed upon, and that it was then directed to the bone which was seized because the large dog was out of the way. Or it may be that when the small dog betook himself to the corner he fell half asleep and was brought to himself by the bark of the other dog. How varied are the interpretations that can be made of the contents of the dog's mind! We may feel convinced from our general knowledge of dog behavior and the special circumstances of the case that there was something in the small dog's mind corresponding to "large dog outside, I can now get the bone;" but our conviction does not constitute proof. And so it goes with story after story.

While the proof of the existence of explicit inference may be difficult though by no means impossible, there is a singular lack of conclusiveness in the arguments sometimes employed to prove its absence. It is argued by Thorndike that the gradual descent of the time curves of learning in his experiments showed the absence of reasoning. But when we examine these curves it becomes apparent that their shape, in a considerable proportion of cases, is far from gradual, as in most of the figures on pp. 18, 20 and 24. Small finds in the curves of learning of the rat that there is, as a rule, a 
marked drop after the first success, and a similar phenomenon is remarked by Hobhouse. Still less indicative of the gradual stamping in process are the results of the experiments of Davis and L. W. Cole on the raccoon. Davis found that the time curves of two children in learning the fastenings of a box were very similar to those of the raccoon, and Lindley in his Study of Puzzles obtains very similar results with young children.

When Thorndike speaks of reasoning he evidently has in mind a fairly typical process of ratiocination, and not the simple process of the inferential type described above, which we should most naturally expect in the animal mind. A man would find his way out of a puzzle box after once discovering the proper method, but granting that a cat has a certain power of inference it would not be surprising that, with her hazy consciousness of the situation, feeble and fluctuating attention and indefinite memory of just what she did before, several trials would be required to enable her to solve her problem. It is quite easy to convict a cat of stupidity by showing that she cannot reason in human fashion. Whether she is capable of mental action of a primitive inferential type is a quite different question.

We are apt to overestimate the importance of the ability to reason as if it were the chief thing of value in intelligent behavior. There are other mental traits which may enable an animal to get what it wants better than an increment of reasoning power. General activity, power of attention, interest, quickness of forming associations, delicacy of discrimination, duration of memory and the ability to form complex associations are all of the utmost importance in many situations in an animal's life. We frequently meet people who, when they are compelled to exercise their reasoning powers, act as if the effort were a painful one and as if 
they were groping in a sort of intellectual fog. We are often amazed at the obvious fallacies they fall into, like Mrs. Eddy's famous method of proving propositions by inversion; but the same people may exhibit an unusual degree of keenness and practical sense in the ordinary affairs of life. In animals these intellectual faculties of a lower order are developed in different ways according to the habits of the species. Give a fox greater power of inferential thinking, but decrease his alertness, curiosity, suspiciousness, and quickness of perception, and he might fall a victim to the hunter while his mind was occupied on some other subject. In the development of these various intellectual qualities there has been an enormous progress from the stupid marsupials to the apes and monkeys, during which the foundations for the superstructure of reason were broadly laid. Just as the various non-intelligent modifications of behavior facilitate the development of intelligence, so do the diverse manifestations of intelligence prepare the way for the advent of reason.

The question as to whether animals imitate acts from which they see that other animals derive an advantage has an important bearing on our views of their psychic development. The word imitation is employed in a very wide sense by some writers such as Tarde and Baldwin, but it is more commonly used to designate the performance of an act after perceiving the act performed by another creature. In imitation of this type we usually distinguish two kinds, the instinctive, and the reflective or rational. In the first the perception of another animal performing an act forms the stimulus which sets off an innate tendency to perform a similar act. In fishes which run in schools the turning about of one individual may cause all the others to turn; each individual has an innate proclivity to follow the 
movements of the others, and by virtue of this trait the fishes keep together and escape common dangers. A similar kind of imitation is met with even in insects. Ants, according to Wasmann, not infrequently imitate one another's acts, and other observers have remarked upon the same proclivity in bees and termites.

Imitation plays an especially important rôle in the life of birds. According to Lloyd Morgan, "If one of a group of chicks learn by casual experience to drink from a tin of of water, others will run and peck at the water, and thus learn to drink. A hen teaches her little ones to pick up grain and other food by pecking on the ground and dropping suitable materials before them, while they seemingly imitate her action in seizing the grain. One may make chicks and pheasants peck by simulating the action of a hen with a pencil point or pair of fine forceps. According to Mr. Peal the Assamese find that the young jungle pheasants will perish if their pecking responses are not thus artifically stimulated; and Professor Claypole tells me that this is also the case with young ostriches hatched in an incubator." Chicks avoid objects which they perceive arouse alarm in others, and if they see other chicks pecking at things of which they stand a little in awe they frequently muster up courage and follow their companions.

Birds learn to fear certain enemies, such as hawks, at least in part, through their instinctive response to the signs of alarm in other birds. Their instinct of following guides them in their migration routes, in which, despite the contention of Herr Gätke, their course is in all probability a matter of tradition.

In contrast to the above cases which may be regarded as instinctive responses to particular stimuli are those instances in which an animal more or less deliberately copies the actions 
of another with the end of securing some advantage which the other animal enjoys. Imitation of this character involves a species of inference, and its occurrence in animals is less widespread than was commonly supposed some years ago. Thorndike tested cats and dogs with the view of ascertaining if they could learn to get out of a puzzle box by seeing other cats and dogs get out. After witnessing a number of times the successful exits of the animals which had learned the means of escape these cats and dogs were unable to get out by themselves any more quickly than other individuals which had not the advantage of seeing how the escape was effected. In all the experiments performed the animals did not show the least tendency to imitate the performanees of their successful comrades. The experiments of Cole and Davis on the raccoon yielded similar negative results.

Small, in his studies on the white rat, finds evidence of a very simple kind of imitation, but no clear cases of imitation of the inferential type. When one rat sees another digging it is apt to dig also, and when one runs over a box it is apt to be followed by others. Berry, who has made a more thorough study of imitation in the white rat, found better evidence of intelligent imitation. "When two rats were put into the box together, one rat being trained to get out of the box and the other untrained, at first they were indifferent to each other's presence, but as the untrained rat observed that the other one was able to get out while he was not, a gradual change took place. The untrained rat began to watch the other closely; he followed him all about the cage, standing up on his hind legs beside him at the string, and pulling it after he had pulled it, etc. We also saw that when he was put back the immediate vicinity of the loop was the point of greatest interest for him, and that he tried 
to get out by working at the spot where he had seen the trained rat try."

It is a significant fact that the untrained rat manifested little interest in the actions of the trained one until he found the latter could make his escape from the cage. If a new rat were put in the cage the untrained rat would follow him also, but if the new rat did not get out his companion would soon cease to follow and imitate him. It is impossible to regard such imitation as this as a series of congenital responses to the perception of particular movements. The rat imitates with the aim of getting out of the cage and apparently recognizes in the movements of his companion the means of deliverance. Further evidence of intelligent imitation is furnished by Berry's work on imitation in cats.

The experiments of Hobhouse yielded many indications of imitation of the inferential type, although most of them leave something to be desired in the way of conclusiveness. Hutchinson in his valuable book on Dog Breaking says that dogs may be taught tricks much more readily if they see other dogs perform the tricks and obtain a reward for it.

A general consideration of the literature on imitation in animals justifies us, I think, in concluding that a certain amount of intelligent imitation occurs in animals below the monkeys, but it must be admitted that there is but a small amount of reliable data upon which to base an opinion.

We have spoken of instinctive and intelligent imitation as if they constituted two discrete classes of behavior. It is important, I believe, in studying this subject to recognize the kinship and transitional stages between these two kinds of imitative activity. Animals tend to imitate those acts 
which are most closely related to their own instinctive movements. There may be no awareness of any advantage to be gained thereby, as in the familiar imitation of sounds by birds. Magpies, ravens, mocking-birds and especially parrots attempt to repeat various sounds which they are accustomed to hear. Their efforts, imperfect at first, improve with repetition. Making a sound like one which is heard seems for some reason to afford these birds an agreeable experience. As Baldwin would say, hearing the sound is followed by an effort to "reinstate the stimulus" and so gives rise to a "circular reaction." Variations of its own notes which approach the sounds heard become "stamped in," and the bird gradually comes to imitate the sounds more closely, much as we gradually improve upon the accuracy of our own movements in playing ball or tennis. In this imitation we need suppose no element of transferred association. Based perhaps upon a primary instinct to utter notes in response to the notes which it hears, which we often find in young birds, the tendency of birds to imitate sounds involves but the rudimentary form of intelligence required for the formation of simple associations.

There is comparatively little imitation which is based on a cold calculation of the advantages derived from copying another animal. The imitation which is shown in a certain stage of the life of the child is intimately related to a certain satisfaction derived from attaining conformity to copy. This trait the child has in common with the bird. Probably our own unconscious or half conscious imitation of the pronunciation and mannerisms of the people we live with is a phenomenon of a similar kind. How far this kind of imitation occurs in the mammals has not been clearly brought out, but there are many indications of its influence in several of our common domesticated species. 


\section{BIBLIOGRAPHY}

Allen, J. The Associative Processes of the Guinea Pig. Jour. Comp. Neur. Psych., 14, 293, '04.

Ament, W. Ein Fall von Ueberlegung beim Hund. Arch. ges. Psych., 6, 249, '05.

Berry, C. S. The Imitative Tendencies of White Rats. Jour. Comp. Neur. Psych., 16, 333, '06.

An Experimental Study of Imitation in Cats, 1. c. 18, 1, '08. Bostok, F. The Training of Wild Animals, N. Y., '03.

Burroughs, J. Do Animals Think? Harpers Mon., 110, 354, '05. Carr, H. and Watson, J. B. Orientation in the White Rat. Jour. Comp. Neur. Psych. 18, 27, '08.

Censaresco, E. M. The Psychology and Training of the Horse, London, '06.

CoLe, L. W. Concerning the Intelligence of Raccoons. Jour. Comp. Neur. Psych., 17, 211, '07.

Davis, H. B. The Raccoon: A Study in Animal Intelligence. Am. Jour. Psych., 18, 479, '07.

Freund, F. Der "kluge" Hans. Ein Beitrag zur Aufklärung. Berlin, 04.

Hachet-Souplet, W. Examen Psychologique des Animaux. Paris, '00.

Hовноuse, L. T. Mind in Evolution. London, '01.

Hutchinson, W. N. Dog Breaking, 6th. ed., London, '79.

Mills, T. W. The Nature and Development of Animal Intelligence, N. Y., '98.

The Nature of Animal Intelligence and the Methods of Investigating It. Psych. Rev., 6, 262, '99.

Pfungst, O. Das Pferd von Herr von Osten (Der kluge Hans), Leipzig, '07. Translation, “Clever Hans," N. Y., '11.

Smald, W. S. An Experimental Study of the Mental Processes of the Rat. Am. Jour. Psych., 11, 133, '99, and 1. c. 12, 206, '00. Thоmpson-Seton, E. Life-Histories of Northern Animals, N. Y. '09. Thorndike, E. L. Animal Intelligence. Psych. Rev. Monogr. Suppl., Vol. 2, No. 4, '98.

Do Animals Reason? Pop. Sci. Mon., 55, 480, '99.

A Reply to "The Nature of Animal Intelligence and the Methods of Investigating It." Psych. Rev., 6, 412, '99.

Toenjies, H. Principles of Animal Understanding, N. Y., '06. Watson, J. B. Animal Education, Chicago, '03.

YeRKes, R. M. The Dancing Mouse, N. Y., '07. 
Yoskum, C. S. Some Experiments on the Behavior of Squirrels. Jour. Comp. Neur. Psych., 19, 541, '09.

ZELL, T. Das rechnende Pferd. Ein Gutachten über den "klugen Hans" auf Grund eigener Beobachtungen, Berlin, '04.

Ist das Tier unvernunftig? Neue Einblick in die Tierseele. Stūttgart, Fr., '04.

ZURN, F. A. Die intellektuellen Eigenschaften (Geist und Seele) des Pferdes. Stüttgart, '99. 


\section{CHAPTER XIII}

\section{THE MENTAL LIFE OF APES AND MONKEYS}

"L'Homme ne possède aucune aptitude psychique fondamentale qui, à un moindre degré, ne se manifeste chez certaines Bêtes."MrLne-EDwards, Leçons sur la Physiologie, T. 14.

"If no organic being excepting man had possessed any mental power, or if his powers had been of a wholly different nature from those of the lower animals, then we should never have been able to convince ourselves that our high faculties had been gradually developed. But it can be shown that there is no fundamental difference of this kind. We must also admit that there is a much wider interval in mental power between one of the lowest fishes, as a lamprey or lancelet, and one of the higher apes, than between an ape and man; yet this interval is filled by numberless gradations."-DARWIN Descent of Man.

I have reserved for a separate chapter a consideration of the mental powers of the animals most closely related to ourselves. Our simian cousins have long enjoyed the reputation of attaining, next to man, the highest psychic development of any members of the animal kingdom. Much has been written concerning their powers and performances, but their psychology has been investigated far less extensively and thoroughly than the importance of the subject demands. It is particularly unfortunate that we know so little of the most anthropoid of the ape tribe. Until recently it has been exceedingly difficult to keep the larger apes long in captivity; and psychologists have had few opportunities to subject them to systematic experimentation. Further difficulties are encountered owing to the large size and strength of these animals, especially when these characteristics are combined, as is often the case, with an unreliable or intractable disposition. 
It is probable that further study may reveal in the anthropoid apes a higher psychic development than is found among the smaller members of the monkey tribe from which has been derived most of our knowledge of the simian mind. Our account therefore will have to do mainly with the smaller species which are more commonly and easily kept in captivity and which are more distantly related to the human family.

Thorndike has performed several series of experiments with three Cebus monkeys by placing food in boxes which could be opened by working one or more mechanical devices. The times taken by the monkeys in learning how to open the boxes were recorded, and it was found that associations were formed much more quickly than in cats, dogs and chicks. "Whereas the latter," says Thorndike, "were practically unanimous save in the cases of the very easiest performances, in showing a process of gradual learning by a gradual elimination of unsuccessful movements, and a gradual reinforcement of the successful one, these are unanimous, save in the very hardest, in showing a process of sudden acquisition by a rapid, often apparently instantaneous, abandonment of the unsuccessful movements and a selection of the appropriate one which rivals in suddenness the selections made by human beings in similar performances." This fact, according to Thorndike, does not show that monkeys reason or even have ideas. Their greater clearness of vision, the greater number and precision of their movements, and their greater curiosity are factors which, aside from the superior development of their brains, give the monkeys an advantage over cats and dogs, in acquiring new associations. The monkey mind shows an advance over that of the lower mammals in the greater number, delicacy, complexity and permanence of its associations, and the readiness with which associations are formed, but in their 
method of learning, according to Thorndike, "the monkeys do not advance far beyond the generalized mammalian type."

Like his cats and dogs, Thordike's monkeys failed to learn acts by being put through them. They also failed to learn acts which they had seen the experimenter perform a large number of times. Neither did they appear to imitate one another. If one monkey had learned to get into a puzzle box, other monkeys failed to learn to do so after witnessing his successful performance. The traditional belief in the propensity of monkeys to imitate, therefore, receives no justification at Thorndike's hands.

The poor opinion of the monkey mind to which Thorndike was led by his experiments is very different from the one commonly held, and most people would be inclined to regard the individuals he experimented with as rather sorry specimens of the monkey family. Experiments on one species form an inadequate basis upon which to base conclusions regarding simian intelligence in general, and it is not surprising that other investigators of the behavior of monkeys should have obtained results more creditable to the mental ability of these animals. Some very interesting investigations have been conducted by Hobhouse upon a rhesus monkey which he called Jimmy, and a chimpanzee which for reasons of his own he named the Professor. Jimmy was an active creature of rather irritable temper and very fond of baked potato, which proved an excellent incentive to the overcoming of obstacles. The Professor, on the other hand, was very timid and unsociable, and could be managed only with difficulty.

Both of these monkeys showed a certain power of adapting means to ends in employing one object in order to get another within reach. The Professor when first received from the zoological gardens had already acquired the habit of throw- 
ing his rug over objects at some distance from his cage and pulling them in. If a nut or piece of banana was placed beyond his reach outside his cage he would get his rug from his bed, stuff it with considerable labor between the bars of his cage, and throw it like a net over the desired object. He was taught to substitute a stick for the rug and succeeded in employing it to secure bits of food. The next day he learned to use a short stick in order to reach a longer one with which he could secure a piece of banana. "I put my stick," says Hobhouse, "out of his reach, and a piece of banana beyond it again, while I gave him a short stick. He did not, however, use it until I first pushed the big stick about with it. He then made an attempt to reach my stick with the short one, but without success. I then gave him rather a larger stick, with which he at once tried to reach mine, but instead of getting hold of it he knocked it slantwise, so that one end was farther off from him than before, and one end nearer. He now directed his stick to the nearer end, pulled mine in, and with its aid reached the banana."

The chimpanzee would use his stick in different ways according to circumstances. "The banana was generally given him inside a cigar box. He would reach out with his stick at the box, and sweep it round by a radial motion, so that in so doing he was not obeying the natural impulse to draw it straight toward him, but merely was bringing it to a point to which he could afterward go and get it. One half of his cage, however, was covered with plate glass, so that if, in describing a quarter circle he swept the box up against the glass he could not reach it at once with his arm. He would then alter the motion, and rake with the point of the stick, drawing the box in in a straight line. When he had to fish for a box close to the wall, he would take trouble to get 
his stick in between the wall and the box, showing that he was quite aware of the way in which he had to push it."

Jimmy, like the Professor, learned to use a stick with which to draw in objects, and he also learned to use a short stick in order to reach a larger one with which he could obtain his food. "If stick and fruit were both too far from him, he would try to help himself by pulling the whole board on which they lay toward him; and he seemed quite clear as to the necessity of getting the stick beyond the thing that he was pulling. If it lay just on his side of the apple or nut he would be careful not to knock the apple away, but to get the stick well beyond it."

Jimmy's resourcefulness in attaining his ends was often quite remarkable. Given a child's skipping rope with which to obtain a piece of bread placed outside his cage he made a cast at it with the wooden handle and finally drew it within reach. After this he would use a cord and then a wire for a similar purpose. Says Hobhouse, "I put a piece of onion in a basket within reach of his stick. After first refusing any effort, he tried to reach it with the stick, and failed. In reaching toward it, he found the big box (one of Jack's boxes, which he also used) lying across his chain, and preventing his reaching forward. He threw the box off. Having failed with the stick, he will not try it again, but makes wild efforts to throw the rope. Then he actually rolls the box at the food; then goes off and gets the dust sheet from the chair and tries unskilfully to sweep at it; finally makes a longer stretch, and just reaches it with his own claw."

Jimmy also learned to use a chair or a box in order to get objects otherwise out of reach. An onion was placed on top of a table and his chain was adjusted so that he could reach the table, but not the onion. After he was allowed to reach the latter by using a box which was placed so that he 
could climb upon it the box was removed. At first Jimmy did not try to move the box back, but began to explore it and opened the lid upon which he climbed and reached the food. The next time he tried to pull the table toward him. After a number of different manœuvers to get the food he learned to drag the box or a chair toward the table and by this means reach the object he was seeking.

In another experiment a box was placed between the fastening of his chain and a piece of potato which was just out of reach, but which could be reached if the chain did

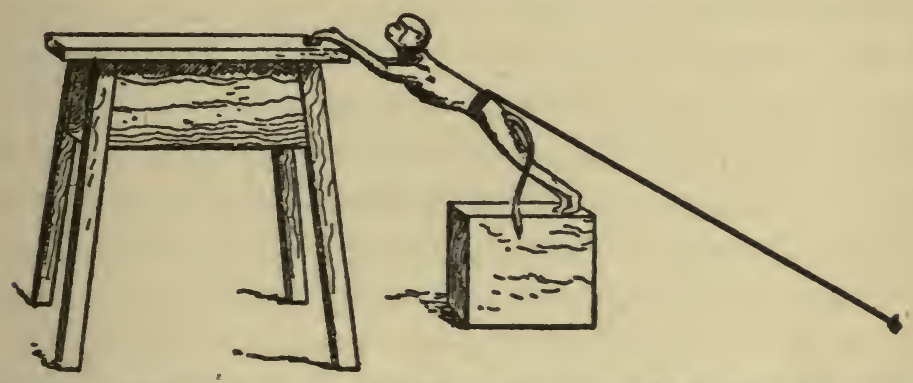

FIG. 16. - Jimmy" using a box in order to reach food on the table. (After Hobhouse).

not pass around the box. Jimmy soon came back to the box, moved it out of the way and got his potato. He repeated the performance two more times without hesitation. When his chain was shortened by a heavy fender being placed over it he would come back and lift off the obstacle. He recognized, apparently, that the box and the fender prevented him from going as far as he otherwise might.

Similar adjustment of means to ends was shown by the monkey kept by Miss Romanes, which she describes as follows: "His chain is fastened to the marble slab of a washhandstand, placed on the floor against the wall. It is too heavy for him to pull along by his chain without hurting himself, so when he desires to do any mischief which is 
beyond the reach of his chain he deliberately goes to the marble and pushes an arm down between the upright part of it and the wall, until he has moved the whole slab sufficiently far from the wall to admit of his slipping down behind the upright part himself. He then places his back against the wall and his four hands against the upright part of the marble, and pushes the slab as far as he can stretch his long legs. He only does this, however, when he is bent on mischief, as the fact of food being beyond the reach of his chain does not furnish a strong enough inducement to lead him to take so much exertion."

Another interesting incident in this connection is furnished by Prof. Möbius. A chimpanzee, Molli, was confined in a wooden cell. When someone from the outside was driving a nail into the wall of her cell, and she saw the nail coming through the board, she went to her drinking vessel, took it in both hands and pounded the nail back again.

The use of implements for various purposes is, according to the testimony of several writers, a not uncommon feature of monkey behavior. Prof. Cope, in describing the performances of a Cebus capucinus says: "He then used the strap in a novel way. He was accustomed to catch his food with his hands when thrown to him. Sometimes it fell short three or four feet. One day he seized his strap and took pretty correct aim and finally drew the pieces to within reach of his hand. This performance he constantly repeats, hooking and pulling the articles to him in turns of the strap. Sometimes he loses hold of the strap. If the poker is handed him he uses it with some skill for the recovery of the strap. After punishment the animal would only exert himself in this way when not watched; as soon as an eye was directed to him he would cease."

Witmer relates that Peter, a trained chimpanzee which 
he had for a time under observation, would use a hammer to drive nails with, string beads on a cord, select the proper key from a bunch and unlock a padlock, and strike a match, light a cigarette, and smoke it with an expression of serene contentment. Peter developed a remarkable expertness in riding a bicycle, a feat which he was accustomed to perform during his public exhibitions.

Mr. Belt tells of a Cebus he observed which would use a stick with which to draw objects toward him. One day some bird skins were placed, as was thought, far beyond his reach, but he took his swing and used it so as to bring the skins near enough to be seized. He also secured some jelly, which was set out to cool, in the same way.

Miss Romanes in her account of the behavior of a Cebus, from which we have already quoted, states that "if a nut or any object he wishes to get hold of is beyond the reach of his chain, he puts out a stick to draw it toward him, or if that does not succeed, he stands upright and throws a shawl back over his head, holding it by the two corners so that it falls down his back; he throws it forward with all his strength, still holding on by the corners; thus it goes out far in front of him and covers the nut, which he then draws toward him by pulling in the shawl." The same monkey when given a hammer to crack a nut with used it effectively for that purpose. We have the testimony of Cuvier to the effect that an orang would pull a chair from one end of the room to the other so that by standing upon it he could open a latch, but how the act was originally learned we are not informed.

The use of sticks and stones by apes and monkeys has been described by several writers. Pechuel-Lösche, who has had excellent opportunities for observing baboons in their native habitat, has come to the conclusion that the accounts 
of these animals throwing stones at their pursuers rest upon inaccurate observation; the stones, he thinks, were merely knocked down unintentionally during the flight of these animals up a declivity. Stories of apes throwing down fruit and other objects from trees he thinks are based on the fact that these things are simply dropped when the animals are put to flight. Father Wasmann, who eagerly adopts these conclusions, proceeds to admonish us that the boasted intelligence of apes is entirely illusory. "Had apes themselves," he tells us "but a trace of intelligence, they would have invented, long ago even in their free state of nature the use of a few simple means of defence, such as branches and stones. But why did they not? The only possible answer is: because they evidently have no intelligence. Not the brain alone makes man an intelligent being, but his spiritual soul, and this spiritual soul is wanting in the highest apes as well as in the insects."

If the failure of apes to use weapons of defence is indicative of lack of intelligence, we may fairly conclude that where weapons are used there is evidence that intelligence exists. Whether or not baboons use sticks and stones in the way alleged, there is good evidence that other members of the ape tribe sometimes employ them as a means of attack. Miss Romanes says regarding her Cebus: "To-day a strange person (a dressmaker) came into the room where he is tied up, and I gave him a walnut that she might see him break it with his hammer. The nut was a bad one, and the woman laughed at his disappointed face. He then became very angry, and threw at her everything he could lay hands on; first the nut, then the hammer, then a coffee-pot which he seized out of the grate, and, lastly all his own shawls. He throws things with great force and precision by holding them in both hands, and extending his long arms well back 
over his head before projecting the missile, standing erect the while." At a later period Miss Romanes says of him: "When he throws things at people now he first runs up the bars of the clothes-horse; he seems to have found out that people do not care much for having things thrown at their feet, and he is not strong enough to throw such heavy objects as a poker or a hammer at peoples' heads; he therefore mounts to a level with his enemy's head, and thus succeeds in sending his missile to a greater height and also to a greater distance." Darwin states in his "Descent of Man:" "As I have repeatedly seen, a chimpanzee will throw any object at hand at a person who offends him." And other well attested observations could be quoted to the same effect. Despite the contention of Wasmann we must admit, I think, that the use of objects by apes as weapons of attack rests upon a fair basis of testimony.

A certain degree of foresight seemed to be manifested by Miss Romanes' monkey in the way in which he disentangled his chain when it became wound around a clothes horse which was given him to run upon. "He looks at it intently and pulls it with his fingers this way and that, and when he sees how the turns are taken, he deliberately goes round and round the bars, first this way, then that, until the chain is quite disentangled. He often carries his chain grasped in his tail and held high over his back to keep it from getting in the way of his feet."

Mr. Hobhouse's Jimmy was not so circumspect. "He would, however, as a rule, undo a single twist by retracing his steps, and sometimes would undo a more complicated one by a developed form of the method of trial and error, which consisted in this: that each time he felt the cord shortening on him, he would go back the way he had come." This method was usually effective, but Jimmy showed little 
improvement in its application. He made but a moderate success in disentangling his chain when it became twisted around among the legs of a chair or table.

While monkeys are generally credited with unusual powers of imitation, the experiments of recent years have shown that imitation is far less frequent than was supposed. Thorndike tried to find if monkeys would learn to enter a puzzle box any more quickly after having witnessed a number of times how he opened the various fastenings. Several kinds of boxes were used, but the monkeys did not, in any case, make sufficient progress to justify the conclusion that they learned by imitation. Neither did monkeys which failed to learn how to enter the puzzle boxes after several trials imitate others which had learned to operate the fastenings. No evidence of imitation was furnished by the general behavior of these animals, but since two of the monkeys were on very unfriendly terms and the third was exceedingly timid their social relations were not such as to favor the imitation of one another's acts.

Further experiments were carried on by Watson on four monkeys, a baboon, a Cebus, and two rhesus monkeys. Watson tested his animals by performing in their presence a number of acts which resulted in securing food, such as drawing in food with a rake or a cloth, getting it from a bottle with a fork, and poking it out of a glass cylinder with a stick. After witnessing his operations a number of times there was no effort on the part of any of the monkeys to get the food in the way they had every opportunity to see was effective. Experiments with puzzle boxes in which the monkeys were given a chance to imitate either the experimenter or a monkey which had already learned the trick gave the same negative results.

While they yielded no evidence of imitation in its higher 


\section{MENTAL LIFE OF APES AND MONKEYS 271}

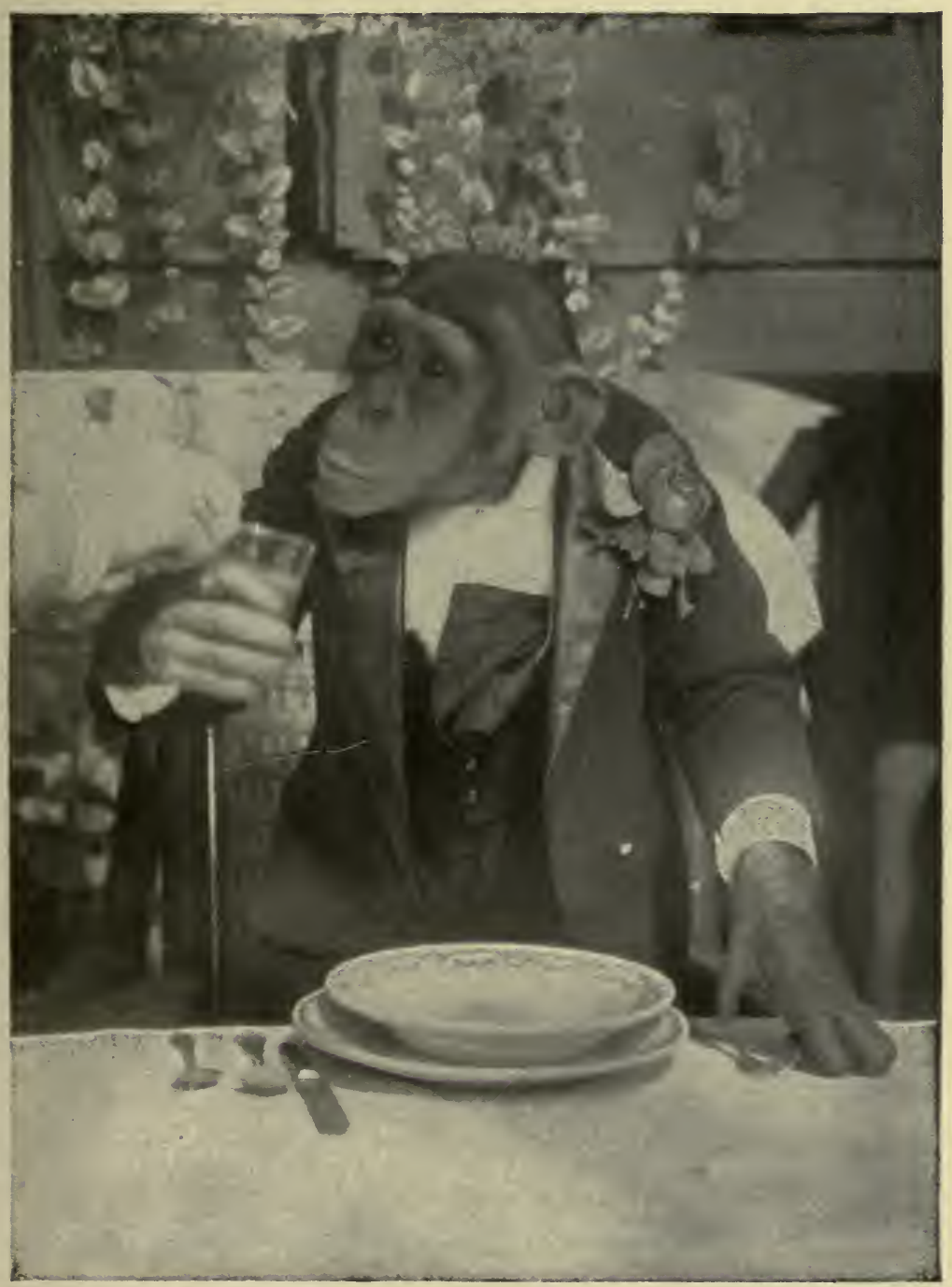

FIG. 17.-Peter at dinner. (By permission of the Psychological Clinic.) 
forms Watson's monkeys occasionally performed acts which were "suggestive of a low order of imitation." One of them found a hole in a window frame. "This one would 'peek' and then another one would push him aside and "peek' in turn. This was observed several times." Hirschlaff in his account of the chimpanzee Consul describes a number of cases in which he considers that imitation was unmistakably shown, but his observations are not described in sufficient detail to enable one to judge of the correctness of the interpretation. Kinnaman reports a few cases of imitation in two rhesus monkeys which he studied. In one instance in which the female pulled out a plug immediately after seeing a male do it the evidence for imitation is not entirely conclusive, since the femaie had pulled out the plug on previous occasions. The second case is a more satisfactory one and is described as follows: "Recalling that she had failed to work the beardown lever for opening the box. . . . I placed it before her. She rushed up, but missing the plug she sat down. The male passed her, pushed the lever down and procured the food. When the box was set again she worked the lever and took the food in the same way that he had done. She manipulated this apparatus several times immediately and 250 times later as a part of a combination lock. Besides these, once when the male peeped under the bottom of one of the trees the female came and peeped in the same manner."

Mr. Witmer states that the chimpanzee, Peter, twice copied a W which was written on a blackboard, and learned to repeat the word "mama." It is unfortunate that more extended and thorough experiments were not carried out with so promising a subject.

The experiments of Shepherd on imitation in rhesus monkeys yielded for the most part negative results. In a few cases, however, the monkeys showed evidence of learn- 
ing by imitating the experimenter's movements. In one such case a piece of banana was suspended by a string a little beyond the monkey's reach, and a pole was so arranged that when it was swung under the banana the monkey could get upon it and reach the fruit. A monkey which had proven himself incapable of solving the problem

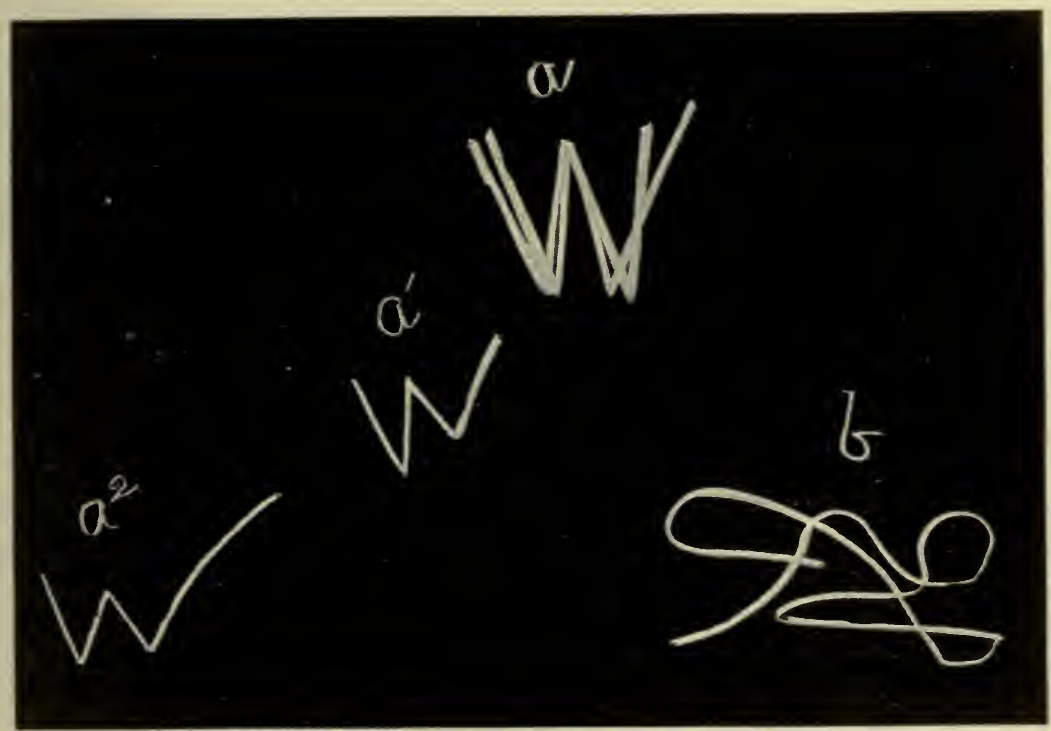

Fig. 18.-Peter's efforts at copying letters on a blackboard. a. Two superimposed letters drawn by Mr. Witmer; $a^{1}$, Peter's copy after the second tracing; $a^{2}$, Peter's second effort when told to make a iw again. (By permisson of the Psychological Clinic.)

alone was shown how to manipulate the pole. After witnessing the experimenter push the pole under the banana the monkey gradually learned to perform the act, although it was some time before he manipulated the apparatus with accuracy and dispatch.

The most extensive study of imitation in monkeys has been made by Mr. Haggerty. While many of the experi- 
ments gave negative results and many others leave us in doubt as to the interpretation of the behavior described, there are some in which the evidence points strongly toward imitation. The monkeys were put in cages in which there were mechanical devices by operating which they could procure food. Each monkey was given five trials of fifteen minutes each on successive days. If he did not secure food by his unaided efforts he was allowed to see another monkey operate the device and was then allowed to try again. The lessons were kept up until 100 tests were made before the monkey was dismissed as a hopeless failure. In many cases monkeys which failed to operate the devices alone did so after watching other monkeys work them one or more times. The attention of the monkeys was usually stimulated when they saw other monkeys obtain food by working the devices. Very frequently the imitation was not perfect at first, but the various features of the trick were learned one after the other.

There is a possible doubt relative to the interpretation of Mr. Haggerty's experiments. Since the monkey which served as a model learned the trick to be copied it is possible that the monkey which performed the trick after watching him may have learned it at first hand also. The case for imitation can be made out only by the accumulation of a sufficient number of instances to rule out coincidences and accidents. How far Mr. Haggerty has made out his case can be judged only by a careful study of the details given in his paper.

Whether apes and monkeys reason is a question whose answer depends on the sense in which the term reason is employed. If we define reason as the derivation of conclusions through the comparison of concepts it is not improbable that no animal below man employs this faculty. But this 
is far from implying that animals cannot perform mental operations which are essentially inferential in their nature. Reason, as has been stated before, is not a faculty which stands sharply marked off from other forms of mental activity. Between simple perception on the one hand and abstract ratiocination on the other there is a fundamental kinship and the latter process may be connected with the first by numerous intermediate stages. Monkeys, in all probability, have the power of using ideas derived from their experience as a means of reaching practical results. The monkey which pulls a chair or stool into a certain position, gets on it and secures food, manifests a certain power of inference. He may not explicitly reason: "This fruit is beyond my reach; if I had something to get upon I could secure the fruit; this chair would serve my purpose and moreover is movable; ergo, I will pull it up and get on it." In all probability a man in a similar situation would not reason as explicitly either. He would perceive that the object was out of his reach; seeing a chair the idea would come of pulling it up and getting on it, and the idea would forthwith issue in the proper act. There would be no formal syllogism gone through with. The process would ordinarily take place so quickly that he would scarcely be conscious of the steps. It is true that the man might think about the matter in a very complex way, and employ a lot of abstract and general ideas, but this process would be dispensed with under ordinary conditions, especially if he were in a hurry. The man's mental operations, even in their simplest form, would nevertheless be in the nature of an inference, and so far as we can judge from appearances, the same statement is true of the mind of the monkey. The latter cannot, in all probability, think the situation over as the man can in terms of a formal syllogism, but he has the more immediately useful 
faculty of arriving at the practical conclusion as to the kind of action which the conditions call for.

Inferences of this simple practical character are of enormous value to such creatures as monkeys. They suffice also for the greater part of our own conduct, at least in certain walks of life. Within the sphere of rational procedure in ourselves there are obviously vast differences in the complexity and abstractness of our mental operations, and it might be said that the gap between the animal and the human mind corresponds roughly with the difference between our more simple and our more complex and abstract thinking. A similar gap is bridged over during the life of every individual in passing from infancy to maturity, and we may well conceive the mind of man to have arisen from the animal mind by a similar process of continuous development.

Father Wasmann is one of the few comparative psychologists of note who hold the human and the animal mind to be fundamentally distinct. While the real basis of his opinion may be his adherence to the traditional theology which he represents, with its peculiar views as to man's relation to nature, Wasmann has attempted to show that animals have no real intelligence, no power of abstraction, and no power of rational thought. Even should we grant all this, we should not be compelled to call into play a miraculous intervention to account for the distinctive attributes of human thinking. Giving names to particular mental faculties tends to exaggerate their distinctiveness, as was done in the faculty psychology of former days. When we say of a stage of mental evolution, here there is reason while at a stage just preceding, reason does not occur, our statement does not necessarily imply an abrupt break or sudden step in the evolutionary series. As Hobhouse has well remarked: 
"If we allow reason to the human species in general, and yet restrict it to that species, it must be by identifying the term reason arbitrarily with a certain grade in the development of analysis. It would be true to say that abstract or explicitly general reasoning emerges in the level of intelligence under consideration, but we have seen that abstractness is only one side of generality, and that the generality of human as opposed to animal reasoning is once more primarily a matter of explicitness. At bottom the function of mind in this as in the lower stages is to organize life by the correlation of experiences. As in every stage of mental growth what is new is that the work of the mind becomes on the one hand more explicit or articulate, on the other, more comprehensive in scope."

Wasmann's position is typical of the attitude which formerly characterized to a greater extent than happily is the case now the relation of theology to science. It is the aim of science to explain phenomena in terms of natural laws. Theology, on the other hand, has always been interested in finding things which cannot be so explained, and in thus compelling us to take refuge in some sort of supernatural intervention. Gaps, barriers, discontinuities, mysterious and inexplicable phenomena have always afforded her, therefore, a peculiar satisfaction; but one by one they have been obliterated or resolved, and there can be little doubt, I believe, that the question of the continuous evolution of the human mind will go the way of the others.

While there is little to indicate that the apes are able to reason in an abstract way, it is obviously absurd to attempt to account for such behavior as we have described on the basis of blind sensori-motor association. It is not going too far, I think, to say that there is good evidence in the apes and monkeys for the existence of ideas and for a certain power 
of grasping relations. A monkey which uses a stool to enable him to reach an object, and which removes an obstacle from his chain so that he may get a piece of food can scarcely be said to be devoid of a certain power of representation. Many features of the behavior of apes and monkeys mark these animals as belonging to a distinctly higher psychic level than cats and dogs. It is not likely that a cat or a dog, with all due allowance for its physical disabilities, would employ a tool with which to pull in a bit of food, much less use a stick in order to get the tool for this purpose. The monkey looks on the tool as a means to an end, and accordingly goes after it. There is less evidence that objects have such a meaning to cats and dogs. These animals might try in various ways to reach food lying on a table; if a chair or box were at hand they would doubtless mount upon it in order to get the food. But even after seeing chairs and boxes pulled around by human beings any number of times it probably would not occur to one of these creatures to pull the chair or box into position for its own use.

The mind of the lower mammals is pretty closely chained to its various objects of perception. It may have ideas, but they are lacking in "articulateness." But the monkey seems to be gifted with a certain degree of initiative; things occur to him, and he apparently thinks about things in the effort to attain a particular result. He shows a decided approach to ourselves in many little ways of doing things. $\mathrm{He}$ is not interested merely in the gratification of his appetites; he is actuated by a sort of intellectual curiosity in regard to objects. Miss Romanes' monkey would almost always set an orange to spinning before eating it just for the fun of seeing it go; he took great delight in breaking objects to pieces and in overturning things; he removed a bell handle from the mantel piece which involved unscrewing three 
screws; and when he was chained in a new place he investigated for hours the new fastenings of his chain. The development of this intellectual interest-if we may call it such-in regard to objects affords an opportunity for further improvement; it leads not only to the acquisition of new knowledge, but to training in discrimination and practical judgment.

\section{BIBLIOGRAPHY}

Brehm, A. E. Thierleben, '76.

Cope, E. D. Note on Intelligence in Monkeys. Am. Jour. Sci. and Arts (3), 4, 147, '72; also in Ann. Mag. Nat. Hist. (4), 10, 229, 72.

Cuvier, F. Description d'un Orang-Outang, et Observations sur ses Facultés Intellectuelles. Ann. du Mus. Hist. Nat., 16, 1808.

Darwin, C. R. Descent of Man, N. Y., '74.

GARNer, R. L. The Speech of Monkeys, N, Y., '92.

Apes and Monkeys, their Life and Language, Boston, '00. H.agerty, M. E. Imitation in Monkeys. Journ. Comp. Neur. Psych., 19, 337, '09. Imitation in Monkeys. Century Mag. '09. 544.

Hartmann, R. Anthropoid Apes, N. Y., '85.

HirschlafF, L. Der Schimpanse Konsul; ein Beitrag zur vergleichenden Psychologie. Zeit. f. päd. Psychol., 7, 1, '05.

Hoвнouse, L. T. Mind in Evolution, London, '01.

Kinnaman, A. J. Mental Life of two Macacus Rhesus Monkeys in

Captivity. Am. Jour. Psych., 13, 98 and 173, '02.

Möвıus, K. Zur Psychologie des Schimpanse. Zool. Garten, 8, $279,{ }^{\prime} 67$.

Romanes, G. J. Animal Intelligence, N. Y., '83.

On the Mental Faculties of the Bald Chimpanzee, Anthropithecus calvus. Proc. Zool. Soc., London, '89, 316.

Shepherd, W. Some Mental Processes of the Rhesus Monkey. Psychol. Rev. Monogr. Suppl. 12, No. 52, '10.

Sokolowsky, A. Beobachtungen über die Psyche der Menschenaffen. Frankfurt, '08.

Thorndike, E. L. The Mental Life of the Monkeys, Psychol. Rev. Monogr. Suppl: 3, No. 15, '01.

The Intelligence of Monkeys. Pop. Sci. Mon., 54, '01. 
280 MENTAL LIFE OF APES AND MONKEYS

Wallace, A. R. The Malay Archipelago, 3d. ed., London, '72.

Watson, J. B. Imitation in Monkeys. Psych. Bull. 5, 169, '08. Some Experiments Bearing upon Color Vision in Monkeys. Jour. Comp. Neur. Psych., 19, 1, '09.

Witmer, L. A Monkey with a Mind. Psych, Clinic, 3, 179, '09.

Intelligent Imitation and Curiosity in a Monkey, l. c. 3, 225, '10. 


\section{INDEX}





\section{INDEX}

Abbott, C. C., intelligence of frogs, 228

Actinians, effect of hunger on, 150 , 151

geotaxis, 222

tidal and daily rhythms, 157

varied reactions, 144-147, 159161

Adams, G. P., phototaxis of earthworm, 47

Adamsia, food taking, 151

Adlerz, G., imitation in ants, 210

intelligence of wasp, 192

Ethalium, rheotaxis, 37

Aikins, H. A. See Hodge, 89

Aiptasia, varied reactions, 146

effect of hunger on, 151

habit formation, 153

Allabach, L. F., reactions of Metridium, 160

Allen, J. ,258

Alligator, intelligence, 230

Allolobophora, positive phototaxis in weak light, 47

Ament, W., 258

Ammophila, homing, 194

stinging prey, 119, 120,131, 132

using stone as a tool, 203, 204 variability of instinct, 131, 132

Amceba, adaptiveness of behavior, 70,71

chemotaxis, $23,26,70$

electrotaxis, 59

food taking, 64, 68, 69

imitation of activities, 67,68

locomotion, 65-67

phototaxis, 70

reactions to contact, $33-35,69$, 70
Amceba, thermotaxis, 58

Amphibia, intelligence, 226-229

Amphipods, phototaxis changed by contact, 50,51

thigmotaxis, 36. See also Orchestia and Talorchestia

Amphipyra, phototaxis, 36

thigmotaxis, 36

Amphithœ, behavior, 30, 94

Anemones. See Actinians

Anemotropsm in insects, 38

Anoplodactylus, phototaxis, 56

Antennularia, geotaxis, 30

Ants, chemotaxis, 29

imitation in, 209, 210, 254

influence of numbers on courage, 207

intelligence, 192, 193, 205, 214

variability in cocooning, 132 , 133

Apes, intelligence, $260 \mathrm{ff}$

Aporus, homing, 195

Aquinas, T., pleasure as a determinant of action in animals, 164

Arenicola, phototaxis of larvæ, 52, 53

Associative memory, 5 ff. See also Intelligence

Asterias, habit formation, 154, 155, 158

Atherina, intelligence, 223, 224

Baboons, use of weapons, 267, 270

Bacterium termo, chemotaxis, 22

Bain, A., 178, pleasure and pain in accommodation, 173-175

Balanus, phototaxis of larva, 47

Balbiani, E. G., capture of food in Didinium, 78 
Baldwin, J. M., 138, 178, imitation, 257

contra Lamarckism, 124 organic selection, $136 \mathrm{ff}$ pleasure and pain in accommodation, 173-175

problem of learning, 172

Ball, W. P., 138

Bancroft, F. W., 61, electrotaxis in Paramœcium, 60

Barotaxis defined, 34

Bateson, W., 230, intelligence in fishes, 220

Bees, communication, 215

homing, 193, $196 \mathrm{ff}$

influence of numbers on pugnacity, 207-209

intelligence, 193, 196-201, 207209, 215

and Lamarkism, $126 \mathrm{ff}$

remembering flowers, 200-202

Beetles, intelligence, 192, 206

Belt, T., intelligence of Cebus, 267 intelligence of wasp, 195

Bentley, I. M., intelligence of chub, 222

Bentley, M. See Day, 87

Berry, C. S., 258, imitation in cats, 256

imitation in white rat, 255, 256

Bethe, A., 16, 189, 215, consciousness in animals, 4, 6

homing of ants and bees, 193, 199

homing of limpets, 187

lack of learning in Carcinus, 182,183

Binet, A., 89, behavior of Protozoa, 63-65

capture of food in Didinium, 78

relation of reason to perception, 248

Birds, fear in, 96, 121-123

imitation in, 254, 257
Birds, intelligence, $165,166,176-$ 178

migration, 108

variations in instinct, 133. See also particular species

Blanchard, E., intelligence of beetle, 206

Blow-flies, instincts, 93

phototaxis of larvæ, 21, 42, 43

Bodo, capture of prey, 64, 65

Bohn, G., 10, 61, 162, consciousness in animals, 4

definition of instinct, 92

differential sensibility, 152

fatigue sensorielle, 143

geotaxis in Convoluta, 31, 156

homing of limpet, 118

law of varied responsiveness, 145

phototaxis of Littorina, 156, 157; of Pleurosigma, 156

reactions of Cerianthus, 144, 145

reactions of animals to colored lights, 47

rhythms of activity, $155 \mathrm{ff}$

tidal rhythms of Convoluta, 31, 156; of Pleurosigma, 156 ; of anemones, 158; of Littorina, 156, 157

tropisms, 18

Bostok, F., 258

Branchellion, interference of reactions, 140

Brehm, A., 279

Bumble-bees, 208, 209, 215

Burroughs, J., 258

Buttel-Reepen, H. von, 216, communication in bees, 215

courage in bees, 207

homing in bees, 193, 197

evolution of the

bee community, 128

Carcinus, intelligence, 182-184 
Cardium, reactions to shadows, 41

Carr, H., and Watson, J. B., 258

Casteel, D. B., 231, intelligence of Chrysemis, 230

Cat, imitation, 256

intelligence, 166, 236-242, 255

Catfish, intelligence, 222

Cebus monkey, intelligence, 262, 264-270

imitation, 270

Centipedes, males eating eggs of female, 96

Cerceris, homing, 195

Cerianthus, geotaxis, 30

reactions to repeated stimuli, 144,145

Cesaresco, E. M., 258

Chemotaxis, 21-29, 70, 75, 76, 187

Chick, imitation, 254

intelligence, $165,166,176-178$

transitory instincts, 99

Chilomonas, chemotaxis, 27

Chlamydomonas, geotaxis, 29

Chromulina, geotaxis, 29

phototaxis affected by temperature, 49

Chrysemis, intelligence, 230

Chimpanzee, imitation, 272, 273

intelligence, 262-266, 270, 272, 273

Cladophora, attracting bacteria, 22

Claparède, E., 10, comparative psychology, 1,7

Claypole, Prof., imitation in young ostrich, 254

Clepsine, phototaxis, 44

reaction to shadows, 41,42

varied behavior, 111, 142

Cockroaches, geotaxis, 32

Cole, L. J., 61, phototaxis of pycnogonids, 56

phototaxis and image forming power of eyes, 56,57

Cole, L. W., 258, intelligence of raccoons, 242-245, 255
Communication in ants, 213, 214 in bees, 215

Compensatory motions, $39 \mathrm{ff}$ in relation to phototaxis, 57

Condillac, instinct, 92

intelligence in animals, 232

Consciousness, criterion of, $3 \mathrm{ff}$

Convoluta, tidal rhythms in, 31, 156

Cope, E. D., 279, intelligence of a Cebus, 266

Cornetz, V., 216, homing of ants, 193

Corymorpha, geotaxis, 31

Cowles, R. P., learning in Ocypoda, 184

Crayfish, compensatory motions, 40

devouring their eggs and young, 95,96

instincts as related to reflexes, $100 \mathrm{ff}$ intelligence, 184-186

reflexes, 13

Ctenophores, geotaxis, 30 statocysts, 30,33

Cucumaria, geotaxis, 31

Cunningham, J. T., 138

Cuvier, F., 279, intelligence of orang, 267

Cypridopsis, phototaxis changed by contact, 50

Cypris, phototaxis changed by contact, 50

Daphnia, movements of eye, 57 phototaxis changed by contact, 50

Darwin, C. R., 114, 138, 162, 279 chimpanzee throwing stones, 269

definition of instinct, 91 evolution of instinct, 115, $130 \mathrm{ff}$ fear in young ducks, 123 in young rabbits, 123 followers of, 1 
Darwin, C. R., imperfect instincts of Molothrus, 96

intelligence of earthworms, 161 Lamarckian theory of instinct inadequate, 126

mental evolution, 260

reactions of earthworms, 28, 140

Davenport, C. B., 61

Davis, H. B., 258, intelligence of raccoons, 243,255

Day, L. M. and Bentley, M., learning in Paramœcium, 87-89

Death-feigning. SeeFeigningDeath.

Delage, Y., equilibrium in crustacea, 31

Delbœuf, J., 231, intelligence ni lizards, 229

Dellinger, O. P., 89, locomotion in Amœba, 66

Descartes, R., consciousness in animals, 4

Didinium, capture of food, 64, 77-79

Dog, imitation in, 256

instinct to swim, 97

intelligence, 235-237, 240, 245, 246, 249-251, 255

Dragon fly, larval and adult instincts compared, 98

Driesch, H., geotaxis in Sertulariella, 30

Drzewina, A., 189, tidal rhythms in phototaxis of hermit crabs, 158

learning in Pachygrapsus, 187

Earthworms, phototaxis, 21, 43, 44,54

intelligence, 161

interference of reactions, 140

reactions to chemicals, 28

varied reactions, 148,149

Earwigs, thigmotaxis, 36

Edinger, L., 231
Eimer, O. E., 38, definition of instinct, 92

origin of instinct, 118,119

Electrotaxis, 59 ff

Eledone, intelligence, 189

Emery, C., 216

Englemann, T. W., chemotaxis of bacteria, 22

influence of oxygen on phototaxis, 49

Epeira, instincts of young, 98

Escherich, K., 216

Eubranchipus, photataxis, 54

Eudendrium planulæ, phototaxis, 52

Euglena, geotaxis, 29

phototaxis, $28,44,45$

Fabre, J. H., 216, constancy of instinct, 132

intelligence of beetles, 206

locality sense of mason bee, 197 nature of instinct, 91

Fatigue as cause of change of behavior, 84, 142-145, 149

Fear of hawks, not innate, 123

in fiddler crabs, 140

in Rhea, 122, 123

in sparrows, 122

in young birds in general, 96, 121-123

in young ducks, 123

in young rabbits, 123

in young terns, 96,97

Feigning death, change of attitude in through fatigue, 143

in young terns, 96,97

Fiddler crabs, interference of reactions, 140

phototaxis, 48, 56, 140, 144

Fishes, intelligence, $219 \mathrm{ff}$

rheotaxis, 37, 38, 57

Fleure, H. J., and Walton, C. L., 162 , reactions of Actinia, 159,160

Fly, behavior of decapitated specimens, 104 
Fly, larvæ, See Blow-fly.

Forel, A., 216

contra Lamarckism, 124

courage in ants, 207

imitation in ants, 210

intelligence of bees, 200-202

intelligence of water beetles, 192

Formica sanguinea, 205, 207, 210

Fox, Rev. D., variant instinct in dog, 134

Freund, F., 258

Frog, instincts, 105-107

intelligence, 227-229

reflexes, $12-15,105-107$

Fundulus, rheotaxis, 37

Garner, R. L., 279

language of apes, 214

Gätke, migration of birds, 254

Geotaxis, 29, 34

Verworn's theory of, 34

Ghinst, van der, 162

Gibbs, D. and Dellinger, O. P., 89

Glaser, O. C., 162, behavior of ophiurans, 181

Goby, intelligence, 224-226

Goldfish, learning to come for food, 223

Goldsmith, M., 231, intelligence of of goby, 224-226

Goltz, F., clasping instinct of brainless male frog, 106

Gonionemus, effect of hunger on behavior, 150

geotaxis, 30

reactions, 16

Goniotaxis, defined, 36

Groom, T. F., and Loeb, J., phototaxis of Balanus larvæ, 47

Groos, K., contra Lamarckism, 124

Gurley, R. R., 231

Haake, W., dancing instinct in shrew, 134
Habits in anemones, $153,157,158$ in birds, 121-123

in hermit crabs, $158,186,187$

in organs, 159

Paramœcium, 86-88

in starfish, 154, 155, 158

various causes of, 153-159

Hachet-Souplet, P., 258

Hadley, P. B., rheotaxis of lobster, 38,57

phototaxis of lobster, 55,56

Haggerty, M. E., 279, imitation in monkeys, 273, 274

Hanel, E., supposed intelligence of earthworms, 161

Hargitt, C. W., 162, reactions of Hydroides to shadows, 142

Harper, E. H., 61, photatxis in Perichæta, 44

Hartley, intelligence in animals, 232

Hartmann, R., 279

Hartmann, von, definition of instinct, 92

Haseman, rhythms in Littorina, 157

Hawks, fear of, 123

Heliotropism, 19. See also Phototaxis.

Heptagenia, intelligence, 192

Hermit crabs, intelligence, 186, 187 tidal rhythms, 158

Herrick, C. J., 231, intelligence in cat-fish, 222

Hertel, E., reactions of Paramocium to ultra violet rays, 75

Hirschlaff, L., 279, imitation in chimpanzee Consul, 272

Hobhouse, L. T., 114, 179, 258, 259 imitation, 256

instinct and intelligence, 112

intelligence of $\mathrm{dog}, 254$

intelligence in monkeys, 262$266,269-270,276,277$ 
Hobhouse, L. T., problem of learning, 176

reason in animals, $249,276,277$

Hodge, C. F., and Aikins, H. A., change of behavior in Vorticella, 89

Holmes, S. J., 61, 89, 179, 231; behavior of Loxophyllum, $16,25,35,79-81,141$

instincts of Amphithœ, 93, 94; of young terns, 96,97

learning in crayfish, 185, 186; in sunfish, 223

phototaxis of blow-fly larvæ, 42, 43; of earthworm, 43, 44, 54; of Eubranchipus, 54; of fiddler crabs, 48, 56,140 ; of Jassa, 49; of Notonecta, 55; of Orchestia, 46, 48, 49, 51, 55; of Ranatra, 48, 51, 52, 55, 56, 140; of Talorchestia, 42,54

reactions of mosquito larvæ to shadows, 142

Holt, E. B., and Lee, F. S., 61

Horse, locality memory, 246-248

Hudson, W. H., 114, fear in birds, 121-123

Huggins, G. E., learning in crayfish, 184

Huggins, Dr., variant instinct in a dog, 134

Hutchinson, W. N., 258, imitation in dogs, 256

Huxley, T. H., 10

Hyalella, change of phototaxis by chemicals, 50

Hydra, geotaxis, 30

reactions to chemicals, 28

reactions to repeated stimulation, 141, 145

thigmotaxis, 36

Hydroides, reaction to repeated stimulation by shadows, 142
Imitation in ants, 209, 210, 254

in birds, 254, 257

in cats, 255

in fishes, 253

in monkeys, $262,270 \mathrm{ff}$

in raccoons, 255

in rats, 255

in dogs, 255, 256

Insects, compensatory motions, 40

geotaxis, 32

instincts, 93, 95, 98, 104, 105, $108,110,118-120,124-$ $133,140,191 \mathrm{ff}$

intelligence in, $191 \mathrm{ff}$

photokinesis, 42

phototaxis, 42, 43, 48, 51, 55

rheotaxis, 38

seat of instincts, 104

thigmotaxis, 36

Instinct, 108

analysis of, 21

deferred, 96,97

defined, 92

dependence on internal conditions, $110 \mathrm{ff}$

evolution of, $115 \mathrm{ff}$

human, 100

illustrations of, 93,95

imperfection of, 95, 96

and intelligence, 112

internally initiated, $107 \mathrm{ff}$

modified by experience, 166

popular conception of, 94,95

and reflex action, $99 \mathrm{ff}$

transitoriness of, 99

variability, $131 \mathrm{ff}$

Intelligence, beginnings of, $164 \mathrm{ff}$ criterion of, 181 deceptive appearances of, 159 in amphibians, 227-229

in apes, 260 in birds (chick), 165, 166, 176178

in crustaceans, 182-187

in fishes, 219-227

in insects, $191 \mathrm{ff}$ 
Intelligence in lower invertèbrates, $63 \mathrm{ff}, 86 \mathrm{ff}, 182$

in mammals, 166, 167, 232 ff

in mollusca, 187-189

in monkeys, 260

in reptiles, 230

Isopods, thigmotaxis, 36

Jackson, H. H. T., phototaxis of Hyalella, 50

James, W., 114, contradictory instincts, 112

instinct as determinant of action, 113

instinct and intelligence, 168

Jassa, change of phototaxis, 49

Jelly-fish, reflexes, 13

Jennings, H. S., 34, 61, 89, 163; Aiptasia, food taking, 151

Amœba, food taking, 59, 68; locomotion, 66; role of surface tension in movements, 67-69

anemones, habits, 153; varied reactions, 146,147

Chilomonas, chemotaxis, 27

Didinium, capture of food, 78

earthworms, varied reactions of, 148,149

Euglena, phototaxis, 44, 45

Paramocium, chemotaxis, 2326 ; motor reflex in, 73, 74; thigmotaxis, 35 ; variations in behavior, 76,77

Spirillum, chemotaxis, 27

starfish habits, 154-155, 158$159,181,182$

Stentor, modifiability of behavior, 83

tropisms, 21

Jesse, E., intelligence in alligator, 230

Keeble, F., 163, tidal rhythms in Convoluta, 156
Kinnaman, A. J., 279, imitation in Rhesus monkeys, 272

Kirby, W. and Spence, W., 216, definition of instinct, 91 intelligence of beetle, 206

Knauer, F. K., intelligence of frogs, 228

Kollmann, J., 189, intelligence of octopus, 189

Kreidl, A., 32, fishes coming to sound of bell, 224

functions of statocysts in Palæmon, 31, 32

Labidocera, geotaxis, 31

phototaxis changed by contact, 50

Lacordaire, J. T., intelligence of instincts, 191

Lady-beetles, geotaxis, 32

Lamarck, J. B., evolution of instinct, $115,118 \mathrm{ff}$

Lamarkian theory of instinct, 115$131,136-138$

Lambs, undefined instinct of young, 96

Landois, H., 231

Lasius, intelligence, 212, 213

variability of cocooning instinct, 132

Lecaillon, A., 231

Lee, F. S., 61

Leibnitz, intelligence of animals, 232

Leucocytes, chemotaxis, 26

Lewes, G. H., 138, origin of instinct, 116

Lillie, R. S., phototaxis of Arenicola, 52, 53

Limpets, homing, 187, 188

Limulus, segmental reflexes, 16

Littorina, tidal rhythms, 156, 157

Lizards, intelligence, 229

Lobster, phototaxis, 55, 56

rheotaxis, 38,57 
Loeb, J., 10, 17, 31, 61, consciousness in animals, 4,6

Amphipyra, tropisms of, 36 geotaxis in Antennularia, 30; in Cerianthus, 30 ; in insects, 32

Gonionemus, rhythmic contractions of, 16

heliotropism, 19, 41, 46

photokinesis and phototaxis, 41

phototaxis, change of in copepods, Gammarus and Polygordius, 49

stereotropism, 33

theory of tropisms, 18-21, 60

Loxocephalus, forming groups, 24

Loxophyllum, behavior, $16,25,35$, 79-81, 141

chemotaxis, 25

reaction of pieces, 80

reactions to repeated stimulation, 141

rhythms, 16

thigmotaxis, 35

Lubbock, Sir J., 216, communication in ants, 214; in bees, 215

homing of bees, 193

intelligence of ants, 211-214

intelligence of wasp, 192

Lukas, F., 17

Lyon, E. P., compensatory motions, 40

phototaxis in Palæmonetes, 49,56

rheotaxis in fishes, $37,38,57$

Mactra, reaction to shadows, 41

Magpie, imitation, 257

Mammals, intelligence, $232 \mathrm{ff}$ compensatory motions, 39

Man, instincts of, 100

Marshall, H. R., 10, 179

Massart, J., chemotaxis absent in Polytoma, 25
Massart, J., effect of temperature on phototaxis of Chromulina, 49

geotaxis in lower organisms, 29

Mast, S. O., 61, 89; Arenicola larvœ, phototaxis of, 53

Didinium, behavior of, 77-79;

Eudendrium, phototaxis, 52;

Stentor, phototaxis, 44

Maxwell, S., thigmotaxis of Nereis, 36

May-fly. See Heptagenia.

McCook, H. C., 216

Mendelssohn, M., 61

Metalnikow, S., food taking in Paramœcium, 72

Metridium, food taking, 151

varied reactions of, 160, 161

Michener, E. J., effect of chemicals on phototaxis, 50

Migration, in birds, 108

Mills, T. W., 258

Milne-Edwards, H., intelligence of animals, 260

Minkiewicz, C., 61, disguisement of spider crabs, 104

reactions to colored lights, 47

Möbius, K., 231, 279, intelligence of pike, 219,220

intelligence of a chimpanzce, 266

Mocking-bird, imitation, 257

Moggridge, J. T., on young trap door spiders, 98

Molluses, change of responsiveness to light and shadows, 143

intelligence, 187-189

Molothrus, imperfect egg-laying instinct, 96

Monkeys, $260 \mathrm{ff}$

Montgomery, T. H., on young Epeiras, 98

Moore,A., geotaxis in Paramœcium, 30

Moore, A. R., habit formation in starfish, 154, 155 
Morgan, C. Lloyd, 10, 114, 138, 190, animal intelligence, 248

behavior of protozoa, 63 consciousness in animals, 4 deferred instincts, 96 evolution of instinct, 121 fear of hawks not innate, 123 homing of limpets, 187-189 imitation in chicks, 254 intelligence in chicks, 165; in dog, 234, 235; in stickleback, 226

instinct and internal impulsion, 108, 109

intelligence in solitary wasp, 203, 204

Lamarckism rejected, 124

organic selection, 136

principle of, 159, 234

varied behavior of Clepsine, 111,112

Morgan's law, 159, 234

Morse, M., tidal rhythms of Littorina, 157

Mosquitoes, geotaxis, 32

reaction of larvæ to shadows, 142

Moth, tropisms, 18

Motor reflex, in Euglena, 28, 44, 45

in Loxophyllum, 79, 80

in Paramceium, 15, 73, 74, 76

in Stentor, 44, 81, 82

Mound-building bird, instinct of flight, 97

Murbach, L., geotaxis in Gonionemus, 30

Mysis, geotaxis, 31

Nagel, W. A., 61, food taking in anemones, 150, 151

light reactions of molluses, 41

Natural selection, origin of instinct by, $134 \mathrm{ff}$

Necturus, intelligence, 227

Nephelis, phototaxis, 44

Nereis, thigmotaxis, 36
Nervous system, of crayfish, 101

Nightingale, variation in singing instinct, 133

Norman, W. W., pain sensations in lower animals, 8

Notonecta, phototaxis, 55

Nuel, J. P., 61

Octopus, intelligence, 188, 189

Ocypoda, intelligence, 184

Odynerus, instinct, 118

Oelzelt-Newin, A., 90, food taking in Loxophyllum, 80

Orang, intelligence, 267

Orbitolites, thigmotaxis, 34

Orchestia, phototaxis, 46, 48, 49, 51,55

Organic selection, 136-138

Osborn, H. F., organic selection, 136

Osmia, parental instincts, 120

Ostrich, imitation in young, 254

Oxytricha, forming of groups, 24 thigmotaxis, 35

Pachygrapsus, intelligence, 187

Pagurus, intelligence, 186

Pain, 6, 164 ff

Palæmon, 32

$$
\text { statocysts, } 31 \mathrm{ff}
$$

Palæmonetes, change of phototaxis, 49

Paley, W., conception of instinct, 108 .

definition of instinct, 91

Paramœeium, behavior, 15, 35, 71 chemotaxis, 21, 23-25, 27, 75,76

choice of food, 72

effect of hunger on, 150

electrotaxis, 59,60

forming groups, 24

geotaxis, 29, 30

interference of reactions, 140

modifications of behavior, 76 ,

77, 140 
Paramœcium, motor reflex, 15,73 , 74,76

reaction to ultra violet rays, 75

swimming, 72

thermotaxis, 58, 75

thigmotaxis, $35,73,76$

Parkèr, G. H., food taking in anemones, 150,151

geotaxis of Labidocera, 31 phototaxis of Labidocera, 31, 50; of Vanessa, 55

Parrot imitation, 257

Patellas, homing, 188

Pawlow, J. P., formation of habits by stomach, 159

Peal, imitation in jungle pheasant, 254

Pearl, R., 163, goniotaxis in Planaria, 36

reactions of Planaria, 53, 147 variability in behavior of Planaria, 147

Pechuel-Lösche, E., intelligence of baboons, 267, 269

Peckham, G. W. and E. G., 216, homing of wasps, 193-196

instincts of solitary wasp, 119, $120,131,132$

intelligence in solitary wasp, 203, 204

variability of instinct in solitary wasp, 131, 132

Perch, intelligence, 220, 221

Pfeffer, W., chemotaxis of bacteria, 22

chemotaxis of spermatozoids of ferns and mosses, 26

Pfungst, $0 ., 258$

Phototaxis, 19-21, 36, 38, $40 \mathrm{ff}, 82$, 186,192

Photokinesis, 41, 42

Pieron, H., intelligence of Crassius, 221

intelligence of Triton, 227

kinæsthetic reflex, 199
Pigeon, compensatory motions, 39

Pike, intelligence, 219

Planaria, reactions to chemicals, 28,53

reactions to light, 41

reactions to mechanical stimulation, 53, 141

reactions to repeated stimulation, 141

thigmotaxis, 36

varied response to stimuli, 144,147

Plants, reactions, 15

Play instinct, 109

Pleasure, 6, 55, $164 \mathrm{ff}$

Pleurosigma, tidal rhythms, 156

Polistes, intelligence, 195, 196

Polyergus, stupidity, 210, 211

variation in cocoon spinning, 132,133

Polytoma, lack of chemotaxis, 25

Pouchet, G., phototaxis of Temora, 50

Preyer, W., 163, behavior of starfish, 181

human instincts, 100

Promethus moth, instincts of, 124, 125

Protozoa, internally initiated activity, 109

intelligence, 63-65, $86 \mathrm{ff}, 181$ reactions, $15,21 \mathrm{ff}, 44-47,49$, $58-60,63 \mathrm{ff}, 140,141,150$

rhythms, 16

tropisms, 18, $21 \mathrm{ff}, 44-47,49$, $58-60,70 \mathrm{ff}$

Prowazek, S. von, 90

Psammobia, reaction to light, 41

Pütter, A., 61, 90

Pycnogonids, phototaxis, 56

Raccoon, intelligence, 242-245, 255

Rádl, E., 62, hovering in flies, 38 movement of eye of Daphnia, 57 
Rádl, E., phototaxis of Arthropoda, 55

relation of phototaxis to vision, 56

Rae, Dr., fear in young ducks, 123

Ranatra, behavior after decapitation, 105

interference of reactions, 5, 140

phototaxis, $48,51,52,55,56$, 144

Random movements, in chemotaxis, 24-26

in phototaxis, 21, 22, 41-45

rôle of in learning, 168

Rat, imitation, 255, 256

Raven, imitation, 257

Reason, in apes and monkeys, $274 \mathrm{ff}$

in insects, $203 \mathrm{ff}$

in mammals, $232 \mathrm{ff}$

Réflex action, 11 ff

Reflexes, 2, $11 \mathrm{ff}$

of pecking, swallowing, 176-

177. See also Motor Reflex.

Reflex action and instinct, 99 ff, 116,117

Reighard, J., 231, intelligence of fishes, 223, 224

Reimarus, H. S., 114

Reptiles, intelligence, 229, 230

Reuter, O. M., intelligence of ants, 193

Rhea, no innate fear of man, 122

Rheotaxis, 34, $37 \mathrm{ff}, 57$

Rhesus monkey, intelligence, 262265

imitation, 271-274

Rhumbler, L., 90, behavior of Amœba, 68

Rhythms, in behavior, $16,79,80$, 155-158

Righting movements, in Loxophyllum, 81

in starfish, $154,155,158$
Romanes, G. J., 10, 114, 138, 279, animal intelligence, 2

definition of instinct, 91,92

evolution of instinct, 120 , 121

homing of bees, 196

intelligence of $\mathrm{dog}, 250$

moth flying to candle, 20

Romanes, Miss, intelligence of

Cebus, 265, 269, 278, 279

Sachs, H., tropisms, 19

Sagartia, effect of hunger on food taking, 150

geotaxis, 30

Schaeffer, A. A., 90, 231, food taking in Paramœcium, 72

selection of food in Stentor, 85, 86

intelligence of frog, 228, 229

Schneider, G. H.; 114, 190, instinct, 1

intelligence of octopus, 188, 189

Schneider, K. C., 114

Schrader, M., 17, segmental reflexes in frog, 107

Sense of direction, in ants, 193

in bees, 193, 196-202

in horses, 247

in wasps, 193-196, 200, 201

Serpula, reactions to light and shadows, 41

varied reaction to shadows, 145

Shepherd, W., 279, imitation in Rhesus monkeys, 272, 273

Sherrington, C. S., 17, reflex action, 11

Small, W. S., 258, imitation in white rat, 255

Smith, S., 90, educability of

Paramœcium, 86-89

Sokolowsky, A., 279

Solen, reaction to shadows, 41 
Sondheim, M., 216, intelligence of damsel-fly, larvae, 191, 192

Spallanzani, Abbe, clasping instinct of brainless male frog, 106

Sparrows, fear in, 122

Spaulding, D. A., 114, instincts of chicks, 99

Spaulding, E. G., 190, learning in hermit crabs, 186, 187

Spence, W. See Kirby.

Spencer, H., 10, 114, 138, 179, definition of instinct, 91 , 107

Lamarckian theory of instinct, 127 mental evolution, 1,9

origin of instinct, 116, 117

pleasure and pain, 167, 172175

relation of intelligence to other activities, 139

Spider crabs, instincts for disguisement, 104

Spiders, devouring their eggs, 96

geotaxis, 32

instincts of young, 98

Spirillum, chemotaxis, 27

geotaxis, 29

Spirostomum, geotaxis, 30

Stahl, E., chemotaxis in myxomycetes, 23

Staphylococcus, attracting leucocytes, 26

Starfish, habit formation, 154-155, 158

Statkewitsch, P., reaction of Paramœcium to induction shocks, 144

Statocysts, functions of in crustacea, 31

function in Ctenophores, 30

Stentor, effect of hunger on, 150

modifiability of behavior, 49, $82-86,141,145,150$

phototaxis, $44,49,82$
Stentor, reactions, $15,81-86$

rhythms, 16

Stereotropism, 33 ff, 42

Stickleback, intelligence, 226

Stoichactis, varied reactions, 146

Stone, intelligence of dog, 250, 251

Strasburger, E., 62, effect of temperature on phototaxis of swarm spores, 49

Sunfish, intelligence, 223

Surface tension theory of movements of Amœba, 67

Swallows, instinct of flight, 97

Swarm spores, change of phototaxis, 47

Talorchestia, photokinesis, 42 phototaxis, 42, 54

Temora, phototaxis changed by contact, 50

Temperature, effect on phototaxis, 49

reactions of organisms to, 58 , 59

Terns, fear in, 96,97

feigning death, 96,97

undefined instinct of young, 96

Thermotaxis, 58, 59

in Paramceium, 58, 75

in Planaria, 59

Thigmotaxis, 33-36, 42

Thompson-Seton, E., 258

Thorndike, E. L., 231, 258, 279, animal intelligence, nature of, 235-242, 251, 252, 255 imitation in monkeys, 270 intelligence in cats, 166,167 intelligence of monkeys, 261, 262

Titchner, E. B., 10

Toads, intelligence, 227, 228

Toenjies, H., 258

Torelle, E., 62

Torrey, H. B., effect of hunger on food reactions of Sagartia, 150 
Torrey, H. B., geotaxis in Corymorpha, 31

geotaxis in Sagartia, 30

Tortoise, intelligence, 229, 230

Towle, E., phototaxis of Cypridopsis, 50

Triplett, N., 231, intelligence of perch, 220, 221

Triton, intelligence, 227

Tropisms, 2, $18 \mathrm{ff}$

Turner, C. H., 216, homing of burrowing bees, 198, 199 homing of mud dauber, 200

Twain, Mark, imbecility of ants, 95

Uexküll, J. von, 17, 163, 190, intelligence in Eledone, 189 tonus, 149

Verworn, M., 62, 90, function of statocyst in Ctenophores, 30

geotaxis, 34

thigmotaxis, 34

thigmotaxis in Oxytricha, 35

Voltaire, 91

Volvox, phototaxis, 47

Vorticella, change of behavior, 89 reactions, 15

rhythms, 16

Wagner, G., reactions of Hydra, 141,145

Wagner, M., 217, bumble bees, 208, 209, 215

communication in bees, 215 homing of bees, 193

Wallace, A. R., 280

Walter, H. E., 62, reactions of planarians to changes of light intensity, 142-143; to repeated jarring, 141

Walton, C. L. See Fleure, 159.

Washburn, M. F., 10

Washburn, M. F., and Bentley, I. M., 231
Washburn, M. F., intelligence of chub, 222

Wasmann, E., 10, 114, 217, communication in ants, 214

courage in bees, 207

imitation in ants, 210, 254

intelligence of animals, nature of, 181

intelligence of ants, 193, 205, 211

intelligence of apes, 268, 276, 277

plasticity of behavior, 139

Wasps, homing, 193-196, 200, 201 intelligence, 192-196, 200, 201, 203, 204

instincts, 119, 120, 131, 132

Watkins, G. P., 90

Watson, J. B., 258, 280, imitation in monkeys, 270,272

Weismann, A., 138, contra Lamarckism, 127

Wheeler, W. M., 217, imitation in ants, 209, 210

White, G., intelligence in tortoise, 229,230

Whitman, C. O., 138, evolution of instinct, 115, 116, 121, 135

Lamarckism, 124

intelligence of Necturus, 227

origin of instincts in pigeons, 135

varied behavior of Clepsine,111

Willcox, M. A., 190

Witmer, L., 280, intelligence of chimpanzee, 266, 267

imitation in chimpanzee, 272 , 273

Wodsedalek, J., intelligence of May-fly nymph, 192

Wundt, W., 138, origin of instinct, 118

Yerkes, A. W., 163, reactions of Hydroides to shadows, 142 


\section{INDEX}

Yerkes, R. M., 190, 231, 258, Yoakum, C. S., 259 intelligence in Carcinus, Yung, E., 190 184 ; in crayfish, 184 ; in frog, 228; in turtles, 230; Zell, T., 259 variability of behavior in Zeigler, H. E., 114 dancing mouse, 133, 134 Zurn, F. A., 259 


\section{LATEST VOLUMES IN \\ THE AMERICAN NATURE SERIES}

(Prospectus of entire Series on request)

\section{INSECTS AND DISEASE.}

By R. W. DOANE, of Stanford University. Illustrated. $\$ 1.50$ net; by mail, $\$ 1.62$.

"Describes lucidly and entertainingly, in language that all may underotand, the discoveries in the disease-bearing qualities of insects, the successful fights that have been made in consequence against yellow fever, malaria and plague, and the present state of the investigations." - New York Sun.

\section{THE CARE OF TREES IN LAWN, STREET, AND PARK}

By B. E. FERnow, of the University of Toronto. Illustrated. $\$ 2.00$ net; by mail, $\$ 2.17$.

Written for amateurs by a forester, this volume furnishes information such as the owner of trees or the "tree warden" may need.

"Truly admirable... eminently practical. . . His list of trees desirable for shade and ornament is a full and most valuable one, and the illustrations are enlightening." -New York Tribure.

\section{HARDY PLANTS FOR COTTAGE GARDENS}

By Helen R. Albee, Author of "Mountain Playmates." Illustrated. I2mo. \$1.60 net; by mail, \$1.75.

"Eminently practical and well arranged. . . . Lists giving manner of growth, height, time of blooming, exact color, special requirements of soil and moisture are provided, and proper classifications and indexes make the book one of the most valuable yet offered to the garden grower."-Boston Transcript.

\section{SHELLFISH INDUSTRIES}

By James L. KellogG, of Williams College. Illustrated. $\$ 1.75$ net; by mail, \$1.9I.

"Interests all classes, the biologist, the oyster grower, the trader and the eater of oysters. The whole book is very readable." -New York Sun.

FISH STORIES: Alleged and Experienced, with a Littlc History, Natural and Unnatural

By Charles F. Holder and David Starr Jordan. With colored plates and many illustrations from photographs. $\$ 1.75$ net; by mail, \$1.87.

"A delightful miscellany, telling about fish of the strangest kind. Nearly everything that is entertaining in the fish world is touched upon and science and fishing are made very readable."-New York Sun.

\section{INSECT STORIES}

By Vernon L. Kellogg. Illustrated. \$1.50 net; by mail, \$1.62.

"The author is among a few scientific writers of distinction who can interest the popular mind. No intelligent youth can fail to read it with delight and profit."-The Nation.

$\begin{aligned} & \text { H E N R Y H O L T A N D } \\ & \text { PUBLISHERS }\end{aligned}$
C O M P A N Y
NEW YORK




\section{ZAmerican ฐcience ฐertes}

The two principal objects of the series are to supply authoritative books whose principles are, so far as practicable, illus. trated by American facts, and also to supply the lack that the advance of science perennially creates, of text-books which at least do not contradict the latest generalizations.

\section{Physics.}

By George F. BARKer. $x+902$ pp. $\$ 3.50$.

\section{Chemistry.}

By Ira Remsen, President of the Johns Hopkins University.

Advanced Course. $\quad x x i i+853$ pp. $\$ 3.00$.

College Chemistry. $\quad \mathrm{xx}+689 \mathrm{pp} . \quad \$ 2.25$.

Briefer Course. $\quad$ xxiv +516 pp. \$1.25.

Elementary Course. $\quad x+287$ pp. 80 cents.

Laboratory Manual. xii +196 pp. 50 cents.

Chemical Experiments. $x+160$ pp. 50 cents.

Astronomy.

By Simon Newcomb and Edward S. Holden.

Advanced Course. $\quad x i i+512$ pp. $\$ 2.00$.

Briefer Course. $\quad x+366$ pp. $\$ \mathbf{1 . 2 0}$.

Elementary Course. $x v+446$ pp. $\$$ I.2O.

\section{Geology.}

By Thomas C. Chamberlin and Rollin D. Salisbury, Professors in the University of Chicago. 3 vols. 8vo.

Advanced Course. 3 vols. 8vo.

Vol. I. Giological Processes and their Results. xix +654 pp. $\$ 4.00$.

Vols. II and III. Earth History. xxxviitr316 pp. (Not sold separately.) \$8.00.

College Text.Book of Geology. xvi +978 pp. $\$ 3.50$.

\section{Physiography.}

By Rollin D. Salisbury, Professor in Chicago University.

Advanced Course. $x x+770$ pp. $\$ 350$.

Briefer Course. viii +53 I pp. $\$ 1.50$.

Elementary Course. $x i+359$ pp. $\quad \$ 1.30$. 

THE LIBRARY

UNIVERSITY OF CALIFORNIA

San Francisco Medical Center

THIS BOOK IS DUE ON THE LAST DATE STAMPED BELOW

Books not returned on time are subject to fines according to the Library Lending Code.

Books not in demand may be renewed if application is made before expiration of loan period. 
7

4 

